\title{
IntechOpen
}

\section{Aluminium Alloys and Composites}

\author{
Edited by Kavian Omar Cooke
}





\section{Aluminium Alloys and Composites}

Edited by Kavian Omar Cooke 

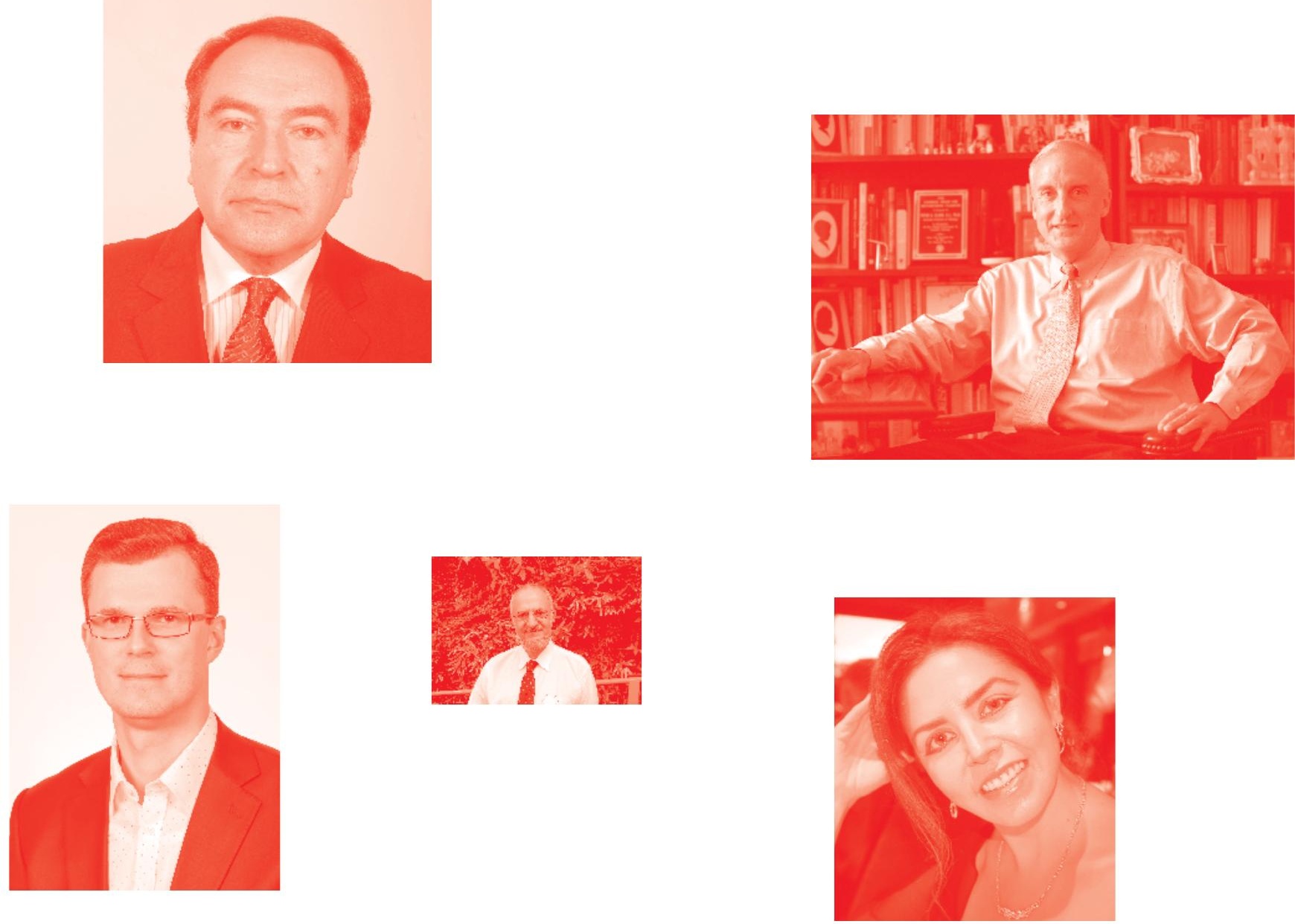

Supporting open minds since 2005
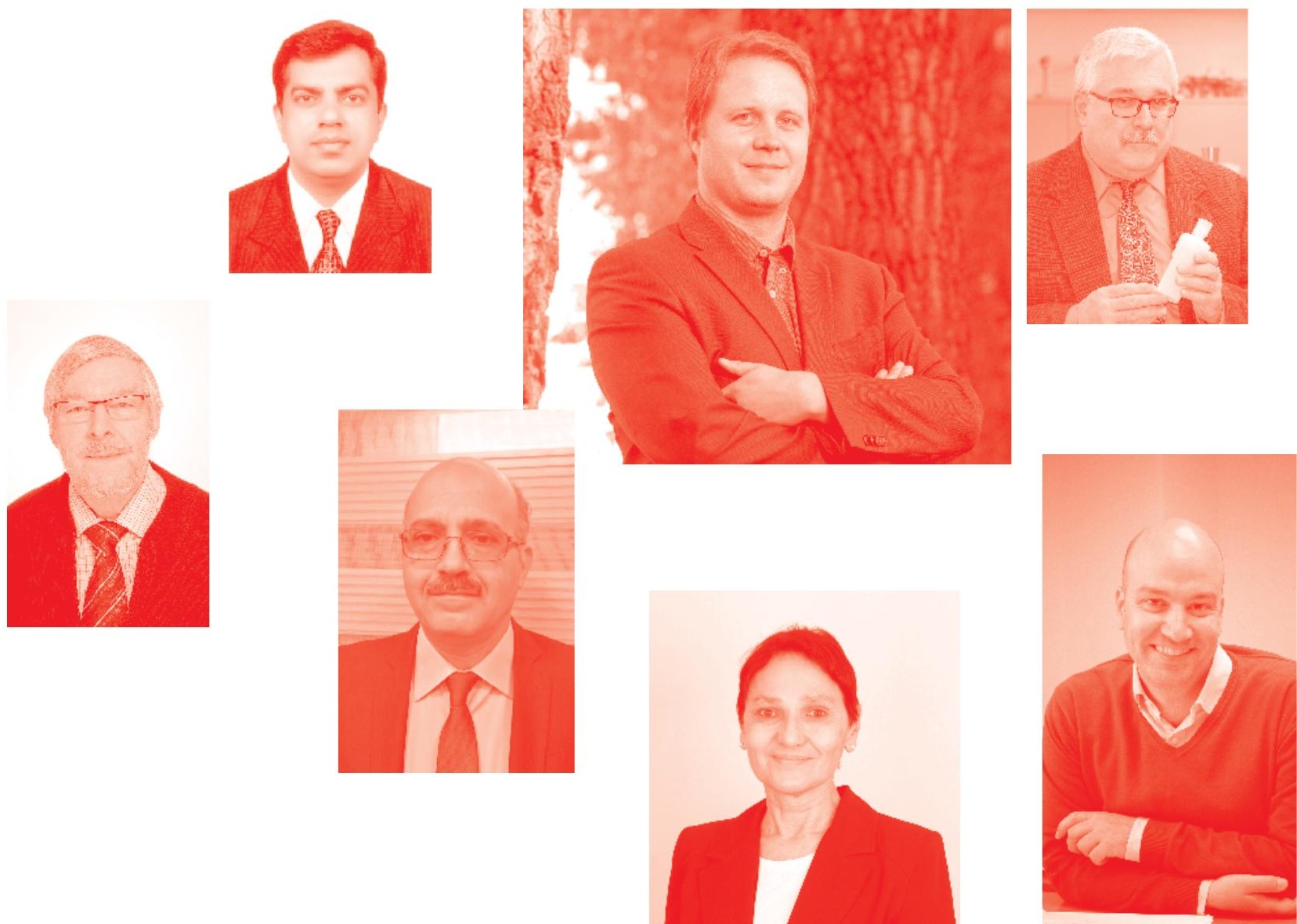
Aluminium Alloys and Composites

http : //dx. doi. org/10.5772/intechopen . 81519

Edited by Kavian Omar Cooke

\section{Contributors}

Yingyi Zhang, Yuanhong Qi, Jiaxin Li, Magibalan S, David Weiss, Kathambarajan Velmanirajan, K Anuradha, Perumalla Janaki Ramulu, P. Hema, Francis Nturanabo, Leonard Masu, John Baptist Kirabira, Jayaganthan Rengaswamy, Raja A, Abhishek Tiwari, Srinivasa Rakesh Ch, Kavian Omar Cooke

( ) The Editor(s) and the Author(s) 2020

The rights of the editor(s) and the author(s) have been asserted in accordance with the Copyright, Designs and Patents Act 1988. All rights to the book as a whole are reserved by INTECHOPEN LIMITED. The book as a whole (compilation) cannot be reproduced, distributed or used for commercial or non-commercial purposes without INTECHOPEN LIMITED's written permission. Enquiries concerning the use of the book should be directed to INTECHOPEN LIMITED rights and permissions department (permissions@intechopen.com).

Violations are liable to prosecution under the governing Copyright Law .

\section{(cc) BY}

Individual chapters of this publication are distributed under the terms of the Creative Commons Attribution 3.๑ Unported License which permits commercial use, distribution and reproduction of the individual chapters, provided the original author(s) and source publication are appropriately acknowledged. If so indicated, certain images may not be included under the Creative Commons license. In such cases users will need to obtain permission from the license holder to reproduce the material. More details and guidelines concerning content reuse and adaptation can be found at http : //www . intechopen . com/copyright-policy . html .

\section{Notice}

Statements and opinions expressed in the chapters are these of the individual contributors and not necessarily those of the editors or publisher. No responsibility is accepted for the accuracy of information contained in the published chapters. The publisher assumes no responsibility for any damage or injury to persons or property arising out of the use of any materials, instructions, methods or ideas contained in the book.

First published in London, United Kingdom, 2020 by IntechOpen IntechOpen is the global imprint of INTECHOPEN LIMITED, registered in England and Wales, registration number: 11086078 , 7th floor, 10 Lower Thames Street, London,

EC3R 6AF, United Kingdom

Printed in Croatia

British Library Cataloguing-in-Publication Data

A catalogue record for this book is available from the British Library

Additional hard and PDF copies can be obtained from orders@intechopen.com

Aluminium Alloys and Composites

Edited by Kavian Omar Cooke

p. cm.

Print ISBN 978-1-78984-514-3

Online ISBN 978-1-78984-515-0

eBook (PDF) ISBN 978-1-83880-๑80-2 


\section{We are IntechOpen, \\ the world's leading publisher of Open Access books}

\section{Built by scientists, for scientists}

\section{$4,600+$}

Open access books available

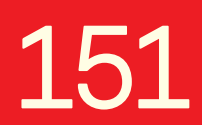

Countries delivered to

\section{$120,000+$}

International authors and editors

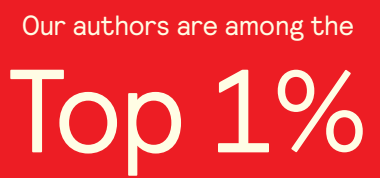

most cited scientists

Contributors from top 500 universities
$135 \mathrm{M}+$

Downloads
$12.2 \%$

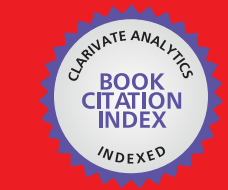

WEB OF SCIENCE ${ }^{\text {M }}$

Selection of our books indexed in the Book Citation Index in Web of Science ${ }^{\mathrm{TM}}$ Core Collection (BKCI)

\section{Interested in publishing with us? \\ Contact book.department@intechopen.com}

Numbers displayed above are based on latest data collected.

For more information visit www.intechopen.com 



\section{Meet the editor}

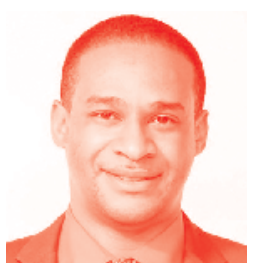

Kavian Omar Cooke is a Lecturer at the University of Bradford, West Yorkshire, United Kingdom and former Director of the Mechanical Engineering program at the University of Technology, Jamaica. He is a Chartered Engineer, a member of the Institution of Engineering and Technology (IET), a member of the Caribbean Academy of Science and former Vice President of the Jamaica Institution of Engineers (JIE). He obtained his $\mathrm{PhD}$ from the University of Calgary in Materials Engineering, a B. Eng. with honors and an MPhil from the University of Technology in Mechanical Engineering and an MBA from Patten University in Management. His research has focused on surface and interface engineering and he has authored three books and numerous journal articles and conference proceedings. 



\section{Contents}

Preface

Section 1

Types and Properties of Aluminium Alloys and Composites

Chapter 1

Introductory Chapter: Structural Aluminum Alloys and Composites by Kavian Omar Cooke

Chapter 2

Aluminum Mineral Processing and Metallurgy: Iron-Rich Bauxite and Bayer Red Muds

by Yingyi Zhang, Yuanhong Qi and Jiaxin Li

Chapter 3

Aluminium and Its Interlinking Properties

by K. Velmanirajan and K. Anuradha

Chapter 4

Composites and Alloys Based on the Al-Ce System

by David Weiss

Chapter 5

Novel Applications of Aluminium Metal Matrix Composites

by Francis Nturanabo, Leonard Masu and John Baptist Kirabira

\section{Section 2}

Processing, Characterisation and Testing

Chapter 6

Effect of Grain Size on Superplastic Deformation of Metallic Materials by Allavikutty Raja, Rengaswamy Jayaganthan, Abhishek Tiwari and Ch. Srinivasa Rakesh

Wear Behaviour of Aluminium Alloy 8011 with 4\% Fly Ash

Composites by Using Sensitivity Analysis

by Subramaniam Magibalan 
Chapter 8

Experimental Investigations on AA 6061 Alloy Welded Joints by Friction Stir Welding

by Pothur Hema

Chapter 9

Aluminum Alloys Behavior during Forming

by Perumalla Janaki Ramulu 


\section{Preface}

Aluminium is the most abundant structural material and it makes up approximately $8 \%$ of the earth's crust. As one of the lightest structural materials available, aluminium alloys and aluminium metal matrix composites find extensive applications in engineering structures that require good strength-to-weight ratios and corrosion resistance among other properties. The demand for weight reduction and energy savings has led to the development of various alloys of aluminium and metal matrix composites with enhanced mechanical properties using various innovative additive manufacturing processes including 3D-printing.

Aluminium has the potential to reduce the weight contribution effects of engineering components on pollution and global warming. This book aims to provide the reader with a complete overview of the advances that have been made in the development of advanced aluminium alloys and composites and explores the joining technologies capable of combining these materials into superior hybrid structures. This text will be a useful handbook for academics, students, and researchers who wish to understand the advanced applications for aluminium.

Students often find it difficult to recognize and understand the impact of the microstructure on the overall properties of the materials being studied. The intention of this book is to demonstrate the link between microstructure and the composition and performance of aluminium alloys and composites. This content will make this an important handbook for students interested in mechanical and materials engineering.

The editor would like to express his sincere gratitude to the authors for participating in this project by contributing their valuable chapters, without your support this edited book would not have been possible. I would also like to thank Ms. Dolores Kuzelj and her team at IntechOpen for their persistent efforts in moving the project forward.

Kavian Omar Cooke

University of Bradford, Bradford, United Kingdom 

Section 1

\section{Types and Properties of Aluminium Alloys and Composites}





\title{
Introductory Chapter: Structural Aluminum Alloys and Composites
}

\author{
Kavian Omar Cooke
}

\section{General background}

Aluminum is a metal of great importance because of its excellent corrosion resistance, high electrical and thermal conductivity, good reflectivity and very good recycling characteristics. Aluminum atoms are arranged in a face-centered cubic (FCC) structure with a melting point of $660^{\circ} \mathrm{C}$. There are nine different series of aluminum, which will be discussed later in this section, four of which are referred to as heat-treatable aluminum alloys, and these alloys are so-called because of the potential to increase the mechanical properties by precipitation strengthening $[1,2]$.

The properties of heat treatable Al-alloys can be further enhanced by the inclusion of a reinforcing phase that increases the mechanical properties of the overall composite. Metal matrix composites (MMC) are usually manmade materials that consist of two or more distinct phases; a continuous metallic phase (the matrix) and a secondary reinforcing phase. The secondary phase may take the form of continuous or discontinuous reinforcement as particles or fibers. When this phase is introduced into the matrix the overall impact is an improvement of the mechanical properties of the material [3]. The properties of MMCs are comparatively superior to those of the unreinforced alloys $[4,5]$.

The properties of discontinuously reinforced aluminum MMCs containing particles or short fibers are modest compared to the continuous fiber reinforced MMCs, however, these materials are less expensive to fabricate and have more flexibility in production making them more cost-effective [6-8]. The reinforcements used in fabricating the composites are dependent on the desired material properties, ease of processing, and part fabrication.

The stability of the reinforcement/metal matrix interface and the differences in properties such as the coefficient of thermal expansion and thermal conductivity are limiting factors that affect the compatibility of the materials used to make the composite. The quality of the bond is dependent on adequate interaction between the reinforcement and the matrix.

Over the last two decade, the application of nano and micro-sized ceramics such as alumina $\left(\mathrm{Al}_{2} \mathrm{O}_{3}\right), \mathrm{MgO}$ nanoparticle [9], boron carbide [10] and silicon carbide (SiC) [11] to aluminum metal matrix composites have become popular reinforcing phases, since these hard phases can lead to an increase in flow stress from the matrix by load transfer across a strong interface from the matrix to the reinforcement [12]. An example of the typical microstructure of a particle reinforced aluminum metal matrix composite is presented in Figure 1 and shows an $\mathrm{Al}_{2} \mathrm{O}_{3}$ particulate reinforced Al-6061 MMC. The properties of these reinforcements include high strength, high modulus of elasticity and high thermal and electrical resistance. The constraint imposed by the ceramic reinforcements on the plastic deformation of the matrix is large tensile hydrostatic stresses. 


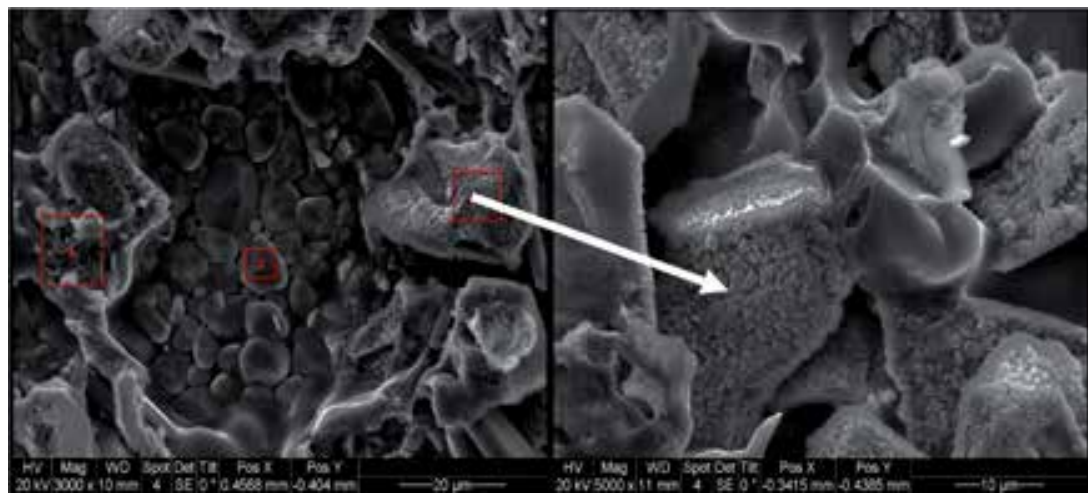

Figure 1.

SEM micrographs of Al-6061 MMC showing $\mathrm{Al}_{2} \mathrm{O}_{3}$ particulate reinforcements.

Recently, researchers have explored the use of graphene as a reinforcing phase within an aluminum metal matrix as a method of improving the mechanical properties of the composite [13]. The results of the study showed that the hardness, tensile strength, and ductility of the aluminum-graphene composite were approximately 2-3 times higher than the properties of the unreinforced aluminum alloys. The authors also demonstrated that the enhancements of the mechanical properties of the aluminum-graphene composite were proportional to the concentration of graphene added. Similar findings were published by Kumar et al. [14] and Jauhari et al. [15] who produced $\mathrm{Al} 6061 \mathrm{MMC}$ reinforced with graphene by ultrasonic liquid processing and microwave sintering respectively.

Metal matrix composites (MMCs) find application extensively in the design and construction of engineering components that require a lightweight material with superior mechanical properties such as high tensile strength, high Young's modulus, good wear resistance [16], and good elevated temperature properties. Al-MMCs are used extensively in industries such as aerospace, automotive, sports goods, and marine.

Numerous processes have been investigated for producing aluminum MMC. These include various casting techniques [17] and powder metallurgy approaches [18]. Currently, several additive manufacturing techniques are used to develop rapidly deposit aluminum alloys and composites $[19,20]$. From the list available additive manufacturing techniques; selective laser melting (SLM), and wire arc additive manufacturing have shown the greatest promise for producing aluminum alloys and composites [19, 21].

\subsection{Nomenclature and crystal structures}

Aluminum is a nonferrous and relatively low-cost material with a high strength to weight ratio. These characteristics make aluminum alloys and composites very attractive and competitive structural materials in several industries. For applications requiring greater mechanical strength, aluminum is alloyed with metals such as copper, zinc, magnesium, and manganese. The alloying components determine the series assigned to the aluminum alloy. The possible series categories range from $1 \mathrm{xxx}$ to $9 \mathrm{xxx}$. Aluminum alloys can be further divided into two categories: heattreatable and non-heat-treatable alloys. Heat-treatable alloys are those in which strength is developed by precipitation hardening [22].

These alloys are found in the 2xxx (aluminum-copper), 6xxx (aluminummagnesium-silicon), and 7xxx (aluminum-zinc-magnesium) series [23]. In 
non-heat-treatable alloys, strength is developed mainly by solid solution strengthening and strain hardening. The non-heat treatable alloys are found in the $1 \mathrm{xxx}$ (Al), 3xxx (Al-Mn), 4xxx (Al-Si) and 5xxx (Al-Mg) aluminum series. The Gibbs free energy curves recorded at a $700^{\circ} \mathrm{C}$ for $\mathrm{Al}-\mathrm{Mn}, \mathrm{Al}-\mathrm{Mg}, \mathrm{Al}-\mathrm{Cu}$, and $\mathrm{Al}-\mathrm{Zn}$ are shown in Figure 2 and suggest the formation of various intermetallic compounds having a hexagonal close pack (HCP) crystal structure within the aluminum matrix having a face-centered cubic structure (FCC). The $2 \mathrm{xxx}$ series which consists of $\mathrm{Al}-\mathrm{Cu}$ is a heat-treatable alloy that strengthens due to the precipitation of copper aluminides within the aluminum matrix [23].

Ternary systems of Al-Mg-Si and Al-Mg-Zn which are found in the 6xxx or 7xxx series respectively are other heat treatable aluminum alloys that are used in many applications within the aerospace and automobile industries. The high strength-toweight ratio and corrosion resistance of heat-treatable aluminum alloys make them a very attractive class of materials. The phase diagrams presented in Figure 3 show the relationship between temperature and composition for the $6 \mathrm{xxx}$ series.

\subsection{Development strategy and key applications}

The research on aluminum alloys and composites has seen substantial development in several new methods of fabricating components using aluminum as the
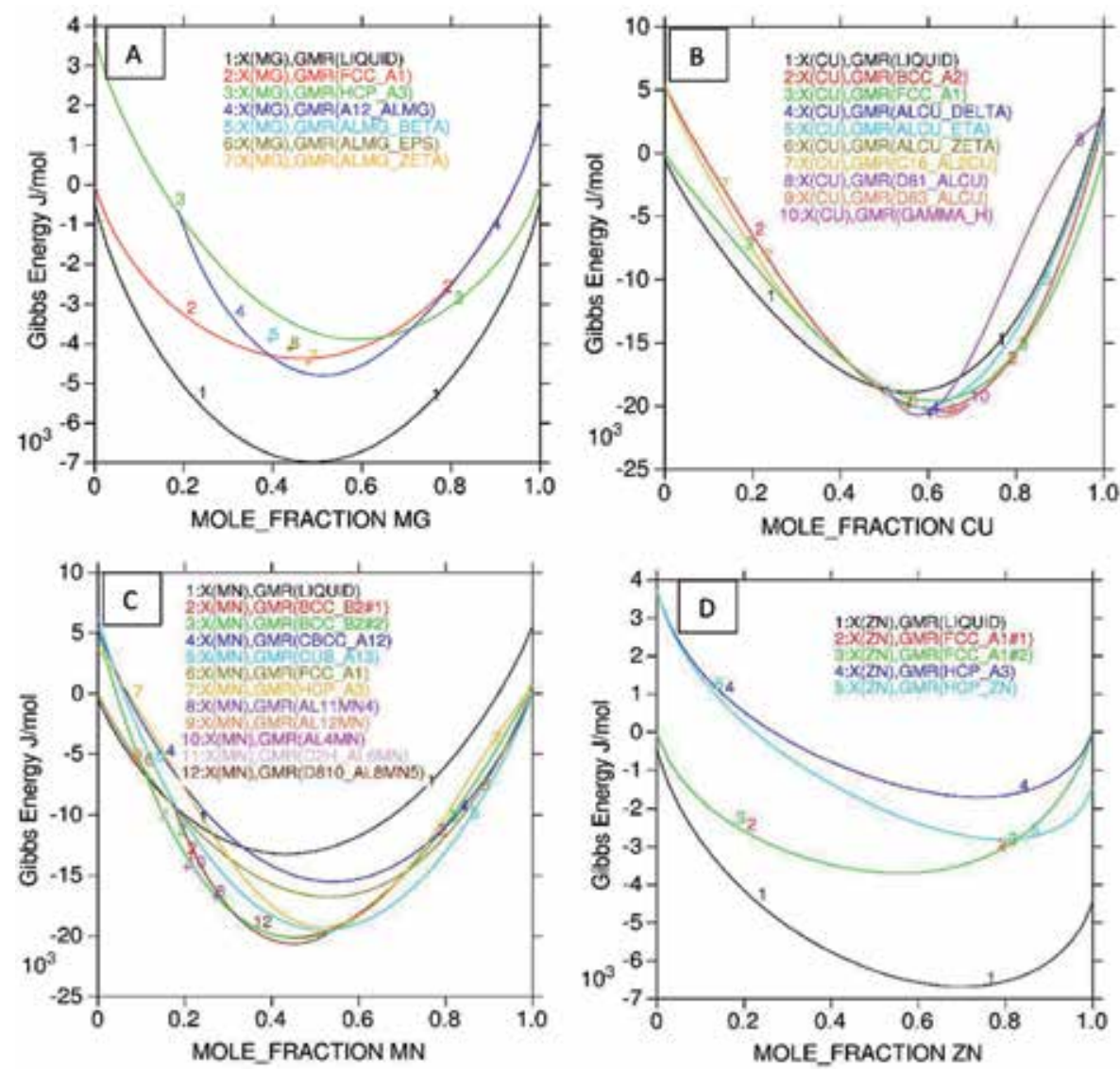

Figure 2.

Gibbs free energy curve plotted at a temperature of $700^{\circ} \mathrm{C}$ for (A) $\mathrm{Al}-\mathrm{Mg}$, (B) $\mathrm{Al}-\mathrm{Cu},(\mathrm{C}) \mathrm{Al}-\mathrm{Mn}$, (D) $\mathrm{Al}-\mathrm{Zn}$ alloys. 

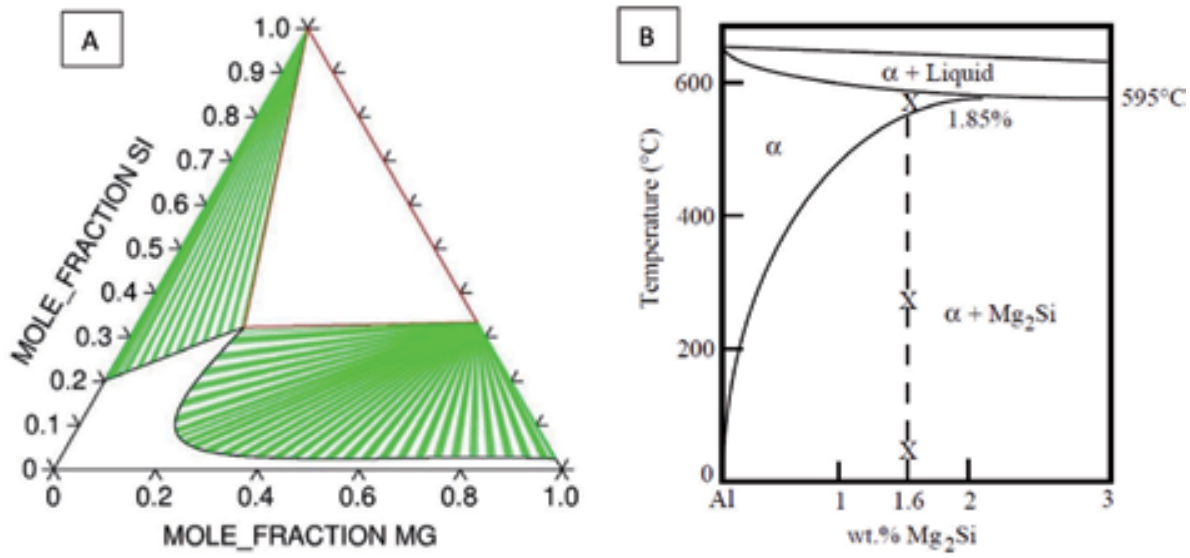

Figure 3.

(A) Isothermal section of the Al-Mg-Si ternary phase diagram at $700^{\circ} \mathrm{C}$ and (B) pseudo-binary phase diagram of $\mathrm{Al}-6061$.

\begin{tabular}{lcccc}
\hline Alloy & YS (MPa) & UTS (MPa) & Elongation (\%) & E (GPa) \\
\hline $6061(\mathrm{~T} 6)$ & 275 & 310 & 20 & 69 \\
\hline $2014(\mathrm{~T} 6)$ & 476 & 524 & 13 & 73 \\
\hline $2124(\mathrm{~T} 6)$ & 325 & 470 & 12 & 72 \\
\hline $2618(\mathrm{~T} 6)$ & 370 & 470 & 9 & 74 \\
\hline $7075(\mathrm{~T} 6)$ & 505 & 570 & 10 & 72 \\
\hline $8090(\mathrm{~T} 6)$ & 415 & 485 & 7 & 80 \\
\hline A356 (T6) & 205 & 280 & 6 & 76 \\
\hline
\end{tabular}

Table 1.

Typical properties of some heat treatable aluminum alloys [5].

base metal and combining the metal with new forms of reinforcements for various new applications. In a recent study, it was demonstrated that a 3D self-assembly of aluminum nanoparticle can be used for plasmon-enhanced solar desalination and [24]. Table 1 shows a summary of the properties of various heat treatable aluminum alloys. These properties justify the pervasive use of aluminum in automotive, aerospace and explosive mixtures for underwater propulsion. Among the available aluminum alloys, the $2 \mathrm{xxx}$ series, $6 \mathrm{xxx}$ series, and $7 \mathrm{xxx}$ series are used frequently in the aerospace and defense sectors, transportation, automotive, medical appliances, dental implants, sports, mobile phones, etc. [1, 2, 11, 25, 26].

Given the low melting point $\left(660^{\circ} \mathrm{C}\right)$ and density $\left(2.7 \mathrm{~g} / \mathrm{cm}^{3}\right)$ aluminum is now a key material used in metal additive manufacturing processes such as selective laser melting (SLM), these processes are largely termed layered manufacturing process in which the subject material is deposited in layers and build up to the required dimension [20]. Given the high strength-to-weight ratio and low melting temperature of aluminum, this material is used to fabricate various near-net-shape complex structures by additive manufacturing. Though additive manufacturing has seen extensive development over the last 5 years, there are several areas of the technology that will require significant research investment and investigation [20]. As the technology matures for depositing aluminum alloys will focus on process optimization to remove weaknesses such as oxide film formation on the surface of the metal powder, improve thermodynamic stability of the aluminum oxide and 
reduce the difficulty of finding low melting point binders to be used with aluminum powders [27-29].

Wire arc additive manufacturing (WAAM) using gas metal arc welding (GTAW) has been used successfully to deposit AA5183 aluminum alloy [21]. The technique demonstrated the potential of rapidly depositing large metal structures [30]; however, there is still the need for further development to optimized materials properties, surface texture and internal defects within the components produced.

The development of new aluminum alloys and composites is expected to continue to lower production costs and increasing the strength-weight ratio. These improvements in the properties of MMCs have made these materials important alternatives to traditional materials for high-temperature applications. Increasingly, aluminum MMCs containing $\mathrm{SiC}$ are used in engines (engine block and pistons), drive shafts and disc brakes (including rail type). It has been reported in the scientific literature that when MMCs are used to make drive-shafts the increase in stiffness, increases the maximum attainable rotation. The application of aluminum MMCs to the construction of pistons is one of the most significant developments in the automotive industry. In the electronics industry, the new generation of advanced integrated circuits generates more heat than previous types given the increase processing power. Therefore, the dissipation of heat has become a major concern. Thermal fatigue may also occur due to a small mismatch of the coefficient of thermal expansion between the silicon substrate and the heat sink. These problems can be solved by using MMCs with matching coefficients (e.g., Al with boron [10] or graphite fibers and $\mathrm{Al}$ with $\mathrm{SiC}$ particles [11]).

In addition, Al-based MMCs can be used in situations in which an "adjustable" coefficient of thermal expansion is required. This is possible because the coefficient of thermal expansion is dependent upon the volume fraction of the fibers or particles added. Components produced using Al-MMCs are not only significantly lighter than those produced from aluminum metal alloys, but they provide significant cost savings through net-shape manufacturing [31].

\subsection{Future challenges}

The research shows that the primary challenges affecting aluminum alloys and composite are directly linked to the properties of the material. An example can be seen in additive manufacturing where the growth in the application of aluminum in additive manufacturing has been driven by several important factors which include; low melting point, corrosion resistance, good strength-to-weight ratio. On the other hand, an important hurdle is finding suitable binders with the appropriate melting point to be used with powdered aluminum metals. The technology is also constrained by several other factors such as the need for a better understanding of the material properties, poor reproducibility, the need for additional material, lack of training and education of users and finally the unavailability of standards and certification.

Most manufacturers are cautious about using additive manufacturing as a viable manufacturing process due to the lack of repeatability and consistency of the manufactured parts. Manufacturers are also skeptical of the structural integrity of the finished products as compared to conventional manufacturing processes [12]. The primary challenge, however, is that materials produced using these processes contain numerous defects that limit the application.

The verification and validation of the relationships between the process parameters and the finished product have been hampered by the lack of available data, poor understanding of the causes of internal defects, and uncertainty in detecting the critical flaw. These gaps in the existing knowledge limit the wide-scale application 
of additive manufacturing technology. Research into this area will aim to bridge the gap by quantifying the relationship between the process parameters, surface quality and defects present within the finished products.

Aluminum alloys and composites (Al-MMCs) are of interest to the automotive and aerospace industries, because of comparably high strength-to-weight ratio, formability, and corrosion resistance. However, despite the unique properties of these materials, the lack of a reliable joining method has limited their use to engineering applications where joining is unnecessary. This can be seen as another major hurdle affecting the proliferation of aluminum alloys as an important material in achieving lightweighting objectives [34, 35].

Over the last two decades, numerous joining techniques have been extensive studied to identify a process that can be successfully used for dissimilar joining of aluminum alloys and composites by minimizing undesirable interfacial reactions between the materials being joined. Some of the processes that have been studied include fusion welding [36], brazing [37], friction stir welding [38], solid-state diffusion bonding [39] and transient liquid-phase (TLP) bonding [35, 40]. The key findings have shown that the inclusion of nanoparticles within the joint regions has the capability of significant increases in joint strength while minimizing unwanted interfacial reactions. The procedure has been applied to the diffusion bonding of aluminum alloys to magnesium as showing in see Figure $\mathbf{4}$ and diffusion bonding of Al-MMCs as shown in Figure 5. Application of the concept to resistance spot welding also proved successful as shown in Figure 6 which demonstrates that $\mathrm{Al}$ and $\mathrm{Mg}$ can be successfully welded together without the formation of undesirable compounds.

\subsection{Chapter plan}

This introductory chapter presents a brief overview of the state of science and the application of aluminum alloys and composites. Particular attention is paid to the application of new/novel methods of producing aluminum alloys while highlighting the future direction of the technology and some of the key challenges that affect the use of these materials. The book contains seven chapters that have been divided into two sections.

The first section of the text is focused on evaluating the types and properties of advanced aluminum alloys and composites. The chapters in this section provide a comprehensive overview of the processing, processing, formability, chemical composition of advance aluminum alloys and composites and the development of new types of alloys.
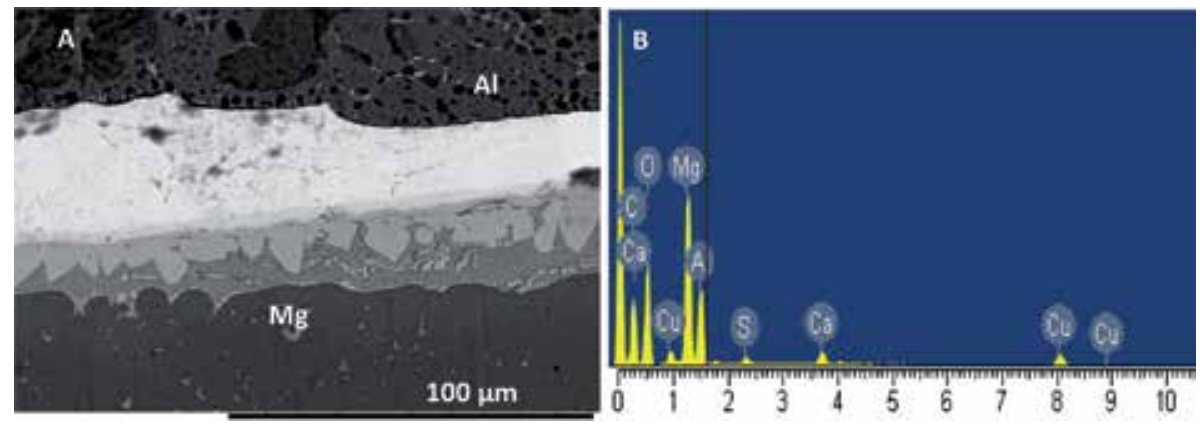

Figure 4 .

Eutectic microstructure formed at the joint interface during TLP bonding: (A) eutectic microstructure formed using $\mathrm{Cu} / \mathrm{Al}_{2} \mathrm{O}_{3}$ interlayer; and (B) EDS spectrum of region-2 [32, 33]. 


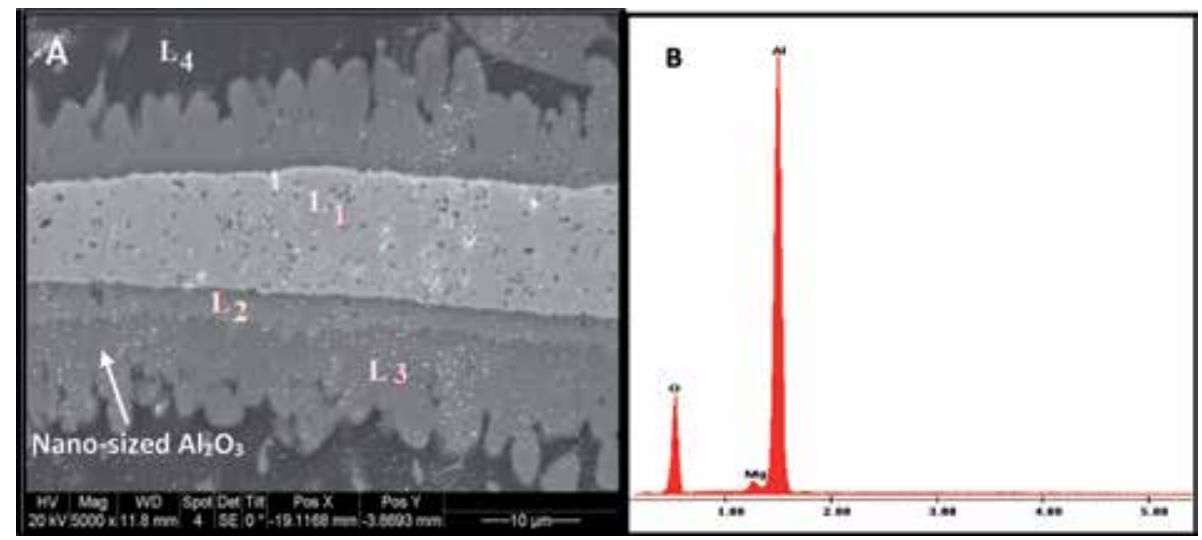

Figure 5.

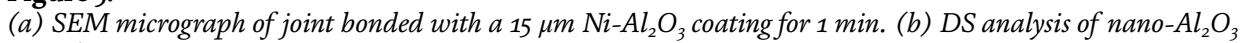
particle.
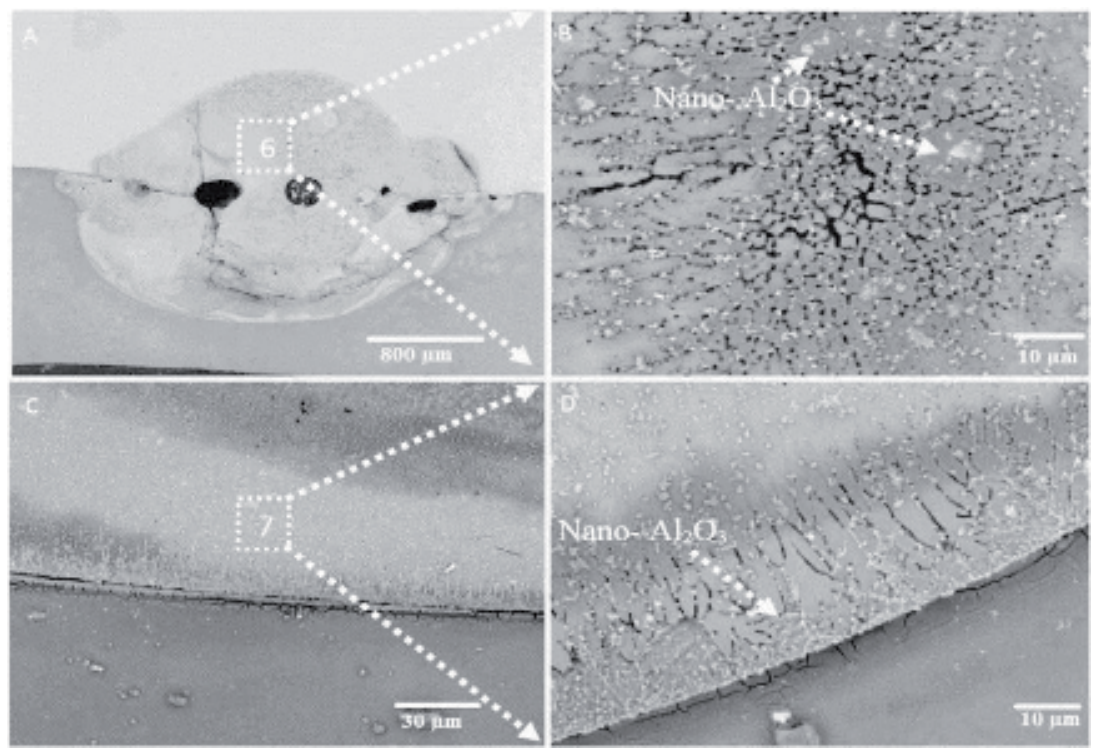

Figure 6.

SEM micrograph showing: (A) Al/Ni-Al $\mathrm{Ol}_{2} / \mathrm{Mg}$ spot weld; (B) microstructure of point-6; (C) weld nugget/Al interface; and (D) microstructure of point-7 $[41,42]$.

The second section of the text contains chapters that are focused on exploring processing, characterization, and testing of aluminum alloys and composites such as wear testing. The advantage of this text is that it provides a detailed review of major advances that have occurred in the development and application of aluminum alloys and composites while outlining a development strategy for these materials. 


\section{Author details}

Kavian Omar Cooke

Faculty of Engineering and Informatics, University of Bradford, West Yorkshire, UK

*Address all correspondence to: kavian_cooke@yahoo.com

\section{IntechOpen}

(C) 2020 The Author(s). Licensee IntechOpen. This chapter is distributed under the terms of the Creative Commons Attribution License (http://creativecommons.org/licenses/ by/3.0), which permits unrestricted use, distribution, and reproduction in any medium, provided the original work is properly cited. (cc) BY 


\section{References}

[1] Rashed HMMA, Bazlur Rashid AKM. Heat treatment of aluminum alloys. In: Compr. Mater. Finish. Vol. 2. Amsterdam, Netherlands: Elsevier; 2017. pp. 337-371. DOI: $10.1016 /$ B978-0-12-803581-8.09194-3

[2] Kurmanaeva L, Topping TD, Wen H, Sugahara H, Yang H, Zhang D, et al. Strengthening mechanisms and deformation behavior of cryomilled $\mathrm{Al}-\mathrm{Cu}-\mathrm{Mg}-\mathrm{Ag}$ alloy. Journal of Alloys and Compounds. 2015. DOI: 10.1016/j. jallcom.2015.01.160

[3] Haghshenas M. Metal-matrix composites. In: Ref. Modul. Mater. Sci. Mater. Eng. Amsterdam, Netherlands: Elsevier; 2016. DOI: $10.1016 /$ b978-0-12-803581-8.03950-3

[4] Chennakesava Reddy A, Zitoun E. Matrix al-alloys for silicon carbide particle reinforced metal matrix composites. Indian Journal of Science and Technology. 2010. DOI: 10.17485/ ijst/2010/v3i12/29857

[5] Davis JR. ASM Specialty Handbook: Aluminum and Aluminum Alloys. Cleveland, Ohio, United States: ASM Int; 1993. DOI: 10.1017/ CBO9781107415324.004

[6] Mavhungu ST, Akinlabi ET, Onitiri MA, Varachia FM. Aluminum matrix composites for industrial use: Advances and trends. Procedia Manufacturing. 2017;7:178-182. DOI: 10.1016/j.promfg.2016.12.045

[7] Cooke K, Oliver G, Buchanan V, Palmer N. Optimisation of the electric wire arc-spraying process for improved wear resistance of sugar mill roller shells. Surface and Coatings Technology. 2007. DOI: 10.1016/j. surfcoat.2007.05.015

[8] Cooke KO. A comparative analysis of techniques used for joining intermetallic MMCs. Journal of Composite Materials. 2018:221-241. DOI: 10.1016/ B978-0-85709-346-2.00009-1

[9] Praveen K, Girisha C, Yogeesha H. Synthesis, characterization and mechanical properties of A356.1 aluminium alloy matrix composite reinforced with Mgo nano particles. International Journal of Engineering and Science Invention. 2014

[10] Reddy PS, Kesavan R, Vijaya Ramnath B. Investigation of mechanical properties of aluminium 6061-silicon carbide, boron carbide metal matrix composite. Silicon. 2018. DOI: 10.1007/ s12633-016-9479-8

[11] Davim JP. Metal Matrix Composites: Materials, Manufacturing and Engineering. Berlin, germany: de Gruyter GmbH; 2014

[12] Saberi Y, Zebarjad SM, Akbari GH. On the role of nano-size $\mathrm{SiC}$ on lattice strain and grain size of $\mathrm{Al} / \mathrm{SiC}$ nanocomposite. Journal of Alloys and Compounds. 2009. DOI: $10.1016 / \mathrm{j}$. jallcom.2009.05.009

[13] Yolshina LA, Muradymov RV, Korsun IV, Yakovlev GA, Smirnov SV. Novel aluminum-graphene and aluminum-graphite metallic composite materials: Synthesis and properties. Journal of Alloys and Compounds. 2016. DOI: 10.1016/j.jallcom.2015.12.084

[14] Kumar P, Kujur MS, Mallick A, Tun KS, Gupta M. Processing and characterization of $\mathrm{Mg}-3 \% \mathrm{Al} /$ graphene nanocomposite. In: Met. 2017-26th Int. Conf. Metall. Mater. Conf. Proc. 2017

[15] Jauhari S, Prashantha Kumar HG, Anthony Xavior M. Synthesis and characterization of AA 6061-graphene$\mathrm{SiC}$ hybrid nanocomposites processed through microwave sintering. In: IOP 
Conf. Ser. Mater. Sci. Eng. 2016. DOI: 10.1088/1757-899X/149/1/012086

[16] Hima Gireesh C, Durga Prasad KG, Ramji K, Vinay PV. Mechanical characterization of aluminium metal matrix composite reinforced with Aloe vera powder. Materials Today: Proceedings. 2018. DOI: 10.1016/j.matpr.2017.11.571

[17] Babu JSS, Nair KP, Kang CG. Fabrication and characterization of aluminum based nano-micro hybrid metal matrix composites. In: ICCM Int. Conf. Compos. Mater. 2007

[18] Bonneville J, Laplanche G, Joulain A, Gauthier-Brunet V, Dubois S. Al-matrix composite materials reinforced by $\mathrm{Al}-\mathrm{Cu}-\mathrm{Fe}$ particles. Journal of Physics Conference Series. 2010. DOI: 10.1088/1742-6596/240/1/012013

[19] Bock FE, Froend M, Herrnring J, Enz J, Kashaev N, Klusemann B. Thermal analysis of laser additive manufacturing of aluminium alloys: Experiment and simulation. In: AIP Conf. Proc. 2018. DOI: $10.1063 / 1.5034996$

[20] Aboulkhair NT, Simonelli M, Parry L, Ashcroft I, Tuck C, Hague R. 3D printing of aluminium alloys: Additive manufacturing of aluminium alloys using selective laser melting, Progress in Materials Science. 2019. DOI:10.1016/j. pmatsci.2019.100578

[21] Horgar A, Fostervoll H, Nyhus B, Ren X, Eriksson M, Akselsen OM. Additive manufacturing using WAAM with AA5183 wire. Journal of Materials Processing Technology. 2018. DOI: 10.1016/j.jmatprotec.2018.04.014

[22] Esmaeili S, Lloyd DJ, Jin H. A thermomechanical process for grain refinement in precipitation hardening AA6xxx aluminum alloys. Materials Letters. 2011. DOI: 10.1016/j. matlet.2010.12.035
[23] Apostol F, Mishin Y. Interatomic potential for the Al-Cu system. Physical Review B: Condensed Matter and Materials Physics. 2011. DOI: 10.1103/ PhysRevB.83.054116

[24] Zhou L, Tan Y, Wang J, Xu W, Yuan Y, Cai W, et al. 3D self-assembly of aluminium nanoparticles for plasmon-enhanced solar desalination. Nature Photonics. 2016. DOI: 10.1038/ nphoton.2016.75

[25] Segal VM. New hot thermomechanical processing of heat treatable aluminum alloys. Journal of Materials Processing Technology. 2016. DOI: 10.1016/j.jmatprotec.2015.12.009

[26] Materials L. Lighweight Materials 2016 Annual Report, 2017

[27] Olakanmi EO, Cochrane RF, Dalgarno KW. A review on selective laser sintering/melting (SLS/SLM) of aluminium alloy powders: Processing, microstructure, and properties. Progress in Materials Science. 2015. DOI: 10.1016/j.pmatsci.2015.03.002

[28] Olakanmi EO, Cochrane RF, Dalgarno KW. Densification mechanism and microstructural evolution in selective laser sintering of $\mathrm{Al}-12 \mathrm{Si}$ powders. Journal of Materials Processing Technology. 2011. DOI: 10.1016/j.jmatprotec.2010.09.003

[29] Olakanmi EO, Cochrane RF, Dalgarno KW. Spheroidisation and oxide disruption phenomena in direct selective laser melting (SLM) of prealloyed Al-Mg and Al-Si powders. In: TMS Annu. Meet. 2009

[30] Gu J, Ding J, Williams SW, Gu H, Ma P, Zhai Y. The effect of inter-layer cold working and post-deposition heat treatment on porosity in additively manufactured aluminum alloys. Journal of Materials Processing Technology. 2016. DOI: 10.1016/j.jmatprotec.2015.11.006 
[31] M RP, Saravanan R, Nagaral M. Fabrication and Wear behavior of particulate reinforced metal matrix composites-an overview. IOSR Journal of Mechanical and Civil Engineering. 2017. DOI: $10.9790 / 1684-1401041020$

[32] Akhtar TS, Cooke KO, Khan TI, Shar MA. Nanoparticle enhanced eutectic reaction during diffusion brazing of aluminium to magnesium. Nanomaterials. 2019. DOI: $10.3390 /$ nano9030370

[33] Cooke KO, Alhazaa A, Atieh AM. Dissimilar welding and joining of magnesium alloys: Principles and application. In: Magnes.-Wonder Elem. Eng. Appl. London, UK: IntechOpen Limited; 2019. DOI: 10.5772/intechopen.85111

[34] Kah P, Suoranta R, Martikainen J, Magnus C. Techniques for joining dissimilar materials: Metals and polymers. Reviews on Advanced Materials Science. 2014;16:229-237. DOI: 10.1007/s10856-005-6684-1

[35] Cooke KO, Khan TI, Oliver GD. Transient liquid phase diffusion bonding Al-6061 using nanodispersed Ni coatings. Materials and Design. 2012;33. DOI: 10.1016/j. matdes.2011.04.051

[36] Song G, Diao Z, Lv X, Liu L. TIG and laser-TIG hybrid filler wire welding of casting and wrought dissimilar magnesium alloy. Journal of Manufacturing Processes. 2018. DOI: 10.1016/j.jmapro.2018.06.005

[37] Muhamed M, Omar M, Abdullah S, Sajuri Z, Wan Zamri W, Abdullah M., Brazed joint interface bonding strength of AR500 steel and AA7075 aluminium alloy. Metals (Basel). 2018. DOI:10.3390/ met8090668

[38] Buffa G, Fratini L, Micari F. Mechanical and microstructural properties prediction by artificial neural networks in FSW processes of dual phase titanium alloys. Journal of Manufacturing Processes. 2012. DOI: 10.1016/j.jmapro.2011.10.007

[39] Panteli A, Robson JD, Chen Y-C, Prangnell $P B$. The effectiveness of surface coatings on preventing interfacial reaction during ultrasonic welding of aluminum to magnesium. Metallurgical and Materials Transactions A, Physical Metallurgy and Materials Science. 2013. DOI: 10.1007/ s11661-013-1928-z

[40] Cooke K, Khan T. Nanostructured $\mathrm{Ni} / \mathrm{Al}_{2} \mathrm{O}_{3}$ interlayer: Transient liquid phase diffusion bonding of Al6061-MMC. In: Encycl. Alum. Its Alloy. Boca Raton, Florida, USA: CRC Press; 2019. DOI: 10.1201/9781351045636-140000277

[41] Cooke KO, Khan TI. Resistance spot welding aluminium to magnesium using nanoparticle reinforced eutectic forming interlayers. Science and Technology of Welding and Joining. 2017;23:271-278. DOI: 10.1080/13621718.2017.1373481

[42] Cooke KO, Khan TI. Microstructure development during low-current resistance spot welding of Aluminum to magnesium. Journal of Manufacturing and Materials Processing. 2019. DOI: 10.3390/jmmp3020046 



\title{
Aluminum Mineral Processing and Metallurgy: Iron-Rich Bauxite and Bayer Red Muds
}

\author{
Yingyi Zhang, Yuanhong Qi and Jiaxin Li
}

\begin{abstract}
Bauxite is the main source for alumina production. With the rapid development of iron and steel industry and aluminum industry, high-quality iron ore and bauxite resources become increasingly tense. However, a lot of iron-rich bauxite and Bayer red mud resources have not been timely and effectively recycled, resulting in serious problems of environmental pollution and wastage of resources. The comprehensive utilization of iron-rich bauxite and red mud is still a worldwide problem. The industrial stockpiling is not a fundamental way to solve the problems of ironrich bauxite and red mud. As to the recovery of valuable metals from iron-rich bauxite and red mud, there are a lot of technical and cost problems, which are serious impediments to industrial development. Applying red mud as construction materials like cement, soil ameliorant applications face the problem of $\mathrm{Na}, \mathrm{Cr}, \mathrm{As}$ leaching into the environment. However, the high-temperature reduction, smelting and alkaline leaching process is a feasible method to recover iron and alumina from iron-rich bauxite and red mud. This chapter intends to provide the reader an overview on comprehensive utilization technology of the low-grade iron-rich bauxite and Bayer red mud sources.
\end{abstract}

Keywords: bauxite, iron-rich bauxite, Bayer red mud, Bayer process, magnetic separation, reduction and smelting process

\section{Introduction}

With $8.30 \%$, aluminum is the third element in the earth's crust after the oxygen and the silicon, and for that reason, aluminum minerals are abundant with more than 250 kinds. They are mainly composed of bauxite, kaolinite and alunite. However, only the bauxite is used as source for alumina $\left(\mathrm{Al}_{2} \mathrm{O}_{3}\right)$ production. As of 2017, approximately $95 \%$ of the world's bauxite production is processed first into alumina, and then into aluminum by electrolysis [1]. The bulk of bauxite production is used as feed for the manufacture of alumina via a wet chemical caustic leach process known as the Bayer process [2]. The majority of the alumina produced from this refining process is smelted using the Hall-Héroult process to produce aluminum metal by electrolytic reduction in a molten bath of natural or synthetic cryolite $\left(\mathrm{NaAlF}_{6}\right)$ [3]. With the rapid development of iron and steel industry and aluminum industry, high-quality iron ore and bauxite resources become increasingly tense. However, a lot of iron-rich bauxite and Bayer red mud resources have not been 
timely and effectively recycled, resulting in serious problems of environmental pollution and resources waste. The comprehensive utilization of low-grade iron-rich bauxite and secondary aluminum mineral sources has attracted worldwide attention. It is an effective way to improve the efficient utilization of resources and the added value of products by using the scientific metallurgical recycling methods. This chapter intends to provide the reader with an overview on comprehensive utilization technology of the low grade iron-rich bauxite and secondary aluminum mineral sources.

\section{Bayer process alumina production}

Bauxite ore is the main raw material used in alumina production. The alumina production in major regions of the world in 2017 is shown in Figure 1. It can be seen that the growth in aluminum production continues to be driven by countries in Asia and the Gulf area, 2017 global aluminum production is nearly 126 million tons, and China has contributed with about 56\% (70.7 million tons).

Though alumina can be produced from bauxite under alkaline conditions using lime sinter process and sodium carbonate (Deville Pechiney process) at high temperature in reducing environment with presence of coke and nitrogen [4], the alkalinization by the use of sodium hydroxide (Bayer process) is the most economical process which is employed for purification of bauxite if it contains considerable amount of $\mathrm{Fe}_{2} \mathrm{O}_{3}$ [5]. Almost $90 \%$ of world's alumina production is from bauxite by the Bayer process. The bauxite ore with high alumina content and a high mass ratio of alumina to silica (A/S ratio) is preferred in the alumina industry. The free silica leads to the formation of Bayer sodalite with important losses of sodium hydroxide and alumina in the muds (near to $30 \%$ ) [6].

The production process of Bayer alumina is shown in Figure 2. In the Bayer process, bauxite is leached with a hot solution of sodium hydroxide $(\mathrm{NaOH})$ at temperature of $150-240^{\circ} \mathrm{C}$ and at $1-6$ atm pressure [7]. The aluminum minerals in the bauxite may be present as gibbsite $\left(\mathrm{Al}(\mathrm{OH})_{3}\right)$, boehmite $(\mathrm{AlOOH})$ or diaspore $(\mathrm{AlOOH})[8]$. The different forms of the aluminum component will dictate the

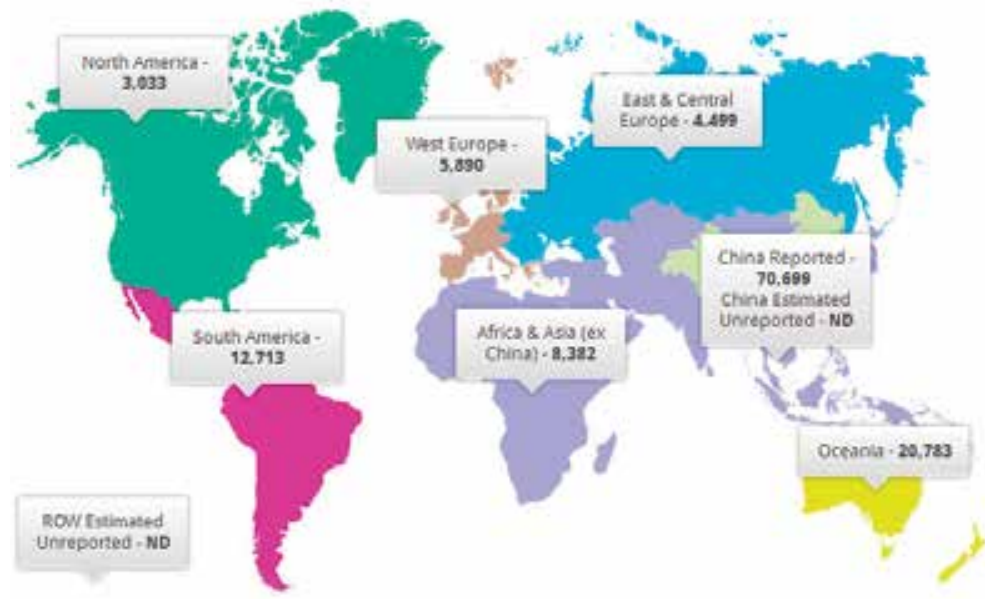

Figure 1.

Alumina production in major regions of the world in 2017. 


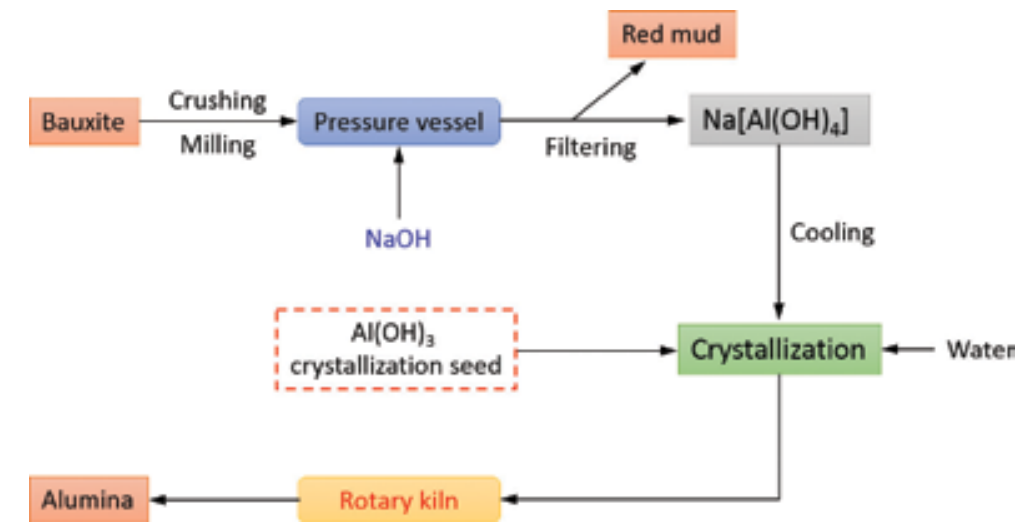

Figure 2.

The process flowsheet of Bayer alumina production.

extraction conditions. The undissolved waste and bauxite tailings contain iron oxides, silica, calcia, titania and some unreacted alumina. After separation of the residue by filtering, pure gibbsite (also known as bayerite) is precipitated when the liquid is cooled, and then seeded with fine-grained aluminum hydroxide. The gibbsite is usually converted into aluminum oxide, and then the aluminum hydroxide decomposes to alumina $\left(\mathrm{Al}_{2} \mathrm{O}_{3}\right)$ by heating in rotary kilns or fluid flash calciners at a temperature in excess of $1000^{\circ} \mathrm{C}$ [9]. This aluminum oxide is dissolved at a temperature of about $960^{\circ} \mathrm{C}$ in molten cryolite. Next, this molten substance is smelted into the metallic aluminum by the process of electrolysis, which is called the Hall-Héroult process, named in Ref. to the American and French inventors of the process [10].

\section{Iron-rich bauxite processing and metallurgy}

Iron-rich bauxite ore usually contains over $40 \mathrm{wt} \%$ iron oxide [11, 12], huge reserves are found in Australia, Guinea, Brazil, Laos, Vietnam and China, but they have not yet been used effectively. It is worth noting that more than 1.5 billion tons of iron-rich bauxite resources have been explored over the last 20 years in western Guangxi, China [13-15], which belong to the high-iron, low-aluminum silicon ratio type bauxite. These bauxites are very difficult to be leached by the Bayer process also and cannot be used as blast furnace burden. Iron-rich bauxite contains large amounts of silica and iron oxide with complex mineralogical composition and characteristics, which limit the use of this material as feedstock for conventional processes.

China's bauxite reserves are only $3 \%$ of the world's bauxite reserves, mainly deposited in Shanxi, Guizhou, Henan and Guangxi provinces. However, the ironrich bauxite accounts for more than $30 \%$ of China's total bauxite resources, which has a great deal of economic value, and more than 1.5 billion tons have been explored in the last 20 years. The typical iron-rich bauxite deposited in Guigang of Guangxi, China is shown in Figure 3.

\subsection{Mineralogical characteristics of iron-rich bauxite}

The typical iron-rich bauxite ore was provided by the Guigang Mine of Guangxi, China. The chemical composition of the iron-rich bauxite is shown in Table 1. It can be seen that the iron-rich bauxite mainly consisted of $40.42 \mathrm{wt} \% \mathrm{Fe}_{2} \mathrm{O}_{3}, 11.70 \mathrm{wt} \%$ 

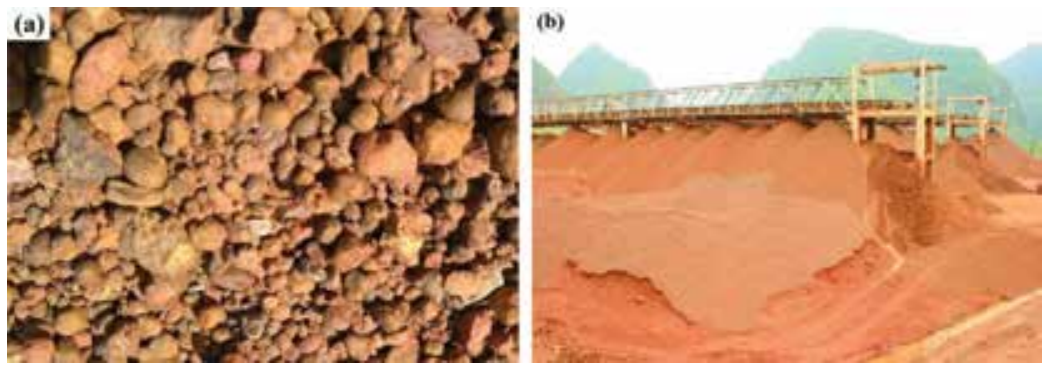

Figure 3.

The typical iron-rich bauxite ore (a) and mineral powder (b) deposited in Guigang of Guangxi, China.

\begin{tabular}{cccccccccc}
\hline $\mathrm{Fe}_{\text {tot }}$ & $\mathrm{Fe}_{2} \mathrm{O}_{3}$ & $\mathrm{FeO}$ & $\mathrm{SiO}_{2}$ & $\mathrm{Al}_{2} \mathrm{O}_{3}$ & $\mathrm{TiO}_{2}$ & $\mathrm{MnO}$ & $\mathrm{MgO}$ & $\mathrm{CaO}$ & LOI \\
\hline 28.29 & 40.42 & 0.20 & 11.77 & 26.53 & 1.57 & 1.21 & 0.48 & 1.38 & 16.42 \\
\hline
\end{tabular}

Table 1.

Chemical composition of iron-rich bauxite sample.

$\mathrm{SiO}_{2}$, and $26.53 \mathrm{wt} \% \mathrm{Al}_{2} \mathrm{O}_{3}$. The particle size distribution of iron-rich bauxite is shown in Figure 4(a) which was obtained with the Malvern Mastersizer 2000 particle size analyzer. The analysis results show that the average particle diameter and specific surface area of mixtures are $88.431 \mu \mathrm{m}$ and $0.149 \mathrm{~m}^{2} / \mathrm{g}$, respectively. The mineral phase composition of iron-rich bauxite was identified by X-ray diffraction (XRD) as shown in Figure 4(b). It can be seen that the gibbsite $\left[\mathrm{Al}(\mathrm{OH})_{3}\right]$, diaspore $[\mathrm{AlO}(\mathrm{OH})]$, goethite $[\mathrm{FeO}(\mathrm{OH})]$, hematite $\left(\mathrm{Fe}_{2} \mathrm{O}_{3}\right)$ and kaolin $\left(\mathrm{Mg}_{2} \mathrm{Si}_{3} \mathrm{O}_{8} \cdot 2 \mathrm{H}_{2} \mathrm{O}\right)$ are major mineral components in bauxite ore, the anatase $\left(\mathrm{TiO}_{2}\right)$ and quartz $\left(\mathrm{SiO}_{2}\right)$ are minor components.

The ore microscope observation shows that the mineral components in the bauxite ores are cryptocrystalline diaspore, hematite, ferrihydrite, kaolinite, anatase, vanadium titanomagnetite and chamosite (Figure 5(a)-(f)). It can be seen that most of the diaspores are cryptocrystalline with a small particle size and mainly coexists with ferrihydrite (Figure 5(d) and (f)). Kaolinite is the major clay mineral in the iron-rich bauxite. Kaolinite mainly coexists with gibbsite and anatase, and the edges of the gibbsite that are adjacent to the kaolinite show clear corrosion (Figure 5(b)), suggesting that kaolinite may have formed partially at the expense of gibbsite. Although most of the gibbsite are lamellar (Figure 5(a)), small amounts of euhedral-hypidiomorphic gibbsite $(50-300 \mu \mathrm{m})$ could be discovered in the matrix of the bauxite ores (Figure 5(b)). Most of the gibbsite in nature was transformed
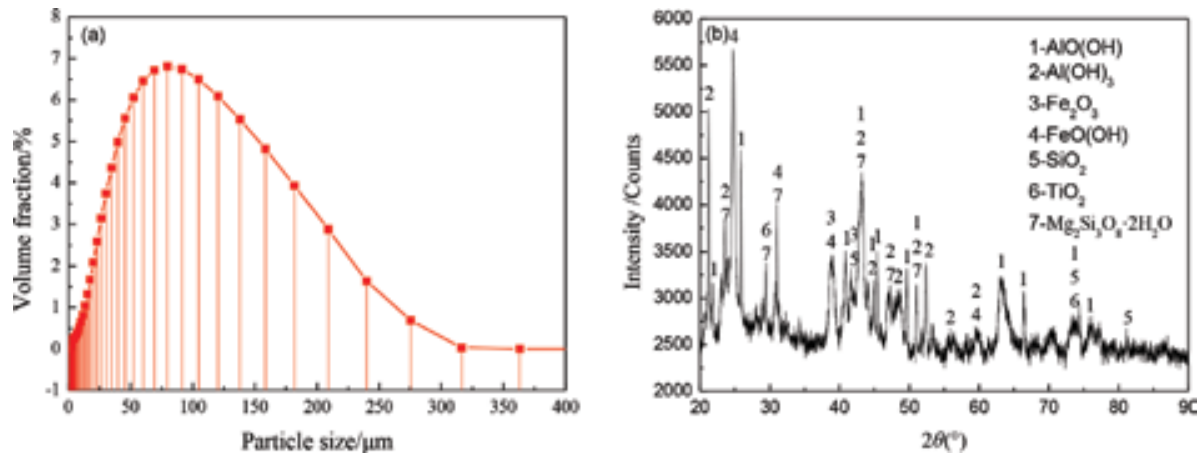

Figure 4 .

The particle size distribution (a) and XRD pattern (b) of typical iron-rich bauxite sample. 

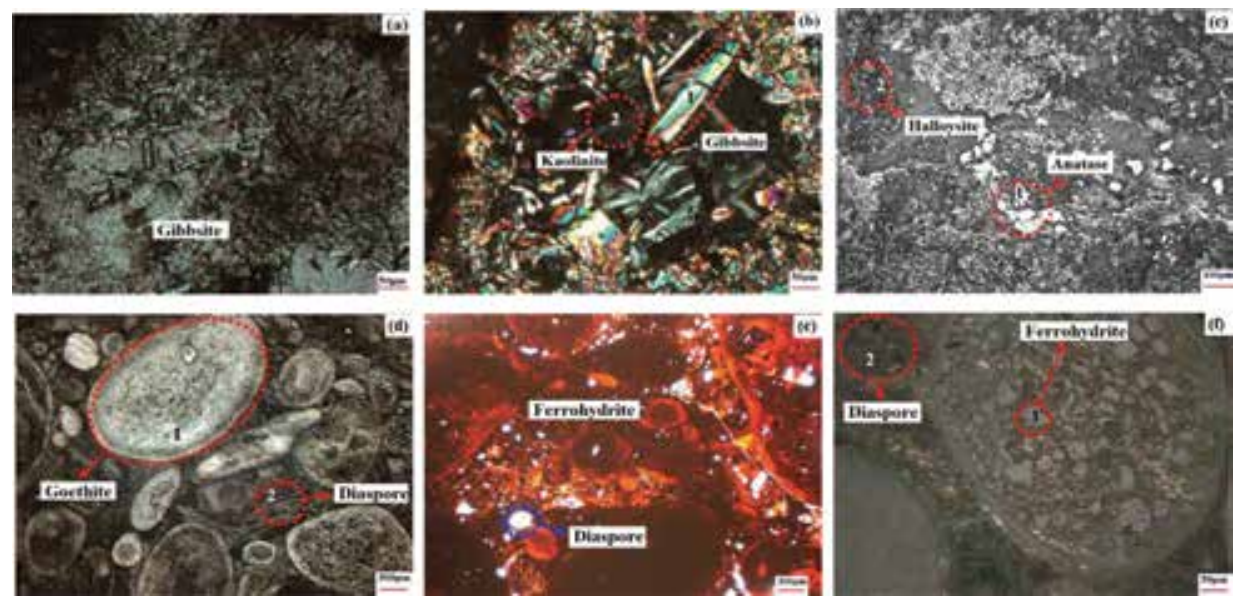

Figure 5 .

The microphotographs of typical iron-rich bauxite sample.

from K-feldspar and clay minerals during laterization processes, and it is characterized by a small crystal size. The gibbsite with relatively perfect crystals was commonly formed via precipitation from Al-rich solutions within the bauxite horizon. Anatase commonly precipitated in a reducing condition in the formation of the karst bauxite deposit $[16,17]$.

\subsection{Comprehensive utilization processes of iron-rich bauxite}

The heterogeneous minerals in iron-rich bauxite are treated with conventional techniques, such as gravity concentration [18], magnetic separation [19], flotation [20], roasting followed by magnetic separation [21, 22] and chemical leaching $[23,24]$. All of these conventional techniques cannot recover iron and aluminum from iron-rich bauxite effectively. The reverse flotation process of iron-rich bauxite cannot achieve effective separation of $\mathrm{Al}_{2} \mathrm{O}_{3}$ and $\mathrm{SiO}_{2}$, because it is characterized by a high content of $\mathrm{Al}_{2} \mathrm{O}_{3}$ and $\mathrm{SiO}_{2}$ and a low ratio of $\mathrm{Al}_{2} \mathrm{O}_{3}$ to $\mathrm{SiO}_{2}\left(m\left(\mathrm{Al}_{2} \mathrm{O}_{3}\right) / m\right.$ $\left(\mathrm{SiO}_{2}\right)=\mathrm{A} / \mathrm{S}$, usually 2-3) [25]. In order to produce a raw material suitable for sponge, the microwave reduction roasting and wet magnetic separation process of red mud was reported, only the total iron concentration of 35.15 and metallization degree of $69.3 \mathrm{wt} \%$ were obtained in the process [21]. The lateritic bauxite hydrochloric acid leaching process showed that when the ore granularity was less than $55 \mu \mathrm{m}$, the liquid/solid ratio (L/S ratio) was 100:7, the leaching temperature was $373-383 \mathrm{~K}$, the leaching time was $120 \mathrm{~min}$ and the $\mathrm{HCl}$ concentration was $10 \%$, both the leaching rates of Al and Fe were over 95\% [26]. But the hydrochloric acid leaching process was very expensive and caused serious environment pollution.

However, the high-temperature reduction and smelting process exhibit a lot of advantages for ironmaking [27, 28]. In this processes, carbon composite pellets are reduced and smelted to produce metallic iron, which is then separated from slag at a furnace temperature of $1573 \mathrm{~K}$ or higher. High-quality iron nuggets are an ideal feed material for steelmaking and can be used for electric arc furnace charging or as a basic oxygen furnace coolant [29, 30]. Zhang et al. [31] successfully obtained iron nuggets and autogenously pulverizable calcium aluminate slag from iron-rich bauxite through a high-temperature reduction and smelting process. The flow diagram for recovering iron and autogenously pulverizable slag from iron-rich bauxite is shown in Figure 6. 


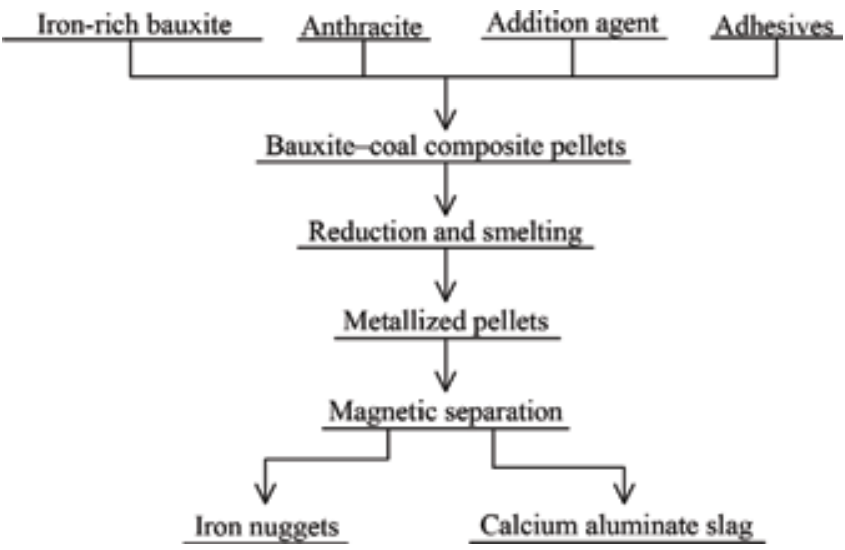

Figure 6.

The flow diagram for recovering iron and autogenously pulverizable slag from high-ferrous bauxite.
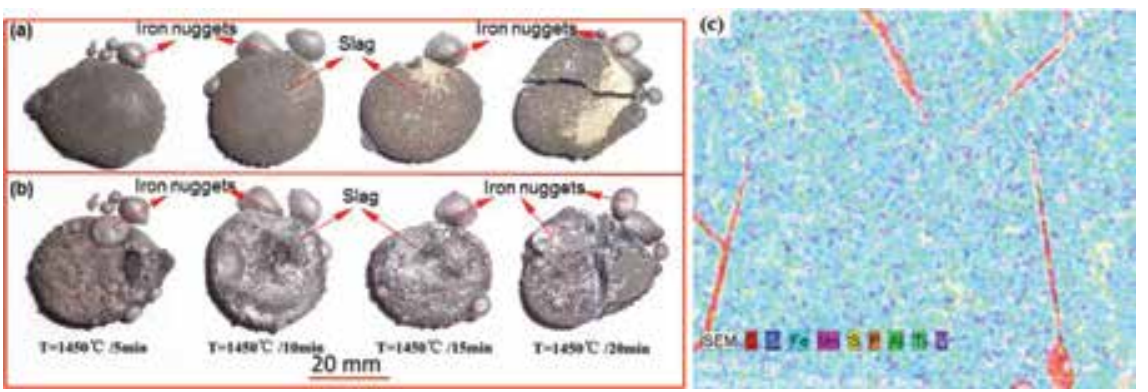

Figure 7.

The photos of iron nuggets and calcium aluminate slag obtained under the optimized process conditions.

(a) metallized pellets surfaces, (b) metallized pellets bottoms, (c) EDS map of an iron nugget.

\begin{tabular}{lcccccc}
\hline \multicolumn{6}{l}{ Chemical composition of the iron nuggets/wt\% } \\
\hline $\mathrm{Fe}$ & $\mathrm{C}$ & $\mathrm{Si}$ & $\mathrm{S}$ & $\mathrm{P}$ & $\mathrm{Mn}$ & \\
\hline 93.28 & 4.17 & 0.12 & 0.0043 & 0.0064 & 1.60 & \\
\hline \multicolumn{7}{l}{ Chemical composition of the autogenously pulverizable slag/wt\% } \\
\hline $\mathrm{FeO}$ & $\mathrm{Al}_{2} \mathrm{O} 3$ & $\mathrm{SiO}_{2}$ & $\mathrm{CaO}$ & $\mathrm{MnO}$ & $\mathrm{TiO}_{2}$ & $\mathrm{MgO}$ \\
\hline 1.28 & 27.21 & 13.69 & 52.83 & 1.35 & 1.74 & 0.85 \\
\hline
\end{tabular}

Table 2.

Chemical composition of the iron nuggets and autogenously pulverizable slag.

They found that the optimized process conditions were bauxite/anthracite/ slaked lime weight ratio of 100:16.17:59.37, reduction temperature at $1450^{\circ} \mathrm{C}$ and reduction time of $20 \mathrm{~min}$. Under these conditions, high-quality iron nuggets and calcium aluminate slag were obtained and shown in Figure 7. The largest size and the highest recovery rate of iron nuggets were $11.42 \mathrm{~mm}$ and $92.79 \mathrm{wt} \%$, respectively. The chemical composition of the iron nuggets and autogenously pulverizable calcium aluminate slag is shown in Table 2. It can be seen that the iron nuggets mainly consist of Fe, C and Mn. The total iron content exceeds $93.28 \mathrm{wt} \%$, and the $\mathrm{C}$ and Mn contents are 4.17 and $1.60 \mathrm{wt} \%$, respectively. Almost no harmful elements are present, specifically $\mathrm{S}$ and $\mathrm{P}$. The chemical composition of autogenously pulverizable slag mainly consisted of $\mathrm{Al}_{2} \mathrm{O}_{3}(27.21 \mathrm{wt} \%), \mathrm{SiO}_{2}$ (13.69 wt\%) and $\mathrm{CaO}$ 

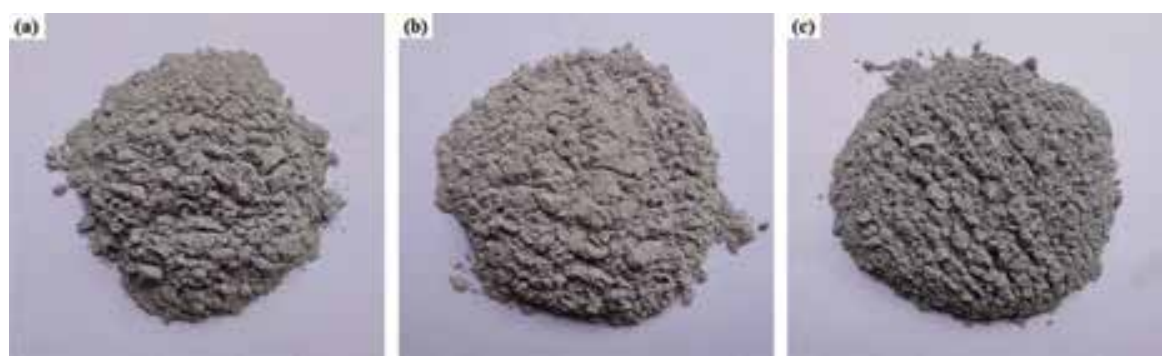

Figure 8.

The cement clinker of autogenously pulverizable slag. (a) $R=3.60$, (b) $R=3.85$, (c) $R=4.10$.

(52.83 wt\%), and the mineral constituent mainly comprised $\mathrm{Ca}_{2} \mathrm{SiO}_{4}$ and $\mathrm{Ca}_{12} \mathrm{Al}_{14} \mathrm{O}_{33}$, with small amounts of $\mathrm{FeAl}_{2} \mathrm{O}_{4}, \mathrm{CaAl}_{2} \mathrm{O}_{4}$ and $\mathrm{Ca}_{2} \mathrm{Al}_{2} \mathrm{SiO}_{7}$.

In addition, Zhang et al. [32] found that the autogenously pulverizable slag (calcium aluminate slag) cement clinker has a higher reactivity during the early stage of the hydration process, and the cement clinker of autogenously pulverizable slag is shown in Figure 8. After hydration for 28 days, the hydration products of autogenously pulverizable slag are mainly composed of killalaite $\left(\mathrm{Ca}_{3.2}\left(\mathrm{H}_{0.6} \mathrm{Si}_{2} \mathrm{O}_{7}\right)\right.$ $(\mathrm{OH})$ ), calcium silicate hydrate $\left(\mathrm{Ca}_{1.5} \mathrm{SiO}_{3.5} \cdot \mathrm{xH}_{2} \mathrm{O}\right)$ and calcium aluminates hydroxide $\left(3 \mathrm{CaO} \cdot \mathrm{Al}_{2} \mathrm{O}_{3} \cdot \mathrm{Ca}(\mathrm{OH})_{2} \cdot 18 \cdot \mathrm{H}_{2} \mathrm{O}, \mathrm{Ca1}_{2} \mathrm{Al}_{13.86} \mathrm{Fe}_{0.14}(\mathrm{OH})_{2}\right)$. With the increase of $\mathrm{w}$ $(\mathrm{CaO}) / \mathrm{w}\left(\mathrm{SiO}_{2}\right)$ ratios, the killalaite disappeared, the $3 \mathrm{CaO} \cdot \mathrm{Al}_{2} \mathrm{O}_{3} \cdot \mathrm{Ca}(\mathrm{OH})_{2 \cdot 18} \cdot \mathrm{H}_{2} \mathrm{O}$ and $\mathrm{Ca}_{12} \mathrm{Al}_{13.86} \mathrm{Fe}_{0.14}(\mathrm{OH})_{2}$ amounts increases gradually as a function of $\mathrm{w}(\mathrm{CaO}) / \mathrm{w}$ $\left(\mathrm{SiO}_{2}\right)$ ratio. The $\mathrm{C}_{3} \mathrm{~A}$ and $\mathrm{C}_{12} \mathrm{~A}_{7}$ have very exothermic hydration characteristic and faster hydration rate, promoted the hydration activity of $\beta-\mathrm{C}_{2} \mathrm{~S}$.

The autogenously pulverizable slag (calcium aluminate slag) can also be applied to leach alumina with $\mathrm{Na}_{2} \mathrm{CO}_{3}$ and $\mathrm{Na}_{2} \mathrm{C}$ solutions $[33,34]$. The ideal composition of calcium aluminate slags is $12 \mathrm{CaO} \cdot 7 \mathrm{Al}_{2} \mathrm{O}_{3}$ and $\gamma-2 \mathrm{CaO} \cdot \mathrm{SiO}_{2}$ [35]. The slag reacts with sodium carbonate solution and yields an alumina leaching efficiency of 85\% [36]. Therefore, the high-temperature reduction, smelting and alkaline leaching process is a feasible method to recover iron and alumina from iron-rich bauxite.

\section{Iron-rich red mud processing and metallurgy}

Red mud is the solid waste residue generated from the alumina refining of bauxite ore, primarily by the Bayer process which utilizes caustic soda to dissolve the aluminum silicate. Approximately, 35-40\% of the processed bauxite ore goes into the waste as alkaline red mud slurry which consists of $15-40 \%$ solids, and 1.0 1.5 tons of red mud is generated per ton of alumina produced [37]. It is estimated that annually 70 million tons of red mud is produced all over the world, with 0.7 million tons in Greece, 2 million tons in India, 30 million tons in Australia, nearly 30 million tons in China $[38,39]$ and presently it has been already accumulated in well over 4.0 billion tons [40]. With the quick development of alumina industry, the disposal of red mud has caused serious environmental problems mainly due to its large quantities and strong alkalinity $(\mathrm{pH}$ 10.0-12.5) [41]. At present, only little red mud is used to produce construction materials and calcination cement $[42,43]$. Most of the red mud is directly placed in landfill, deep sea and storage in settling ponds, as shown in Figure 9. Despite the harmful impact that these methods pose on our environment, the risks of failure of a poorly engineered storage dam can result in even greater social and economic damage. 

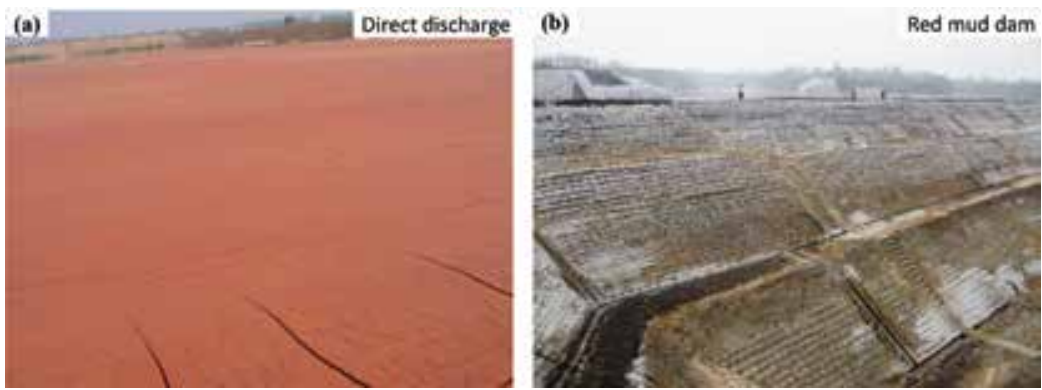

Figure 9.

The traditional disposal method of red mud.

\begin{tabular}{lccccc}
\hline $\begin{array}{l}\text { Chemical } \\
\text { composition }\end{array}$ & $\begin{array}{c}\text { Concentration } \\
(\mathbf{w t} \%)\end{array}$ & $\begin{array}{c}\text { Major } \\
\text { elements }\end{array}$ & $\begin{array}{c}\text { Concentration } \\
(\mathbf{w t} \%)\end{array}$ & $\begin{array}{c}\text { Minor } \\
\text { elements }\end{array}$ & $\begin{array}{c}\text { Concentration } \\
(\mathbf{m g} / \mathbf{k g})\end{array}$ \\
\hline $\mathrm{Fe}_{2} \mathrm{O}_{3}$ & $30-65$ & $\mathrm{Fe}$ & $4.52-50.6$ & $\mathrm{U}$ & $50-60$ \\
\hline $\mathrm{Al}_{2} \mathrm{O}_{3}$ & $10-20$ & $\mathrm{Al}$ & $4.42-16.06$ & $\mathrm{Ga}$ & $60-90$ \\
\hline $\mathrm{SiO}_{2}$ & $3-30$ & $\mathrm{Si}$ & $2.16-14.86$ & $\mathrm{~V}$ & 730 \\
\hline $\mathrm{Na}_{2} \mathrm{O}$ & $2-10$ & $\mathrm{Na}$ & $0.98-7.79$ & $\mathrm{Zr}$ & 1230 \\
\hline $\mathrm{CaO}$ & $2-8$ & $\mathrm{Ca}$ & $0.39-16.72$ & $\mathrm{Sc}$ & $54-120$ \\
\hline $\mathrm{TiO}_{2}$ & $\mathrm{Trace}-15$ & $\mathrm{Ti}$ & $0.98-5.34$ & $\mathrm{Cr}$ & 497 \\
\hline
\end{tabular}

Table 3.

Typical chemical composition and metal content of red mud $[37,45,46]$.

\subsection{Mineralogical characteristics of iron-rich red mud}

Red mud is mainly composed of coarse sand and fine particles of mud. Its composition, property and phase vary with the origin of the bauxite and the alumina production process, and will change over time when stocked [44]. No matter what the production process is, the chemical composition of red mud contains six major constituents. Chemical analysis shows that red mud contains $\mathrm{Si}, \mathrm{Al}, \mathrm{Fe}, \mathrm{Ca}$, $\mathrm{Ti}, \mathrm{Na}$, as well as an array of minor elements, namely $\mathrm{U}, \mathrm{Ga}, \mathrm{V}, \mathrm{Zr}, \mathrm{Sc}, \mathrm{Cr}, \mathrm{Mn}, \mathrm{Ni}$, $\mathrm{Zn}$ etc. $[37,45,46]$. The variation in chemical composition between red mud worldwide is very high. Typical chemical composition and metal content of Bayer process red mud are shown in Table 3. The calcium oxide $(\mathrm{CaO})$ and silica $\left(\mathrm{SiO}_{2}\right)$ are the major constituents for red mud from the sintering process, but the contents of $\mathrm{Fe}_{2} \mathrm{O}_{3}$ in red mud from the sintering process and combined process are much lower than that from the Bayer process. The major chemical composition of ironrich red mud generated in alumina plants in various countries over the world is presented in Table 4.

Generally, the major mineralogical constituents of iron-rich red mud from the Bayer process are gibbsite $\left(\mathrm{Al}(\mathrm{OH})_{3}\right)$, boehmite $(\gamma$-AlOOH $)$, hematite $\left(\mathrm{Fe}_{2} \mathrm{O}_{3}\right)$, goethite $(\mathrm{FeO}(\mathrm{OH}))$, quartz $\left(\mathrm{SiO}_{2}\right)$, rutile $\left(\mathrm{TiO}_{2}\right)$, anatase $\left(\mathrm{TiO}_{2}\right)$ and calcite $\left(\mathrm{CaCO}_{3}\right)[47,48]$, and the principal mineralogical constituents of red mud from the sintering process are $\beta-2 \mathrm{CaO} \cdot \mathrm{SiO}_{2}$, calcite $\left(\mathrm{CaCO}_{3}\right)$, aragonite $\left(\mathrm{CaCO}_{3}\right)$, hematite $\left(\mathrm{Fe}_{2} \mathrm{O}_{3}\right)$, gibbsite $\left(\mathrm{Al}(\mathrm{OH})_{3}\right)$ and perovskite $\left(\mathrm{CaTiO}_{3}\right)[49,50]$. Red mud is a very fine grained material with an average particle size $<10 \mu \mathrm{m}$. Typical values for particle size distribution are $90 \mathrm{wt} \%$ below $75 \mu \mathrm{m}$ [51]. The specific surface area (BET) of red mud is between 10 and $30 \mathrm{~m}^{2} / \mathrm{g}$, depending on the degree of grinding of bauxite. 
Aluminum Mineral Processing and Metallurgy: Iron-Rich Bauxite and Bayer Red Muds DOI: http://dx.doi.org/10.5772/intechopen.78789

\begin{tabular}{|c|c|c|c|c|c|c|c|c|c|}
\hline \multirow[t]{2}{*}{ Country } & \multirow[t]{2}{*}{ Plant } & \multicolumn{7}{|c|}{ Major composition (wt\%) } & \multirow[t]{2}{*}{ Ref. No. } \\
\hline & & $\mathrm{Al}_{2} \mathrm{O}_{3}$ & $\mathrm{Fe}_{2} \mathrm{O}_{3}$ & $\mathrm{SiO}_{2}$ & $\mathrm{TiO}_{2}$ & $\mathrm{CaO}$ & $\mathrm{Na}_{2} \mathrm{O}$ & $\mathrm{A} / \mathrm{S}$ & \\
\hline Italy & Eurallumina & 20.00 & 35.2 & 11.6 & 9.20 & 6.70 & 7.50 & 1.72 & {$[52]$} \\
\hline Turkey & Seydisehir & 20.39 & 36.94 & 15.74 & 4.98 & 2.23 & 10.10 & 1.30 & {$[53]$} \\
\hline UK & ALCAN & 20.00 & 46.00 & 5.00 & 6.00 & 1.00 & 8.00 & 4.00 & {$[54]$} \\
\hline Canada & ALCAN & 20.61 & 31.60 & 8.89 & 6.23 & 1.66 & 10.26 & 2.32 & {$[55]$} \\
\hline \multirow[t]{2}{*}{ Australia } & Tomakomai & 19.78 & 46.14 & 10.92 & 9.79 & 6.15 & 7.14 & 1.81 & {$[56]$} \\
\hline & Pinjarra & 19.77 & 41.85 & 27.51 & 4.51 & 4.51 & 1.85 & 0.72 & {$[57]$} \\
\hline Brazil & Alunorte & 15.1 & 45.60 & 15.60 & 4.29 & 1.16 & 7.50 & 0.97 & {$[58]$} \\
\hline Germany & AOSG & 16.20 & 44.80 & 5.40 & 12.33 & 5.22 & 4.00 & 3.00 & {$[58]$} \\
\hline \multirow[t]{2}{*}{ USA } & RMC & 18.4 & 35.50 & 8.50 & 6.31 & 7.73 & 6.10 & 2.16 & {$[58]$} \\
\hline & Point Comfort & 20.67 & 46.44 & 11.13 & 9.85 & 8.79 & 3.12 & 1.86 & {$[56]$} \\
\hline \multirow[t]{2}{*}{ India } & Damanjodi & 17.01 & 62.99 & 7.36 & 4.25 & 2.87 & 5.52 & 2.31 & {$[59]$} \\
\hline & Belgaum & 21.57 & 50.00 & 7.87 & 15.17 & 0.90 & 4.49 & 2.74 & [59] \\
\hline China & Chinalco & 19.08 & 36.13 & 28.19 & 0.77 & 2.84 & 12.99 & 0.68 & {$[60]$} \\
\hline
\end{tabular}

Table 4.

Major chemical composition of iron-rich red mud generated in alumina plants in various countries.

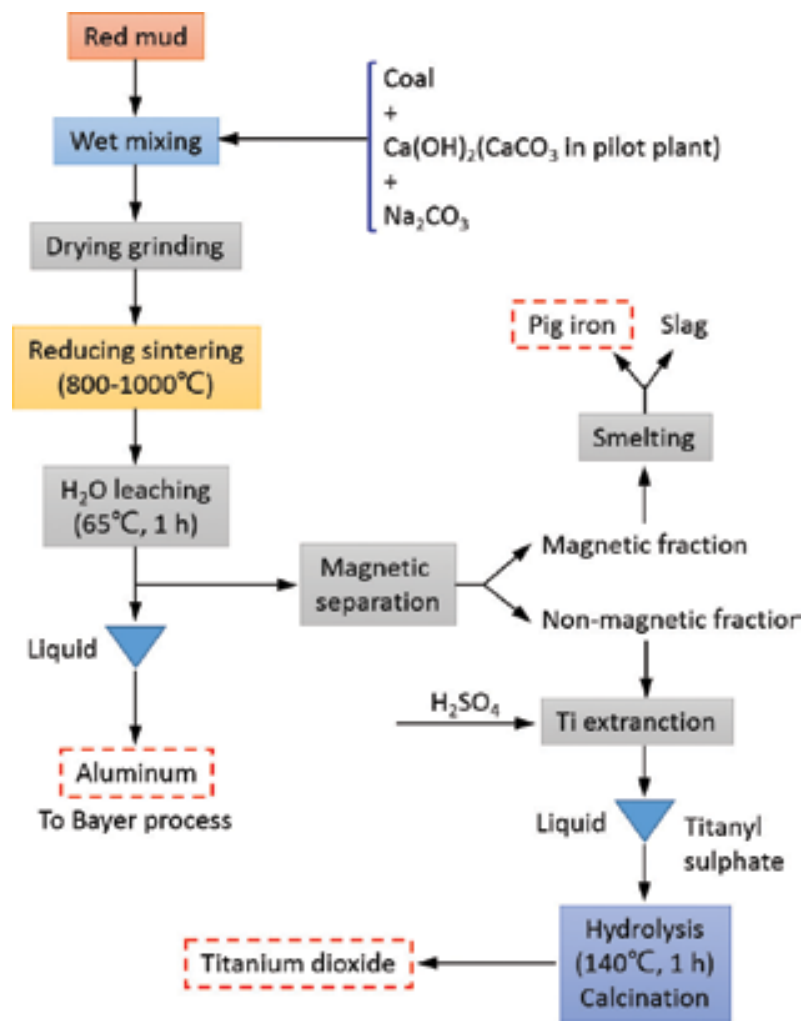

Figure 10.

Process flowsheet for metal extraction from red mud by a combined pyro- and hydrometallurgical process [67]. 


\subsection{Comprehensive utilization processes of iron-rich red mud}

During the past decades, extensive work has been done by a lot of researchers to develop various economic ways for the utilization of red mud. Such as the red mud from sintering process, containing some reactive substance such as $\beta-2 \mathrm{CaO} \cdot \mathrm{SiO}_{2}$, can be used to produce construction materials directly $[49,61]$. However, in Bayer process, $\mathrm{Al}_{2} \mathrm{O}_{3}$ is dissolved depending on sodium hydroxide from high-iron, highaluminum boehmite and gibbsite bauxite without calcination. Thus, there is less pozzolanic active substance in the Bayer red mud. It is not feasible to use red mud from Bayer process as construction materials directly [62]. Tsakiridis et al. [43] reported the research work on Bayer red mud addition in the raw meal for the production of Portland cement clinker. However, only 3-5\% red mud can be mixed with other raw materials, and it is not an effective way compared with the huge amount of the produced red mud. Pontikes et al. [63] did some research work on the thermal behavior of clay mixtures with bauxite residue for the production of heavyclay ceramics, which has potential utilization of red mud in industries. However, this method does not give full play to the potential value of red mud, and the

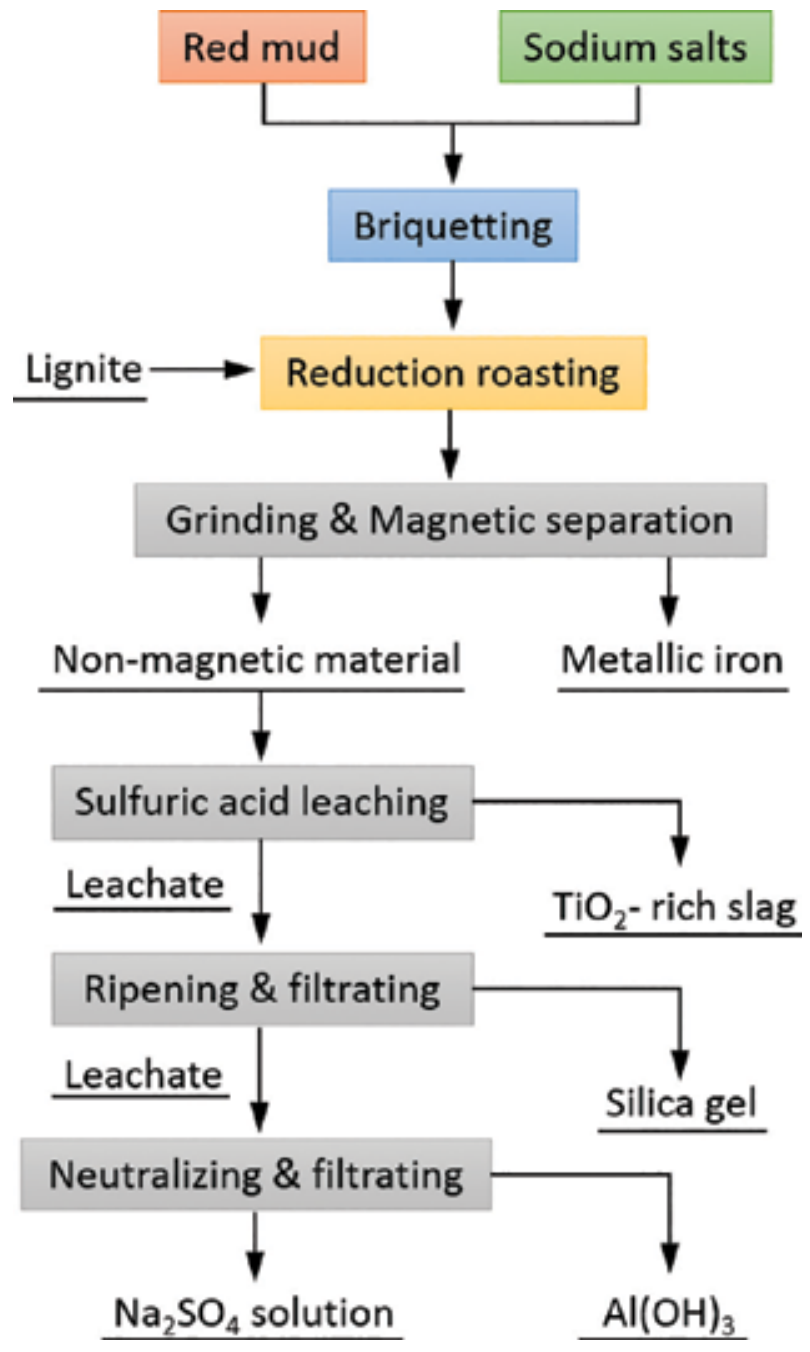

Figure 11.

Process flowsheet for reduction, roasting and magnetic separation process of red mud [68]. 
valuable metals in red mud are not utilized effectively. Some techniques of recovery of rare elements from red mud are not applied because of the complicated procedure and high cost, although some useful production such as gallium ( $\mathrm{Ga})$, titanium dioxide $\left(\mathrm{TiO}_{2}\right)$ and scandium (Sc) can be obtained [64-66].

As the high-iron content of the Bayer red mud, there are many techniques that have been intensively investigated for practical implementation with the purpose of recovering valuable components from this waste, such as combined pyrometallurgy and hydrometallurgical process [67], solid-state carbothermic reduction and magnetic separation [68], acid leaching [67] and smelting in a blast furnace [69]. A new concept of using red mud directly for ironmaking/smelting gives further promise.

A combined pyrometallurgical and hydrometallurgical process could also be employed to recover aluminum, iron and titanium elements [67]. The process flowsheet is shown in Figure 10. It can be seen that the red mud was first dried and then mixed with coal, lime and sodium carbonate. The mixture is reduced and sintered at $800-1000^{\circ} \mathrm{C}$. The sintered products underwent water leaching at $65^{\circ} \mathrm{C}$ for $1 \mathrm{~h}$ and $89 \%$ aluminum involved in the products was leached out. The filtrate obtained can be recycled in the Bayer process, and the residue was subjected to high-intensity magnetic separation. The titanium in the non-magnetic portion was taken to the solution by leaching with sulfuric acid. The titanyl sulfate was filtered and then hydrolyzed to metatitanic acid. This acid was then roasted to form $\mathrm{TiO}_{2}$ (87-89\% grade). At last, the magnetic portion was smelted at $1480^{\circ} \mathrm{C}$ and a product containing $93-94 \% \mathrm{Fe}, 4.5 \% \mathrm{C}$, was obtained.

$\mathrm{Li}$ et al. [68] carried out stepwise extraction of valuable components like $\mathrm{Fe}_{2} \mathrm{O}_{3}$, $\mathrm{Al}_{2} \mathrm{O}_{3}$ and $\mathrm{SiO}_{2}$ from reduced red mud by magnetic separation and sulfuric acid leaching. During the reductive roasting of red mud, sodium played an important role in reducing the dispersity of iron and hence increased the efficiency of magnetic separation. They found that the red mud was reduced at $1050^{\circ} \mathrm{C}$ for $60 \mathrm{~min}$ in

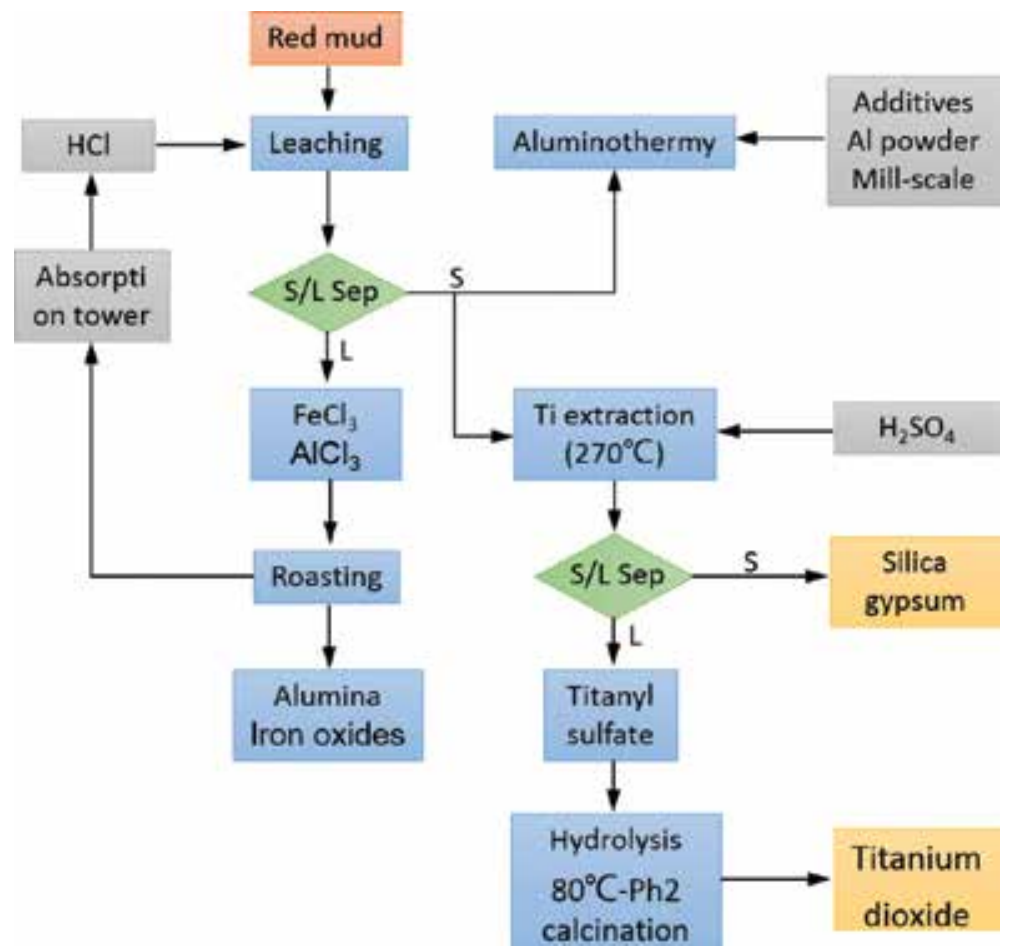

Figure 12.

Process flowsheet for metal recovery from red mud [67]. 
the presence of $6 \% \mathrm{Na}_{2} \mathrm{CO}_{3}$ and $6 \% \mathrm{Na}_{2} \mathrm{SO}_{4}$. In the enrichment of $\mathrm{TiO}_{2}$ by sulfuric acid leaching, $94.7 \% \mathrm{Fe}, 98.6 \% \mathrm{Al}$ and $95.9 \% \mathrm{Si}$ were extracted and left behind a material having $37.8 \% \mathrm{TiO}_{2}$. The process flowsheet for reduction, roasting and magnetic separation process of red mud is shown in Figure 11.

Piga et al. [67] used the acid leaching process to dispose the red mud, and they found that the titanium is soluble in sulfuric acid but not in hydrochloric acid. This process increased the recovery of $\mathrm{TiO}_{2}$ content in the residue from 31 to $58 \%$. The solids were then leached with sulfuric acid at $270^{\circ} \mathrm{C}$, followed by hydrolysis and roasting. The $\mathrm{TiO}_{2}$ content obtained was $96 \%$. The product can be used directly as $\mathrm{TiO}_{2}$ pigment or chlorinated to form $\mathrm{TiCl}_{4}$. The process flowsheet for $\mathrm{TiO}_{2}$ recovery from red mud is shown in Figure 12.

\section{Conclusions}

The comprehensive utilization of iron-rich bauxite and red mud is still a worldwide problem. At current levels of technology and practice, the capacity of consumption and secondary utilization is seriously insufficient. A large number of ironrich bauxite and red mud have not been used effectively. The industrial stockpiling is not a fundamental way to solve the problems of iron-rich bauxite and red mud. As to the recovery of valuable metals from iron-rich and red mud, there are a lot of technical and cost problems, which cause serious impediments to industrial development. Therefore, we must decrease the recycling process costs and energy consumption, promote the industrialization of valuable metals recovery processes, optimize complex processes and develop new processes. Applying red mud as construction materials like cement, soil ameliorant applications, face the problem of $\mathrm{Na}, \mathrm{Cr}$, As leaching into the environment. However, the high-temperature reduction, smelting and alkaline leaching process is a feasible method to recover iron and alumina from iron-rich bauxite and red mud. Due to the simple process, low cost, it is worth promoting its application in the field of iron and steel industry and aluminum industry.

\section{Acknowledgements}

This work was supported by the National Key Research and Development Program of China (2017YFB0603800 \& 2017YFB0603802) and the International Scientific and Technological Cooperation and Exchange Projects of China (No. 2013DFG50640). 


\section{Author details}

Yingyi Zhang ${ }^{1,2 *}$, Yuanhong $\mathrm{Qi}^{3}$ and Jiaxin $\mathrm{Li}^{1}$

1 School of Metallurgical Engineering, Anhui University of Technology, Maanshan, Anhui Province, PR China

2 College of Material Science and Engineering, Chongqing University, Chongqing, PR China

3 State Key Laboratory of Advance Steel Processes and Products, Central Iron and Steel Research Institute, Beijing, PR China

*Address all correspondence to: zhangyingyi@cqu.edu.cn

\section{IntechOpen}

(C) 2018 The Author(s). Licensee IntechOpen. This chapter is distributed under the terms of the Creative Commons Attribution License (http://creativecommons.org/licenses/ by/3.0), which permits unrestricted use, distribution, and reproduction in any medium, provided the original work is properly cited. (c) BY 


\section{References}

[1] Boni M, Rollinson G, Mondillo N, et al. Quantitative mineralogical characterization of karst bauxite deposits in the southern Apennines, Italy. Economic Geology. 2013;108(4): 813-833. DOI: 10.2113/econgeo.108. 4.813

[2] Djurić I, Mihajlović I, Živković Ž. Kinetic modelling of different bauxite types in the bayer leaching process. Canadian Metallurgical Quarterly. 2013; 49(3):209-218. DOI: 10.1179/ cmq.2010.49.3.209

[3] Mahadevan H, Ramachandran TR. Recent trends in alumina and aluminium production technology. Bulletin of Materials Science. 1996; 19(6):905-920. DOI: $10.1007 /$ BF02744627

[4] Yu ZL, Chen YM, Niu YJ, et al. Efficient and sustainable production of alumina by electrolysis of sodium carbonate. Angewandte Chemie. 2011; 50(49):11719-11723. DOI: 10.1002/ ange. 201104444

[5] Ostap S. Control of silica in the bayer process used for alumina production. Canadian Metallurgical Quarterly. 2013; 25(2):101-106. DOI: 10.1179/ cmq.1986.25.2.101

[6] Zhang R, Zheng SL, Ma SH, et al. Recovery of alumina and alkali in Bayer red mud by the formation of andradite-grossular hydrogarnet in hydrothermal process. Journal of Hazardous Materials. 2011;189(3): 827-835. DOI: $10.1016 / \mathrm{j}$.

jhazmat.2011.03.004

[7] Hind AR, Bhargava SK, Grocott SC. The surface chemistry of Bayer process solids: A review. Colloids and Surfaces A: Physicochemical and Engineering Aspects. 1999;146(1-3): 359-374. DOI: 10.1016/S0927-7757(98) 00798-5
[8] Kloprogge JT, Duong LV, Wood BJ, et al. XPS study of the major minerals in bauxite: Gibbsite, bayerite and (pseudo-) boehmite. Journal of Colloid and Interface Science. 2006;296(2):572-576. DOI: 10.1016/j.jcis.2005.09.054

[9] Xie ZP, Lu JW, Huang Y, et al. Influence of $\alpha$-alumina seed on the morphology of grain growth in alumina ceramics from Bayer aluminum hydroxide. Materials Letters. 2003;57 (16-17):2501-2508. DOI: 10.1016/ S0167-577X(02)01301-0

[10] Solheim A, Rolseth S, Skybakmoen $\mathrm{E}$, et al. Liquidus temperatures for primary crystallization of cryolite in molten salt systems of interest for aluminum electrolysis. Metallurgical and Materials Transactions B. 1996; 27(5):739-744. DOI: $10.1007 /$ BF02915602

[11] Papassiopi N, Vaxevanidou K, Paspaliaris I. Effectiveness of iron reducing bacteria for the removal of iron from bauxite ores. Minerals Engineering. 2010;23(1):25-31. DOI: 10.1016/j.mineng.2009.09.005

[12] Pickles C A, Lu T, Chambers B, et al. A study of reduction and magnetic separation of iron from high iron bauxite ore. Canadian Metallurgical Quarterly 2013:51(4):424-433. DOI: 10.1179/1879139512Y.0000000038

[13] Liu XF, Wang QF, Zhang QZ. Mineralogical characteristics of the superlarge quaternary bauxite deposits in jingxi and debao counties, Western Guangxi, China. Journal of Asian Earth Sciences; 2012; 52(3):53-62. DOI: 10.1016/j. jseaes.2012.02.011

[14] Wang QF, Deng J, Liu XF, et al. Discovery of the REE minerals and its geological significance in the Quyang bauxite deposit, West Guangxi, China. 
Journal of Asia Earth Sciences. 2010; 39(6):701-712. DOI: 10.1016/j. jseaes.2010.05.005

[15] Liu XF, Wang QF, Deng J, et al. Mineralogical and geochemical investigations of the Dajia Salento-type bauxite deposits, western Guangxi, China. Journal of Geochemical Exploration. 2010;105:137-152. DOI: 10.1016/j.gexplo.2010.04.012

[16] Özlü N. Trace element contents of karst bauxites and their parent rocks in the Mediterranean belt. Mineralium Deposita. 1983;18:469-476. DOI: 10.1007/BF00204491

[17] Zarasvandi A, Charchi A, Carranza E J M, Alizadeh B. Karst bauxite deposits in the Zagros Mountain belt, Iran. Ore Geology Reviews 2008;34:521-532. DOI: 10.1016/j.oregeorev.2008.05.005

[18] Smith P. The processing of high silica bauxites-review of existing and potential processes. Hydrometallurgy. 2009;98(1-2):162-176. DOI: 10.1016/j. hydromet.2009.04.015

[19] Bolsaitis P, Chang V, Schorin H, Aranguren R. Beneficiation of ferruginous bauxites by high-gradient magnetic separation. International Journal of Mineral Processing. 1981; 8(3):249-263. DOI: $10.1016 / 0301-7516$ (81) $90015-6$

[20] Massola CP, Chaves AP, Lima JRB, Andrade CF. Separation of silica from bauxite via froth flotation. Minerals Engineering. 2009;22:315-318. DOI: 10.1016/j.mineng.2008.09.001

[21] Michail S, Maria T, Petros ET, Konstantinos P. Greek "red mud" residue: A study of microwave reductive roasting followed by magnetic separation for a metallic iron recovery process. Journal of Hazardous Materials. 2013;254-255:193-205. DOI: 10.1016/j. jhazmat.2013.03.059
[22] Liu YY, Zhao BC, Tang Y, Wan PY. Recycling of iron from red mud by magnetic separation after co-roasting with pyrite. Thermochimica Acta. 2014; 588:11-15. DOI: 10.1016/j. tca.2014.04.027

[23] Zhao AC, Liu Y, Zhang TA, et al. Thermodynamics study on leaching process of gibbsite bauxite by hydrochloric acid. Transactions of Nonferrous Metals Society of China. 2013;23(1):266-270. DOI: 10.1016/ S1003-6326(13)62455-3

[24] Sancho JP, Ayala J, García MP, Fernández B. Leaching behavior of a bayer electro filter fines in sulphuric acid. Hydrometallurgy. 2009;(96): 35-41. DOI: 10.1016/j.hydromet. 2008.07.007

[25] Wang Y, Hu Y, He P, Gu G. Reverse flotation for removal of silicates from diasporic-bauxite. Minerals Engineering. 2004;17(1):63-68. DOI: 10.1016/j.mineng.2003.09.010

[26] Zhao AC, Liu Y, Zhang TA, Lv GZ, Dou $\mathrm{ZH}$. Thermodynamics study on leaching process of gibbsitic bauxite by hydrochloric acid. Transactions of Nonferrous Metals Society of China. 2013;23(1):266-270. DOI: 10.1016/ S1003-6326(13)62455-3

[27] Zhai XJ, Li NJ, Zhang X, Fu Y, Jiang L. Recovery of cobalt from converter slag of chambishi copper smelter using reduction smelting process.

Transactions of Nonferrous Metals

Society of China. 2011;21(9):2117-2121. DOI: 10.1016/S1003-6326(11)60982-5

[28] Kapure GU, Rao CB, Tathavadkar VD, Sen R. Direct reduction of low grade chromite overburden for recovery of metals. Ironmaking \& Steelmaking. 2011;38(38):590-596. DOI: 10.1179/ 1743281211Y.0000000028

[29] Ding YG, Wang JS, Wang G, Ma S, Xue QG. Comprehensive utilization of 
Paigeite ore using iron nugget making process. Journal of Iron and Steel Research, International. 2012;19(6): 9-13. DOI: 10.1016/S1006-706X(12) 60119-8

[30] Guo YH, Gao JJ, Xu HJ, Zhao K, Shi $\mathrm{XF}$. Nuggets production by direct reduction of high iron red mud. Journal of Iron and Steel Research, International. 2013;20(5):24-27. DOI: 10.1016/S1006-706X(13)60092-8

[31] Zhang YY, Wei L, Qi YH, et al. Recovery of iron and calcium aluminate slag from high-ferrous bauxite by hightemperature reduction and smelting process. International Journal of Minerals, Metallurgy, and Materials. 2016;23(8):881-890. DOI: 10.1007/ s12613-016-1303-3

[32] Zhang YY, Qi YH, Zou ZS. Early stage hydration properties of calcium aluminosilicate slag. International Conference on Advanced Design and Manufacturing Engineering (ICADME 2016); 23-24 July 2016; Shenzhen. 2016. pp. $32-38$

[33] Yu HY, Pan XL, Ding TT, Zhang W, Liu H, Bi SW. Adsorption of sodium polyacrylate at interface of dicalcium silicate-sodium aluminate solution. Transactions of Nonferrous Metals Society of China. 2011;21(10):

2323-2326. DOI: 10.1016/S1003-6326 (11) 61015-7

[34] Wang B, Sun HL, Guo D, Zhang XZ. Effect of $\mathrm{Na}_{2} \mathrm{O}$ on alumina leaching property and phase transformation of $\mathrm{MgO}$ containing calcium aluminate slags. Transactions of Nonferrous Metals Society of China. 2011;21(12): 2752-2757. DOI: 10.1016/S1003-6326 (11)61119-9

[35] Yu HY, Pan XL, Wang B, Zhang W, Sun HL, Bi SW. Effect of $\mathrm{Na}_{2} \mathrm{O}$ on formation of calcium aluminates in $\mathrm{CaO}-\mathrm{Al}_{2} \mathrm{O}_{3}-\mathrm{SiO}_{2}$ system. Transactions of Nonferrous Metals Society of China.
2012;22(12):3108-3112. DOI: 10.1016/ S1003-6326(11)61578-1

[36] Bi SW, Yang YH, Li YT, Zhang JD, Duan ZY. Study of alumina leaching from calcium aluminate slag. Light Metals. 1996:10-15

[37] Zhang R, Zheng S, Ma S, et al. Recovery of alumina and alkali in Bayer red mud by the formation of andraditegrossular hydrogarnet in hydrothermal process. Journal of Hazardous Materials. 2011;189(3):827-835. DOI: 10.1016/j. jhazmat.2011.03.004

[38] Agrawal A, Sahu KK, Pandey BD. Solid waste management in non-ferrous industries in India. Resources, Conservation and Recycling. 2004; 42(2):99-120. DOI: 10.1016/j. resconrec.2003.10.004

[39] Wang S, Ang HM, Tadé MO. Novel applications of red mud as coagulant, adsorbent and catalyst for environmentally benign processes. Chemosphere. 2008;72(11):1621-1623. DOI: 10.1016/j.chemosphere.2008.05.013

[40] Liu Y, Naidu R. Hidden values in bauxite residue (red mud): Recovery of metals. Waste Management. 2014; 34(12):2662-2673. DOI: 10.1016/j. wasman.2014.09.003

[41] Liu X, Zhang N, Yao Y, et al. Microstructural characterization of the hydration products of bauxitecalcination-method red mud-coal gangue based cementitious materials. Journal of Hazardous Materials. 2013; 262(8):428. DOI: 10.1016/j. jhazmat.2013.08.078

[42] Yang JK, Fan C, Hou J, et al. Engineering application of basic level materials of red mud high level

pavement. China Municipal

Engineering. 2006

[43] Tsakiridis PE, Agatzini-Leonardou $\mathrm{S}$, Oustadakis P. Red mud addition in 
the raw meal for the production of Portland cement clinker. Journal of Hazardous Materials. 2004;116(1-2): 103-110. DOI: $10.1016 / j$. jhazmat.2004.08.002

[44] Liu DY, Wu CS. Stockpiling and comprehensive utilization of red mud research progress. Materials. 2012;5(7): 1232-1246. DOI: 10.3390/ma5071232

[45] Sutar H. Progress of red mud utilization: An overview. American Chemical Science Journal. 2014;4(3): 255-279. DOI: 10.9734/ACSJ/2014/7258

[46] Wang W, Pranolo Y, Chu YC. Recovery of scandium from synthetic red mud leach solutions by solvent extraction with D2EHPA. Separation and Purification Technology. 2013; 108(16):96-102. DOI: 10.1016/j. seppur.2013.02.001

[47] Nan XL, Zhang TA, Liu Y, et al. Analysis of comprehensive utilization of red mud in China. The Chinese Journal of Process Engineering. 2010;10: 264-270

[48] Nenadović SS, Mucsi G, Kljajević LM, et al. Physicochemical, mineralogical and radiological properties of red mud samples as secondary raw materials. Nuclear Technology and radiation Protection. 2017;32(3):261-266. DOI: 10.2298/ NTRP1703261N

[49] Yang J, Xiao B. Development of unsintered construction materials from red mud wastes produced in the sintering alumina process. Construction and Building Materials. 2008;22(12): 2299-2307. DOI: $10.1016 /$ j. conbuildmat.2007.10.005

[50] Ying Z, Wang J, Liu CJ, et al. Characterization and risk assessment of red mud derived from the sintering alumina process. Fresenius Environmental Bulletin. 2009;18(6): 989-993
[51] Tian Y, Wang FX, Ma SC. The mechanical properties of red mud stockpiling. Light Metals. 1998;2:32-34

[52] Sglavo VM, Campostrini R, Maurina $\mathrm{S}$, et al. Bauxite 'red mud' in the ceramic industry. Part 1: Thermal behaviour. Journal of the European Ceramic Society. 2000;20(3):235-244. DOI: 10.1016/S0955-2219(99)00088-6

[53] Soner Altundoğan H, Altundoğan S, Tümen F, et al. Arsenic adsorption from aqueous solutions by activated red mud. Waste Management. 2002;22(3):

357-363. DOI: 10.1016/S0956-053X(01) 00041-1

[54] Srikanth S, Ray AK, Bandopadhyay A, et al. Phase constitution during sintering of red mud and red mud-fly ash mixtures. Journal of the American Ceramic Society. 2005;88(9):2396-2401. DOI: 10.1111/j.1551-2916.2005.00471.x

[55] Vachon P, Tyagi RD, Auclair JC, et al. Chemical and biological leaching of aluminum from red mud.

Environmental Science \& Technology. 1994;28(1):26. DOI: 10.1021/ es00050a005

[56] Hamdy MK, Williams FS. Bacterial amelioration of bauxite residue waste of industrial alumina plants. Journal of Industrial Microbiology \& Biotechnology. 2001;27(4):228-233. DOI: $10.1038 / \mathrm{sj} / \mathrm{jim} / 7000181$

[57] Zhang Y, Xu HJ, Cheng XL, et al. Comprehensive utilization of high-iron bauxite and high-iron red mud. Mining Research \& Development. 2015;6:30-35

[58] Snars K, Gilkes RJ. Evaluation of bauxite residues (red muds) of different origins for environmental applications. Applied Clay Science. 2009;46(1):13-20. DOI: 10.1016/j.clay.2009.06.014

[59] Prasad P, Subramanian S. Problems and prospects of red mud utilization. 
Transactions of the Indian Institute of Metals. 1997;50(5):427-442

[60] Liu W, Yang J, Xiao B. Review on treatment and utilization of bauxite residues in China. International Journal of Mineral Processing. 2009;93(3-4): 220-231. DOI: 10.1016/j.minpro.2009. 08.005

[61] Mymrin VA, Vázquez-Vaamonde AJ. Red mud of aluminium production waste as basic component of new construction materials. Waste Management \& Research the Journal of the International Solid Wastes \& Public Cleansing Association Iswa. 2001;19(5): 465-469. DOI: $10.1177 / 0734242 X 010$ 1900512

[62] Liu W, Yang J, Bo X. Application of Bayer red mud for iron recovery and building material production from alumosilicate residues. Journal of Hazardous Materials. 2009;161(1): 474-478. DOI: 10.1016/j.jhazmat.2008. 03.122

[63] Pontikes Y, Nikolopoulos P, Angelopoulos GN. Thermal behaviour of clay mixtures with bauxite residue for the production of heavy-clay ceramics. Journal of the European Ceramic Society. 2007;27(2-3):1645-1649. DOI: 10.1016/j.jeurceramsoc.2006.05.067

[64] Smirnov DI, Molchanova TV. The investigation of sulphuric acid sorption recovery of scandium and uranium from the red mud of alumina production. Hydrometallurgy. 1997;45(3):249-259. DOI: 10.1016/S0304-386X(96)00070-9

[65] Lu F, Xiao T, Lin J, et al. Recovery of gallium from Bayer red mud through acidic-leaching-ion-exchange process under normal atmospheric pressure. Hydrometallurgy. 2017;175:124-132.

DOI: 10.1016/j.hydromet.2017.10.032

[66] Liu Z, Li H, Jing Q, et al. Recovery of scandium from leachate of Sulfationroasted Bayer red mud by liquid-liquid extraction. Journal of Metals. 2017; 69(7):1-6. DOI: 10.1007/s11837-0172518-0

[67] Piga L, Pochetti F, Stoppa L. Recovering metals from red mud generated during alumina production. JOM. 1993;45(11):54-59. DOI: 10.1007/ BF03222490

[68] Li G, Liu M, Rao M, et al. Stepwise extraction of valuable components from red mud based on reductive roasting with sodium salts. Journal of Hazardous Materials. 2014;280:774-780. DOI: 10.1016/j.jhazmat.2014.09.005

[69] Trushko VL, Utkov VA, Sivushov AA. Reducing the environmental impact of blast furnaces by means of red mud from alumina production. Steel in Translation. 2017;47(8):576-578. DOI: 10.3103/S0967091217080149 


\title{
Aluminium and Its Interlinking Properties
}

\author{
K. Velmanirajan and K. Anuradha
}

\begin{abstract}
Aluminium and its alloys are preferred materials, because of its varied desirable properties, availability and inexpensiveness. Aluminium alloys exist in several different grades available in the market commercially, from pure (about 99\% Al content) to specific varieties based on the impurities contained in it by chemical composition. The properties are differing in nature which can be scientifically seen and justified in different perspectives. The properties such as forming, fracture mode, tensile, etc. can be seen through the metallurgical aspect, chemical aspect, crystallographic texture, forming limits and mechanical properties. The truth of its properties can be viewed by interlinking/correlating nature of its different studies. The purpose of this chapter is to show the correlating nature of different properties of aluminium of same and different grades.
\end{abstract}

Keywords: crystallographic texture, annealing, tensile, formability, void

\section{Introduction}

Ease of possessing light weight, formability and good strength-to-weight ratio are the desirable properties opted by the designer in the selection of materials for most modern engineering applications. Aluminium alloys vary by their tensile properties, formability properties and surface characteristics from one another at different dimensions, annealing temperatures, duration of annealing and mode of cooling, composition and percentage of initial strain [30-35]. In sheet metal forming, force is applied to a piece of sheet metal to modify its geometry rather then to remove any material. The applied force and stress on the sheet metal beyond its yield strength causes the material to plastically deform, without failing. As a result, the sheet can be bent or stretched into a variety of complex and required shapes. The forming operations of sheet metal include various types and conditions of strains, which can be significantly evaluated to predict the properties of the metal and its forming limit [2]. Preferably, the forming operation is done in most of the engineering applications, which require annealing procedures, microstructure examination, characterization of the sheets and their relations to attain higher formability [3].

The characterization involves the experimental determination of the microstructural aspects, tensile properties and formability parameters such as average plastic strain ratio and planar anisotropy [4]. For evaluating the forming limit diagrams (FLD), the results from the three strain conditions are combined. The formation of the crystallographic texture on the initial material also influences 
the formability of the sheet metal. Fracturing occurs in sheet metal forming when the strain exceeds a critical value and is considered as a factor determining the fracture limit diagram. The effect of sheet thickness on formability is a trend in study [5] (Rahavan et al., 2010). It is undertaken to interlink the formability of commercially pure aluminium grades of sheet metal through the study of mechanical (tensile) properties, formability property, forming limit diagrams, void coalescence properties and texture properties by experiments from the established results. Thus the study of the properties by one mode to the other is based on its correlation and interlinking properties.

\section{Chemical composition}

The aluminium alloy of grades, namely, $\mathrm{Al}$ 1350, $\mathrm{Al} 8011$ and $\mathrm{Al}$ 1145, available in the market in the form of cold-rolled sheets with different thickness of 1.2, 1.5 and $1.8 \mathrm{~mm}$, respectively, with different chemical compositions are chosen for the study.

$\mathrm{Fe}$ and Si particles are capable of stabilizing finer grains, which enhance the strength and ductility [13]. The presence of iron increases the recrystallization temperature, and silicon improves the fluidity of the alloy [25]. The addition of copper reduces pitting corrosion [25]. With the least presence of chromium or manganese and iron, aluminium alloy $\mathrm{Al} 8011$ may form $\mathrm{FeAl}_{3}$. The other elements include copper, manganese, magnesium, zinc, chromium, nickel, cadmium, lead and titanium, which are represented in Table 1 and are in negligible amounts.

\begin{tabular}{lcccccccccc}
\hline $\begin{array}{l}\text { Thickness and } \\
\text { grade }\end{array}$ & $\begin{array}{c}\text { Remainder } \\
\text { Al }\end{array}$ & Si & Cu & Fe & Sn & Zn & Cr & Mn & Ni & Ti \\
\hline 1.2 mm AA 1350 & 99.07 & 0.090 & 0.139 & 0.392 & 0.098 & 0.010 & 0.14 & 0.015 & 0.019 & 0.021 \\
\hline 1.5 mm AA 8011 & 98.13 & 0.919 & 0.013 & 0.653 & 0.096 & 0.01 & 0.004 & 0.026 & 0.013 & 0.019 \\
\hline 1.8 mm AA 1145 & 99.4 & 0.102 & 0.100 & 0.254 & 0.082 & 0.010 & 0.003 & 0.016 & 0.008 & 0.025 \\
\hline
\end{tabular}

Table 1.

Chemical composition of commercially pure aluminium alloy sheets of different thicknesses (In wt \%) [34, 35].

\section{Annealing}

Figure 1 indicates the duration of annealing (1hr) which was followed by cooling in furnace. These sheet metals were subjected to four different annealing temperature treatments, namely, 200, 250, 300 and $350^{\circ} \mathrm{C}$; soaking time was $1 \mathrm{~h}$, and furnace cooling was considered for experimentation and for forming operations.

\section{Microstructure}

In a microstructural analysis of $\mathrm{Al} 1350$, the result of the microstructural analysis of $\mathrm{Al} 1350$ has been tabulated in Table 2, which has partial recovery and no crystallization at an annealing temperature of $200^{\circ} \mathrm{C}$. But at an annealing temperature of $250^{\circ} \mathrm{C}$, it has partially recrystallized fully recovered microstructure.

The $200^{\circ} \mathrm{C}$ annealed sheet shows partial recovery with no recrystallization. The sheet annealed at $250^{\circ} \mathrm{C}$ is fully recovered and is partially recrystallized 


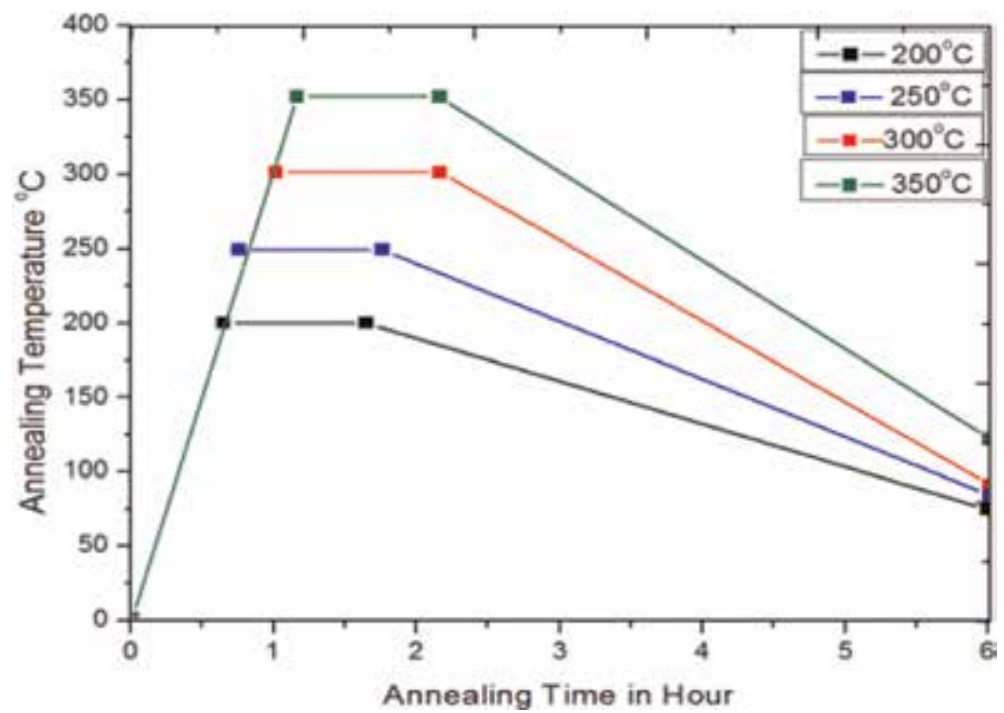

Figure 1.

Diagram showing plot of annealing time versus annealing temperature: (a) $200^{\circ} \mathrm{C},(\mathrm{b}) 250^{\circ} \mathrm{C},(\mathrm{c}) 300^{\circ} \mathrm{C}$ and (d) $350^{\circ} \mathrm{C}[30,32-35]$.

\begin{tabular}{|c|c|c|c|c|c|c|c|}
\hline $\begin{array}{l}\text { Annealing } \\
\text { temperature } \\
\left({ }^{\circ} \mathrm{C}\right)\end{array}$ & Orientation & n-value & r-value & $\begin{array}{c}\text { k-value } \\
(\mathrm{MPa})\end{array}$ & $\begin{array}{c}\text { Yield } \\
\text { strength } \\
(\mathrm{MPa})\end{array}$ & $\begin{array}{c}\text { Ultimate } \\
\text { strength } \\
(\mathrm{MPa})\end{array}$ & $\begin{array}{c}\% \\
\text { elongation }\end{array}$ \\
\hline \multirow[t]{4}{*}{200} & $0^{\circ}$ & 0.122 & 0.583 & 166.2 & 119.2 & 139.9 & 14.42 \\
\hline & $45^{\circ}$ & 0.144 & 0.530 & 171.1 & & & \\
\hline & $90^{\circ}$ & 0.166 & 0.521 & 176.5 & & & \\
\hline & Average & 0.144 & 0.541 & 171.2 & & & \\
\hline \multirow[t]{4}{*}{250} & $0^{\circ}$ & 0.135 & 0.56 & 189.4 & 112.6 & 129.9 & 23.58 \\
\hline & $45^{\circ}$ & 0.154 & 0.692 & 192.1 & & & \\
\hline & $90^{\circ}$ & 0.240 & 0.59 & 180.8 & & & \\
\hline & Average & 0.171 & 0.6335 & 188.6 & & & \\
\hline \multirow[t]{4}{*}{300} & $0^{\circ}$ & 0.146 & 0.753 & 211.3 & 101.3 & 116.1 & 31.10 \\
\hline & $45^{\circ}$ & 0.164 & 0.602 & 210.6 & & & \\
\hline & $90^{\circ}$ & 0.280 & 0.724 & 225.4 & & & \\
\hline & Average & 0.189 & 0.670 & 214.5 & & & \\
\hline \multirow[t]{4}{*}{350} & $0^{\circ}$ & 0.167 & 0.925 & 290.2 & 95.6 & 106.0 & 45.34 \\
\hline & $45^{\circ}$ & 0.175 & 0.853 & 264.14 & & & \\
\hline & $90^{\circ}$ & 0.290 & 0.771 & 280.4 & & & \\
\hline & Average & 0.202 & 0.851 & 274.7 & & & \\
\hline
\end{tabular}

Table 2.

Tensile properties of $A l 1350$ alloy sheets annealed at different temperatures [30, 32-35].

microstructure, similarly at $300^{\circ} \mathrm{C}$ also. The sheet annealed at $350^{\circ} \mathrm{C}$ shows fully recovered and recrystallized microstructure.

The microstructure of the aluminium alloy containing silicon and iron consists of inter metallic phases which appeared as dark areas in the aluminium matrix as shown in Figure 2, and certain second-phase particles were found to be present in 


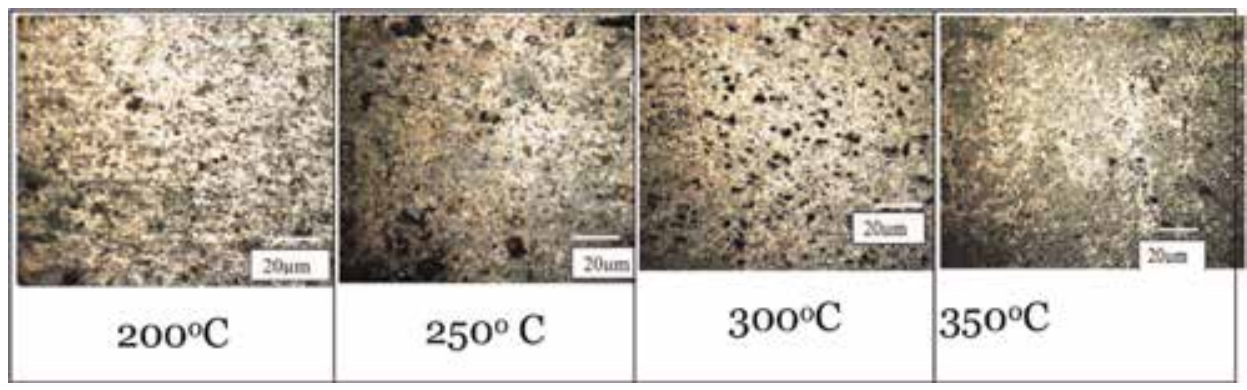

Figure 2.

Microstructure of aluminium alloy 1350 sheets annealing at four different temperatures [32, 33].

these alloys. An increase in the annealing temperature shows the presence of a larger amount of precipitated particles; the colour may be grey, which is due to the presence of silicon and white spots [25] is due to the presence of iron, which might ultimately increase the formability. The Fe and Si particles were capable of stabilizing a fine-grain/sub-grain structure, which could be used to develop interesting combinations of strength and ductility [2,30-35]. Titanium increased the recrystallization temperature, induced grain refinement and remained mostly in solution [26].

\section{Mechanical/tensile properties}

Ductility and formability could be better indicated by average strain hardening exponent $\left(n_{a v}\right)$, normal anisotropy value $\left(r_{a v}\right)$, strain rate sensitivity $(m)$ and $n_{a v} r_{a v}$ value, and these parameters increased as the annealing temperature increased

(Figure 3).

As temperature increased, the $\mathrm{n}_{\mathrm{av}} \mathrm{r}_{\mathrm{av}}$ value increased, and formability also increased. The average strength coefficient $(\mathrm{K})$ is comparatively less for the sheet

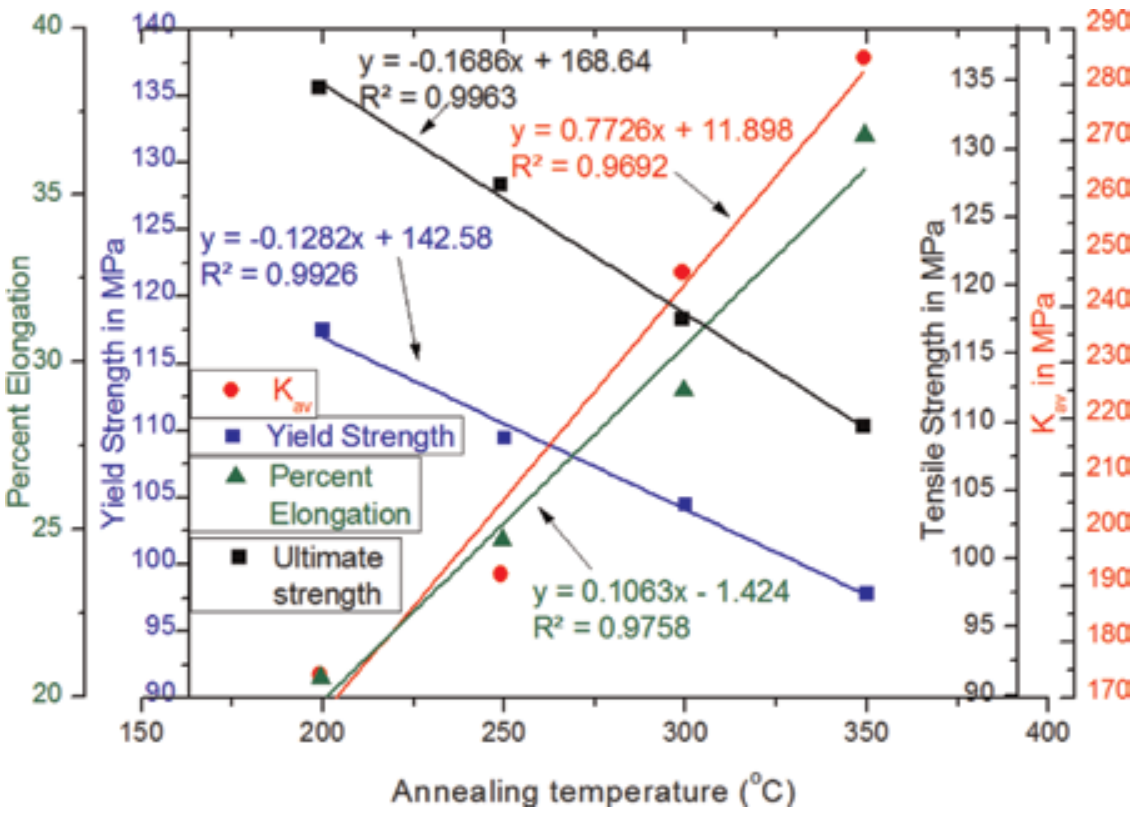

Figure 3.

The variation of mechanical/tensile properties with respect to annealing temperatures [30, 32-35]. 
annealed at $200^{\circ} \mathrm{C}$ (i.e., low temperature) due to the presence of cold-worked microstructure. At annealing temperatures of 250,300 and $350^{\circ} \mathrm{C}$, the ultimate tensile strength and yield stress of metal sheets were found to be low. The percentage elongation, strain hardening index, anisotropy and k-value, however, increased with annealing temperature. At $350^{\circ} \mathrm{C}$, the annealed sheet showed fully recrystallized microstructure, which may be due to relieving of internal strain energy formed during cold working and formation of new strain-free grains which increased the percentage elongation.

This may be due to the softening of metal at higher annealing temperatures. Similar behaviour was observed for all grades of aluminium sheets selected. In $\mathrm{Al}$ alloy sheet, the factor $\mathrm{n}_{\mathrm{av}} \mathrm{r}_{\mathrm{av}}$ formability index showed a direct relationship with formability of sheet metal. As the factor $n_{a v} r_{a v}$ increased, the formability also increased $[2,27,28]$. The percentage increase of $n_{a v} r_{a v}$ index in zone 3 was found to be highest due to fully recrystallized microstructure as shown in Figure 4. The next highest was observed in zone 1 (due to full recovery) followed by zone 2. Similar behaviour was observed in all commercially available $\mathrm{Al}$ sheets annealed at different temperatures.

Tables 2 and 3 show the different annealing temperatures of aluminium alloy sheet metals with different mechanical properties and formability properties, namely, strain hardening exponent, yield strength, tensile strength, $r$-value (plastic

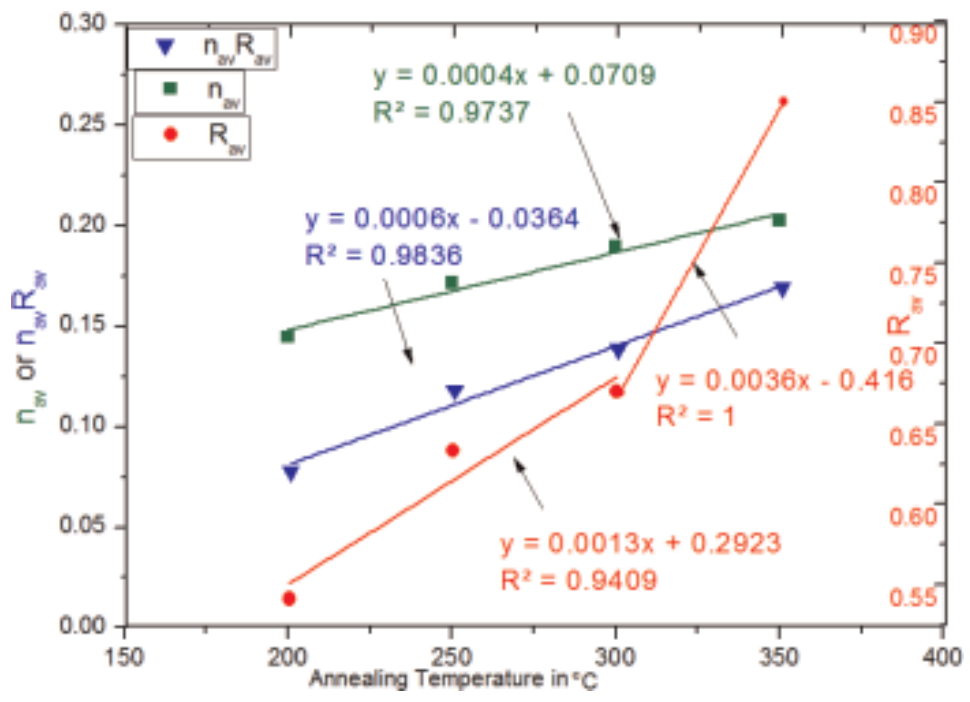

Figure 4.

The variation of formability properties with respect to annealing temperatures.

\begin{tabular}{|c|c|c|c|c|}
\hline Annealing temperature $\left({ }^{\circ} \mathrm{C}\right)$ & Orientation & $\mathbf{n r}_{\mathrm{av}}$ & $\Delta \mathbf{r}$ & $\mathbf{r}_{\mathrm{av}}$ \\
\hline \multirow[t]{4}{*}{200} & $0^{\circ}$ & 0.071126 & 0.0220 & 0.541 \\
\hline & $45^{\circ}$ & 0.07632 & & \\
\hline & $90^{\circ}$ & 0.086486 & & \\
\hline & Average & 0.077563 & & \\
\hline \multirow[t]{4}{*}{250} & $0^{\circ}$ & 0.09423 & 0.0025 & 0.693 \\
\hline & $45^{\circ}$ & 0.106568 & & \\
\hline & $90^{\circ}$ & 0.16584 & & \\
\hline & Average & 0.118302 & & \\
\hline
\end{tabular}




\begin{tabular}{|c|c|c|c|c|}
\hline Annealing temperature $\left({ }^{\circ} \mathrm{C}\right)$ & Orientation & $\mathbf{n} \mathbf{r}_{\mathrm{av}}$ & $\Delta \mathbf{r}$ & $\mathbf{r}_{\mathrm{av}}$ \\
\hline \multirow[t]{4}{*}{300} & $0^{\circ}$ & 0.10994 & 0.0005 & 0.738 \\
\hline & $45^{\circ}$ & 0.12103 & & \\
\hline & $90^{\circ}$ & 0.20272 & & \\
\hline & Average & 0.13868 & & \\
\hline \multirow[t]{4}{*}{350} & $0^{\circ}$ & 0.15448 & -0.0050 & 0.851 \\
\hline & $45^{\circ}$ & 0.14928 & & \\
\hline & $90^{\circ}$ & 0.22359 & & \\
\hline & Average & 0.169153 & & \\
\hline
\end{tabular}

Table 3.

Formability parameters of Al 1350 alloy sheets annealed at different temperatures.

strain ratio) and percentage elongation, were evaluated in this work. Since the sheet metals were anisotropic in nature, the normal anisotropy parameters such as $r_{a v}$, $\mathrm{nr}_{\mathrm{av}}$ and $\Delta \mathrm{r}$ were also evaluated.

The $\mathrm{n}$-value and $\mathrm{k}$-value were found to be maximum at $90^{\circ} \mathrm{C}$ to the rolling direction (RD) and minimum along the RD for the $\mathrm{Al} 1350$ alloy sheet annealed at $200^{\circ} \mathrm{C}$. Under similar conditions, the r-value was maximum along the RD and minimum at $90^{\circ} \mathrm{C}$; the $\mathrm{n}$-value showed similar observations, whereas the $\mathrm{k}$-value and $\mathrm{r}$-value were maximum at $45^{\circ}$ to the $\mathrm{RD}$ and minimum at $90^{\circ}$ to the $\mathrm{RD}$.

\section{Forming properties}

\subsection{Evaluation of forming limit diagram}

Tension-compression, tension-tension and plane strains are the three regions of strain conditions formed due to the variation in the width of the specimen. The forming limit diagram was plotted based on the grid circles from Figure 5a and stretched various ellipses from Figure $5 \mathbf{b}$ with respect to the strain condition as a base.

Using a travelling microscope, the ellipse dimensions like minor and major diameters were measured with an accuracy of $0.01 \mathrm{~mm}$. These measurements of major and minor diameters were used to calculate the major strain $\left(\varepsilon_{1}\right)$ and the minor strain $\left(\varepsilon_{2}\right)$. The strains $\varepsilon_{1}$ and $\varepsilon_{2}$ were measured at the safe, neck and fracture
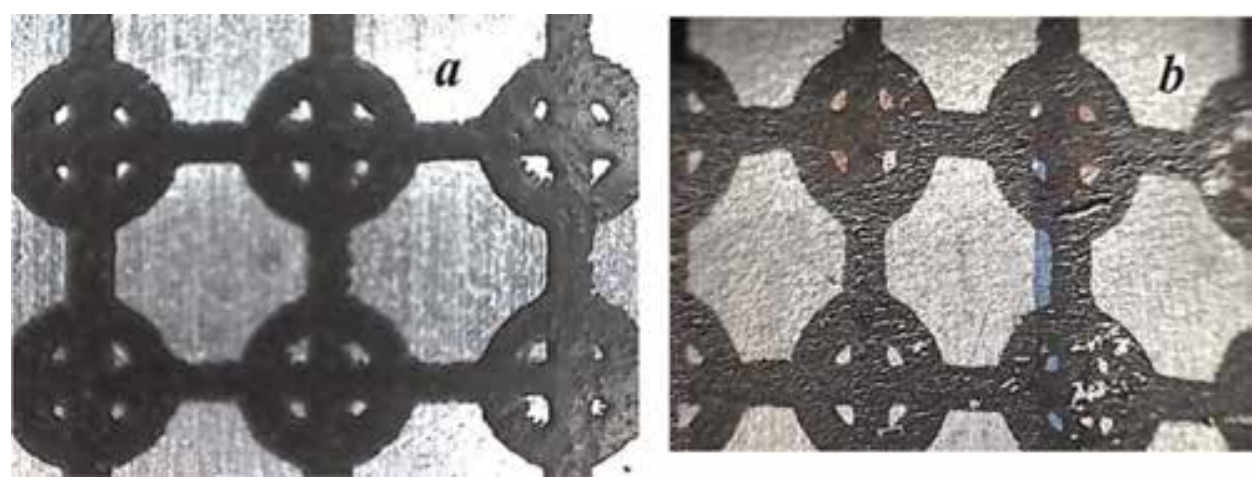

Figure 5.

Chemically etched grid circles (a) before and (b) after the forming process. 


\begin{tabular}{lccccc}
\hline $\begin{array}{l}\text { Annealing } \\
\text { temperature }\left({ }^{\circ} \mathrm{C}\right)\end{array}$ & \multicolumn{2}{c}{$\begin{array}{c}\text { Tension-tension strain } \\
\text { condition }\end{array}$} & $\begin{array}{c}\text { Plane strain } \\
\text { condition }\end{array}$ & \multicolumn{2}{c}{$\begin{array}{c}\text { Tension-compression } \\
\text { strain condition }\end{array}$} \\
\cline { 2 - 6 } & $\begin{array}{c}\text { Major } \\
\text { strain }\end{array}$ & $\begin{array}{c}\text { Minor } \\
\text { strain }\end{array}$ & Major strain & $\begin{array}{c}\text { Major } \\
\text { strain }\end{array}$ & $\begin{array}{c}\text { Minor } \\
\text { strain }\end{array}$ \\
\hline 200 & 35 & 18 & 17 & 28 & -3 \\
\hline 250 & 38 & 17 & 21 & 32 & -6 \\
\hline 300 & 43 & 15 & 29 & 38 & -13 \\
\hline 350 & 50 & 13 & 31 & 45 & -14 \\
\hline
\end{tabular}

Table 4.

Value of limiting strain in percentage for various strain conditions of Al 1350 alloy sheets.

\begin{tabular}{lccc}
\hline \multirow{2}{*}{$\begin{array}{l}\text { Annealing } \\
\text { temperature } \\
\left({ }^{\circ} \mathbf{C}\right)\end{array}$} & \multicolumn{3}{c}{ Major strain values in percentage } \\
\cline { 2 - 4 } & $\begin{array}{c}\text { TC region at minor strain } \\
-\mathbf{0 . 0 7 5}\end{array}$ & $\begin{array}{c}\text { PS } \\
\text { region }\end{array}$ & $\begin{array}{c}\text { TT region at minor strain } \\
\mathbf{0 . 1 5}\end{array}$ \\
\hline 200 & 109 & 98 & 83 \\
\hline 250 & 111 & 102 & 85 \\
\hline 300 & 116 & 108 & 91 \\
\hline 350 & 125 & 116 & 99 \\
\hline
\end{tabular}

Table 5.

The maximum major strain at fracture for Al 1350 alloy sheets.

regions to plot the forming limit diagrams. These strains were measured in three distinct regions like safe region, neck region and fracture region using the formulae natural $\log$ of deformed to the original dimension, whereas thickness strain $\left(\varepsilon_{3}\right)$ was determined at fracture region. The limiting strains and major strains at fracture were calculated for $\mathrm{Al}$ alloy sheets from major and minor dimensions at four different annealing temperatures and have been presented in Table 4.

The minor and major diameters of ellipse were measured using different mode of strain conditions. They are tension-tension (TT), plane strain (PS) and tensioncompression (TC). The grid circles were etched over the shape of the plate and became elliptical with different major and minor diameters based on the strain conditions, which is the input to plot forming limit diagram (Table 5).

Studies on ductile material models have been used to investigate the nucleation of voids and void coalescence as well as the interaction between different size and scales of voids [2]. This could be used to predict fracture mechanisms in structural components or test specimens. Ductile crack growth by void coalescence is an application [26]. Hence, fractography and void coalescence properties are analysed in the following sections.

\section{Limiting strains}

The forming and fracture limit diagrams of various grades of aluminium alloys chosen have been presented in Figure 7 along with the limiting strains of various grades of aluminium at different annealing temperatures. A minor strain of $19 \%$ and major strain of $21 \%$ have been recorded at the lowest temperature of $200^{\circ} \mathrm{C}$. The major strain of the same sheet at PS condition was 31\%. In TC region major and minor strains were found to be $33 \%$ and $3 \%$ respectively. Due to the presence of cold rolled refined grains in microstructure, poor formability was shown by the 
sheet annealed at $200^{\circ} \mathrm{C}$. The proportionate increase in formability with the annealing temperature has been confirmed through these experiments.

In tension-tension region, the sheet annealed at $250^{\circ} \mathrm{C}$ possessed a maximum minor strain of $17 \%$ and maximum major strain of $37 \%$. In plane strain condition, the limiting major strain was about $39 \%$. In tension-compression strain condition, the maximum minor and major strains were -7 and $38 \%$, respectively. In tensiontension region, the sheet annealed at $300^{\circ} \mathrm{C}$ possessed a maximum minor strain of $15 \%$ and maximum major strain of $41 \%$. In plane strain condition, the limiting major strain was about $41 \%$. In tension-compression strain condition, the strain values increased as the annealing temperature increased. At an annealing temperature of $350^{\circ} \mathrm{C}$ TT region, the minor strain was $13 \%$ and major strain $51 \%$. The fracture limit minor strain was found to be-17\% and limit major strain was $53 \%$ in the TC region.

The sheet annealed at $350^{\circ} \mathrm{C}$ exhibited lower yield stress, higher n-value, higher r-value and favourable microstructure for its better formability, when compared to the other sheets. These results were in good agreement with the findings of Narayanasamy et al. [1]. The increased value of $n$ and $r$ for sheet annealed at $350^{\circ} \mathrm{C}$ showed good stretchability, and it was in agreement with the evaluation carried out using FLD. The tendency for earing was very less during drawing operations due to its very high $r$-value. This was in good agreement with the findings of Ravindran et al. [26].

\section{Fractography}

The fractured surfaces were studied using scanning electron microscopy (SEM) which revealed the nature of fracture and correlated with formability and its parameters. The fracture zone of formed samples in $10 \mathrm{~mm} \times 10 \mathrm{~mm}$ size portion was removed from the fractured specimen, and SEM images were captured from perpendicular face having dimples and voids as a result of fracture. The fractured surfaces were observed using a SEM model LEO 420. The void parameters were recorded from the SEM images through void coalescence studies using CAD 2010 modelling software. Magnifications at 3000, 2000 and $800 \mathrm{X}$ were done using an accelerating voltage of $3 \times 10^{4} \mathrm{~V}$ and an emission current of $9.1 \times 10^{5} \mathrm{nA}$.

\subsection{Void coalescence study}

The voids were analysed with respect to perimeter $(\pi \mathrm{d})$, relative spacing of the ligaments present between the two consecutive voids $(\delta d)$, length of void $(L)$ and width of void (W) by using the mouse of the computer. From the perimeter (Tables 6 and 7), the diameter of the voids was determined. In the void parameter, $\mathrm{d}$-factor was determined by using the empirical relation arrived by dividing ( $\delta \mathrm{d})$ by the average radii of the voids present in void perimeters. To find the void area fraction, the total area of voids in that particular area (called representative material area) was calculated:

$$
\mathrm{d}-\text { factor }=\text { ligament thickness/average radii of the voids }
$$

Void area fraction $=$ total area of the voids/representative material area

SEM images were used to measure the relationship between fracture and fomability parameters from the blank shown in Figures 6 and 7. 


\begin{tabular}{|c|c|c|c|c|c|c|c|c|}
\hline \multirow[t]{3}{*}{ Annealing temperature $\left({ }^{\circ} \mathrm{C}\right)$} & \multicolumn{8}{|c|}{ Average void size in $\mu \mathrm{m}$ for various metal specimens } \\
\hline & \multicolumn{3}{|c|}{$\begin{array}{c}\text { Deep drawing } \\
\text { (tension-compression) }\end{array}$} & \multicolumn{2}{|c|}{ Plane strain } & \multicolumn{3}{|c|}{$\begin{array}{l}\text { Biaxial stretching } \\
\text { (tension-tension) }\end{array}$} \\
\hline & $60 \mathrm{~mm}$ & $80 \mathrm{~mm}$ & $100 \mathrm{~mm}$ & $120 \mathrm{~mm}$ & $140 \mathrm{~mm}$ & $160 \mathrm{~mm}$ & $180 \mathrm{~mm}$ & $200 \mathrm{~mm}$ \\
\hline 200 & 7.3 & 6.19 & 6.08 & 5.09 & 4.51 & 4.11 & 3.9 & 3.7 \\
\hline 250 & 7.8 & 7.5 & 6.55 & 6.1 & 5.5 & 5.2 & 4.8 & 4.2 \\
\hline 300 & 8.5 & 8.3 & 7.9 & 7.5 & 7.2 & 6.751 & 6.24 & 5.76 \\
\hline 350 & 10.22 & 9.92 & 9.89 & 9.01 & 8.5 & 8.21 & 8.1 & 7.99 \\
\hline
\end{tabular}

Table 6.

Average void size found on formed and annealed Al 1350 alloy sheets with different specimen width.

\begin{tabular}{lcccccc}
\hline Annealing temperature range & \multicolumn{7}{c}{ Percentage change in void parameters } \\
\cline { 2 - 7 } & Region & $\mathbf{\delta d}$ & Void size & d-factor & (L/W) ratio & $\mathbf{V}_{\mathbf{a}}$ \\
\hline \multirow{2}{*}{$200-250^{\circ} \mathrm{C}$ zone 1 } & TC & 15.96 & 7.73 & -41.90 & -40.41 & 42.67 \\
\cline { 2 - 7 } & PS & 13.34 & 19.84 & -32.39 & -31.13 & 19.52 \\
\cline { 2 - 7 } & TT & 12.07 & 23.07 & -31.42 & -25.05 & 7.35 \\
\hline $250-300^{\circ} \mathrm{C}$ zone 2 & TC & 10.22 & 8.97 & -30.99 & -20.25 & 25.51 \\
\cline { 2 - 7 } & PS & 10.12 & 22.95 & -24.37 & -18.32 & 18.07 \\
\cline { 2 - 7 } & TT & 5.54 & 29.92 & -16.65 & -14.56 & 11.38 \\
\hline $300-350^{\circ} \mathrm{C}$ zone 3 & TC & 18.85 & 19.51 & -51.70 & -24.15 & 29.10 \\
\cline { 2 - 7 } & PS & 30.48 & 21.61 & -52.46 & -23.27 & 24.76 \\
\cline { 2 - 6 } & TT & 33.02 & 38.71 & -51.88 & -28.49 & 20.11 \\
\hline
\end{tabular}

Table 7.

Percentage change in void parameters for different annealing temperature ranges.

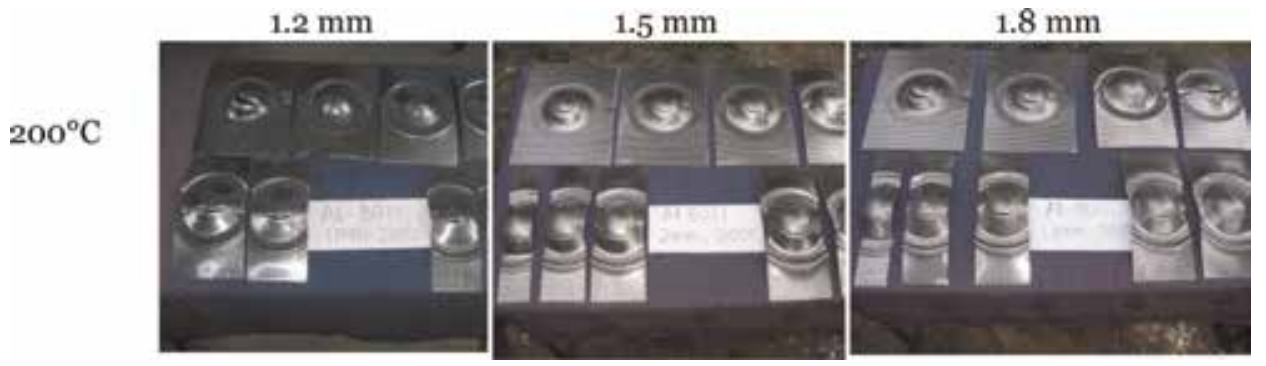

Figure 6.

Cupping test specimens of aluminium alloy of three thicknesses, annealed at different temperatures (after forming) $[30,32-35]$.

\subsection{Void shape}

The shape of the voids and L/W ratio was found to vary with stress/strain ratios. The L/W ratio was high in TT conditions and less in the TC condition. The prolate voids showed elongation along the thickness region whereas the oblate along the plane of the sheet [29].

\subsection{Void size}

For the blanks subjected to tension-compression strain condition, the SEM images showed many bigger micro-voids and dimples, and their surface was rough 


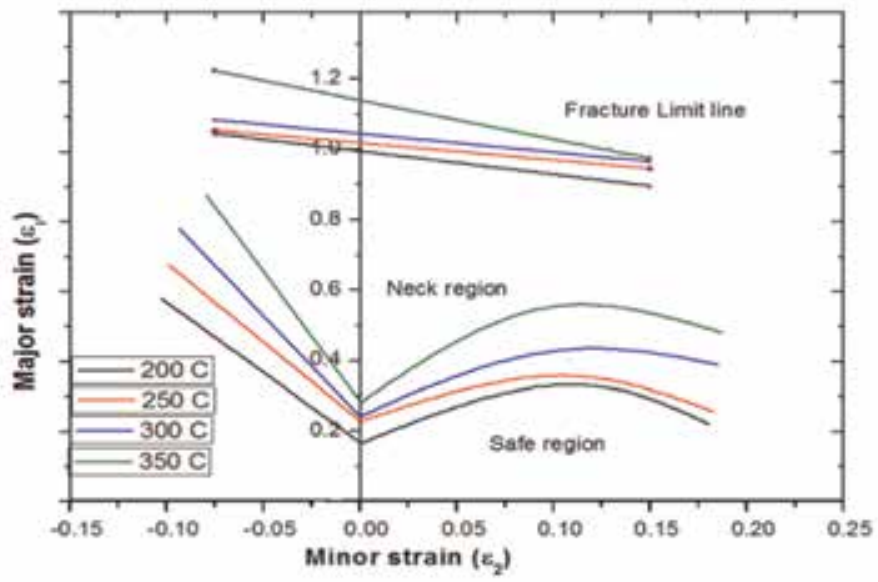

Figure 7.

Forming limit diagram of Al sheet of various grades [34, 35].

and irregular. This showed shear type of fracture with deep dimples [1]. The surface of the metal sample was smooth with shallow dimples and less voids in plain strain condition, whereas in TC condition, the SEM images showed larger voids and deep dimples, and hence the surface was irregular. This indicated the presence of shear type fracture with deep dimples [2]. For the blanks subjected to plane strain condition (blank width of $120 \mathrm{~mm}$ ), the surface was smooth compared to the tension-compression condition with less number of voids, shallow dimples and less fracture area.

\subsection{Void area fraction}

The number of voids as well as their type were affected by the forming conditions [1]. The sheets annealed at $350^{\circ} \mathrm{C}$ showed a larger number of voids and deformation than sheets annealed at 200,250 and $300^{\circ} \mathrm{C}$. This could be due to the presence of fully recrystallized grains. The microstructure also clearly indicated a favourable interaction between precipitation and recrystallization [26] at $350^{\circ} \mathrm{C}$. If the strain hardening index (n) value was more, the strain required for the plastic deformation was also more. During annealing at $350^{\circ} \mathrm{C}$, the strain hardening index value was high.

\section{5 $\mathrm{L} / \mathrm{W}$ ratio}

Length-to-width ratio in the void. The $\mathrm{L} / \mathrm{W}$ ratio of void for the sheet annealed at $200^{\circ} \mathrm{C}$ was found to be the highest.

\section{Interlinking effects of void parameters}

\subsection{Effect of void properties with annealing temperatures}

Figures 8 and 9 showed the variation of void properties with respect to annealing temperatures in different regions such as (a) TC, (b) PS and (c) TT. 


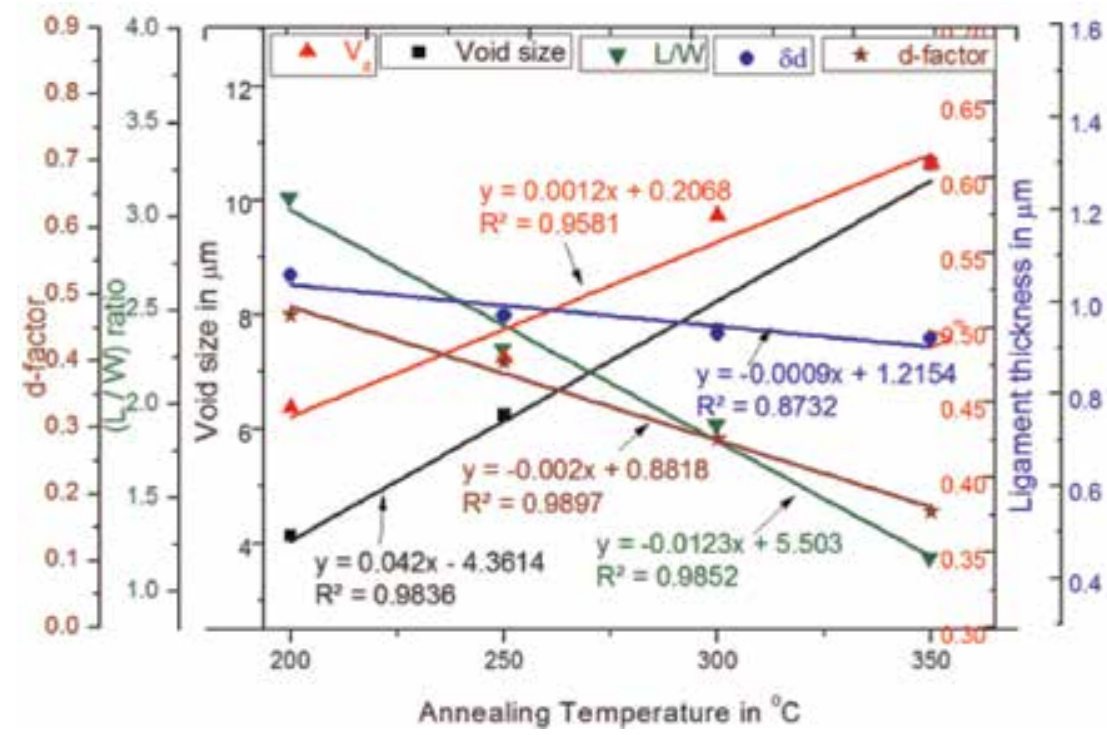

Figure 8.

Variation of void properties in Al 1350 alloy with respect to annealing temperatures in different regions.

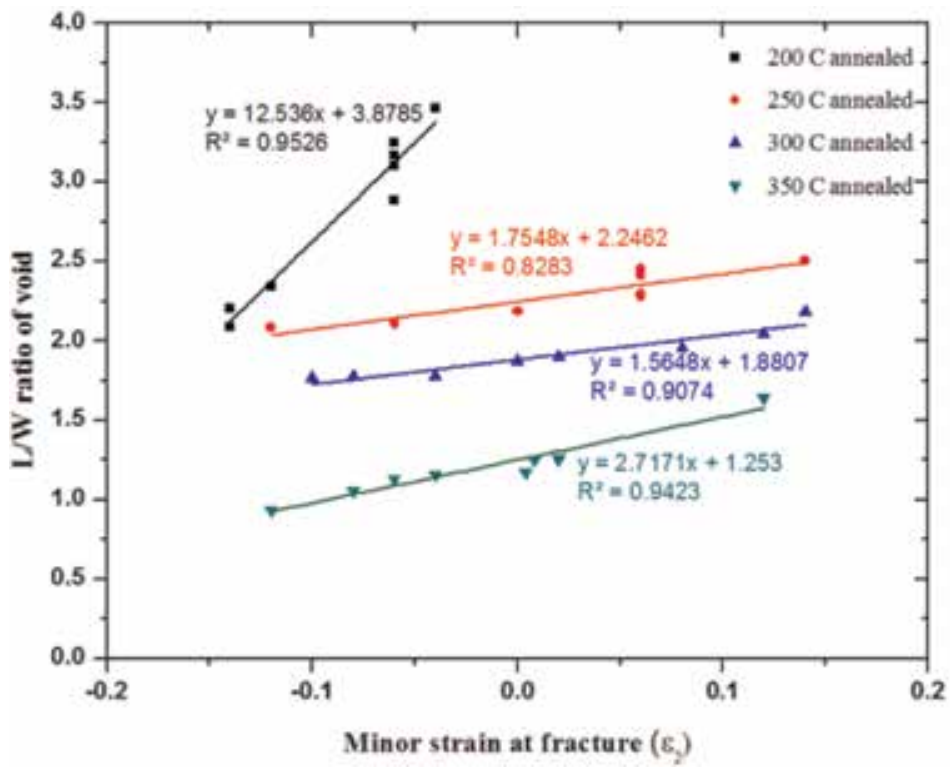

Figure 9.

$L / W$ ratio of voids vs. minor strain at fracture $\left(\varepsilon_{2}\right)$ at various annealing temperatures and thickness.

The slope value obtained for void size was high for TC region because they showed more plastic deformation.

This might be due to the fact that one stress was tension and the other was compression which increased the maximum shear stress of the Mohr's circle. The intercept value for void area fraction plot was high for TC region compared with TT region because in TC region the plastic deformation was higher.

The slope value and the ligament thickness of annealed sheet were found to decrease in the TC region than that in TT region. This might be due to plastic deformation of the metal sheet. 


\subsection{Effect of L/W with minor strain}

\subsection{Effect of void area with minor strain}

Figure 10 shows a plot between void area fraction and the mean strain for all sheets which have been tested. As observed from the figure, the void area fraction for the sheet annealed at $200^{\circ} \mathrm{C}$ has been found to be the lowest of all sheets tested.

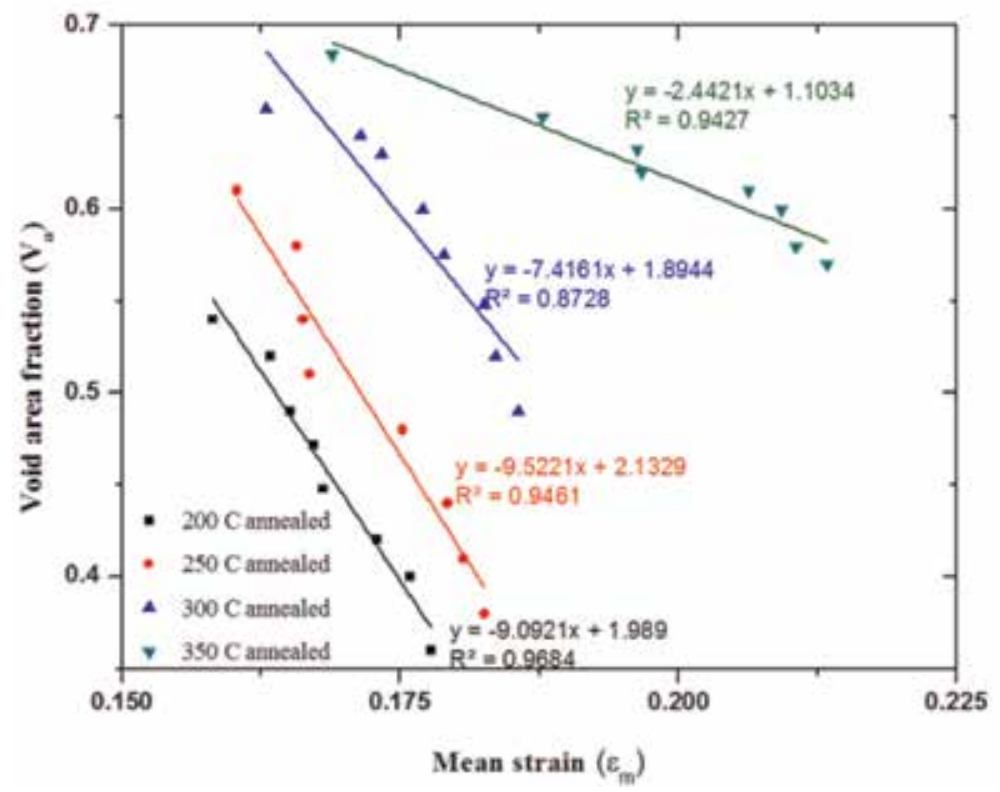

Figure 10.

Void area fraction $\left(V_{a}\right)$ vs. mean strain $\left(\varepsilon_{m}\right)$ at various annealing temperatures.

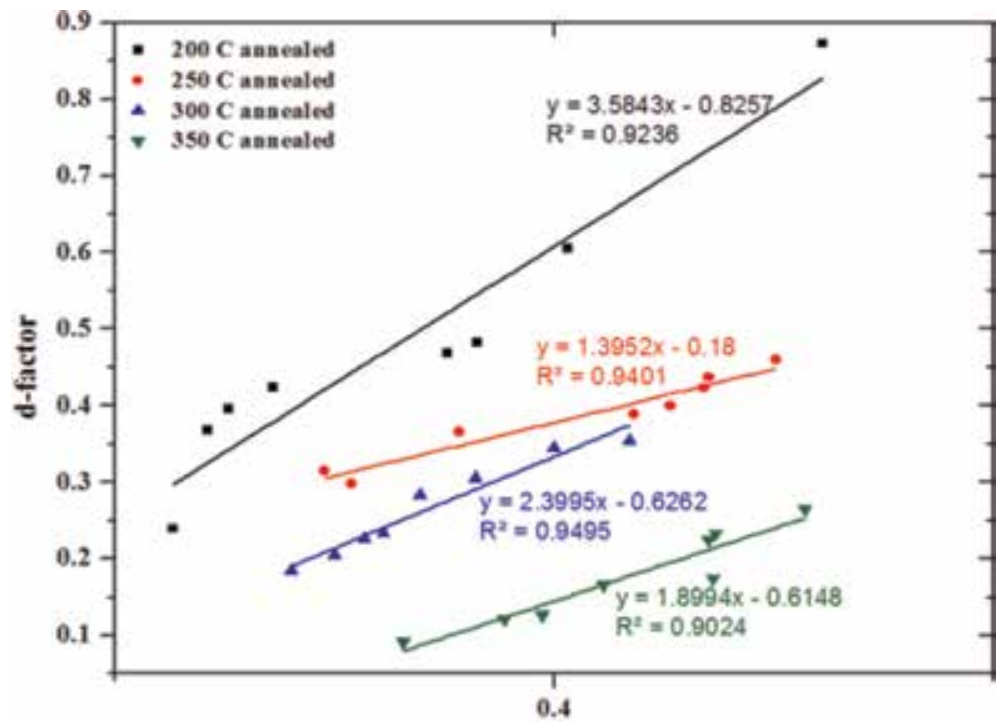

Strain triaxiality factor $\left(\mathrm{T}_{\mathbf{0}}\right)$

Figure 11.

$d$-factor vs. strain triaxiality factor $\left(T_{o}\right)$ at various annealing temperatures. 


\subsection{Effect of d-factor with strain triaxiality ratio}

Figure 11 shows a plot between d-factor and strain triaxiality ratio for all sheets tested. As the strain triaxiality ratio increase, the d-factor also increased. As the $\mathrm{d}$-factor increased, the formability of the sheet decreased and vice versa.

The d-factor was found to be lowest for the metal sheet annealed at $350^{\circ} \mathrm{C}$ indicating formability property compared to the sheets annealed at different temperatures.

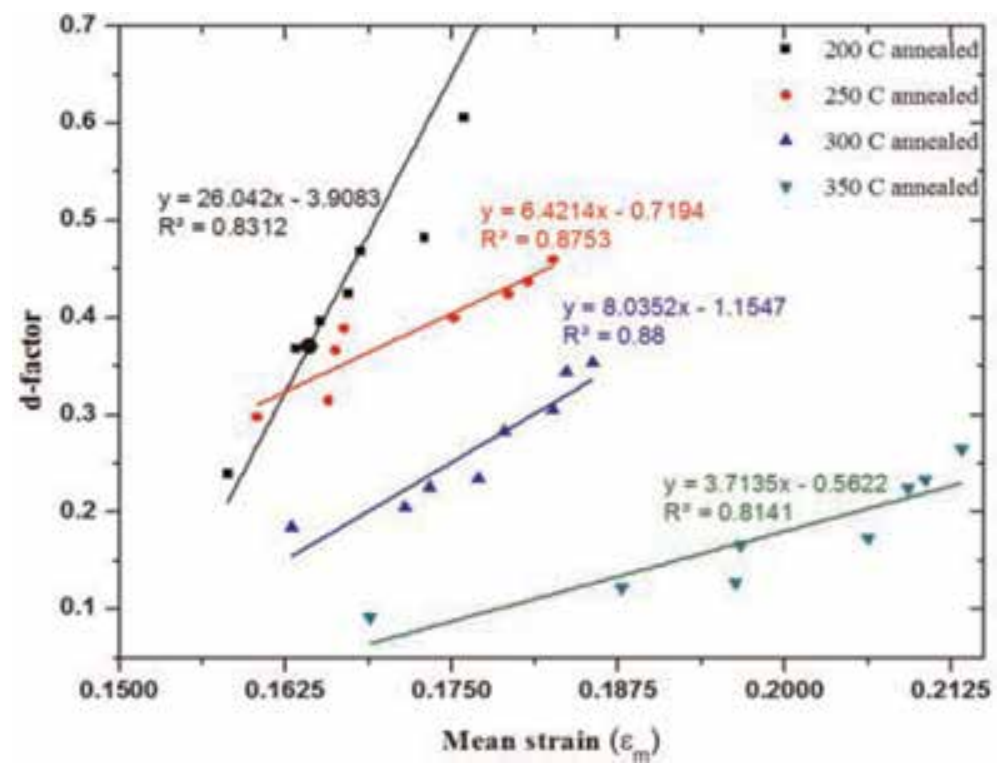

Figure 12.

$d$-factor vs. mean strain $\left(\varepsilon_{m}\right)$ at various annealing temperatures.

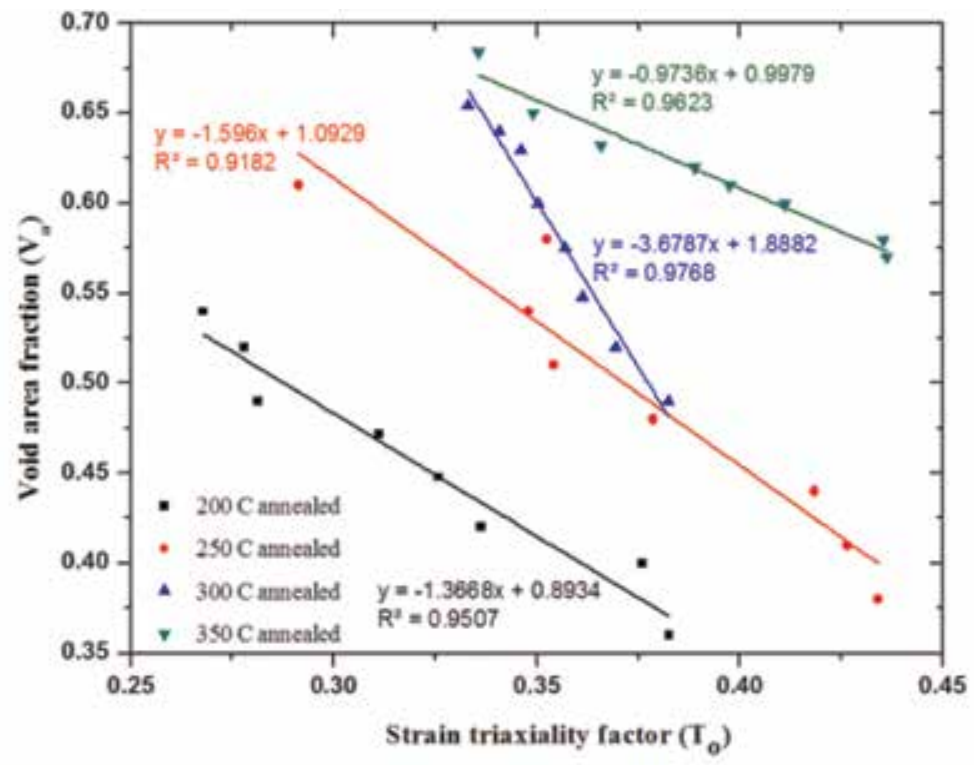

Figure 13.

Void area fraction $\left(V_{a}\right)$ vs. strain triaxiality factor $\left(T_{o}\right)$ at various annealing temperatures. 
In the case of sheet annealed at $350^{\circ} \mathrm{C}$, the ligament thickness was lowest and exhibited the best formability among the sheets tested. As the stress state moved from tension-compression to tension-tension region, the ligament thickness decreased. Similar behaviour was observed for all grades of aluminium sheets selected. The sheets annealed between these temperature show the corresponding changes recorded in the ligament thickness, which confirms with the prediction of Narayanasamy et al. [2].

\subsection{Effect of d-factor with mean strain}

The relationship between the hydrostatic/mean strain and the $\mathrm{d}$-factor has been shown in Figure 12. The d-factor linearly increase as the hydrostatic strain increases for all sheets tested. Even for a large mean strain developed during forming, the d-factor value was less. The rate of change was in good agreement with the findings of Narayanasamy et al. [1], whereas the d-factor was found to be the highest for sheet annealed at $200^{\circ} \mathrm{C}$ due to the presence of $\mathrm{Si}$ and poor recovery in processing.

\subsection{Effect of void area fraction and strain triaxiality ratio}

It has been observed that the void size of the sheet annealed at $350^{\circ} \mathrm{C}$ was approximately $8.21-12.9 \mu \mathrm{m}$, whereas for the sheets annealed at 250 and $300^{\circ} \mathrm{C}$, the void size was $3-6 \mu \mathrm{m}$. The larger void size may be due to good recrystallization, and smaller void size may be due to poor formability at lower annealing temperature. The sheets annealed at $200^{\circ} \mathrm{C}$ possessed low $\mathrm{V}_{\mathrm{a}}$ and sheets annealed at $350^{\circ} \mathrm{C}$

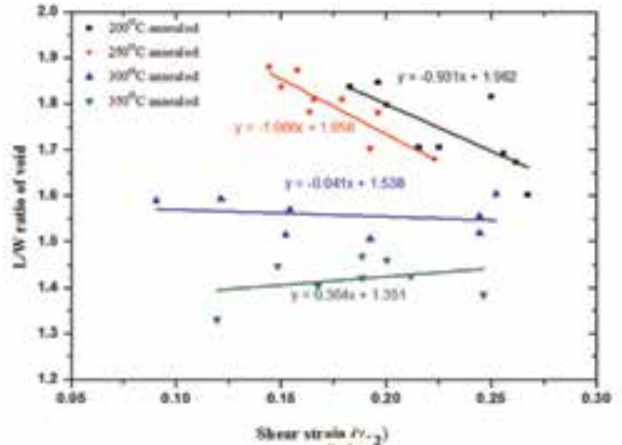

(a)

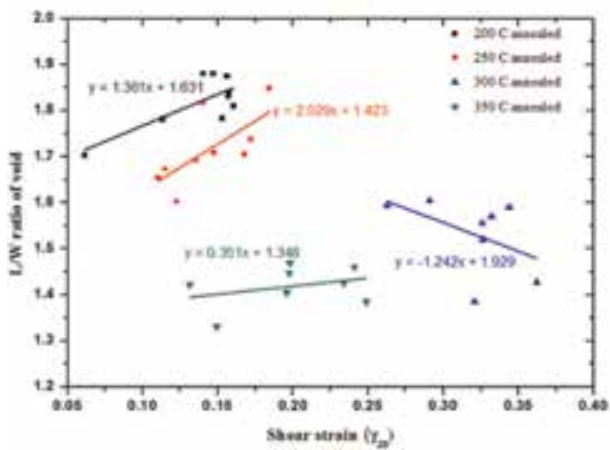

(c)

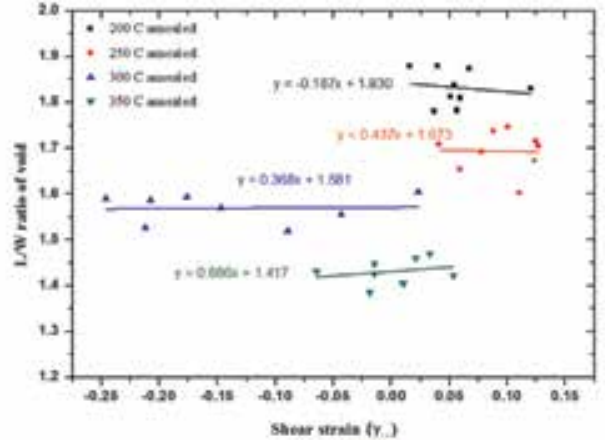

(b)

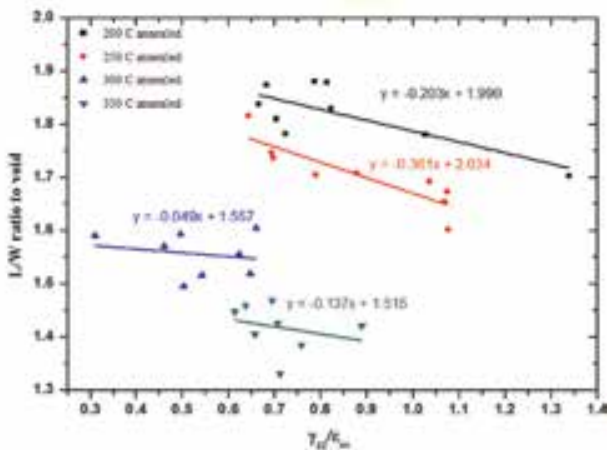

(d)

Figure 14.

$L / W$ ratio of voids vs. shear strains at various annealing temperatures for Al alloys: (a) $\gamma_{12}$, (b) $\gamma_{13}$, (c) $\gamma_{23}$, (d) $\gamma_{12} / \varepsilon_{m}$. 
showed higher value of $\mathrm{V}_{\mathrm{a}}$ (Figure 13) which was in close agreement with the findings of Narayanasamy et al. [2].

\subsection{Effect of $\mathrm{L} / \mathrm{W}$ ratio of voids and shear strains}

The L/W ratio of voids was correlated with various shear stresses calculated from Mohr's circle like $\gamma_{12}, \gamma_{13}, \gamma_{23}$ and $\gamma_{12 /} \varepsilon_{\mathrm{m}}$ at all annealing temperature conditions which has been shown in Figures 14-16. For sheets annealed at $350^{\circ} \mathrm{C}$, negative sloped curves were obtained due to high $\mathrm{L} / \mathrm{W}$ ratio, whereas the sheet annealed at

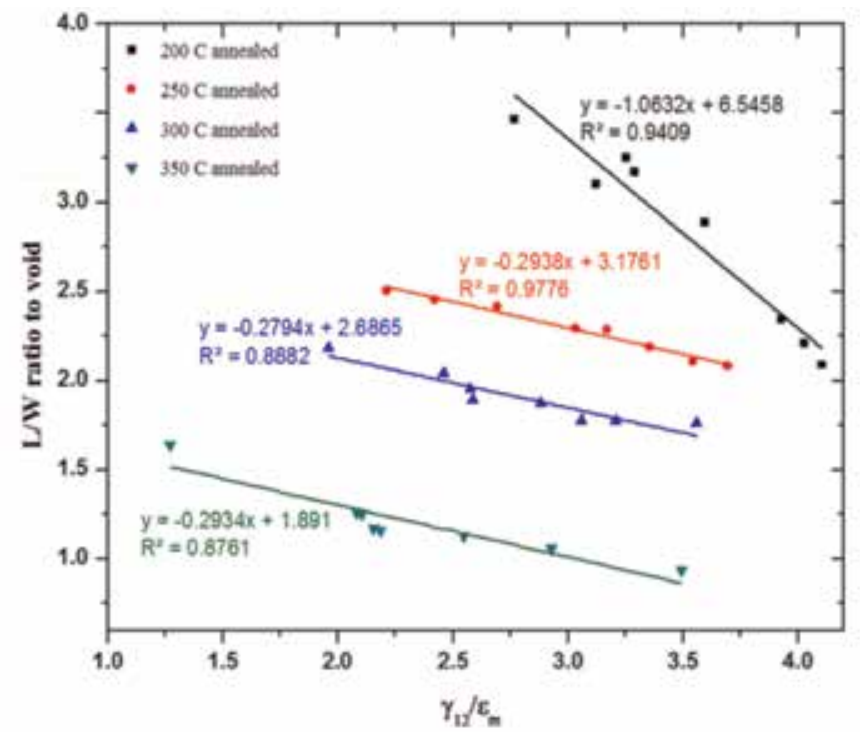

Figure 15.

$L / W$ ratio of void vs. shear strains at various annealing temperatures for Al 1145 alloy.

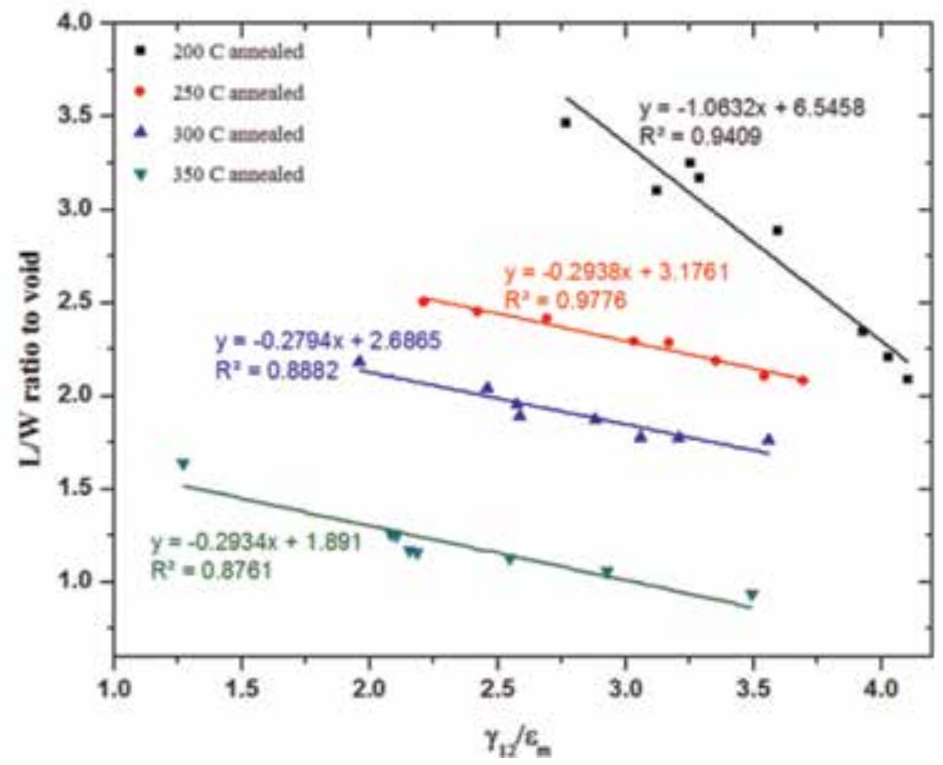

Figure 16.

$L / W$ ratio of void vs. shear strains at various annealing temperatures for Al1350 alloy. 
$200^{\circ} \mathrm{C}$ showed positive sloped curves because of their low $\mathrm{L} / \mathrm{W}$ ratio. These findings were in good agreement with those of Narayanasamy et al. [1, 26].

\section{Crystallographic texture}

A crystal is characterized by the periodic arrangement of its elements (atoms, ions) in space. In the field of material science and engineering, the distribution of the crystallographic orientations of a polycrystalline sample is called as texture. If these orientations were fully random in a sample, it had no texture. If the crystallographic orientations have some preferred orientation but were not random, then the sample has different textures, namely, weak, moderate and strong. The crystal having the preferred orientation and its degree was dependent on the percentage [6]. Texture can have a great influence on the material properties and is seen in almost all engineered materials. If all crystallites had the same orientation, the anisotropy of the polycrystal exactly equals that of the single crystal [7]. In an isotropic texture, all orientations occur with the same probability; the behaviour of the polycrystalline material was isotropic even though every single element (crystallite) showed an anisotropic behaviour (Engler et al., 2001).

\subsection{Crystallographic texture analysis}

Texture can be determined by various methods, namely, quantitative analysis and qualitative analysis. In quantitative techniques, the most widely used is X-ray diffraction using texture goniometry. Often texture has been represented using a pole figure, in a stereographic projection, a specified crystallographic axis (or pole) from each of which a representative number of crystallites which was plotted, along with the directions relevant to the material's processing history. These defined directions are called as a sample reference frames.

\subsection{Common textures}

The commonly found textures in processed materials are cube $\left(\begin{array}{lll}0 & 0 & 1\end{array}\right)<1 \quad 0 \quad 0>$, brass $(110)<-112>$, copper $(112)<11-1>$ and S(1 23) $<63-4>$ [9]. These were given in miller indices for simplification purposes.

\subsection{Orientation distribution function}

The ODF is defined as the volume fraction of grains with a certain orientation. The orientation is normally identified using three Euler angles. The orientation distribution function cannot be measured directly by any technique. But it can be state by a sum of functions or expand it in a series of harmonic function [9]. Others, known as discrete methods, divide the ODF space in cells and focus on determining the value of the ODF in each cell.

\subsection{Origin}

The making of metal sheet often involves compression in one direction and, in efficient rolling operations, tension in another, which can orient crystallites in both axes, by a process known as the grain flow. New crystallites that arise with annealing usually have a different texture [7]. The control of texture was extremely important during the making of a silicon steel sheet for transformer cores (to reduce 
magnetic hysteresis) and of aluminium cans (since deep drawing requires extreme and relatively uniform plasticity) [8].

\section{Texture properties}

Texture significantly affects the formability which is usually evaluated in terms of forming limit diagrams [1]. Although much research has been carried out, their correlations have not yet been completely clarified. Aluminium alloys exhibit typical pure metal texture (Cu-type) on rolling comprising of $\mathrm{Cu}\{112\}<111>$, brass $\left\{\begin{array}{lll}1 & 1 & 0\end{array}\right\}<1 \quad 12>$ and $S\left\{\begin{array}{lll}1 & 2 & 3\end{array}\right\}<634>$ orientations, and Cube $\left\{\begin{array}{lll}1 & 0 & 0\end{array}\right\}<0 \quad 01>$ and Goss $\left\{\begin{array}{lll}1 & 1 & 0\end{array}<<001>\right.$ components were common during annealing $[7,10]$. In this aspect an attempt has been made to correlate the tensile properties, formability properties and void coalescence parameters, with texture of sheet metal at different annealing temperatures. The effect of the cube texture on the initiation of localized necking has been studied using numerical methods by Wu et al. [12]. They have inferred that, when a sheet undergoes biaxial tension, ideal cube texture significantly delays the initiation of localized necking [11]. Aluminium alloys exhibit typical pure metal texture ( $\mathrm{Cu}\{112\}<111>$-type) on rolling comprising of $\mathrm{Cu}\{11$ $2\}<111>\{112\}<111>$, brass $\{110\}<112>$ and $S\left\{\begin{array}{lll}1 & 2 & 3\end{array}\right\}<634>$ orientations, and Cube $\left\{\begin{array}{lll}1 & 0 & 0\end{array}\right\}<0 \quad 0 \quad 1>$ and Goss $\left\{\begin{array}{lll}1 & 1 & 0\end{array}\right\}<0 \quad 0 \quad 1>$ components are common during annealing [10] as seen in Figure 1. An Al 8011 aluminium alloy sheet cold-rolled by $95 \%$ had a typical fibre texture, which runs from the copper orientation $\begin{cases}1 & 12\}<1\end{cases}$ $1>$ over the S-orientation $\left\{\begin{array}{lll}1 & 2 & 3\end{array}\right\}<634>$ to the brass orientation $\left\{\begin{array}{lll}1 & 1 & 0\end{array}\right\}<112>$ in the Euler space. The results were discussed, based on the interaction between precipitation and recrystallization $[13,14]$. The cube component recovered quite easily during deformation after large strains as well as during the first step of the annealing treatment, as per the findings of Gerber et al. [15].

Matthies et al. [16] have consolidated all methods of the analysis of texture by pole figure and orientation distribution function (ODF) in Euler space. Knorr et al. [17] and Kocks et al. [18] studied the material property such as strength and deformation behaviour, through texture and failure analysis. Bennett et al. [6] examined the cube $\left(\begin{array}{lll}1 & 0 & 0\end{array}\right)<0 \quad 01>$ grains before and after stretching and found that there was a translocation. In this aspect this work investigates the mode of evolution of texture components, in commercially available aluminium alloy sheets of three different thicknesses at three different annealing temperatures using numerical modelling practice. The works related to the crystal plastic models are given below. From the results of $\mathrm{Al}$ 8011, $\mathrm{Al} 1145$ and $\mathrm{Al} 1350$ alloy, pole figures ODF and alphabeta fibre, the following discussions were made (Figure 17).

\subsection{Volume fraction}

A plot of the texture component with the annealing temperature for $\mathrm{Al} 8011$ alloy showed a linear relationship for the cube and Goss component. Similarly from Figures 17 and 18, cube and RD cube were increasing linearly for Al 1145 alloy. The components $\mathrm{S}$ and $\mathrm{Cu}$ were in decreasing nature, and a deviation occurred at an annealing temperature of $300^{\circ} \mathrm{C}$.

\subsection{Al alloy}

The evolution of Goss intensity was very negligible in Al 1145 alloy as compared to alloy 8011 . The dominant texture component in the annealed microstructure, 
that is, cube, was due to the higher nucleation rate of cube grains at the already existing cube bands.

Wu et al. [12] and 1998 have shown that ideal cube texture could lead to sharper yield locus under biaxial stretching and thereby sheet formability. Figure 18c and $\mathbf{d}$ was clear that the fraction of ideal cube was almost negligible compared to the fraction of cube spread in the microstructure. Apart from the cube component, it was observed that the fractions of RD- and ND-rotated cubes have been enhanced (ND-rotated cube $\left.\left\{\begin{array}{lll}0 & 0 & 1\end{array}\right\}<\begin{array}{lll}1 & 3 & 0\end{array}\right)$ and RD-rotated cube $\left\{\begin{array}{lll}1 & 3 & 0\end{array}\right\}<\begin{array}{lll}0 & 0 & 1\end{array}$ > were deviated by about $18^{\circ}$ along $\mathrm{ND}$ and $\mathrm{RD}$, respectively, from the ideal cube orientation). A similar behaviour was observed for the alloy $\mathrm{Al} 1350$.

\subsection{Pole figure}

From Figure 17, the recalculated 111 pole figures with imposed orthotropic sample symmetry could be seen. Here, a gradual diminishing of deformation components can be seen with the simultaneous development of cube texture with annealing temperature for Al 8011 alloy. From Figure 18, it can be seen that the difference in elongation along the major and minor axes was significant which implied that the anisotropy was higher in these rolled Al 8011 alloy sheets. Figures 17 and 18 represent the recalculated 111 pole figures from the ODF with imposed orthotropic sample symmetry for Al 1145 and Al 1350, respectively. It can be seen that significant deformations were retained up to $250^{\circ} \mathrm{C}$ beyond which cube texture became prominent with increasing annealing temperature.
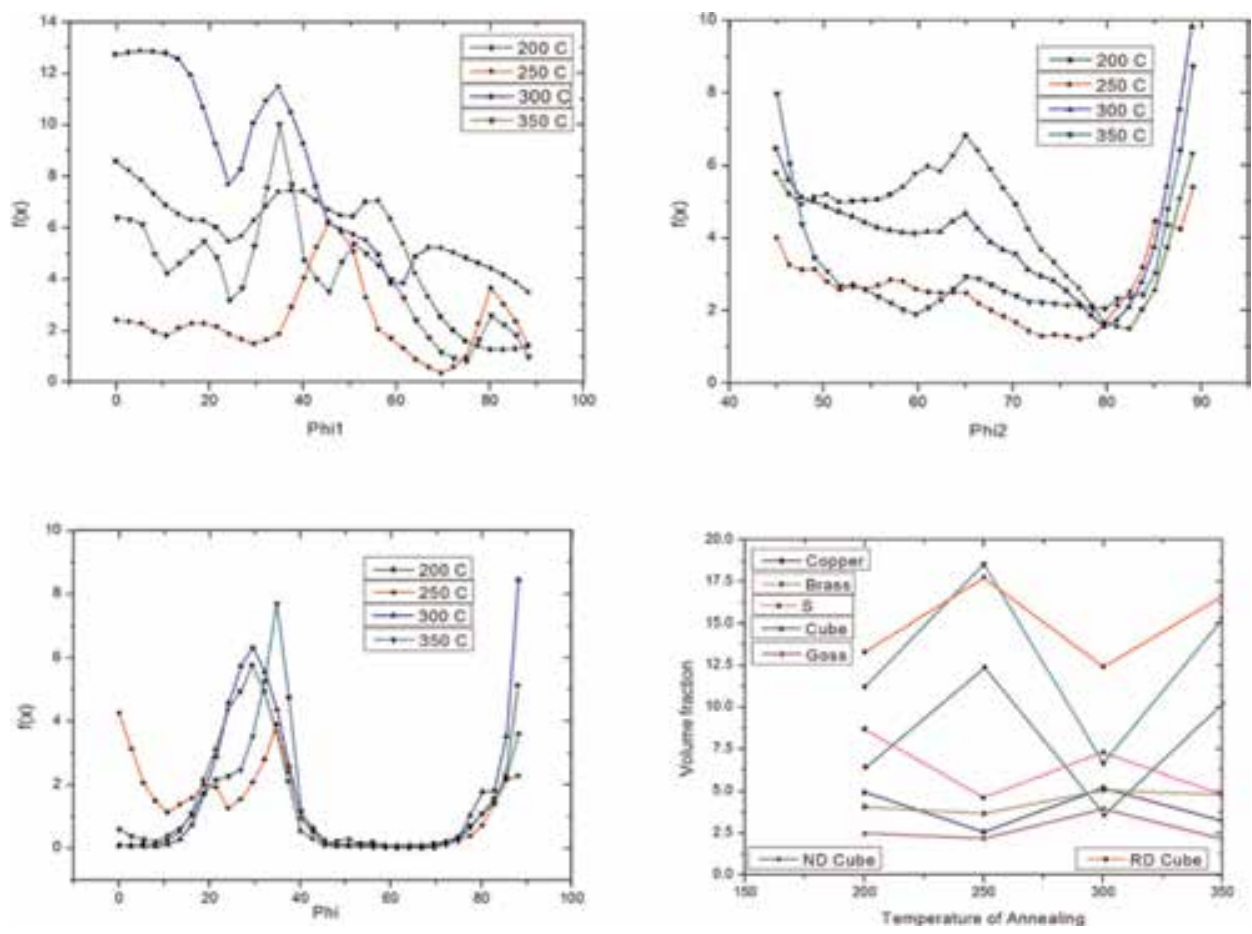

Figure 17.

Texture analysis based on ODF for the annealed samples of $A l$ 1350: (a) alpha-fibre, (b) beta-fibre, (c) phi, (d) volume fraction of texture components. 

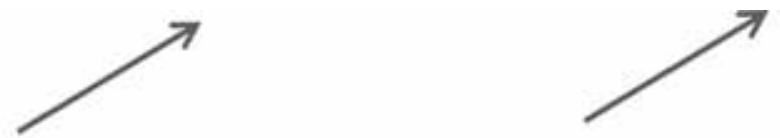

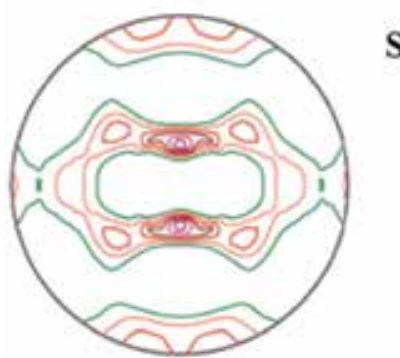

(a)

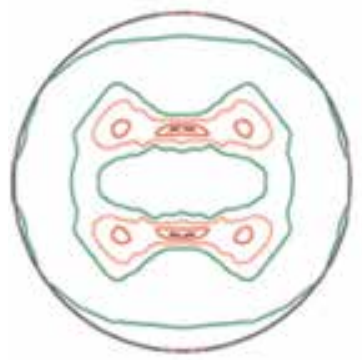

(c)

S

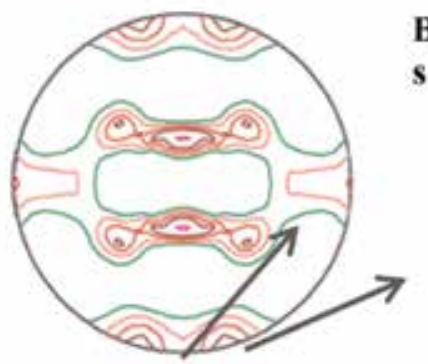

(b)

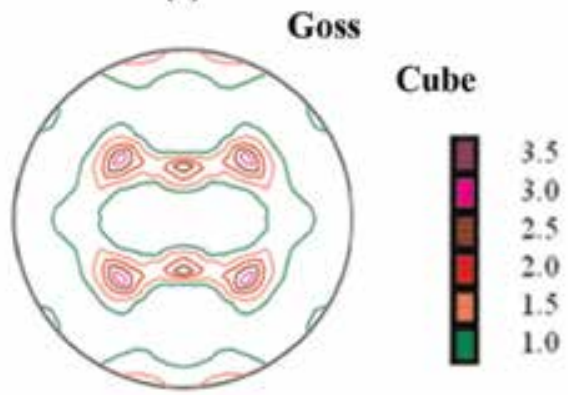

(d)

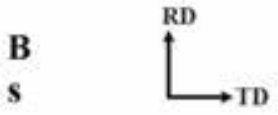

Figure 18.

111 pole figures of annealed samples of $\mathrm{Al} 8011$ : (a) $200^{\circ} \mathrm{C},\left(\right.$ b) $250^{\circ} \mathrm{C},(c) 300^{\circ} \mathrm{C},(d) 350^{\circ} \mathrm{C}[30,32-35]$.

\subsection{ODF}

The intensity of $\mathrm{Cu}$ and $\mathrm{S}$ components in the $\varphi_{2}-45^{\circ}$ and $\varphi_{2}-65^{\circ}$ sections, respectively, has decreased with temperature. The $\varphi_{2}-0^{\circ}$ section showed qualitatively the strengthening of cube and Goss intensities as a function of temperature.

\section{$11.5 \alpha$-Fibre and $\beta$-fibre}

From the $\alpha$-fibre, it can be inferred that the Goss components increased with simultaneous fall in the orientation densities $(f(g))$ of deformation components as can be seen from the $\beta$-fibre (Figure 17) for Al 8011 alloy. The cube orientation showed a strong scattering along the RD in the $\varphi_{2}-0^{\circ}$ section.

Figure 18 showed that the formability in the present set of samples improved with increasing annealing temperature. The presence of precipitates could significantly suppress the cube fraction in the microstructure in turn retaining the deformation components at lower temperatures.

The alpha-fibre plots followed a similar trend in all the cases, particularly at starting $\left(\phi=0^{\circ}\right)$ and end $\left(\phi=90^{\circ}\right)$ locations. As there is an increased annealing temperature, the intensity of alpha-fibre also increases. The trend was different at $\phi_{1}=35^{\circ}$, where a peak change is observed at all alpha-fibre components. In general, a deep change (intensity of alpha-fibre component) was observed at other annealing temperatures except $300^{\circ} \mathrm{C}$. This was due to the equilibrium between precipitation and recrystallization at that temperature. Hence alpha-fibre 
component represented $300^{\circ} \mathrm{C}$ (blue colour) at $\phi_{1}=35^{\circ}, \phi=45^{\circ}$ and $\phi_{2}=0^{\circ}$ shows inconsistent intensity.

Hence these experimental results could not be directly interpreted, but it can be interpreted by fitting these results into the models by simulation approach, which has been discussed in the later part of the section using response surface methodology.

\section{FLD using crystal plasticity models}

Efforts have been made in recent years to incorporate the plastic anisotropy resulting mainly from a crystallographic texture to the modelling of the deformation of polycrystalline solids [19]. Two types of procedures have been currently being used. The first involved direct crystal plasticity [20], whereas the second represented the yield surface by a closed-form, analytical expression [10, 21]. FLD predictions were compared with the experimental data of annealed aluminium (AA6xxx) sheet. It was found that the Goss orientation $\left\{\begin{array}{llll}0 & 1 & 1\end{array}\right\}<1 \quad 00>$ present in the initial texture and the microstructure influenced the formability significantly.

\section{Effect of cube texture on sheet metal formability}

Wu et al. [12] investigated the effect of the cube texture on the initiation of localized necking, while the ideal cube texture showed decreased formability; for a sheet undergoing biaxial tension, a spread about the cube significantly delayed the initiation of localized necking. The effect of a widespread cube texture on the FLD was path dependent; it decreased the formability for strain paths far away from the equi-biaxial stretching but increased the formability significantly near the equibiaxial stretching mode. Theoretically, the change in formability near equi-biaxial stretching could be correlated to the sharpness of the yield locus at equi-biaxial tension.

As the annealing temperature increased, the recrystallization and precipitation rates increased $[22,23]$, which, in turn, resulted in a decrease in time to obtain the conductivity saturating level, and the solute solubility increased resulting in a decrease in the peak conductivity. Creating better texture helped to develop sheet metals with higher formability. By correlation of the parameters, the texture can be optimized. Literatures related to texture optimization have been given.

\section{Microstructure and texture versus annealing}

Galand et al. [24] have focused on the influence of interconnected $\mathrm{Cu}$ microstructure on the electro-migration phenomenon. The microstructure and texture of copper were characterized by electron backscatter diffraction (EBSD). In both cases, no significant differences were observed in terms of the reliability performance versus annealing conditions. On the contrary, a large difference was observed on the electron backscatter diffraction results. Then, a statistical approach was used to investigate local microstructure and texture of copper for $150 \mathrm{~nm}$ line width. The results indicated that the morphological parameters of copper can vary with annealing conditions but could lead to similar reliability performances.

It was concluded that these parameters had no relationship with electromigration phenomena in the interconnects. On the other hand, a high amount of disorientation has been highlighted as responsible for early failures. Also 
disorientation resulting in high mean disorientation and high grain boundary densities were the root cause of early failures.

\section{Conclusions}

This chapter clearly explains the interlinking nature of aluminium and its alloys in terms of its physical size like sheet thickness, annealing temperature, sheet (rolling) orientation, chemical composition versus tensile properties, formability properties, texture properties and void coalescence properties. The desired formability can be seen through the better crystallographic evolution and microstructure or from the fractography void coalescence results. Furthermore investigations could be carried out to prove a well-established strong outcomes in this area.

\section{Acknowledgements}

The authors would like to thank our masters, Dr. R. Narayanasamy and Dr. Satyam Suwas, for their input and our beloved daughter V. Suryameena for her support.

\section{Author details}

K. Velmanirajan ${ }^{1 *}$ and K. Anuradha ${ }^{2}$

1 Department of Mechanical Engineering, VSVN Polytechnic College, Virudhunagar, Tamil Nadu, India

2 Department of Chemistry, Sri Meenatchi Government Arts College, Madurai, Tamil Nadu, India

*Address all correspondence to: velmanirajan@gmail.com

\section{IntechOpen}

(C) 2019 The Author(s). Licensee IntechOpen. This chapter is distributed under the terms of the Creative Commons Attribution License (http://creativecommons.org/licenses/ by/3.0), which permits unrestricted use, distribution, and reproduction in any medium, provided the original work is properly cited. (c) BY 


\section{References}

[1] Narayanasamy R, Parthasarathi NL, Ravindran R, Sathiya Narayanan C. Analysis of fracture limit curves and void coalescence in high strength interstitial free steel sheets formed under different stress conditions. Materials Science. 2008;43:3351-3363

[2] Narayanasamy R, Sathiya NC. Some aspects on fracture limit diagram developed for different steel sheets. Materials Science and Engineering A. 2006;417:197-224

[3] Xing ZP, Kang SB, Kim HW. Softening behavior of 8011 alloy produced by accumulative roll bonding process. Scripta Materialia. 2001;45: 597-604

[4] Takuda H, Yamazaki N, Hatta N, Kikuchi S. Influence of coldrolling and annealing conditions on formability of aluminium alloy sheet. Journal of Materials Science. 1995;30:957-963

[5] Kumar A, Satapathy S, Ravi Kumar D. Effect of sheet thickness and punch roughness on formability of sheets in hydromechanical deep drawing. Journal of Materials Engineering and Performance. 2010;19(8):1150-1160

[6] Bennett TA, Petrov RH, Kestens LAI. Texture-induced surface roping in an automotive aluminium sheet. Scipta Materialia. 2009;61(7):733-736

[7] Engler O, Randle V. Introduction to Texture Analysis:Macrotexture, Microtexture, and Orientation Mapping. Second ed. CRC Press; 2009

[8] Engler O, Lucke K. Mechanisms of recrystalization texture formation in aluminium alloys. Scripta Metallurgica. 1992;27:1527-1532

[9] Lademo OG, Pedersen KO, Berstad T, Furub T, Hopperstad OS. An experimental and numerical study on the formability of textured Al-Zn-Mg alloys. European Journal of MechanicsA/Solids. 2008;27:116-140

[10] Lequeu PH, Gilormini P, Montheillet F, Bacroix B, Jonas JJ. Yield surfaces for textured polycrystals-I. Crystallographic approach. Acta Metallurgica. 1987;35:439

[11] Crumbach M, Goerdeler M, Gottstein G. Modelling of recrystallisation textures in aluminium alloys II. Model performance and experimental validation. Acta Materialia. 2006;54:3291-3306

[12] Wu PD, MacEwen SR, Lloyd DJ, Neale KW. Effect of cube texture on sheet metal formability. Materials Science and Engineering A. 2004;364: 182-187

[13] Ryu J-H, Lee DN. The effect of precipitation on the evolution of recrystallization texture in AA8011 aluminum alloy sheet. Materials Science and Engineering A. 2002;336:225-232

[14] Lee J-K, Lee DN. Texture control and grain refinement of AA1050 Al alloy sheets by asymmetric rolling. International Journal of Mechanical Sciences. 2008;50:869-887

[15] Gerber PH, Tarasiuk J, Th C, Bacroix B. A quantitative analysis of the evolution of texture and stored energy during annealing of cold rolled copper. Acta Materialia. 2003;51:6359-6371

[16] Matthies S, Wenk HR, Vinel GW. Some basic concepts of texture analysis and comparison of three methods to calculate orientation distributions from pole figures. Journal of Applied Crystallography. 1988;21:285-304

[17] Knorr DB, Peltier JM, Pelloux RM. Influence of Crystallographic texture 
and test temperature on initiation and propagation of iodine stress-corrosion cracks in zircaloy. In: Zirconium in the Nuclear Industry: Sixth International Symposium. Philadelphia, PA: ASTM; 1972. pp. 627-651

[18] Kocks UF, Tomé CN, Wenk H-R, Mecking H. Texture and Anisotropy: Preferred Orientations in Polycrystals and their Effects on Materials Properties. Cambridge University Press; 2000

[19] Ma Q, Mao W, Feng H, Yu Y. Rapid texture measurement of cold-rolled aluminum sheet by X-ray diffraction. Scripta Materialia. 2006;54:1901-1905

[20] Friedman PA, Pan J. Effects of plastic anisotropy and yield criteria on prediction of forming limit curves. International Journal of Mechanical Sciences. 2000;42:29-48

[21] Aretz H. Applications of a new plane stress yield function to orthotropic steel and aluminium sheet metals. Modelling and Simulation in Materials Science and Engineering. 2004;12:491-509

[22] Jining Q Di Z, Guoding Z, Lee J-C. Effect of temperature on texture formation of 6061 aluminum sheet in equal channel angular pressing. Materials Science and Engineering A. 2005;408:79-84

[23] Aghaie-Khafri M, Mahmudi R. Optimizing homogenization parameters for better stretch formability in an Al$\mathrm{Mn}-\mathrm{Mg}$ alloy sheet. Materials Science and Engineering A. 2005;399:173-180

[24] Galand R, Haxaire K, Arnaud L, Petitprez E, Clement L, Waltz P, et al. Microstructure and texture analysis of narrow copper line versus widths and annealing for reliability improvement. Microelectronic Engineering. 2011;88: 661-665

[25] Kim J, Gao X, Srivatsan TS. Modelling of crack growth in ductile solids: A three-dimensional analysis. International Journal of Solids and Structures. 2003;40:7357-7374

[26] Narayanasamy R, Ravindran R, Manonmani K. An analysis of void coalescence in AL 5052 alloy sheets annealed at different temperature formed under different stress conditions. Materials Science and Engineering A. 2009;507:252-267

[27] Ravikumar D, Swaminathan K. Formability of two aluminium alloys. Materials Science and Technology. 1999; 15:1241-1252

[28] Kristensson O. Numerically produced forming limit diagrams for metal sheets with voids considering micromechanical effects. European Journal of Mechanics-A/Solids. 2006; 25:13-23

[29] Son H-S, Kim Y-S, Na K-H, Hwang S-M. Effect of void shape and its growth on forming limits for anisotropic sheets containing non-spherical voids. ASME: The American Society of Mechanical Engineers. 2004;47:512-520

[30] Velmanirajan K, Thaheer ASA, Narayanasamy R, Basha CA. Numerical modelling of aluminium sheets formability using response surface methodology. Materials \& Design. 2012; 41:239-254. DOI: doi.org/10.1016/j. matdes.2012.05.027

[31] Chandra Sekhar K, Narayanasamy R, Velmanirajan K. Experimental investigations on microstructure and formability of cryorolled AA 5052 sheets. Materials \& Design. 2014;53: 1064-1070. DOI: 10.1016/j. matdes.2013.08.008

[32] Velmanirajan K, Anuradha K, Thaheer ASA, Narayanasamy R, Madhavan R, Suwas S. Experimental investigation of forming limit, void coalescence and crystallographic textures of aluminum alloy 8011 sheet 
annealed at various temperatures. Archives of Civil and Mechanical Engineering. 2014a;14(3):398-416

[33] Velmanirajan K, Anuradha K, Thaheer ASA, Ponalagusamy R, Narayanasamy R. Statistical evaluation of forming limit diagram for annealed Al 1350 alloy sheets using first order reliability method. Applied

Mathematical Modeling. 2014b;38(1): 145-167

[34] Velmanirajan K, Thaheer ASA, Narayanasamy R. Effect of annealing temperature in $\mathrm{Al} 1145$ alloy sheets on formability void coalescence and texture analysis. Journal of Materials Engineering and Performance. 2013; 22(4):1091-1107

[35] Velmanirajan K, Narayanasamy R, Anuradha K. Effect of chemical composition on texture using response surface methodology. Journal of Materials Engineering and Performance. 2013;22(11):3237-3257 


\title{
Chapter 4
}

\section{Composites and Alloys Based on the Al-Ce System}

\author{
David Weiss
}

\begin{abstract}
Aluminum alloys containing small amounts of cerium have been investigated to improve the grain refining, casting characteristics, and mechanical properties of aluminum alloys. These additions were usually made at levels of $1 \%$ or less but did not produce appreciable improvements. Recent work has shown that additions between $4 \%$ and the approximate eutectic composition of $10 \%$ improve the high-temperature performance of aluminum alloys. Corrosion performance of aluminum alloys can also be improved through the addition of Ce. Traditional aluminum alloying elements such as magnesium and silicon can be used to control casting characteristics and thermal and physical properties. Cerium oxide is the predominate oxide in rare earth mining. Much of it is discarded after separation from the heavy rare earth oxides containing $\mathrm{Nd}$ and Dy. The beneficial use of Ce should reduce the cost of the more desirable rare earths. Results of using $\mathrm{Ce}$ as an addition to aluminum in multiple manufacturing methods such as additive manufacturing, extrusion, and casting are explored. The results show significant strengthening and improved mechanical property retention at higher temperatures than in other aluminum alloys and, in some compositions, show complete recovery of mechanical properties at room temperature when exposed to elevated temperatures as high as $500^{\circ} \mathrm{C}$ for 1000 hours.
\end{abstract}

Keywords: aluminum-cerium alloys, aluminum-cerium composites, casting, extrusion, additive manufacturing

\section{Introduction}

Auto manufacturers are under commercial and regulatory pressure to improve engine efficiency. Potential solutions include direct fuel injection, higher compression ratios, and turbochargers. All these solutions can cause higher operating temperatures and pressures. Al-Si-Mg or Al-Si-Cu-Mg alloys, typically solution treated and aged, are used for automotive products because of their good mechanical properties at room temperature and easy processing. However, these alloys rapidly lose strength above their aging temperature, typically around $155^{\circ} \mathrm{C}$. For engines to be able to operate between 180 and $300^{\circ} \mathrm{C}$, a different paradigm for alloy design is needed. The requirement for high-temperature lightweight alloys is not restricted to automobile components. Aerospace and military sectors, as well as commercial sectors such as trucking and industrial equipment, all require alloys that meet the increased demands of new fuel-efficient designs.

Several strategies have been employed to improve the performance characteristics of aluminum alloys. The addition of Cu generally improves both room temperature and high-temperature strength, although there can be an impact on corrosion 
because of a greater change in electrode potential with variations in the amount of copper in solid solution and the presence of nonuniformities in solid solution concentration [1]. The addition of transition metals such as $\mathrm{Zr}, \mathrm{Mn}$, and V is being used to stabilize the precipitates in alloys of the Al-Cu-Mg and Al-Si-Mg system. Many types of metal matrix composites have been developed that will generally improve modulus, yield strength, and elevated temperature properties although the composites are generally less ductile and are more difficult to process.

Cerium addition can improve the performance characteristics of both solid-solution-strengthened and precipitation-strengthened aluminum alloys, particularly at elevated temperatures.

\section{Background and history}

Mondolfo [2] reviewed the aluminum-cerium and the aluminum-ceriumiron system and reported that small additions of Ce do not produce appreciable improvements and that the alloys did not have a wide application. He reported that a eutectic is formed with $13 \% \mathrm{Ce}$ at $638^{\circ} \mathrm{C}$. In a later work [3], he reported that an increase of strength without loss of conductivity and improved machinability had been claimed for cerium additions to aluminum alloys. He referenced sources that claimed an $\mathrm{Al}-\mathrm{CeAl} l_{4}$ eutectic at approximately $12 \% \mathrm{Ce}$.

An analysis of the Al-Ce-Fe system produced via powder metallurgy showed extraordinary strengths in an Al-8Fe-4Ce alloy at temperatures up to $343^{\circ} \mathrm{C} \mathrm{[4].}$ There was no documented attempt to cast these materials.

There has been some experimental work to use Ce as a component of cast aluminum alloys. Shikun $[5,6]$ reviewed the effect of cerium additions on the cast microstructure and solidification range of an $\mathrm{Al}-4.5 \mathrm{Cu}$ alloy. He concluded that the addition of cerium improved castability but the mechanical properties were not studied. Belov [7] explored Ce for the development of creep-resistant aluminum alloys in combination with transition metals such as $\mathrm{Zr}, \mathrm{Mn}, \mathrm{Cr}, \mathrm{Fe}$, and Ni. Later [8], Belov focused on the Al-Ce-Ni system. He concluded that alloys of the Al-Ce-Ni ternary eutectic system had high mechanical properties at room and elevated temperatures along with good casting characteristics.

Al-Si alloys are the most important Al-based foundry alloys. They have good mechanical properties, narrow solidification ranges, and good fluidity. Gröbner [9] considered aluminum alloys containing up to 25 at.\% Ce and 45 at.\% Si and studied several Al-Ce-Si systems where the aluminum was held at a constant 90 at.\% and the concentrations of $\mathrm{Ce}$ and $\mathrm{Si}$ varied between 0 and $10 \%$. He showed that small Ce additions could provide high-temperature stable AlCeSi phases in equilibrium with Al-Si-rich melt. He concluded that Ce between 1 and 5 at.\% could be used as a grain refiner.

The development of Al-Ce casting alloys is driven by the increasing demands for high-temperature-tolerant aluminum alloys and the use for the excess cerium that was available as a by-product of the production of the heavy rare earths.

\section{Metallurgical aspects of the Al-Ce system}

The equilibrium diagram, Ce-Al crystal structure data, and Ce-Al lattice parameter date were reviewed in 1988 [10], and a eutectic composition of $\mathrm{Al}$ and $\mathrm{Al}_{11} \mathrm{Ce}_{3}$ was shown at 4 at. $\% \mathrm{Ce}$ at $640^{\circ} \mathrm{C}$. This reference confirms the $\mathrm{Al}$-rich compound had previously been incorrectly identified as $\mathrm{Al}-\mathrm{CeAl}_{4}$. Recently calculated Thermo-Calc data predicted a eutectic of $\mathrm{Al}_{11} \mathrm{Ce}_{3}$ at $580^{\circ} \mathrm{C}$ at $10 \mathrm{wt} . \%$ [2.09 at.\%] [11]. 
Typical microstructures of the Al-Ce binary composition are shown in Figure 1 [12]. The as-cast microstructures show a very fine interconnected $\mathrm{Al}_{11} \mathrm{Ce}_{3}$ eutectic microstructure in a pure aluminum phase. The intermetallic can be as small as $50 \mathrm{~nm}$ wide at permanent mold cooling rates. These structures are stable up to the melting point of the aluminum phase. The intermetallics cannot dissolve since Ce has extremely low solubility in the aluminum matrix. A solubility diagram for the binary Al-Ce system is shown in Figure 2. Yield strength retention is about three times conventional alloys when tested at $300^{\circ} \mathrm{C}$. When $\mathrm{Ce}$ is used with solid solution strengthening elements such as $\mathrm{Mg}$ or $\mathrm{Zn}$, room temperature properties remain stable regardless of exposure times with exposure temperatures up to $400^{\circ} \mathrm{C}$. The data in Figure 3 shows an actual increase in room temperature properties after exposure at $400^{\circ} \mathrm{C}$. This is due to the homogenization of magnesium that is not uniformly distributed because of low and variable cooling rates in the cast structure. In solid-solution-strengthened alloys, there are no phases that dissolve or coarsen such as the $\mathrm{Mg}_{2} \mathrm{Si}$ in 300 series alloys or the $\mathrm{Al}_{2} \mathrm{Cu}$ in 200 series.

Load partitioning studies in compression conducted by Oak Ridge National Laboratory at their Vulcan Beam Line show unusual load sharing behavior between the matrix and the $\mathrm{Al}_{11} \mathrm{Ce}_{3}$ intermetallic. As illustrated in Figure 4, as the compressive stress increases, a higher proportion of that stress is transferred to the intermetallic. An extensive analysis of the strengthening mechanisms and microstructural analysis of the Al-Ce system can be found in Ref. [11].
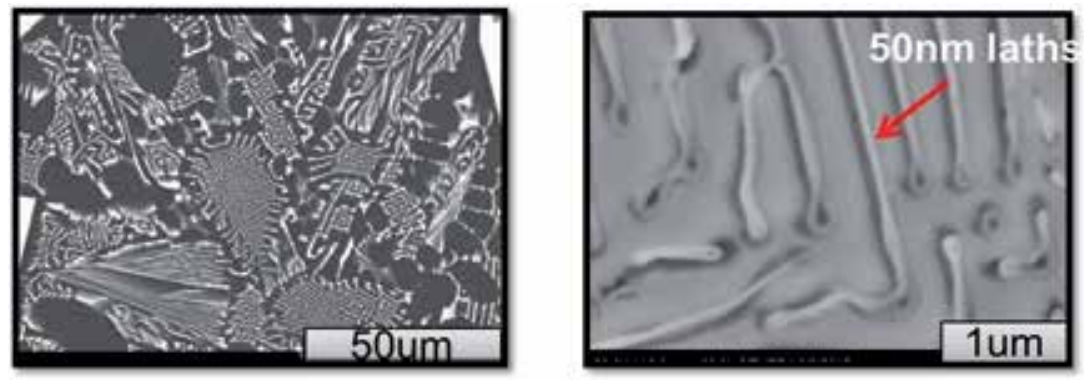

Figure 1.

(A) As-cast microstructure of Al-Ce8 binary alloy. (B) Al-Ce8 binary showing sub-micron width laths.

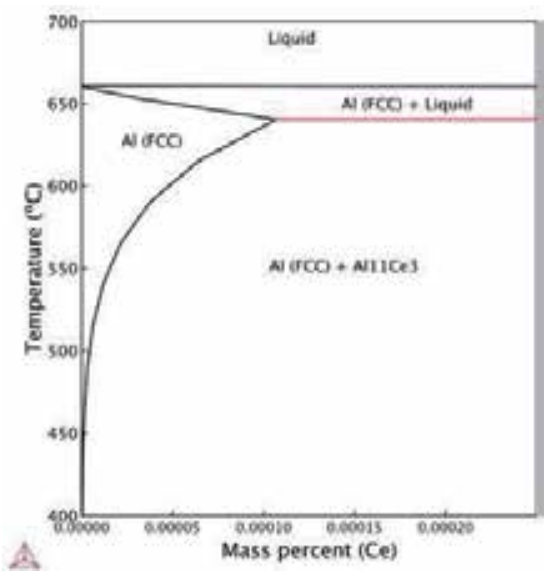

Figure 2.

Ce solubility in aluminum. 


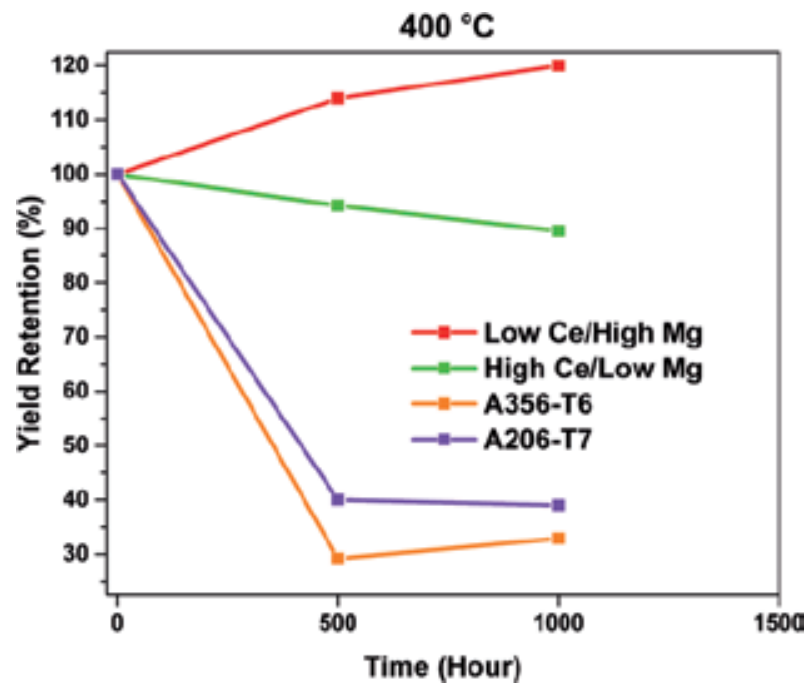

Figure 3.

Long-term exposure data of Al-Ce alloys measured at room temperature compared to some standard casting alloys.

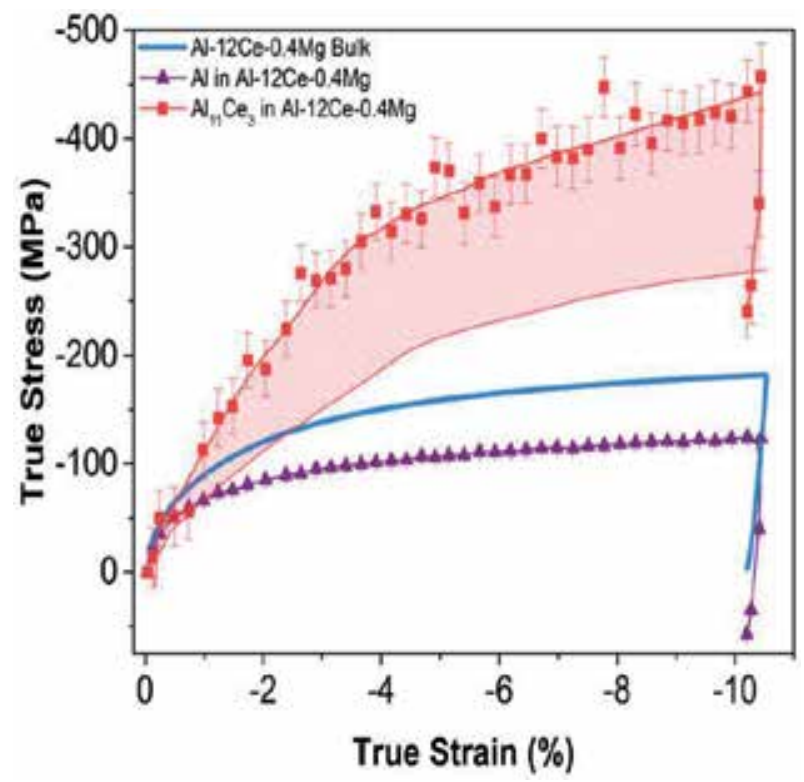

Figure 4.

Phase load sharing for $\mathrm{Al}-12 \mathrm{Ce}-0.4 \mathrm{Mg}$ under compressive load. Shaded region denotes differences between binary and ternary alloy composition's mechanical response from Ref. [4].

\section{Alloying element interactions}

At room temperature, the $\mathrm{Al}_{11} \mathrm{Ce}_{3}$ intermetallic is not an effective strengthening mechanism. Mechanical properties for pure binary compositions are shown in Table 1. To develop reasonable room temperature strengths, other alloying elements such as $\mathrm{Mg}, \mathrm{Zn}, \mathrm{Cu}, \mathrm{Si}$, or others can be added along with Ce to strengthen the aluminum matrix. Sun [13] reported on a comprehensive study of 19 binary systems of $\mathrm{Ce}$ and $4 \mathrm{~d}$ or $5 \mathrm{~d}$ transition metals using high-throughput first-principles calculations. Understanding the reaction mechanics between Ce and other alloying 
elements can be used to identify elements that could independently strengthen the aluminum matrix without interference from the $\mathrm{Ce}$ as well as those that form compounds with the Ce that can synergistically increase the strength or potentially immobilize elements required for strengthening during heat treatment.

In commercially pure aluminum, magnesium in solid solution gives a near-linear concentration dependence of strength at a given strain. The solid solution hardening is a result of an interaction between the mobile dislocations and the solute atoms [14]. In an Al-8Ce alloy, the addition of 10\% magnesium increases the yield strength by over $300 \%$ from about $50 \mathrm{MPa}$ to about $162 \mathrm{MPa}$. There is no evidence that the formation of some CeMg intermetallic is a significant factor in the strength increase, with the primary mechanism being the matrix strengthening by the magnesium.

The addition of copper to the alloy forms immobile $\mathrm{Cu}$-Ce phases. This is illustrated in Figure 5 using a $4.5 \% \mathrm{Cu}$ alloy with the addition of 1 and $8 \% \mathrm{Ce}$. Most of the $\mathrm{Cu}$ is not free to strengthen the alloy since it is tied up with the Ce phase. On the other hand, the modification of the traditional grain boundary phases improves the hot tear resistance of the alloy and reduces intergranular corrosion. Additional $\mathrm{Cu}$ needs to be added to create "free $\mathrm{Cu}$ " that can participate in heat treat response. For copper-containing alloy such as A206 (Figure 6), the cerium acts as a diffusion barrier, preventing the formation of copper-depleted zones. In all alloys tested, the addition of small amounts of cerium increases their resistance to intergranular corrosion, as shown in Figure 7.

\begin{tabular}{cccc}
\hline & Tensile MPa & Yield MPa & \%E \\
\hline Al-16Ce & 144 & 68 & 2.5 \\
\hline Al-12Ce & 163 & 58 & 13.5 \\
\hline Al-10Ce & 152 & 50 & 8 \\
\hline Al-8Ce & 148 & 40 & 19 \\
\hline Al-6Ce & 103 & 30 & 25 \\
\hline
\end{tabular}

Table 1.

Mechanical properties of Al-Ce binary alloys.

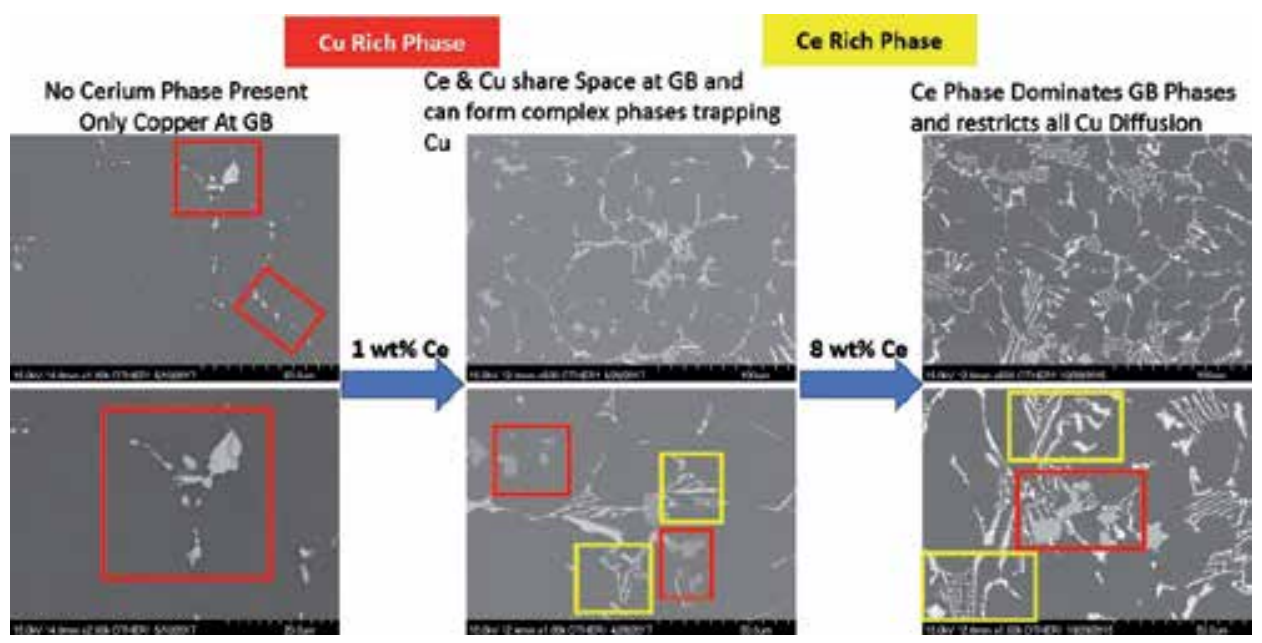

Figure 5.

As cerium addition moves from o to 8\%, the cerium phase dominates grain boundary phases and restricts $\mathrm{Cu}$ diffusion. 
The addition of scandium to Al-Ce alloys has been investigated [15]. At levels of $0.4 \% \mathrm{Sc}$, room temperature hardness levels increased by $20 \%$, and room temperature hardness values after $300^{\circ} \mathrm{C}$ exposure for 100 hours increased by $60 \%$. While the ternary Al-Ce-Sc had good thermal stability, the room temperature hardness values are not sufficient for structural castings. The addition of $\mathrm{Mg}$ at levels of up to $12.15 \%$ resulted in significant improvement in hardness at room and elevated temperatures.

Silicon as an alloying element in the Al-Ce system can be used to control the coefficient of thermal expansion, but the additions at higher levels cause several processing issues. While increasing the silicon in a binary composition with aluminum will reduce the solidification range up to the eutectic composition, the addition of Ce will increase that range which may make the alloy more difficult to feed in traditional casting applications. The solidification range of a standard Al7Si alloy is approximately $70^{\circ} \mathrm{C}$. It was experimentally determined using thermal analysis that as the ratio of $\mathrm{Ce}$ to $\mathrm{Si}$ in an alloy is increased, the solidification range increases as

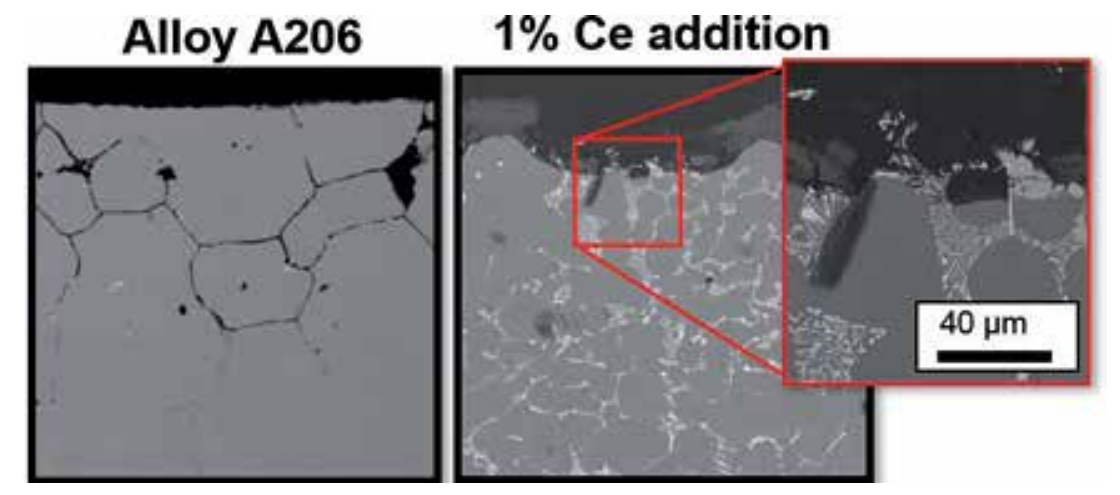

Figure 6.

The addition of Ce to Al-Cu alloys acts as a diffusion barrier by blocking grain boundary motion.

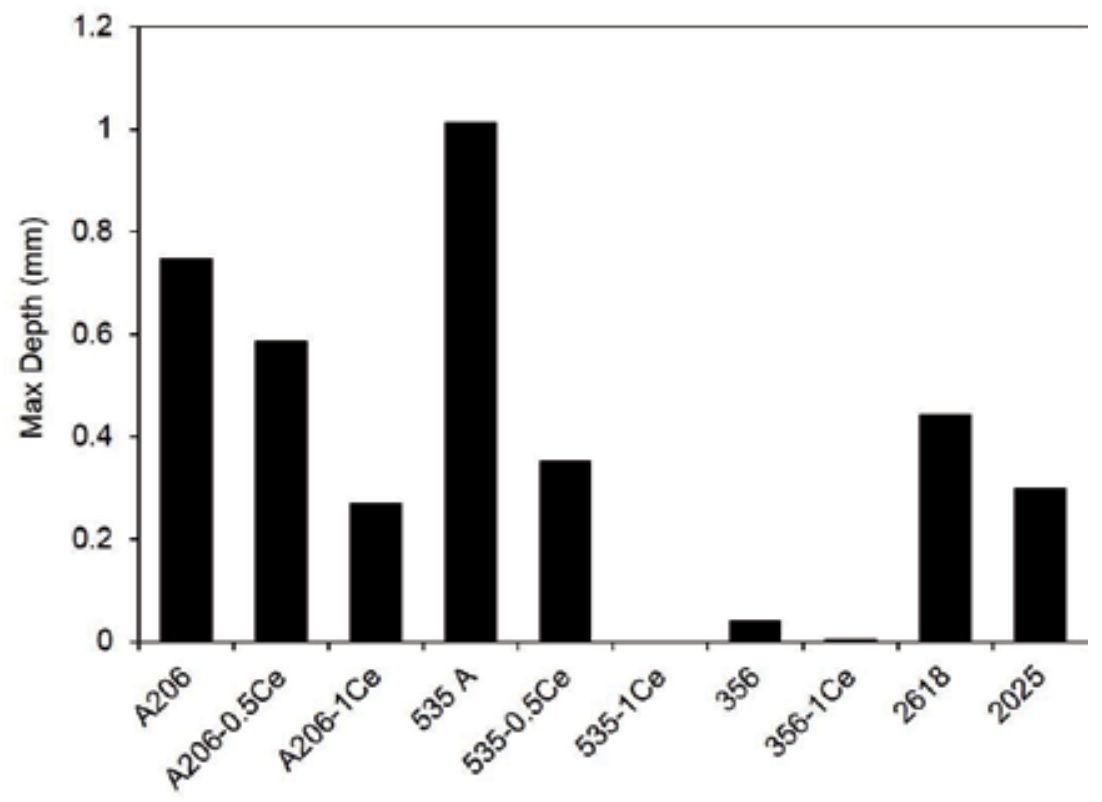

Figure 7.

ASTM G110-92(15) intergranular attack test; submerged in hydrogen peroxide with $\mathrm{NaCl}$. 
well. At a Ce/Si ratio of 3.16 , the solidification range increases to $120^{\circ} \mathrm{C}$. At a Ce/Si ratio of 0.46 , that solidification range is reduced to $82^{\circ} \mathrm{C}$. Generally, maintaining a $\mathrm{Ce} / \mathrm{Si}$ ratio of about 0.5 results in an alloy with excellent castability. The Ce will also form $\mathrm{CeSi}$ phases making some of the Si unavailable for combining with $\mathrm{Mg}$ when added to form $\mathrm{Mg}_{2} \mathrm{Si}$ strengthening precipitates. However, Si-rich alloys contain enough excess $\mathrm{Si}$ that the response to heat treatment is not affected.

\section{Composite potential in Al-Ce alloys}

In conventional hard particle-reinforced aluminum alloys, failure at elevated temperature can occur when the matrix softens and causes particle decoherence. Secondarily, the aluminum loses stiffness at high temperature, minimizing the modulus improvement attempted by the introduction of high modulus particles. Alloys containing Ce retain a higher percentage of modulus at elevated temperatures. Figure 8 shows the modulus retention of an Al10Mg8Ce-F alloy compared with 7075-T6.

Preliminary work has been completed using $\mathrm{SiC}$ and carbon nanotubes as reinforcement in $\mathrm{AlCe}$ and $\mathrm{AlCeSi}$ alloys as well as $\mathrm{Al}_{2} \mathrm{O}_{3}$ in $\mathrm{AlCeMg}$ alloys. The addition of $50 \mathrm{~nm} \mathrm{Al}_{2} \mathrm{O}_{3}$ at reinforcement levels of about $0.1 \%$ results in a tensile strength improvement of 12\%. As shown in Figure 9, a substantial number of particles are in the grain and are not exclusively pushed into the grain boundaries. Particles in the grain enhance Orowan strengthening by resisting dislocation passing in the presence of closely spaced hard particles. Whether this is directly due to the cerium content of the alloy or other processing techniques is unknown. More data and functional testing is required to fully understand the use of Al-Ce alloys as a composite matrix material.

\section{Product forms}

Much of the early work in the Al-Ce system concentrated on casting alloys. The casting characteristics of the binary Al-Ce systems are as good as the aluminum-silicon system but can change as additional alloying elements are added [16]. When other alloying elements are used such as silicon, magnesium,

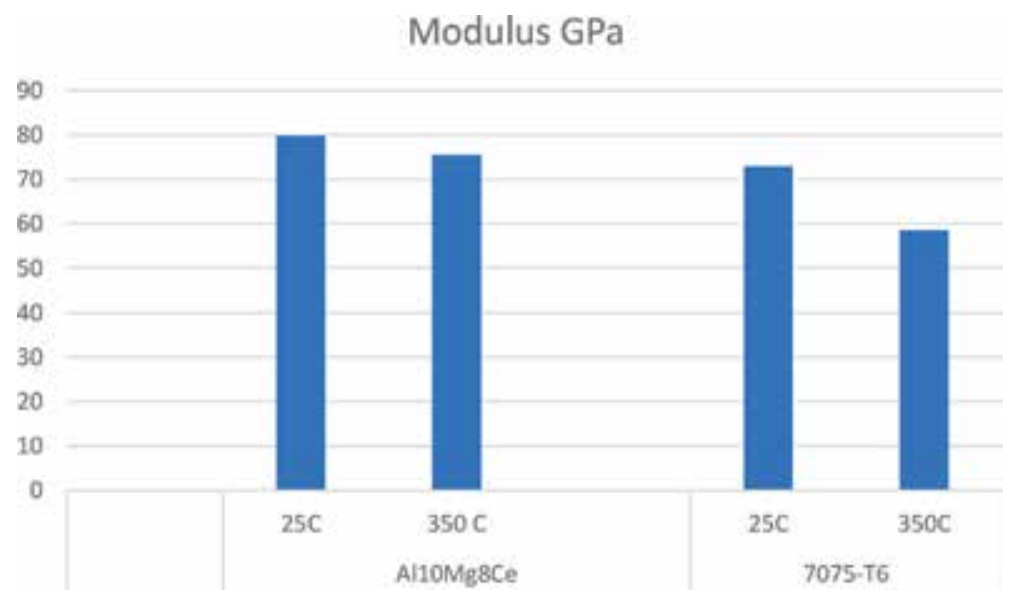

Figure 8.

Comparison of room temperature and 350C modulus between Al10Mg8Ce-F and 7075-T6. 


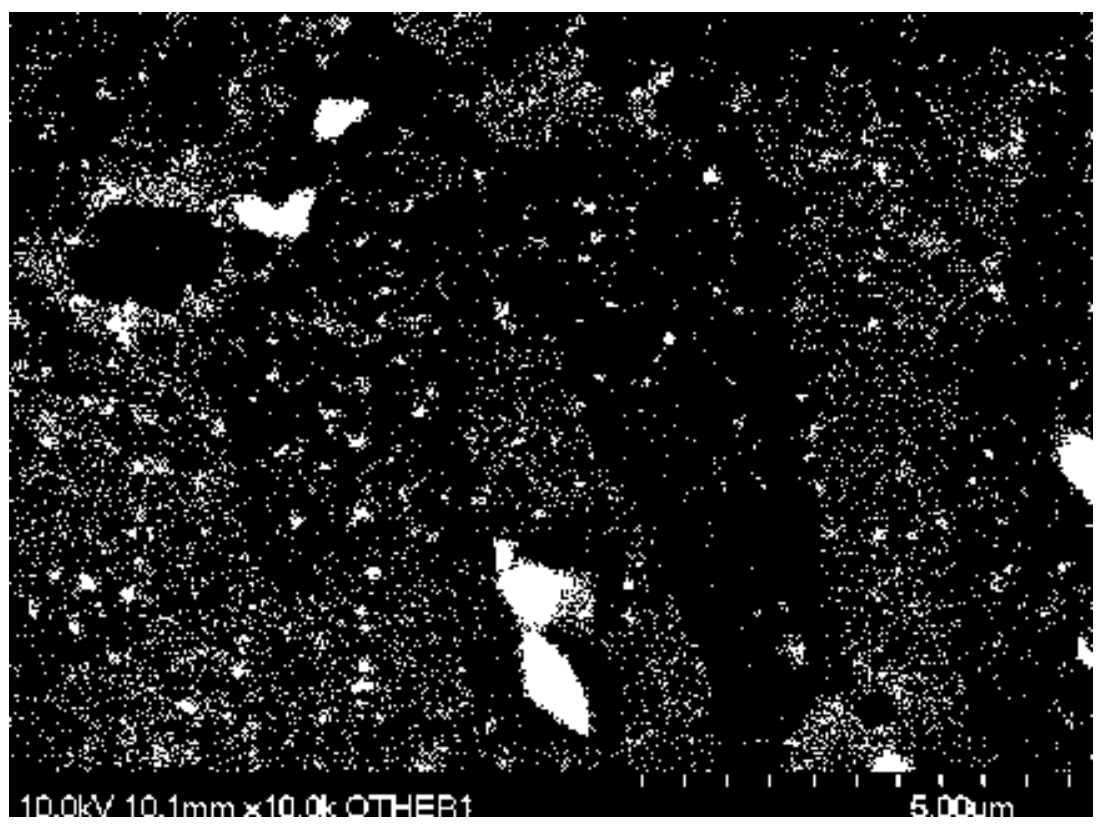

Figure 9.

Fifty nm alumina particles in a matrix of AlMg1oCe8 alloy. Large white particles are aluminum oxide formed during melt processing.

or copper, the solidification range is determined primarily by the secondary alloying elements. Standard systems for melting, degassing, and alloy cleaning of cast alloys can be used without modification for the conventional casting of aluminum-cerium alloys.

At solidification rates typical of castings in Ce alloys that contain more than $7 \%$ $\mathrm{Mg}$, a homogenization heat treatment can be used to improve mechanical properties [17]. This treatment reduces the size and volume fraction of magnesium pools that can segregate in high magnesium alloys. The amount of cerium does not affect the segregation behavior. The alloys have been cast successfully in most traditional casting processes, such as sand, permanent mold, low pressure permanent, and die casting. Figure 10 shows a cylinder head poured as a gravity casting showing the good fluidity of the alloy system.

Mechanical properties for the ternary Al-Ce-Mg system have been studied at both room and elevated temperatures (Table 2). The room temperature properties can be improved by both homogenization and hot isostatic pressing. One of the key attributes in the $\mathrm{Al}-\mathrm{Ce}-\mathrm{Mg}$ system is the recovery of mechanical properties at room temperature when exposed to elevated temperatures for prolonged periods of time. This alloy system does not contain any precipitates that become unstable after prolonged high-temperature exposure.

Extrusions have been produced for applications where improved high-temperature performance or resistance to corrosion is desired. In these alloys, extrusion improves the properties through a combination of work hardening and alignment of the intermetallic. Extrusions have been produced at $300^{\circ} \mathrm{C}$ billet temperature and at extrusion ratios of 5.75-1 and 52-1 from an Al10Mg8Ce alloy. A comparison of average permanent mold properties to extruded properties is shown in Table 3. As the extrusion ratio increases, tensile strength remains constant, with the elongation increasing and yield strength decreasing. The mechanical properties can be affected by the starting microstructure of the billet. Structural extrusions have also been produced as shown in Figure 11. 


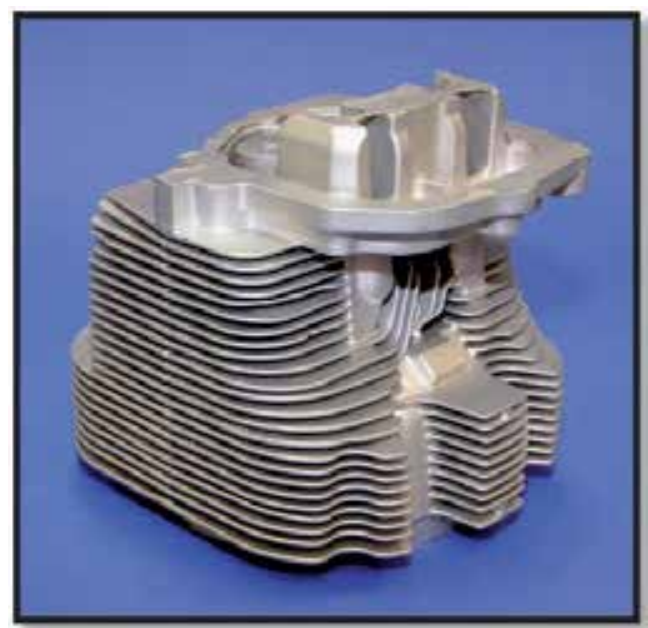

Figure 10.

Air cooled cylinder head poured from Al-Ce binary alloy.

\begin{tabular}{|c|c|c|c|c|c|c|c|c|}
\hline & \multirow[b]{2}{*}{ Temp } & \multirow{2}{*}{$\begin{array}{l}\text { Time } \\
\text { Hours }\end{array}$} & At Temp & \multirow[b]{2}{*}{ Yield } & \multirow[b]{2}{*}{ \%:E } & \multicolumn{3}{|c|}{ At RT After Heating } \\
\hline & & & Tensile & & & \begin{tabular}{|l|} 
Tensile \\
\end{tabular} & \begin{tabular}{|l|l|} 
Yield & \\
\end{tabular} & \%,E \\
\hline Al-10Mg-8Ce & $260 \mathrm{C}$ & 0.5 & 137 & 131 & 4 & & & \\
\hline All-10Mg-8Ce & $260 \mathrm{C}$ & 336 & 137 & 97 & 5 & 159 & 137 & 1 \\
\hline 2618-T61 & $260 \mathrm{C}$ & 0.5 & 90 & 62 & 50 & & & \\
\hline $40132-16$ & $200 \mathrm{C}$ & 0.5 & 90 & 62 & 30 & & & \\
\hline Al-10Mlg-8Ce & $315 \mathrm{C}$ & 0.5 & 97 & 5.5 & 20 & & & \\
\hline 2618-T61 & $315 \mathrm{C}$ & 0.5 & 52 & 31 & 80 & & & \\
\hline $4032-16$ & $300 \mathrm{C}$ & 0.5 & 38 & 24 & 70 & & & \\
\hline $\mathrm{Al}-10 \mathrm{Mg}-8 \mathrm{Ce}$ & $315 \mathrm{C}$ & 216 & 94 & 56 & 13.8 & 172 & 159 & 1 \\
\hline Al-10Mg-8Ce & $400 \mathrm{C}$ & 120 & & & & 218 & 191 & 1.5 \\
\hline Al-10Mg-8Ce & 5000 & 500 & & & & 252 & 185 & 3 \\
\hline
\end{tabular}

\begin{tabular}{|l|l|l|l|l|l|}
\hline Baseline Room Temperature Properties Al - 10Mg-8Ce-F & Cast & 228 & 186 & 1 \\
\hline & & T4 & 248 & 200 & 2 \\
\hline & & HIP & 262 & 207 & 2 \\
\hline & $2618-T 61$ & Forged & 380 & 290 & 4 \\
\hline
\end{tabular}

Tensile and Yield (Mpa)

All Al-Ce properties as cast unless otherwise noted

Table 2.

Room and elevated temperature properties of $\mathrm{Al}-10 \mathrm{Mg}$-8Ce compared to common piston alloys.

\begin{tabular}{|l|c|c|r|}
\hline & Tensile (Mpa) & Yield (Mpa) & $\% \mathrm{E}$ \\
\hline Extrusion 5:1 & & & \\
\hline Extrusion 52:1 & 375 & 342 & 6 \\
\hline Permanent Mold & 228 & 274 & 12 \\
\hline
\end{tabular}

Table 3.

Comparison of extruded data at different extrusion ratios with cast Al10Mg8Ce. 


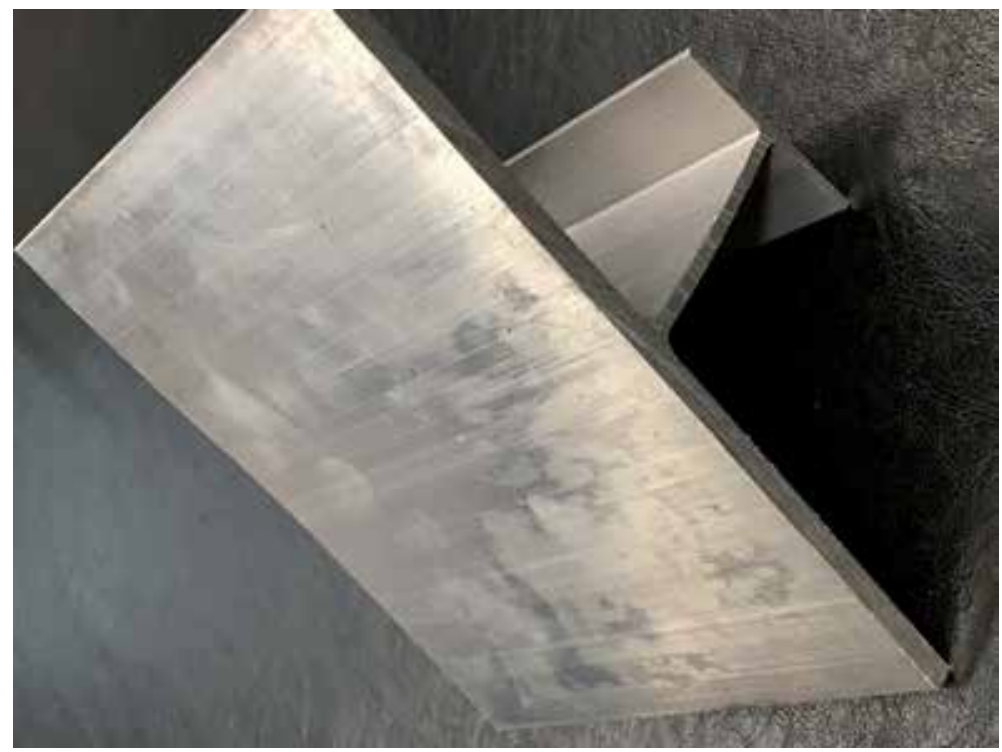

Figure 11.

Structural extrusion produced for the marine industry.

The alloy system has been used for both the direct write and powder bed fusion. Manca [18] has reported high mechanical properties of Al-3Ce-7Cu in both hightemperature tension and compression testing via selective laser melting. Fine eutectic phases of $\mathrm{Al}_{11} \mathrm{Ce}_{3}$ and $\mathrm{Al}_{6.5} \mathrm{CeCu}_{6.5}$ were found in the microstructure. High hardness values were noted after annealing at $400^{\circ} \mathrm{C}$ due to the precipitation of nanosized particles. Kessler [19] used induction heated Al-Ce wire to take advantage of the inherent rheology of molten Al-Ce and the high enthalpy of fusion for the reactive Ce-containing intermetallic. This intermetallic phase enhances the surface energy and stabilizes the extruded filament, imparting shape stability and facilitating layer-to-layer joining.

\section{Economics of Al-Ce alloys}

As an alloying element used typically in the $1-10 \%$ weight range, cerium is relatively inexpensive. Its cost is in the range of $\$ 4-5 / \mathrm{lb}$. and is widely available. The as-alloyed cost of Al-Ce material is competitive with other high-performance aluminum alloy systems. Further cost reduction in Ce is enabled by direct metallothermic reduction of cerium oxide. Luna [20] directly reduced the oxide on a laboratory scale in aluminum alloys containing between 0.5 and $4.0 \mathrm{wt} \% \mathrm{Mg}$. This technique is now being developed on a commercial scale.

\section{Conclusions}

Aluminum-cerium alloys are being rapidly developed as alternatives to $\mathrm{Al}-\mathrm{Si}$ and $\mathrm{Al}-\mathrm{Cu}$ alloys. These alloys have good fabrication characteristics and excellent corrosion performance. The alloys have superior performance at elevated temperatures and long exposure times. The use of the least expensive of the rare earth elements and standard processing methods makes the transition to use Al-Ce alloys available for lightweight high-performance applications in the automotive, trucking, aerospace, and other industrial sectors. 


\section{Author details}

David Weiss

ECK Industries, Inc. Manitowoc, WI, USA

*Address all correspondence to: david.weiss@eckindustries.com

\section{IntechOpen}

(C) 2019 The Author(s). Licensee IntechOpen. This chapter is distributed under the terms of the Creative Commons Attribution License (http://creativecommons.org/licenses/ by/3.0), which permits unrestricted use, distribution, and reproduction in any medium, provided the original work is properly cited. (cc) BY 


\section{References}

[1] Metals Handbook. 9th ed. Vol. 13. ASM International; 1987, p. 585

[2] Mondolfo LF. Metallography of Aluminum Alloys. John Wiley \& Sons, Inc.; 1943

[3] Mondolfo LF. Aluminum Alloys: Structure and Properties. Butterworths \& Co Ltd; 1976

[4] Griffith WM, Sanders RE, Hildeman GJ, Elevated temperature aluminum alloys for aerospace applications (high-strength powder metallurgy aluminum alloys). In: Proceedings of a symposium sponsored by the Powder Metallurgy Committee of the Metallurgical Society of AIME; 1982

[5] Shikun X, Rongxi Y, Zhi G, Xiang X, Chagen H, Xiuyan G. Effects of rare earth Ce on casting properties of Al-4.5Cu alloy. Advanced Materials Research. 2010;136:1-4

[6] Shikun X, Yongping A, Zhi G, Xiang X, Rongxi Y, Zhi G, et al. Effects of Ce addition on the mobility and hot tearing tendency of $\mathrm{Al}-4.5 \mathrm{Cu}$ alloy. Advanced Materials Research. 2010;146-147:481-484

[7] Belov NA. Principles of optimising the structure of creep-resisting casting aluminum alloys using transition metals. Journal of Advanced Materials. 1994;1(4):321-329

[8] Belov NA, Naumova EA, Eskin DG. Casting alloys of the $\mathrm{Al}-\mathrm{Ce}-$ Ni system: A microstructural approach to alloy design. Materials Science and Engineering A. 1999;271(1):134-142

[9] Gröbner J, Mirkovic D, Schmid-Fetzer R. Thermodynamic aspects of the constitution, grain refining, and solidification enthalpies of Al-Ce-Si alloys. Metallurgical and Materials Transactions A. 2004;35A:3349

[10] Gschneidner K, Calderwood FW. The Al-Ce (aluminum-cerium) system. Bulletin of Alloy Phase Diagrams. 1988;9(6):699-672

[11] Sims Z et al. High performance aluminum-cerium alloys for hightemperature applications. Materials Horizons. 2017;4:1070

[12] Weiss D. Improved hightemperature aluminum alloys containing cerium. Journal of Materials Engineering and Performance. 2019

[13] Sun X, Lei Y, Zhou R, Zhang B. Novel compounds of cerium binary alloys from high-throughput first-principles calculations. Journal of Applied Physics. 2018;123:235102

[14] Ryen O et al. Strengthening mechanisms in solid solution aluminum alloys. Metallurgical and Materials Transactions A. 2006;37A

[15] Weiss D. Developments in aluminum-scandium ceramic and aluminum-scandium cerium alloys. In: Light Metals. Corleen Chesonis, editor, The Minerals: Metals \& Materials Society; 2019

[16] Weiss D. Development and casting of high cerium content aluminum alloys. In: Transactions of the American Foundry Society 17-013. Schaumburg: American Foundry Society; 2017

[17] Weiss D. Thermal treatment of Al-Mg-Ce alloys. In: Transaction of the American Foundry Society 18-101. Schaumburg: American Foundry Society; 2018

[18] Manca DR et al. Microstructure and properties of novel resistant $\mathrm{Al}-\mathrm{Ce}-\mathrm{Cu}$ alloy for additive manufacturing. Metals and Materials International. 2018;22 
Composites and Alloys Based on the Al-Ce System

DOI: $h t t p: / / d x$.doi.org/10.5772/intechopen.89994

[19] Kesler $\mathrm{M}$ et al. Liquid direct reactive printing of structural aluminum alloys. Applied Materials Today. 2018;13:339-343

[20] Luna, J.S., et al. “Cerium extraction by metallothermic reduction using cerium oxide powder injection" Journal of Rare Earths, Vol 29, No. 1, 2011, pg. 74 



\title{
Novel Applications of Aluminium Metal Matrix Composites
}

\author{
Francis Nturanabo, Leonard Masu and John Baptist Kirabira
}

\begin{abstract}
Advanced materials have offered the materials designer a wide range of options in the specification and selection of materials for various applications. Material properties are continually being improved to meet safety and operational standards in line with prevailing technological developments. Modern technological requirements, together with the consumers' demands for systems and machines that are more energy efficient, stronger, light-weight, cost-effective, etc., dictate that the search for new and advanced materials will remain a subject of interest all the time. The difficulty in designing materials for such stringent specifications cannot be overstated, owing to the conflicting nature of these specifications. Aluminium metal matrix composites (AlMMCs) are a class of materials that have proven successful in meeting most of the rigorous specifications in applications where light-weight, high stiffness and moderate strength are the requisite properties. With a variety of reinforcement materials and flexibility in their primary processing, AlMMCs offer great potential for the development of composites with the desired properties for certain applications. In this review, the development, utilisation and future potential of AlMMCs in various industrial and commercial applications is discussed, together with the existing challenges hindering their full market penetration.
\end{abstract}

Keywords: aluminium, metal matrix composites, novel applications, light-weight, high-temperature

\section{Introduction}

The choice of the right materials is an arduous engineering challenge to the materials engineer and, if done carefully, can be a springboard to the proper and successful implementation and subsequent operation of the design. There are a host of materials available to the designer, and making the right decision is a vital achievement in putting forth a successful design. Materials are required to perform according to the designer's expectations and must possess and retain the right properties in the working environment throughout the working period.

Material selection is in most cases a contradictory decision-making process. Light-weight materials will most likely not possess sufficient strength, and brittle materials will not necessarily be good in fatigue resistance, stiffness or toughness. It is also almost impossible to find a single monolithic material with the required property profile for engineering applications. Moreover, material properties are greatly affected by the working environment (such as temperature, pressure, humidity, etc.) and the nature of loading (gradual, fluctuating, impact, fatigue, etc.). There is need, therefore, to combine two or more materials, as alloys or composites so as to utilise the 
different useful properties offered by the different materials. Most engineering materials appear in this configuration, and very few applications utilise pure monolithic materials [1]. This is true of aluminium, the most abundant metallic element in the Earth's crust, accounting for $8 \%$ of the planet's soil and rocks. Aluminium has been a metal of tremendous importance to the domestic and manufacturing industries from the mediaeval period (fifth-fifteenth century) and played an important role in the early years of the industrial revolution. The successful extraction and the first commercial applications of aluminium took place in the nineteenth century, the period in which the enthusiasm for new materials and their possible uses was immense [2].

The first mention of aluminium as a metal of industrial importance indicated the metal was first utilised in the manufacture of household and ornamental items before becoming an important material in the construction of large industrial structures and machine components. With the advent of alloying technology, the use of aluminium was developed farther and positioned aluminium as the most utilised industrial metal for decades. The popularity of aluminium grew due to its good attributes related to its unique properties, mainly of light-weight combined with good thermal/electrical conduction and reasonably good strength and resistance to corrosion. With alloying, aluminium has found more applications than previously envisioned, making aluminium a serious competitor with (and sometimes a preferred alternative to) the traditional "strong" metals iron and steel [3].

Aluminium alloys and composites have, in most applications, exhibited superior performance compared to their rival metals. The choice of aluminium alloys and composites derives from one important attribute of aluminium metal-lightweight. Light-weight translates into many important outcomes in engineering applications. In the automotive industry, it means less dead weight, lower fuel consumption, lower emissions, increased payload (for passengers and cargo) and easier handling. In the aerospace and aircraft industry, it translates into more payload (cargo), less fuel and lower emissions. There are similar advantages in all areas where aluminium is utilised-marine, rail, packaging, thermal management, building and construction, sports and recreation, etc. Aluminium's good electrical and thermal conductivity have seen its increased use in electrical conductors, electronic packaging and thermal management. Nowadays, aluminium is viewed as an important material for energy conservation and environmental protection [4].

Modern technology aims at meeting the market whose standards are ever appreciating. The market demands faster, more comfortable and hassle-free transport, more compact and lighter machines and tools, more efficient methods of power generation, etc. Most engineered materials can easily meet or surpass design specifications that would not have been envisaged a few years back. Today's materials are subjected to more critical loads, more stresses and more severe operating conditions in an environment never experienced before. In a spacecraft, for example, the operating conditions experienced are quite unique and require special types of materials to withstand the severe stresses imposed on the spacecraft during take-off and maintenance in the orbiting space. Traditional materials have been found wanting in meeting these operating conditions and hence the need to intensify research and development (R\&D) efforts in new and advanced materials for specific applications and efficiency improvement. Among the advanced materials on the $\mathrm{R} \& \mathrm{D}$, the menu is the metal matrix micro- and nanocomposites. Metal matrix composites (MMCs) are metals or metal alloys that incorporate particles, whiskers, fibres or hollow microballoons made of a different material and offer unique opportunities to tailor materials to specific design needs [5]. In automotive applications, for example, these materials can be tailored to be light-weight and with various other useful properties including high specific strength and specific stiffness, high hardness and wear resistance, high thermal conductivity, high energy absorption and a damping capacity and low coefficients of friction and thermal expansion. 
MMCs, therefore, offer more possibilities for wider applications of materials by manipulating their processing to suit the requisite properties under different working environments. The design of composite materials with specific properties can, moreover, be accomplished with the use of finite element modelling techniques. It is possible to predict the properties of a certain material of specified composition by using these techniques. In the same way, it is possible to design materials to offer specified properties by the use of these techniques [1].

\section{Types of metal matrix composites and their methods of production}

\subsection{An overview of metal matrix composites}

A composite is a mixture of two or more constituents or phases which are chemically distinct on a microscopic scale, separated by a distinct interface, and can easily be specified. In addition, other criteria are normally satisfied before a material can be called a composite. The constituents have to be present in reasonable proportions, and the constituent phases should have distinctly different properties, such that the properties of the composite are noticeably different from the properties of the constituents [4]. The constituent which is continuous and in most cases available in larger quantities is termed the matrix. It is commonly viewed that it is the properties of the matrix that are improved upon in the process of producing a composite. The second constituent is known as the reinforcing phase, or reinforcement, as it enhances or reinforces the mechanical properties of the matrix. In most cases the reinforcement is harder, stronger and stiffer than the matrix, although there are some exceptions. The matrix may be in form of a ceramic material, metallic or polymeric, with each of these three classes of materials having considerably different /unique mechanical properties. Generally, polymers have low Young's moduli and strengths; ceramics are strong, stiff and brittle; and metals have intermediate moduli, strengths and good ductility [6].

Composite materials are usually classified according to the physical or chemical nature of the matrix, e.g. metal matrix, polymer matrix and ceramic composites. Additionally, the emergence of the intermetallic matrix and carbon matrix composites as reported by [7] has broadened the scope of composites. Intermetallic compounds are metal-based systems centred on the fixed atomic compositions occurring in metallic systems of aluminium with nickel (Ni), titanium ( $\mathrm{Ti}$ ) and niobium $(\mathrm{Nb})$, such as $\mathrm{Ni}_{3} \mathrm{Al}, \mathrm{Ti}_{3} \mathrm{Al}$, TiAl and $\mathrm{Nb}_{3} \mathrm{Al}$. Intermetallic compounds are of interest because they often exhibit higher melting points and less ease of deformation due to the lattice arrangement of their atoms [8].

In certain applications, metal matrix composite materials, formed by combining two or more materials—one of which is a metal—exhibit a primary advantage over their counterpart organic matrix composites in regard to the maximum operating temperature. To support this point, [9] reports that the boron/aluminium composite offers useful mechanical properties up to a temperature of $510^{\circ} \mathrm{C}$, whereas an equivalent boron/epoxy composite is limited to about $190^{\circ} \mathrm{C}$. Furthermore, composites of graphite/aluminium, graphite/copper and graphite/magnesium exhibit higher thermal conductivity due to the significant contribution from the metallic matrix. A metal matrix composite retains the desirable properties of both the matrix and the reinforcement by combining the strength of its reinforcement with the ductility of its matrix [10]. The reinforcing constituent may be a particle, platelet, short fibre or continuous fibre and may range from sub-micrometre to millimetre in size. There is a difference between metal matrix composites and multiphase metallic alloys as the concept of MMCs introduces additional degrees of 
freedom into designing the microstructure. Materials with desirable properties not obtainable by conventional alloying and heat treatment can be created compositing. This can be achieved by altering the reinforcement type (metallic, ceramic or polymeric), content (volume fraction), size, shape, distribution and orientation [11].

In the early development of MMCs, continuous ceramic fibres and single-crystal ceramic whiskers were the preferred reinforcements as they provided the most remarkable increase in strength and stiffness. Later, particulate and discontinuously reinforced MMCs then followed, registering substantial progress on many fronts especially in composites with aluminium as the metal matrix. In aluminium metal matrix composites (AlMMCs), aluminium or its alloy forms a percolating network and is the matrix phase, while the other constituent, which is embedded in this matrix, is the reinforcement. The reinforcement is usually ceramic such as silicon carbide $(\mathrm{SiC})$ or aluminium oxide $\left(\mathrm{Al}_{2} \mathrm{O}_{3}\right)$. The properties of AlMMCs can be varied by varying the nature of the constituent phases and their volume fractions [4].

Although the MMCs have been in existence since the 1960s, they have not been put to full commercial use due to their higher production costs and lack of proper understanding of their high-temperature behaviour [12]. The higher costs are mainly attributed to the machining processes requiring tool materials to have very high wear resistance because of the reinforcement component being extremely abrasive [13]. However, with the invention of functionally graded materials (FGMs), it is now possible to reduce the cost of secondary processing. FGMs are an emerging category of advanced materials that exhibit gradual microstructural transitions and/or the composition in a specific direction and hence different functional performances within a part [14, 15].

The rapid growth and development of AlMMCs happened in the years after the launch of the Aluminium Metal Matrix Composites Roadmap 2002, a policy document produced by the Aluminium Metal Matrix Composites Consortium with support from the Technology Research Corporation (TRC) of the United States and other stakeholders. The document spelt out a pathway for the AlMMCs' growth in 20 years from 2002 and asserted the industry's vision to position AlMMCs as the material of choice in a broad range of structural and nonstructural applications. This vision was to be achieved by addressing three strategic goals, namely:

i. To reduce the cost of discontinuously reinforced AlMMCs to be comparable to existing alternatives by 2010

ii. To develop the necessary infrastructure to provide design confidence for AlMMCs

\section{iii. To increase the market size for AlMMCs}

By that time, AlMMCs had proved their potential in such applications as aerospace, automotive, electronic packaging, commercial and industrial markets. The market was projected to grow at a $14 \%$ overall rate to $\$ 173$ million by 2004 . The industry believed then that there was much greater unrealised potential for growth [16].

\subsection{Classification of metal matrix composites}

Metal matrix composites can be classified into several distinct classes, generally defined with reference to the type, shape and method of their reinforcements. The following classification is relevant to MMCs with aluminium as the matrix metal as explained in [4] and [11]. Typical microstructures are shown in Figures 1 and 2.

Particle-reinforced MMCs: Invariably known as particulate-reinforced MMCs, these composites generally contain equi-axed ceramic reinforcements, mainly 
oxides (e.g. alumina, $\mathrm{Al}_{2} \mathrm{O}_{3}$ ), carbides (e.g. silicon carbide, $\mathrm{SiC}$ ) or borides (e.g. titanium bromide, $\mathrm{TiB}_{2}$ ), with an aspect ratio less than 5 and present in volume fraction less than $30 \%$. They can be produced by blending metal and the ceramic powders, followed by solid-state sintering or by liquid-metal techniques such as stir casting, squeeze infiltration and in situ processes.

Continuous fibre-reinforced MMCs: These contain either relatively fine continuous fibres, usually of $\mathrm{Al}_{2} \mathrm{O}_{3}, \mathrm{SiC}$ or carbon, with a diameter below $20 \mu \mathrm{m}$, or coarser fibres or monofilaments. The former can be either parallel or pre-woven prior to infiltration to form a composite, while the bending flexibility of the latter limits the range of shapes that can be produced. Monofilaments are large diameter (100-150 $\mu \mathrm{m}$ ) fibres, usually produced by chemical vapour deposition (CVD) of either $\mathrm{SiC}$ or boron (B) into a core of carbon fibre or tungsten (W).

Whisker-and short-fibre-reinforced MMCs: These contain reinforcements with an aspect ratio of greater than 5 but are not continuous. Short $\mathrm{Al}_{2} \mathrm{O}_{3}$ fibre-reinforced MMCs have been dominantly used in pistons. Whisker-reinforced composites, produced by either powder metallurgy or squeeze infiltration into a fibre preform, are generally produced to net/near-net shape. However, usage of whiskers as reinforcements is being restricted due to perceived health hazards.

Hybrid MMCs: Hybrid MMCs essentially contain more than one type of reinforcement, for example, a mixture of particle and whisker, a mixture of fibre and particle or a mixture of hard and soft reinforcements. With the discovery of carbon nanotubes (CNT), composites with superior mechanical properties over those of carbon have been produced [19].

Other MMCs with variety of matrices other than aluminium include: Cemented carbides (cermets) — which are made by powder blending of a high proportion (60-75\%) of ceramic or titanium carbide ( $\mathrm{TiC}$ ) with a metal such as cobalt, followed by holding for a short period at a temperature sufficient to melt the metallic constituent (liquid-phase sintering). In situ composites-in which directional solidification is used to form relatively fine aligned two-phase fibre or lamellar structures, resulting in an intermetallic reinforcement with high stiffness and strength. Co-deformed composites - in which immiscible metals are co-deformed such that filaments of the second phase with very large aspect ratio are formed within the matrix material. Typical examples include $\mathrm{Cu}-\mathrm{Cr}$ and $\mathrm{Cu}-\mathrm{Nb}$ systems. Cermets have outstanding high-temperature strength and are widely used for tool bits [11].

\subsection{Methods of production of AlMMCs}

Primary compositing processes for manufacturing of AlMMCs at industrial scale can be classified into two main groups, namely, (1) liquid-state processes and (2) solid-state processes [4]. The liquid-state processes are further classified into liquid-metal-mixing processes and liquid-metal-infiltration processes. Specifically, liquid-metal mixing is the primary compositing route for producing materials

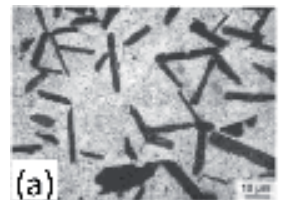

(a)

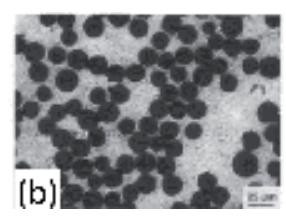

(b)
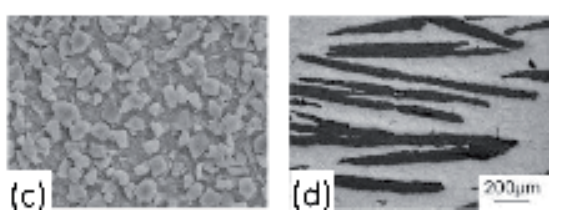

Figure 1.

Typical microstructures of AlMMCs. (a) $\mathrm{Al}_{\mathrm{AAl}} \mathrm{O}_{3}$ platelets. (b) $\mathrm{Al} / \mathrm{Al}_{2} \mathrm{O}_{3}$ continuous fibres. (c) $\mathrm{Al} / \mathrm{SiC} \mathrm{C}_{\mathrm{p}}$. (d) Al/graphite with 20 vol.\% graphite flakes taken along the basal plane (source: [17, 18]). 

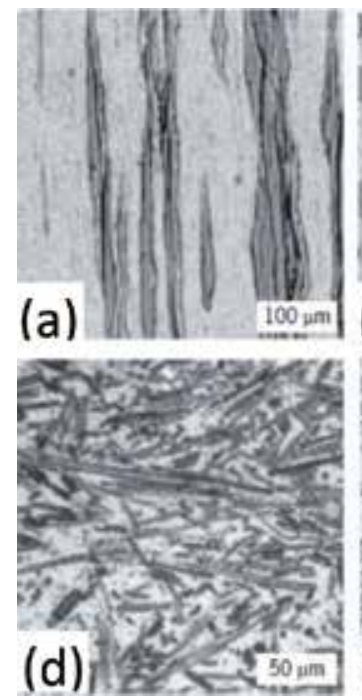
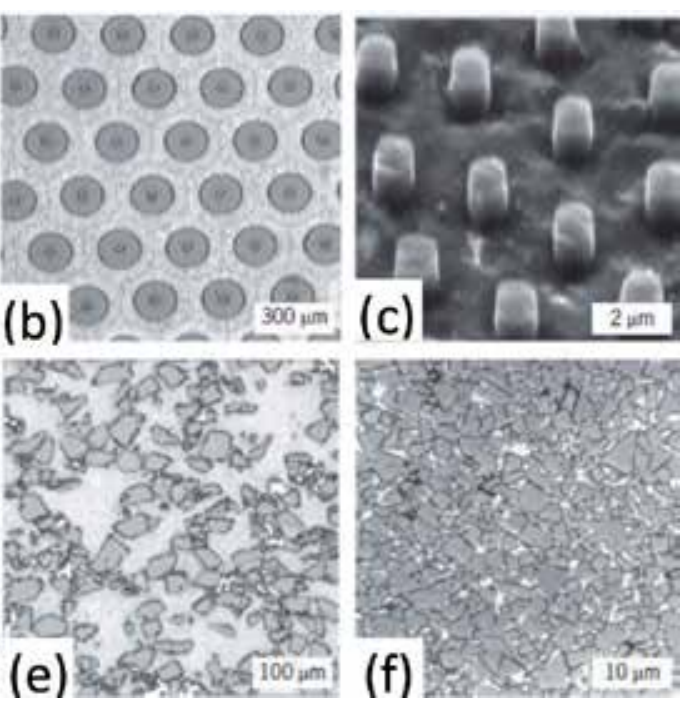

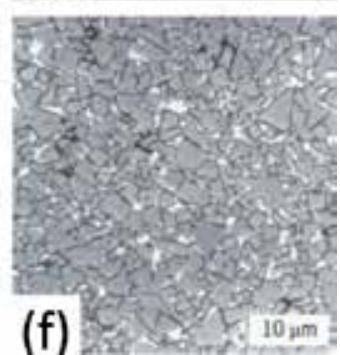

Figure 2.

Typical microstructures of MMCs. (a) Cu/Cr co-deformed composite. (b) Ti-6Al-4 V/SiC monofilament.

(c) $\mathrm{NiAl} / \mathrm{Mo}$ in situ composite. (d) $\mathrm{Mg} / \mathrm{Al}_{2} \mathrm{O}_{3}$ short-fibre composite. (e) Al/SiC particulate composite.

(f) Co/WC cermet (source: [11]).

considered for high-volume automotive applications, liquid-metal infiltration for high-volume electronic packaging applications and solid-state processing for highperformance aerospace applications [20].

\subsubsection{Liquid-metal-mixing processes}

The liquid-metal-mixing process involves the incorporation of reinforcement particles or short fibres into a molten or semi-solid aluminium matrix through a stirring process. In stir casting technique, the process involves the incorporating of ceramic particulate into liquid aluminium melt and allowing the mixture to solidify. It is crucial to ensure that good wettability between the particulate reinforcement and the liquid aluminium alloy melt is achieved. Generally it is possible to incorporate up to $30 \%$ ceramic particles in the size range from 5 to $100 \mu \mathrm{m}$ in a variety of molten aluminium alloys [16]. Surappa [4] identifies another variation of the stir casting process, called compo-casting, in which ceramic particles are incorporated into the alloy in the semi-solid state.

Particulate-reinforced AlMMCs have been commercially available in significant quantities since the 1990s. The interest in these MMCs was driven by the combination of improved mechanical and physical properties imparted by the reinforcement while still maintaining the favourable metalworking characteristics and predominantly metal-like behaviour. A second motivating factor was the ability to tailor the mechanical and physical properties through selection of the reinforcement composition along with the matrix alloy.

\subsubsection{Liquid-metal-infiltration processes}

In the liquid-metal-infiltration process, the molten aluminium or its alloy is moved into a preform of the reinforcement, either as a packed bed or a rigid, free-standing structure. In order for the preform to retain its integrity and shape, it is often necessary to use silica- and alumina-based mixtures as a binder. Some degree of pressure is needed to overcome the wetting and capillary resistance, and this can vary from 
atmospheric to thousands of Pascal. In this process, the concept was to take advantage of the excellent reinforcement properties in a product that was essentially formed to net shape by the casting process. This process can produce materials with a range of reinforcement volume fraction but is especially well suited for reinforcement levels above $50 \%$ and in some cases approaching $80 \%$. As a result, the materials produced by this process are well suited for electronic packaging [19, 21].

Other variations of this technique include spray deposition and in situ (reactive) processing. In spray deposition techniques, the droplet stream may either be produced from a molten bath (Osprey process) or by continuous feeding of cold metal into a zone of rapid heat injection (thermal spray process). This process has been extensively explored for the production of AlMMCs by injecting a ceramic reinforcement into the spray. The AlMMC processed by spray deposition technique is relatively inexpensive with a cost that is usually intermediate between stir cast and P/M processes. In situ processing applies to several different processes, which include liquidsolid, liquid-liquid, liquid-gas and mixed salt reactions. These processes lead to the formation of a refractory reinforcement in the aluminium alloy matrix. For example, in the directional oxidation of aluminium (the DIMOX process) [4], the alloy of $\mathrm{Al}-\mathrm{Mg}$ is placed in a crucible on top of a ceramic preform and the entire assembly heated to a suitable temperature in an atmosphere of free-flowing nitrogen-carrying gas mixture. The molten Al-Mg alloy then infiltrates into the preform-forming the composite [22].

The liquid-metal-infiltration process was first successfully demonstrated in the production of the Toyota piston in which a discontinuous fibre preform was infiltrated by squeeze casting to provide a local improvement in wear resistance in the piston ring land area. The technology has since been adopted for the manufacture of several automotive and military powertrain and suspension components [20].

\subsubsection{Solid-state processes}

Solid-state processes involve the mixing of reinforcement (particles or whiskers) into a solid-state matrix. Historically, these methods employed solid-state-based processes, such as powder metallurgy $(\mathrm{P} / \mathrm{M})$, to produce AlMMCs with the highest combinations of properties. Therefore, these materials are primarily employed in higher-performance applications, especially in the aerospace and automotive markets, where these materials are used in high-performance components, mostly those dominated by fatigue. Initially, ceramic-whisker materials were produced, and subsequently, ceramic-particulate-reinforced materials followed. These materials, while expensive both in terms of the reinforcement and processing costs, developed dramatically improved properties over the base metal and were used in a number of high-performance applications, both military and commercial. However, due to the health risks posed by whisker-reinforced MMCs, particulate-reinforced MMCs have replaced them in many applications, leaving the whisker-reinforced MMCs for specialised military applications [23]. Particulate reinforcement, besides being of lower cost, also exhibited improvements in strength and stiffness almost as high as those obtained in whisker-reinforced materials.

Variations in solid-state processing have been identified (see, e.g. [4]):

Powder blending and consolidation ( $P / M$ processing): Blending of aluminium alloy powder with ceramic short fibre/whisker is a versatile technique for the production of AlMMCs. Blending is usually followed by cold compaction, canning, degassing and high-temperature consolidation stages such as hot isostatic pressing (HIP) or extrusion. Depending on processing conditions, AlMMCs processed through the $\mathrm{P} / \mathrm{M}$ route may contain oxide particles in volume fractions ranging from 0.05 to 0.5 and in the form of platelets of few tens of nanometres in thickness. 
Diffusion bonding: Monofilament-reinforced AlMMCs are mainly produced by the diffusion bonding route or by evaporation of relatively thick layers of aluminium on the fibre surface. The $6061 \mathrm{Al}$-boron fibre composites have been produced by this process. The process is more commonly used in production of Ti-based fibre-reinforced composites. However, it is a cumbersome process and is not suitable for production of complex shapes.

Physical vapour deposition: In this process, the continuous passage of fibre is passed continuously through a region of high partial pressure of the metal to be deposited. Here condensation takes place, producing a relatively thick coating on the fibre. Vapour deposition is then accomplished by directing a high-power electron beam onto the end of a solid bar feedstock. Typically, deposition rates per minute are in the range of 5-10 $\mu \mathrm{m}$. Composites with volume fraction as high as $80 \%$ can be produced by this technique.

\subsection{Properties of AlMMCs and resulting end uses}

\subsubsection{Properties of aluminium and AlMMCs}

Generally, aluminium has derived its importance in industrial and commercial applications due to the following attributes, most of which are imparted to its alloys and/or composites:

i. Aluminium is light; its density is only one-third that of steel.

ii. Aluminium is resistant to weather, common atmospheric gases and a wide range of corrosive liquids.

iii. Aluminium is safe and can be used in contact with a wide range of foodstuffs.

iv. Due to its high reflectivity, aluminium is usually employed in a number of decorative applications.

v. The strength of aluminium alloys can equal (and sometimes exceed) the strength of normal construction steel.

vi. Aluminium is highly elastic, a property which qualifies it to be employed in structures subjected to shock loads.

vii. Aluminium has a unique behaviour of maintaining its toughness down to very low temperatures, unlike carbon steels which would otherwise suffer embrittlement.

viii. Aluminium exhibits ease of workability and formability and can easily be rolled to very thin gauges.

ix. Aluminium conducts electricity and heat nearly as well as copper.

With alloying and compositing, these attributes are enhanced, and the shortcomings of the base aluminium metal are improved tremendously. The major improvements in the properties of AlMMCs are manifested in form of greater strength and improved stiffness, reduced density, improved abrasion and wear resistance, improved high-temperature properties, better control of thermal expansion 
coefficient, better thermal/heat management, enhanced and tailored electrical performance, better control of reciprocating mass and improved damping capabilities.

The above advantages have been quantified for a better appreciation. For example, [4] reports that the elastic modulus of pure aluminium can be enhanced from 70 to $240 \mathrm{GPa}$ by reinforcing with 60 vol\% continuous alumina fibre. Also, a decrease in the coefficient of thermal expansion from 24 to $7 \mathrm{ppm} /{ }^{\circ} \mathrm{C}$ can be achieved by incorporation of $60 \mathrm{vol} \%$ alumina fibre in pure aluminium.

With the advent of nanostructured materials, new materials have been developed with exceptional properties exceeding those expected for monolithic alloys or composites. For example, carbon nanotubes have ultrahigh strength and modulus; when included in a matrix, they could impart significant property improvements to the resulting nanocomposite [5]. Jun and co-workers [24] present quantifiable results to the effect that incorporating only $10 \mathrm{vol} \%$ of $50 \mathrm{~nm}$ alumina particles to an aluminium alloy matrix using the powder metallurgy process increased yield strength to $515 \mathrm{MPa}$ - which is 15 times stronger than the base alloy and over 1.5 times stronger than AISI 304 stainless steel.

\subsubsection{AlMMCs end uses}

Aluminium metal matrix composites are increasingly registering success as "high-tech" materials in various applications. Significant performance-related benefits and economic as well as environmental benefits have been realised as a result of utilisation of AlMMCs. Notable among them are improved properties, increased component lifetime, improved productivity, energy savings, lower maintenance costs and environmental benefits such as lower noise levels and fewer airborne emissions. These composites can replace monolithic materials that include ferrous alloys, aluminium and titanium alloys and polymer-based composites in many applications. For widespread replacement, the whole system may be redesigned in order to gain additional weight and volume savings. Ideally, AlMMCs can be viewed not only as a replacement for existing materials but also as a means of enabling radical changes to the product or system design [4].

Engineering viability of AlMMCs in a number of applications has been well-documented. AlMMCs having a different type of reinforcements and produced both by solid-state and liquid-state processing have been used in many engineering applications. Some of the newer and visible applications of different types of AlMMCs are detailed below.

Particle-reinforced aluminium metal matrix composites produced by $\mathrm{P} / \mathrm{M}$ stir cast/ melt infiltration/spraying/in situ processing techniques at industrial level with particulate reinforcements of $\mathrm{SiC}, \mathrm{Al}_{2} \mathrm{O}_{3}, \mathrm{TiC}, \mathrm{TiB}_{2}$ and $\mathrm{B}_{4} \mathrm{C}$ have been successfully used in the manufacture of automotive and aerospace components and thermal management. In the gas turbine engine, particle-reinforced AlMMCs have been used in fabrication of fan exit guide vanes (FEGV). They are also used as rotating blade sleeves in helicopters and as ventral fins and fuel access cover doors in military aircraft [25]. Flight control hydraulic manifolds made of particulate silicon carbide (about 40 vol\%) reinforced AlMMCs have been successfully used. On a high-volume basis, applications of particle-reinforced AlMMCs have been reported in braking systems of trains and automobiles. Presently AlMMC brake discs are extensively used in European railways and certain models of passenger cars in the United States. Other applications in the automotive industry include valves, crankshafts, gear parts and suspension arms. In recreation and sports, particle-reinforced AlMMCs are used in production of a variety of products including golf club shaft and head, skating shoe, baseball shafts, horseshoes and bicycle frames. Aluminium metal matrix composites containing high volume fractions of ceramic particles are 
used as microprocessor lids and integrated heat sinks in electronic packaging. They are also in use as carrier plates and microwave housing.

Whisker-and short-fibre-reinforced aluminium metal matrix composites: In the wake of greater health risks associated with the handling of ceramic whiskers, production of whisker-reinforced aluminium composites has been limited to specialised use such as the production of track shoes in advanced military tanks. Short-fibre-reinforced AlMMCs are being used in piston and cylinder liner applications [26].

Continuous fibre-reinforced aluminium matrix composites: Carbon fibre-reinforced AlMMCs have been used as antenna waveguides for the Hubble Space Telescope for their ability to provide high dimensional accuracy and high thermal and electrical conductivity with no outgassing oxidation resistance. The 6061 Al-boron continuous fibre composites have been used as struts in the main cargo bay of space shuttles. The $3 \mathrm{M}^{\mathrm{TM}}$ company developed continuous fibre AlMMCs which offer strength equivalent to that of high-strength steel at less than half the density and which retain their strength beyond $300^{\circ} \mathrm{C}$ [4]. These composites possess four times the electrical conductivity of steel (or half that of pure aluminium) and have been targeting various functional applications, such as (a) core of overhead electrical conductors, (b) automotive push rods, (c) energy storage flywheels, (d) retainer rings for high-speed motors and (e) automotive brake callipers. Aluminium metal matrix composites enable the use of smaller flywheels compared to polymer composites. Thin-walled retainer rings of AlMMCs provide excellent advantages in high-speed motors and can resist very high rotational speeds and still maintain their precise shape. Compared to cast iron, AlMMCs brake callipers made of continuous fibre reinforcement offer such benefits as increased damping, reduced unsprung weight, increased fuel efficiency and improved performance, handling and ride.

Detailed applications and the current state of utilisation are covered in Chapter 3.

\section{The current state of applications of AlMMCs in various industries}

\subsection{AlMMCs in innovative light-weight designs}

\subsubsection{Automotive industry}

The automotive market represents the largest current market for AlMMCs on a volume basis. The potential for AlMMCs in this area is barely tapped, however, and represents a great opportunity for substantial growth. Through R\&D, lighter, engineered materials are being developed which offer better performance than the existing materials. Replacement of steel and cast iron in internal combustion engine applications as well as in unsprung weight components, such as the brake system, is judged the most promising for the near term.

Aluminium metal matrix composites are suitable replacements, not only for steel but also for aluminium alloys in various automotive systems and components. There are many ways to achieve light-weight without compromising the strength and safety requirements. Ideally, it is common practice to completely replace the existing structural material with the material of higher yield strength, with a possible reduction in section dimensions. The other way of achieving weight saving is to selectively replace conventional steel at specific areas with the lighter materials. By applying the mass reduction techniques, the mass of vehicles can be reduced independent of vehicle size, functionality, class or model [1]. In most of these techniques, lower density aluminium composites continue to replace the carbon steels. Aluminium-based engine blocks, suspension components, 
body panels and frame members are increasingly becoming common [27]. Most cylinder heads are aluminium-based, and by 2005, engine blocks made from aluminium in the US light-duty vehicles passed the $50 \%$ mark, surpassing steel in this area for the first time [28]. However, engine blocks typically require cast iron cylinder liners due to the inferior wear properties of aluminium-a shortcoming that has attracted considerable research and development (R\&D) efforts, leading to some positive results. For example, [5] reports about the progress made in the development of aluminium alloy cylinder liners containing dispersed graphite particles that provide solid lubrication. Aluminium alloys and composites are also competing to replace many various traditional steel components in vehicles, such as valve covers, torque converter and transmission housings, crankcase, control arms, cradles, suspension links, door frames, steering wheels, dashboards, sheet panels and beams are also being replaced by alloy aluminium alloys and composites [29]. New areas are being explored for aluminium-based materials, and these include "all aluminium" bodies, bumpers, crash management systems and unibody construction [30].

The automotive breaking system components, such as the disc brakes and callipers, are another area where significant weight savings can be realised by utilising AlMMCs. Most modern vehicle models including Lotus Elise, General Motors EV1, Chrysler Prowler, Volkswagen Lupo $3 \mathrm{~L}$ and Toyota RAV4 EV have used SiCreinforced aluminium brake rotors [31]. Regarding the chassis, the requirements for vehicle performance and survivability of occupants in severe crashes dictate that chassis materials should possess adequate strength and toughness. Aluminium-fly ash (a waste by-product of coal power plants) cenosphere syntactic foams can be used to reinforce box or tubular frame sections in crumple zones to increase torsional rigidity and energy absorption upon vehicle impact [32]. Further cost/ weight savings can be realised by incorporating fly ash in the aluminium matrix for components that do not experience extreme loading. In the suspension system, the use of aluminium-based materials has led to reduction in the unsprung weight, consequently, improving vehicle dynamics. Control arms and wheel hubs made of SiC-reinforced aluminium nanocomposites have exhibited improved strength characteristics similar to cast iron while using less material than aluminium. Selflubricating graphite-reinforced aluminium bushings can also be incorporated into control arm castings to allow for service-free components [5].

Apart from the core body frame structure, weight saving technology features in other areas can add up to substantial secondary weight reductions elsewhere. Lighter roof panels, side panels and beams are being offered by different vehicle manufacturers with thinner gauge high-strength steel (HSS), aluminium and some limited magnesium [33]. Significant weight reductions are being registered within the suspension and chassis system by utilising "alloy" (i.e. aluminium alloy) wheels and redesigned braking systems. In addition, many suspension and chassis parts can realise secondary weight savings from reduction in their size that result from weight reductions elsewhere on the vehicle [1].

There is a limit to the savings made. Although primary weight savings also enable downsizing many of the other vehicle systems, a study sponsored by the National Highway Traffic Safety Administration (NHTSA) evaluated the maximum weight reductions possible for some car models. Using Honda Accord as the study sample, it was found out that the baseline body-in-white (BIW) mass, which was $48 \%$ HSS, could be reduced by $22 \%$ with advanced high-strength steel (AHSS) and by up to $35 \%$ with an aluminium-intensive design $[1,34]$. In another study conducted by IKA, University of Aachen (Germany), it was observed that it was possible to obtain a weight reduction of their "alumaximised" model car from 1229 to $785 \mathrm{~kg}$, after primary and maximum secondary weight savings [35]. 
Weight reduction has been driven to higher heights by new and advanced technologies and concepts. The new concept of "multi-material designs", used mainly for high-volume production, is an alternative to the "all-aluminium" designs of BIW. The concept consists of mixing various materials to benefit from their individual advantages. To this end, it is possible to use aluminium together with high- and ultrahigh-strength steels, magnesium and plastics or composites, where applicable [1]. The driving force behind this concept is to use the "best and most suitable" material for the appropriate functions in order to achieve an overall costefficient light-weight design. This concept has been championed by some European car manufacturers, notably, BMW, in their 5 E60 series which utilises $20 \%$ as deep-drawing steels, $42 \%$ as higher-strength steels, $20 \%$ as ultrahigh-strength steels and $18 \%$ aluminium alloys. The front-end substructure consists of $16.4 \mathrm{~kg}$ steel, and $29.4 \mathrm{~kg}$ is made of 86 aluminium-based parts (stamped sheet, extrusions, high-pressure die castings and hydroformed tubes) [35, 36].

The multi-material design concept was adopted and further developed by the SuperLIGHT-CAR (SLC) project. Under the umbrella of the European Council for Automotive Research (EUCAR), the European Commission (EC) in the year 2005 co-funded the 4-year collaborative SLC project, whose overall objective was to develop truly light-weight multi-material car concepts up to $50 \%$ lighter than the high-volume cars produced in the year 2004. The SLC project, recognising the importance of weight reduction as one of the most effective ways of reducing fuel consumption and $\mathrm{CO}_{2}$ emissions in the road transport sector, embarked on developing the integrated knowledge and technological capabilities needed to design and manufacture multi-material car bodies with reduced raw material consumption of up to $30 \%$ [37]. This was achieved by an ingenious mix of metals headed by aluminium. The multi-material concept consequently exceeded the initial target and yielded a $35 \%$ (or an equivalent of $101 \mathrm{~kg}$ ) weight reduction compared to the reference 2004 benchmark of a VW Golf V [38].

Lutsey [27] reports that reductions are more likely to be registered in manufacturing costs for vehicle mass reduction options up to about $20 \%$ for the light-duty vehicles in the 2009 fleet. Quoting the IMPACT Ford F150 project as an example, it is reported that the vehicle designs that reduced the pickup's mass by $19 \%$ were achieved at net-zero manufacturing cost, whereas the full $25 \%$ mass reduction package came with a $\$ 500$ per vehicle cost increase. Other studies involving aluminium-intensive designs also showed the potential for minimal net-vehicle costs with substantial mass reductions. The SLC multi-material design also shows the feasibility of a unibody structure of aluminium, magnesium and composites that delivers up to a $39 \%$ body mass reduction and with costs that are less than $€ 10 / \mathrm{kg}$-saved. The Lotus High Development vehicle study [39] found out that a $33 \%$ mass reduction is achievable at a $3 \%$ cost increase, which would roughly correspond to a \$400-600 per vehicle increase in manufacturing cost. All these studies attest to the fact that it is possible to register significant cost reductions by increasingly making use of AlMMCs.

\subsubsection{Aerospace and aircraft industry}

Aluminium alloys and composites have played a big role in the advancement of aircraft and rocket technology. Right from the Wright brothers' utilisation of aluminium in the engine of their first biplane to NASA's use of an aluminiumlithium alloy in the spacecraft, aluminium has created and enhanced the mankind's potential to fly around the Earth and into the outer space.

Aluminium alloys and/or composites are the favoured choice for the fuselage, wing and supporting structures of commercial airliners and military or cargo 
aircraft. The airframe of a typical modern commercial transport aircraft is composed of $80 \%$ aluminium by weight. Attention is now focused towards aluminium casting technology, which offers lower manufacturing costs, the ability to form complex shapes and the flexibility to incorporate innovative design concepts.

Aluminium metal matrix composites have been the material of choice for space structures of all types ever since the launch of Sputnik 1 (October 4, 1957). Chosen for their light-weight and their ability to withstand the stresses that occur during launch and operation in space, AlMMCs and alloys have been used on Apollo spacecraft, the Skylab, the space shuttles and the International Space Station. Aluminium alloys/composites consistently exceed other metals in such areas as mechanical stability, dampening, thermal management and reduced weight [40].

\subsubsection{Rail transport}

Aluminium railroad cars were pioneered for the railroad industry in the late 1950s and are still the material of choice for this mode of transportation. Rail cars, designed with aluminium-based extrusions, require one-third the number of components, have reduced welding needs and are two-thirds the weight of comparable steel cars. The higher carrying capacity of aluminium repays its higher initial cost in less than 2 years, and the life-cycle fuel costs are lower due to the lighter weight of the car [41]. Aluminium-based materials offer excellent resistance to corrosion and high salvage value.

Designing with aluminium results in light-weight cars that retain the strength of steel cars but can carry greater loads, hence saving money in increased freight and reduced fuel costs. The third generation of the French TGV Duplex high-speed train is a good example in this case. The train converted from steel to aluminiumbased materials, resulting in a $20 \%$ weight saving, while at the same time converting to two decks and keeping the axle load below 17 tons. Similarly, the Japanese high-speed "bullet" train and the Washington DC Metro trains are also made with aluminium-based materials.

The durability of aluminium makes it a suitable material for the railroad environment. Extensive shaking tests and decades of use offer testimony to aluminium's superiority for this application. A recent study shows that after 20 years of service, there is a negligible loss of metal thickness or surface defects on cars used to ship different materials an average of 110,000 miles per year. Metal loss on floors and sidewalls from corrosion and wear measured approximately $25 \%$ less than comparable steel cars [42].

\subsubsection{Marine transport}

Marine transport has also been revolutionised with the use of aluminium alloys and composites. The use of these materials has enabled an increase in the speed and size of boats, yachts, ferries and ships while improving their fuel efficiency, seaworthiness, safety and reliability and reducing maintenance costs. By substituting aluminium for steel, weight savings of $35-45 \%$ in hulls and $55-65 \%$ in superstructures can be achieved [42]. Higher vessel speeds and load capacities translate into extra traffic volume and profits for a ship or boat operator.

It is also possible to increase vessel volume and height without loss of stability. Passenger compartments can be larger, and more cabins can be located above sea level. The use of aluminium-based materials also ensures increased manoeuvrability and access to shallow draught ports.

Aluminium-intensive cargo ships with load capacities up to 3000 metric tons have been designed to operate at up to 60 knots, crossing the Atlantic in under 
60 hours. Military requirements seek smaller, more agile vessel designs with a lower radar cross section and capable of 60-80 knots or more-another excellent fit for aluminium, which is made possible due to advances in manufacturing methods, such as friction-stir welding and structural bonding.

Aluminium-based materials satisfy the requirements of the International Maritime Organization high-speed code for vessel design, safety and control of fire risk. Compared to steel, aluminium performs better in handling the torsional, flexural, compression and impact loads of high-speed water travel [42].

\subsubsection{Building and construction industry}

In 2009 the building and construction market constituted the third largest North American market for aluminium. Strength and stiffness are the two most important characteristics for structural applications of aluminium-based materials. The composites of aluminium such as the fibre-reinforced alloys of aluminium, discontinuously reinforced aluminium (DRA) and the conventional metals and graphite/epoxy composites provide the good uniaxial specific stiffness and specific strength and hence are the materials of choice for applications where maximum structural efficiency is the primary selection criterion [43].

Aluminium was first used in large quantities for building and construction in the 1920s, with the applications primarily oriented towards decorative detailing and art deco structures. Nowadays, aluminium-based materials are recognised as some of the most energy efficient and sustainable construction materials. Moreover, an estimated $85 \%$ of the aluminium used in modern buildings comes from recycled material. Bridge decks made from aluminium-based materials need minimal maintenance, are corrosion-resistant, require no painting and, unlike concrete, require no extension framework or cure time. Advanced aluminium alloys and composites can easily support the weight of heavy glass spans, thus maximising the building's capability for using natural sunlight.

Aluminium has, over time, been viewed as a vital component of sustainable buildings since the metal is easily recycled and loses none of its properties during recycling. Moreover, the recycling process reduces energy consumption by more than $90 \%$ compared to the energy required to produce new aluminium [44]. Aluminium and its alloys are infinitely recyclable. More than $75 \%$ of all aluminium produced is still in use today.

\subsubsection{Offshore applications}

Offshore platforms, helidecks and seawalls are other possible areas where aluminium-based materials can be effectively utilised. In water depths of 400 feet, a 1 ton weight saving in platform superstructure means weight savings of 6 tons in the supporting structure [42].

Aluminium-based materials are often used in the construction of helicopter decks (helidecks) for resupply of oil rigs. Here, marine-grade aluminium alloys offer maintenance-free service with remarkable corrosion resistance. Using aluminium components reduces handling and offshore lifting costs and speeds the task of assembly. Aluminium is safe to use as it does not burn and presents no thermite sparking risks. It requires minimal maintenance. Even in salty water applications, little or no protective coatings are required for aluminium seawalls.

Marine-grade aluminium alloys are used for helidecks, telescoping bridges, accommodation modules, stair towers, cable ladders, fire walls, mud mats, gratings and many other applications. Aluminium structures weigh 40-70\% less than equivalent steel structures. Handling is made easier since larger, lighter aluminium 
structures can be handled and lifted with smaller, less expensive equipment. In marine environments, properly selected aluminium alloys/composites require no painting and require little or no maintenance.

Aluminium seawall shapes are generally extruded, achieving the most strength with the least material. Aluminium is easy to extrude and fabricate; hence, retrofitting of the offshore platforms and customisation become cost-effective. Installation is also easy since designers can create either a single-piece component, bolted connections or interlocking sections for fast and simple fit-up on site. Various proven mechanical methods joining can be applied to aluminium. Its weldability is good as it can be welded three times faster than steel, using inexpensive MIG machines. Aluminium offers excellent safety advantages as it is non-combustible and gives off no flammable vapour when heated-an important consideration when choosing materials for offshore applications such as helidecks [42].

\subsection{High-temperature applications}

\subsubsection{Automotive industry}

The high-temperature applications in the automotive industry are mainly concerned with the engine, transmission and braking components. These experience temperatures up to about $300^{\circ} \mathrm{C}$. The AlMMCs suitable for use under these circumstances must be able to retain the desired properties of the part/component operating under these conditions [1].

The major automotive components that have been successfully manufactured from AlMMCs are the following:

Pistons and cylinder liners. The University of Wisconsin-Milwaukee (UWM) reportedly developed aluminium alloy pistons and cylinder liners containing dispersed graphite particles that provide solid lubrication [5]. The graphite-containing aluminium has a lower friction coefficient and wear rate and does not seize under boundary lubrication. Aluminium/graphite pistons and liners were tested in gas and diesel engines and in race cars, and the results showed reduced friction coefficients and wear rates. The friction coefficient of $\mathrm{Al}$-graphite composites was measured and found to be as low as 0.2 [45]. This makes it a suitable material for cylinder liners in light-weight aluminium-engine blocks, for its ability to enable engines reach operating temperatures more quickly while providing superior wear resistance, improved cold start emissions and reduced weight [46]. Aluminium-based composite liners can be cast in situ using conventional methods, including sand, permanent mould, die casting and centrifugal casting.

Main bearings. Lead-free aluminium or copper matrix composites containing graphite particles, as developed at UWM [5], can replace the copper-lead bearings used in crankshaft main-bearing caps. The bearings also improve wear characteristics because deformation of the graphite particles results in the formation of a continuous graphite film, which provides self-lubrication of the component, allowing for improved component longevity. Virtually all journal bearings in the power train could benefit from these materials. Selectively reinforced functionally gradient bearings of aluminium-graphite and copper-graphite alloys can be manufactured in a single step by centrifugal casting of metal-graphite suspensions [47].

Connecting rods. For components requiring high strength at high temperatures, such as connecting rods, cast aluminium matrix nanocomposites may be ideal to produce near-net-shape components to replace steel, forged aluminium and titanium components while reducing reciprocating mass.

Accessories. For components not exposed to extreme loading, further cost and weight reductions can be realised by incorporating fly ash in the aluminium matrix. 
Components such as A/C pump brackets, timing belt/chain covers, alternator housings, transmission housing, valve covers and intake manifolds can be replaced with aluminium-fly ash composites, reducing the vehicle cost and weight, thereby improving emissions and saving energy. Adding fly ash to aluminium also reduces its coefficient of thermal expansion and increases its wear resistance along with making lighter and less expensive material [46].

Suspension. Although many automakers use aluminium and light gauge steel for suspension components to reduce unsprung weight and improve vehicle dynamics, a big number of components are still being made from cast iron. Components such as control arms or wheel hubs made of strong silicon carbide ( $\mathrm{SiC}$ )-reinforced aluminium or aluminium nanocomposites can further improve aluminium alloy designs by enhancing strength while using less material than similar aluminium arms [31].

Brakes. Automotive disc brakes and brake callipers, typically made of cast iron, are an area where significant weight reduction can be realised. SiC-reinforced aluminium brake rotors have been embraced by a number of prominent vehicle manufacturers [47]. High cost and machinability issues need to be addressed for widespread use of aluminium composite brake rotors. UWM developed aluminium-silicon carbide-graphite composites, aluminium alumina-graphite and hypereutectic aluminium-silicon graphite alloys with reduced silicon carbide to help overcome cost and machinability barriers. Aluminium-fly ash composites developed at UWM have been explored to make prototype brake rotors in Australia [31]. Strength improvements seen in aluminium nanocomposites being developed at UWM can provide significant improvements in component rigidity without adding a significant amount of material, resulting in lower-weight components.

\subsubsection{Applications in aerospace and aircraft industry}

Aerospace propulsion and power systems are ever placing increasing demands on load bearing materials. The quest to propel bigger payloads into space and provide electrical power for space experiments while at the same time meeting the demands of manned and unmanned spacecraft flying at hypersonic velocities requires the right materials. The materials must be light-weight and be able to withstand high temperatures for long periods of time in hostile environments.

Metal matrix composites have the potential to meet the wide variety of these requirements. By selection of the proper high-temperature fibre and combining the fibres with an appropriate matrix, a high temperature, light-weight MMC can be produced. Extensive research is needed on advanced fibres and matrices. Since the fibres provide the characteristics that dominate the strength, stiffness and conductivity of a composite, superior fibres need to be developed. Fibres having high melting points and coefficients of thermal expansion matching those of the matrices need to be evaluated for high-temperature strength, modulus and compatibility with various matrices. In case of matrices, intermetallic compounds offer higher melting points, light-weight and (in the case of aluminides and silicides) good oxidation resistance for aerospace propulsion systems [48].

\subsection{Other novel applications of AlMMCs}

\subsubsection{Electronic packaging and thermal management}

Heat sinks play two key roles in electronic packaging: thermal management and mechanical support. Heat sinks support electronic devices and provide a path for heat dissipation. They are used in packages and with printed circuit boards 
(PCBs). Traditional heat sinks were primarily aluminium, copper or unalloyed blends of two metals, such as copper-tungsten or copper-molybdenum. The traditional heat sinks have exhibited a number of shortcomings, which has necessitated designing of new improved materials, primarily composites reinforced with fibres and particles. The new materials exhibit better properties including high thermal conductivities; low, controllable coefficients of thermal expansion; weight reductions; high strength and stiffness; and availability of net-shape fabrication processes.

The packaging density is ever on the increase, which has resulted in the demand for materials with high thermal conductivities. In addition, to minimise thermal stresses that can cause component or solder failure, it is desirable that the packaging material should have a coefficient of thermal expansion (CTE) matching that of the ceramic component it supports. Utilisation of composite materials is not a new phenomenon in electronic packaging. For example, polymer matrix composites (PMCs) in the form of E-glass fibre-reinforced polymer PCBs are well-established packaging materials.

Aluminium metal matrix composites with the high volume fraction of reinforcement are attractive materials for thermal management. This is in view of the possibility to further enhance the thermal conductivity (TC) of the composite material by the use of high TC reinforcements and the flexibility to adjust the CTE by controlling the volume fraction of the reinforcement. Aluminium and copper were usually used as matrices due to their high TCs, and the reinforcements involved $\mathrm{SiC}$, carbon and diamond. However, owing to the fact that the specific thermal conductivity of aluminium-based composites was higher than that of $\mathrm{Cu}$-based composites, aluminium-based composites are more desirable in avionic applications where light-weight is demanded [49].

\subsubsection{Packaging and containerisation}

In 2009, containers and packaging regained their position as the top market for aluminium-based materials. The aluminium industry shipped 4.73 billion pounds for packaging applications or $26.5 \%$ of all shipments [42]. Aluminium-based materials are used in products such as beverage cans and bottles, food containers and household and institutional foil. Manufacturers and consumers appreciate foil for its impermeability to light, water and air-making it a preferred packaging material for food, beverage and pharmaceutical products. Moreover, aluminium's light-weight gives it a competitive advantage over other materials with regard to shipping costs and volume.

Regarding containerisation, it is difficult to discuss rail transport of freight and commercial goods without reference to the ubiquitous container. The cargo can be packed into large containers and conveniently shipped to their destinations interchangeably by rail, road, sea or air. The container has greatly simplified the transport of goods and has been adapted to the different modes of transport. With a backbone of aluminium extrusions and with considerable use of aluminium-based sheet material, the growth of containerisation has greatly facilitated the transportation industry.

\subsubsection{Electrical transmission}

Aluminium-based materials have many advantages for electrical applications. Properties such as light-weight, strength, corrosion resistance and high efficiency in electrical conduction (aluminium has twice the conductivity of copper) render these materials the best choice for transmitting power from generating stations 
to homes and businesses. Their ease of recyclability makes them a perfect fit for today's environment.

In 2010, electrical market applications rose by $13.1 \%$, and shipments of aluminium conductor steel-reinforced (ACSR) cable, bare cable, insulated wire and cable products soared to 631 million pounds, an increase of 11 million pounds from the previous year. The North American electrical market was the fourth largest for aluminium worldwide, accounting for $7.3 \%$ of all aluminium shipments during the year [42].

\subsubsection{Sports and recreation}

The sporting goods industry is not left behind as far as utilisation of AlMMCs is concerned. Aluminium metal matrix composites are very attractive as materials for sporting goods applications. The material used generally consists of an aluminium matrix reinforced with particles of silicone carbide or boron carbide. The specific strength and modulus of these materials can offer design advantages not possible with steel or carbon/epoxy composites. In addition, they have a tremendous marketing appeal for the high-end sporting goods consumer as they are a new phenomenon [50]. Recreational products, including those used in golf, cycling, baseball, skiing and other leisure as well as competitive sporting activities, have always offered profitable opportunities for high-performance materials due to the focus on performance over cost. Although AlMMCs have been used in niche applications, more widespread opportunities are available if an improved combination of performance, manufacturability and cost can be achieved through specific R\&D activities.

Finally, AlMMCs have been considered for specialised applications in which the combination of properties makes them especially well suited. Examples of these applications include robotics, medical, biomedical and nuclear shielding. These applications may require specific $R \& D$ activities to be carried out and technical problems solved before substantial use can occur but may represent high-value market opportunities for the industry if successful [16].

\section{Challenges and barriers in the development of AlMMCs}

Several challenges must be overcome in order to intensify the engineering usage of AlMMCs. Design, research and product development efforts and business development skills are required to overcome these challenges. Surappa [4] emphasised the need to address the following issues:

i. A more and thorough understanding of the science of primary processing, especially the factors affecting the microstructural integrity including agglomerates in AlMMCs.

ii. Need to improve the damage tolerant properties particularly fracture toughness and ductility in AlMMCs.

iii. Need for work to be done towards the production of high-quality and lowcost reinforcements from industrial wastes and by-products.

iv. An urgent need to develop simple, economical and portable non-destructive kits to quantify undesirable defects in AlMMCs. 
v. Work in developing less expensive secondary processing tools for machining and cutting AlMMCs.

vi. Work must be done to develop recycling technology for AlMMCs.

The challenges and barriers listed above are echoed by [16]. Further penetration of AlMMCs will largely depend on their primary production processes and secondary machining processes being affordable. Generally, the cost of aluminium is around 4-5 times that of steel. In addition, the manufacturability of these composites is cumbersome. These challenges are being addressed through R\&D activities. In early development of AlMMCs, the industry was modelled on the roadmap drawn by the Aluminium Metal Matrix Composites Roadmap 2002, which spelt out a pathway for the AlMMCs growth in 20 years from 2002 and asserted the industry's vision to position AlMMCs as the material of choice in a broad range of structural and nonstructural applications [1]. During the workshop that gave birth to the AlMMCs Roadmap 2002, a number of critical barriers hampering the market penetration of AlMMCs were identified, and common themes agreed on how to mitigate these barriers and realise their vision [16].

\section{Conclusion}

AlMMCs present a great opportunity and a host of possibilities for the materials/design engineer. There are now many possibilities for manipulation of properties/property combinations to suit specific requirements of material and component properties in order to enhance performance and reliability. New and emerging technological developments point to increased utilisation of AlMMCs in current and future industrial developments. Some of the existing barriers and challenges are being addressed through various R\&D efforts to find a lasting solution.

From the foregoing review, it is evident that the future of AlMMCs in various industrial and commercial applications is very bright. Advanced technological developments in primary and secondary processing of AlMMCs will continue to give them a competitive edge over the alternative materials such as Mg, AHSS and polymer composites. The main challenges and barriers that have been identified include lack of property modelling (especially the high-temperature behaviour of AlMMCs), lack of design data and high costs of primary and secondary processes. However, there are promising signs of technological breakthroughs by various research efforts dedicated to finding solutions to these challenges. New developments in CNT and nanotechnology have, for example, offered possibilities of production of AlMMCs with enhanced properties for high-temperature applications and improved wear and corrosion resistance. Other developments such as the novel rheocasting process of semi-solid alloys [e.g. see [51]] and FGMs have also offered new possibilities of cost reduction in primary production and secondary processing of AlMMCs, respectively. New alloys of aluminium have been developed for application in such areas as crash management (crash alloy) —an area previously dominated by steel. These alloys offer new R\&D opportunities for further development of AlMMCs and will redefine new roles and potential of AlMMCs in automotive applications. Various researchers are also coming up with innovative cost-reduction techniques to bring down the cost of replacing conventional ferrous materials with aluminium metal matrix composites. 


\section{Acknowledgements}

The authors would like to sincerely acknowledge the material and financial support extended by the Vaal University of Technology, Department of Mechanical Engineering and the collaborating institutions-The Council for Scientific and Industrial Research, Pretoria and Makerere University, Kampala Uganda.

\section{Conflict of interest}

The authors envisage no conflict of interest.

\section{Author details}

Francis Nturanabo ${ }^{1,2 *}$, Leonard $\mathrm{Masu}^{1}$ and John Baptist Kirabira ${ }^{2}$

1 Department of Mechanical Engineering, Vaal University of Technology, Andries Potgieter Boulevard, Vanderbijlpark, South Africa

2 Department of Mechanical Engineering, College of Engineering, Design, Art and Technology, Makerere University, Kampala, Uganda

*Address all correspondence to: fmpazi@yahoo.com

\section{IntechOpen}

(C) 2019 The Author(s). Licensee IntechOpen. This chapter is distributed under the terms of the Creative Commons Attribution License (http://creativecommons.org/licenses/ by/3.0), which permits unrestricted use, distribution, and reproduction in any medium, provided the original work is properly cited. (cc) BY 


\section{References}

[1] Nturanabo F, Masu LM, Govender G. Automotive light-weighting using aluminium metal matrix composites. In: Materials Science Forum Aug 1, 2015. Vol. 828. Switzerland: Trans Tech Publications Ltd; 2015. p. 485

[2] Nappi C. The global aluminium industry 40 years from 1972 . World Aluminium. Feb 2013:1-27. Available at: http://www.world-aluminium. org/media/filer_public/2013/02/25/ an_outlook_of_the_global_aluminium_ industry_1972_-_present_day.pdf [Accessed: Mar 15, 2019]

[3] The Aluminum Association. The Aluminum Advantage-History of Aluminum. Available from: https:// www.aluminum.org/aluminumadvantage/history-aluminum [Accessed: Jan 25, 2019]

[4] Surappa MK. Aluminium matrix composites: Challenges and opportunities. Sādhanā. 2003;28 (Parts 1 \& 2):319-334

[5] Macke A, Schultz BF, Rohatgi P. Metal matrix composites-Offer the automotive industry an opportunity to reduce vehicle weight, improve performance. Advanced Materials \& Processes. March 2012;170(3):19-23

[6] Matthews FL, Davies GA, Hitchings D, Soutis C. Finite Element Modelling of Composite Materials and Structures. UK: Elsevier; 2000

[7] Cheng SL, Yang GC, Man ZH, Wang JC, Zhou YH. Mechanical properties and fracture mechanisms of aluminum matrix composites reinforced by $\mathrm{Al}_{9}(\mathrm{Co}, \mathrm{Ni})_{2}$ intermetallics. Transactions of Nonferrous Metals Society of China. 2010;20(4):572-576

[8] Sims CT. High-temperature materials. In: AccessScience. USA:
McGraw-Hill Education; 2014. DOI: 10.1036/1097-8542.318600

[9] Rawal S. Metal-matrix composites for space applications. Journal of Management. 2001;53(4):14-17

[10] Kurumlu D, Payton EJ, Young ML, Schöbel M, Requena G, Eggeler G. High-temperature strength and damage evolution in short fiber reinforced aluminum alloys studied by miniature creep testing and synchrotron microtomography. Acta Materialia. 2012;60(1):67-78

[11] Withers PJ. Metal matrix composite. In: AccessScience. United Kingdom: McGraw-Hill Education; 2014. DOI: 10.1036/1097-8542.418600

[12] Perez Ipiña JE, Yawny AA, Stuke R, Gonzalez Oliver C. Fracture toughness in metal matrix composites. Materials Research. 2000;3(3):74-78

[13] Di Ilio A, Paoletti A, D’Addona D. Characterization and modelling of the grinding process of metal matrix composites. CIRP Annals. 2009;58(1):291-294

[14] Bolzon G, Chiarullo EJ, Egizabal P, Estournes C. Constitutive modelling and mechanical characterization of aluminium-based metal matrix composites produced by spark plasma sintering. Mechanics of Materials. 2010;42(5):548-558

[15] Rajan TP, Pillai RM, Pai BC. Characterization of centrifugal cast functionally graded aluminum-silicon carbide metal matrix composites. Materials Characterization. 2010;61(10):923-928

[16] Aluminium Metal Matrix Composites Technology Roadmap TRC Document 0032RE02; Aluminium Metal Matrix Composites 
Consortium-National Centre for Manufacturing Sciences. Ann Arbour, Michigan. 2002. Available from: http:// www.almmc.com

[17] Chen JK, Huang IS. Thermal properties of aluminum-graphite composites by powder metallurgy. Composites Part B: Engineering. 2013;44(1):698-703

[18] Aghajanian MK, Rocazella MA, Burke JT, Keck SD. The fabrication of metal matrix composites by a pressureless infiltration technique. Journal of Materials Science. 1991;26(2):447-454

[19] Mahendra KV, Radhakrishna K. Characterization of stir cast Al-Cu(fly ash + SiC) hybrid metal matrix composites. Journal of Composite Materials. 2010;44(8):989-1005

[20] Mortensen A, Llorca J. Metal matrix composites. Annual Review of Materials Research. 2010;40:243-270

[21] Hashim J, Looney L, Hashmi MS. Metal matrix composites: Production by the stir casting method. Journal of Materials Processing Technology. 1999;92:1-7

[22] Schiroky GH, Miller DA, Aghajanian MK, Fareed AS. Fabrication of CMCs and MMCs using novel processes. In: Key Engineering Materials. Vol. 127. Trans Tech Publications; 1997. pp. 141-152

[23] Srivatsan TS, Ibrahim IA, Mohamed FA, Lavernia EJ. Processing techniques for particulate-reinforced metal aluminium matrix composites. Journal of Materials Science. 1 Nov 1991;26(22):5965-5978

[24] Jun Q, Linan A, Blau PJ. Sliding friction and Wear characteristics of $\mathrm{Al}_{2} \mathrm{O}_{3}$-Al Nanocomposites. In: STLE/ ASME 2006 International Joint Tribology Conference. San Antonio,
Texas, USA: American Society of Mechanical Engineers; 23-25 October 2006. pp. 59-60

[25] Subramanian R, Kannan G, Nanjappan N, Vijayan K. Analysis of temperature distribution in wire electrical discharge machine on hybrid Al-MMCs. Indian Journal of Engineering and Materials Sciences. 2018;25:301-306

[26] Lu H, Wang X, Zhang T, Cheng Z, Fang Q. Design, fabrication, and properties of high damping metal matrix composites-A review. Materials (Basel). 2009;2(3):958-977. (published Aug 18, 2009). DOI: 10.3390/ ma2030958

[27] Lutsey N. Review of technical literature and trends related to automobile mass reduction technology. California Air Resources Board. 2010. UCD-ITS-RR-10-10. Available from: https://escholarship. org/uc/item/9t04t94w [Accessed: Jan 25, 2019]

[28] Simpson J. Aluminum advances: Aluminum passes iron among automotive materials in use worldwide; what lies ahead? Aluminum Now. 2006. Available from: https://www. thefreelibrary.com/Aluminum+advance s\%3a+aluminum+passes+iron+among+ automotive+materials +in...-a01681 30424. [Accessed: Jan 25, 2019]

[29] Caceres CH. Economical and environmental factors in light alloys: Automotive applications. Metallurgical and Material Transactions A. 2007;38(A):1649-1662

[30] Muneer S, Khairul AI.

Forecasting of global automotive industry-key trends in passenger vehicles. ARPN Journal of Engineering and Applied Sciences. Sep 2015;10(17):7830-7834

[31] Withers G, De Waas Tilakaratna P. Performance evaluation of ULTALITE ${ }^{\circledR}$ 
low cost aluminium metal matrix composite based brake drums. SAE transactions. 1 Jan 2005:902-907

[32] Maddever W, Guinehut S. Use of Aluminum Foam to Increase Crash Box Efficiency. SAE Technical Paper. 11 Apr 2005

[33] Ghassemieh E. Materials in automotive application, state of the art and prospects. In: Chiaberge $\mathrm{M}$, editor. New Trends and Developments in Automotive Industry. Croatia: InTech; 2011. ISBN: 978-953-307-999-8

[34] Lewis AM, Kelly JC, Keoleian GA. Vehicle light-weighting vs.

electrification. Life cycle energy and GHG emissions results for diverse powertrain vehicles. Journal of Applied Energy. 2014;126:13-20

[35] Lahaye C, Hirsch J, Bassan D, Criqui B, Sahr C, Goede M, Volkswagen AG. Contribution of aluminium to the multimaterial light-weight BIW design of superlight-car [C]. In: Hirsch J, Skrotzki B, Gottstein G, editor. Proceedings of the 11th International Conference on Aluminium Alloys. Weinheim: WileyVCH Verlag GmbH \& Co. KGaA; 2008. pp. 2363-2373

[36] Goede M, Stehlin M. SuperLIGHTcar project-An integrated research approach for lightweight car body innovations. In: Innovative Developments for Lightweight Vehicle Structures. Wolfsburg: Conference proceedings. May 2009. pp. 26-27

[37] SuperLIGHT-CAR (SLC) Project. Sustainable Production Technologies of Emission-reduced Lightweight Car Concepts. 2009. Available from: http:// www.superlightcar.com and http:// ec.europa.eu/ [Accessed: Jan 31, 2017]

[38] van der Wiel JW. Future of Automotive Design \& Materials Trends and Developments in Design and Materials. Automotive Technology Center-Acermr. eu. 2011
[39] Caffrey C, Bolon K, Harris H, Kolwich G, Johnston R, Shaw T. CostEffectiveness of a Lightweight Design for 2017-2020: An Assessment of a Midsize Crossover Utility Vehicle. SAE Technical Paper 2013-01-0656. 8 Apr 2013. Available from: https://doi.org/10.4271/2013-010656 [Accessed: Mar 15, 2019]

[40] Finckenor MM. Materials for Spacecraft. Alabama: NASA, Marshall Space Flight Center. Available from: https://ntrs.nasa.gov/archive/nasa/ casi.ntrs.nasa.gov/20160013391.pdf [Accessed: Feb 11, 2017]

[41] Skillingberg M, Green J. Aluminum applications in the rail industry. Light Metal Age-Chicago. Oct 2007;65(5):8

[42] The Aluminum Association. Product markets. Available from: https://www.aluminum.org/productmarkets/other-markets [Accessed: Jan 25, 2019]

[43] Miracle DB. Metal matrix composites-From science to technological significance. Composites Science and Technology. 2005;65:2526-2540

[44] The Aluminum Association. Product markets. Available from: https://www.aluminum.org/productmarkets/building-construction [Accessed: Jan 25, 2019]

[45] Rohatgi PK, Ray S, Liu Y. Tribological properties of metal matrix graphite particle composites. International Materials Reviews, (USA-UK). 1992;37(3):129

[46] Gumus M. Reducing cold-start emission from internal combustion engines by means of thermal energy storage system. Applied Thermal Engineering. 2009;29:652-660

[47] Hunt WH, Miracle DB. Automotive applications of metal matrix composites. In: Miracle DB, Donaldson SL, 
editors. ASM Handbook: Composites.

Vol. 21. Materials Park, Ohio: ASM

International; 2001. pp. 1029-1032

[48] Stephens J. High temperature metal matrix composites for future aerospace systems. In: 24th Joint Propulsion Conference. Boston, MA, USA. 1 Oct 1987. p. 3059

[49] Zweben C. Ultrahigh-thermalconductivity packaging materials. In: Semiconductor Thermal Measurement and Management IEEE Twenty First Annual IEEE Symposium. San Jose, CA, USA. 15 Mar 2005. pp. 168-174

[50] Berg JS. Composite material advances in the golf industry. Available from: http://www.iccm-central.org/ Proceedings/ICCM12proceedings/site/ papers/pap338.pdf [Accessed: Jan 25, 2019]

[51] Ivanchev L, Wilkins D, Govender S, Du Preez W, Bean R. Rheo-processing of semi-solid alloys: A new technology for manufacturing automotive and aerospace components. South African Journal of Science. Aug 2008;104(7-8):257-259 
Section 2

\section{Processing, \\ Characterisation and \\ Testing}





\title{
Chapter 6
}

\section{Effect of Grain Size on Superplastic Deformation of Metallic Materials}

\author{
Allavikutty Raja, Rengaswamy Jayaganthan, Abhishek Tiwari \\ and Ch. Srinivasa Rakesh
}

\begin{abstract}
The superplastic deformation exhibited by metals with different grain sizes and their corresponding deformation mechanism influences the industrial metalforming processes. The coarse-grained materials, which contain grain size greater than $20 \mu \mathrm{m}$, exhibited superplastic deformation at high homologous temperature and low strain rate of the order of $10^{-4} \mathrm{~s}^{-1}$. Fine grain materials $(1-20 \mu \mathrm{m})$ are generally considered as favorable for superplastic deformation. They possess highstrain-rate sensitivity " $\mathrm{m}$ " value, approximately, equal to 0.5 at the temperature of 0.5 times the melting point and at a strain rate of $10^{-3}$ to $10^{-4} \mathrm{~s}^{-1}$. Ultrafine grains (100 $\mathrm{nm}$ to less than $1 \mu \mathrm{m}$ ) exhibit superplasticity at high strain rate as well as at low temperature when compared to fine grain materials. It is attributed to the fact that both temperature and strain rates are inversely proportional to the grain size in Arrhenius-type superplastic constitute equation. The superplastic phenomenon with nano-sized grains (10 $\mathrm{nm}$ to less than $100 \mathrm{~nm}$ ) is quite different from their higher-scale counterparts. It exhibits high ductility with high strength. Materials with mixed grain size distribution (bimodal or layered) are found to exhibit superior superplasticity when compared to the homogeneous grain-sized material. The deformation mechanisms governing these superplastic deformations with different scale grain size microstructures are discussed in this chapter.
\end{abstract}

Keywords: grain size, superplasticity, deformation mechanism, coarse-grained superplasticity, fine-grained superplasticity, ultrafine-grained superplasticity, nano-grained superplasticity, superplasticity of mixed grain sizes

\section{Introduction}

Newtonian flow is the flow of a material in which the shear stress $(\tau)$ has linear relationship with the shear rate. The proportionality constant $(\mu)$ is called coefficient of viscosity. It is given by Eq. (1):

$$
\tau=\mu \frac{d v}{d y}
$$

The materials which exhibit Newtonian flow completely undergo shear by diffusion without the contribution of dislocations and cavities. If the relationship 
between shear stress and shear strain is nonlinear, it is called non-Newtonian flow. Superplastic deformation is such a flow in which shear stress does not follow linear relationship. Backofen and Avery [1] proposed a power-law relationship for superplastic deformation which is given in Eq. (2):

$$
\sigma=K \dot{\varepsilon}^{m}
$$

where $\sigma$ is the true stress, $\dot{\varepsilon}$ is the strain rate, $\mathrm{n}$ is the strain-hardening exponent, $m$ is the strain-rate sensitivity, and $\mathrm{K}$ is material parameter. For Newtonian fluids, $m=1$. Superplasticity is exhibited by certain polycrystalline materials at the deformation temperature of above $0.5 \mathrm{~T}_{\mathrm{m}}$, where $\mathrm{T}_{\mathrm{m}}$ is the absolute melting point of the material and strain rate ranges from $10^{-5}$ to $10^{-3} \mathrm{~s}^{-1}$ [2]. For a material to exhibit superplasticity, it should have stable, equiaxed, fine grain microstructure. Materials deformed at lower temperatures resist necking by work hardening, while superplastic materials resist necking due to the sensitivity of flow stress to strain rate, called strain-rate sensitivity $(m)$ [3].

The superplastic materials generally exhibit $m$ value greater than 0.3 .

Observations through scratch offsets at grain boundaries established grain boundary sliding (GBS) as a primary deformation mechanism [4-6]. Other than diffusional creep, dislocation creep and grain boundary sliding (GBS) were the different mechanisms that govern high-temperature deformation. Mukerjee et al. proposed a semiempirical relationship correlating strain rate, grain size, temperature, activation energy, and stress to define the nature of superplastic deformation. The empirical relationship is given by Eq. (3):

$$
\dot{\varepsilon}=\frac{A D_{0} G b}{k T}\left(\frac{b}{d}\right)^{p}\left(\frac{\sigma}{G}\right)^{n} \exp \left(\frac{-Q}{R T}\right)
$$

where $\mathrm{D}_{0}$ is the diffusion coefficient, $\mathrm{G}$ is the shear modulus, $\mathrm{Q}$ is the activation energy, $\mathrm{T}$ is the absolute temperature, $\mathrm{R}$ is the gas constant, $\mathrm{b}$ is the magnitude of the Burgers vector, $d$ is the grain size, $\mathrm{p}$ is the grain size exponent, $\mathrm{n}$ is the stress

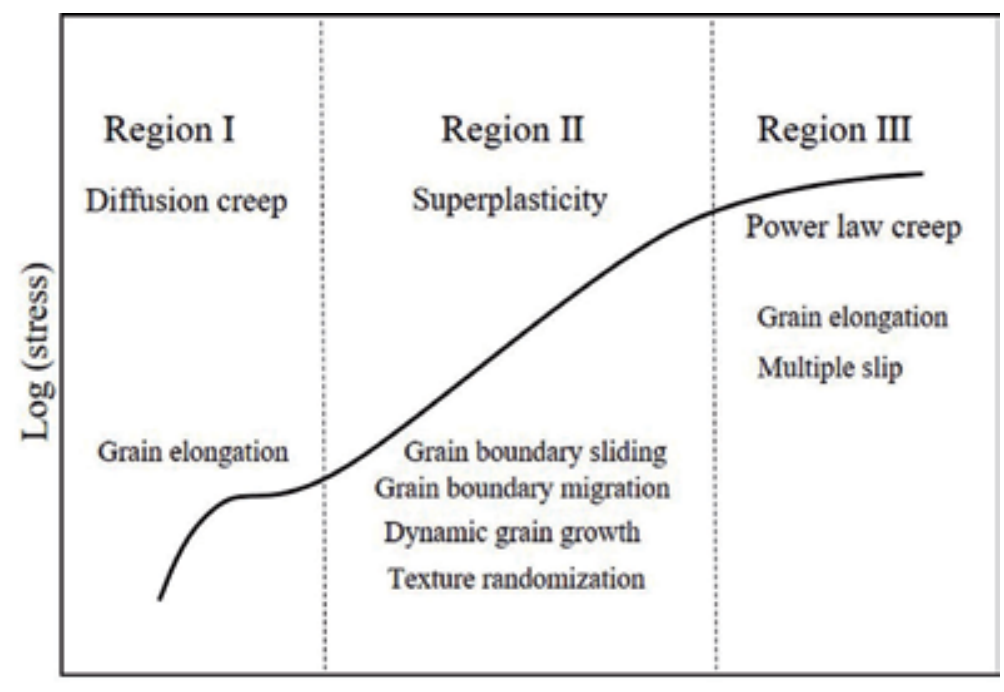

$\log$ (strain rate)

Figure 1.

Schematic illustration of the strain-rate dependence of flow stress in a superplastic material. 
exponent $(1 / \mathrm{m}), A$ is the constant dependent on microstructure and mechanism, and $\mathrm{k}$ is the Boltzmann constant. In general superplastic deformation was divided into three regions, as shown in Figure 1, based on the stress and strain rate range in which the deformation is taking place. The detailed discussion of these regions was discussed elsewhere [7]. The strain-rate dependence of stress, in turn, depends on the microstructure of the material and temperature range of the deformation. According to Eq. (3), the strain rate of superplastic deformation has an inverse relationship with grain size to the power "p." Moreover, with the advent of severe plastic deformation methods, fabrication of ultrafine grain (UFG) and nano-sized grains can be obtained using cryo forming $[8,9]$, multiaxial forging, equal-channel angular pressing (ECAP), friction stir processing (FSP), and high-pressure torsion (HPT). According to the Hall-Petch relationship, improvement in room-temperature mechanical properties in different alloys was studied extensively [10-13]. The advancement in superplastic deformation due to these UFG and nano-grain sizes is multifold. They are high-strain-rate, low-temperature, and room-temperature superplasticity due to grain refinement and uniform thinning during superplastic bulge forming by controlling the grain size at the apex and edge. Hence, in this chapter, the effect of grain size varying from microscale to nanoscale on the superplastic deformation was studied and discussed.

\section{Superplastic deformation mechanisms}

Three important deformation mechanisms at high-temperature deformation are diffusion creep, grain boundary sliding (GBS), and slip by dislocation movement. The mechanisms are common to both creep and superplasticity. Creep is the ability to resist deformation, while superplasticity is the ability to deform without necking. Diffusion creep is the vacancy movement. If the vacancy transfer occurs through grain boundaries, then the diffusion creep is called Coble creep. If the stress applied is parallel to grain boundaries, then the grain boundaries experience tension, while transverse grain boundaries experience compression (perpendicular to applied stress). As the vacancies occupy the transverse grain boundaries and get absorbed, a counter flux of atoms occurs toward the parallel-to-applied stress grain boundaries and causes grain elongation. If the vacancy transfers take place through the crystal lattice, then the diffusion creep is called Nabarro-Herring creep. Diffusion creep can be accommodated by another deformation mechanism GBS [4] and contains elongated grains [14]. The GBS that accommodates diffusion creep is called Lifshitz GBS. The other type of GBS called Rachinger GBS or simply GBS is a mechanism where adjacent grains are displaced at the grain boundaries between them but the grains remain equiaxed. GBS is impeded by obstacles like triple junctions or other types of stress concentration. Hence, GBS also required accommodation process. The accommodation process for GBS is delivered by slip activities like dislocation slip, grain rotation, grain boundary migration, and grain rearrangement $[15,16]$.

Dynamic recrystallization (DRX) is one another important deformation mechanism in many metals and alloys including $\mathrm{Mg}$ which produce fine grain microstructure. Fine grain microstructure is essential to improve material's mechanical properties, and it helps in improving the superplastic elongation of the material. The important factors that influence DRX are initial grain size, second-phase particles, stacking fault energy (SFE), thermomechanical processing, and severe plastic deformation conditions [17]. There are three types of DRX, namely, discontinuous DRX (DDRX), continuous DRX (CDRX), and geometric DRX (GDRX). Nucleation 
of new grains and grain growth at the expense of regions full of dislocations are called DDRX [18] which is mostly observed during hot deformation of materials with low to medium SFE. In materials with high SFE, the subgrains or cell structure with low-angle grain boundaries (LAGBs) formed during deformation is gradually evolved into high-angle grain boundaries (HAGBs) due to efficient dynamic recovery, which is known as CDRX [19]. In material like aluminum, the grains elongate with local serrations at high temperatures and large strain. On further increase in strain, these serrations pinch off and form high-angle grain boundaries which are called GDRX [20].

\section{Coarse-grained superplasticity}

In 1982, Wadsworth et al. [21] fabricated a commercial C103 niobium alloy $(\mathrm{Ni}+10 \mathrm{wt} . \% \mathrm{Hf}+1 \mathrm{wt} . \% \mathrm{Ti})$ by duplex hipping process for high-performance missile and space application systems. The microstructure of the fabricated metal had an average grain size of $75 \mu \mathrm{m}$. It exhibited a rupture at $125 \%$ elongation during a creep test at $1650^{\circ} \mathrm{C}$. The deformation mechanism in this work was predicted as solute drag of dislocations caused by the diffusion of hafnium in niobium, which is of type class I solid solutions. Morgan and Hammond [22] used a method of pre-strain at high strain rate, region III of superplastic regime, followed by cyclic strain to generate subgrain boundaries inside the coarse-grained beta-Ti alloys. The material exhibited maximum elongation of $101 \%$ at $830^{\circ} \mathrm{C}$. The superplastic deformation was due to diffusional creep mechanism. The vacancy generation and absorption were accommodated by the subgrain boundaries during the diffusional creep. In coarse-grained $(62 \mu \mathrm{m}) \mathrm{Ti} 40$ alloy, the grains initially elongated and are then refined to lesser than $10 \mu \mathrm{m}$ due to CDRA at $840^{\circ} \mathrm{C}$ and at a strain rate of $1 \times 10^{-3} \mathrm{~s}^{-1}$. It exhibited $436 \%$ elongation attributed lattice diffusion. Lin and Sun [23] reported $287.5 \%$ elongation in TiAl with $95 \mu \mathrm{m}$ grain size at $1100^{\circ} \mathrm{C}$ and at a strain rate of $4 \times 10^{-5} \mathrm{~s}^{-1}$ due to CDRX grain refinement followed by dislocation glide and climb accommodated GBS.

Woo et al. [24] observed superplasticity (300\% elongation) in $150 \mu \mathrm{m}$ grainsized Al-Mg alloy due to diffusion of $\mathrm{Mg}$ in $\mathrm{Al}$, solute-drag creep. Reduction in strain-rate sensitivity during solute-drag creep was observed in Al-Mg alloy after the addition of $\mathrm{Mn}$ or $\mathrm{Zr}$. It is due to the change in the failure mechanism from necking-controlled-failure to cavitation-controlled-failure [25]. Further, Si addition on coarse-grained Al-Mg alloys also exhibited 350\% elongation by solute-drag creep. Thus, Si addition, which did not affect the superplasticity but the high Si content of $0.2 \mathrm{wt} \%$, formed higher volume fraction of $\mathrm{Mg}_{2} \mathrm{Si}$ particles, which generates more cavity nucleation. These cavities reduce the post-forming tensile properties of the material [26]. On the addition $\mathrm{Cu}$ with $\mathrm{Al}-\mathrm{Mg}$ alloy, the superplastic elongation (320\%) was more than that of Al-Mg alloy $\left(260 \%\right.$ at $450^{\circ} \mathrm{C}$ and at a strain rate of $10^{-2} \mathrm{~s}^{-1}$ ) [27]. Though the solute drag was explained as responsible deformation mechanism, the effect of $\mathrm{Cu}$ addition was not reported. When solute-drag creep was the responsible deformation mechanism, the material exhibited superplasticity at high homologous temperature as well as at high strain rate. Similarly, addition of $\mathrm{Zn}$ in $\mathrm{Al}-\mathrm{Mg}$ alloy also improved the superplastic elongation due to solute drag coupled with CDRX before fracture [28]. Unlike GBS, solute-drag creep mechanism was independent of grain size. Hong [29] reported that if solid solution strength increases due to the increase in strain rate, during solute drag, it would increase the strain-rate sensitivity and superplastic deformation. Meanwhile, the microstructure would contain homogeneously distributed dislocations rather than dislocation clusters. 
Malek [32] observed superplastic elongation of 150-200\% in the coarsegrained $\mathrm{Zn}-1.1 \mathrm{wt} . \% \mathrm{Al}$ alloy at $227^{\circ} \mathrm{C}$ and at a strain rate of $4.2 \times 10^{-4} \mathrm{~s}^{-1}$. The coarse-grained $(70 \mu \mathrm{m})$ in this work was refined to fine grain size $(20 \mu \mathrm{m})$ with straining due to CDRX. Similar results of CDRX was observed during superplastic deformation in the $\mathrm{Fe}_{3} \mathrm{Al}-\mathrm{Ti}$ alloy with $100 \mu \mathrm{m}$ large grains when tested at $850^{\circ} \mathrm{C}$ at a strain rate of $1 \times 10^{-3} \mathrm{~s}^{-1}$ [33]. Chu et al. [34] also observed superplastic elongation of up to $180 \%$ in $\mathrm{Fe}-27 \mathrm{Al}$ alloy with an initial grain size of $700-800 \mu \mathrm{m}$. The grain size reduced to $100-200 \mu \mathrm{m}$ with strain due to continuous grain boundary migration, also called CDRX. CDRX is accountable only for grain refinement, but these works did not report about the superplastic deformation mechanisms. Mohri et al. [35] observed CDRX during superplastic deformation of rolled AZ91 Mg alloy with an initial grain size of $39.5 \mu \mathrm{m}$. The grain size reduced to $9.1 \mu \mathrm{m}$ at a true strain 0.6 due to CDRX. The CDRX in Mg alloy was not because of the effect of SFE but due to the easily activated non-basal slip systems at elevated temperature. After grain refinement, GBS was observed to contribute in $604 \%$ superplastic elongation at $300^{\circ} \mathrm{C}$ and at a strain rate of $1.5 \times 10^{-3} \mathrm{~s}^{-1}$. On the similar mechanism of grain refinement followed by GBS, elongation of $512 \%$ was obtained by Lin et al. [36] in $155 \mu \mathrm{m}$ grain-sized $\mathrm{Mg}$-Li alloy at $250^{\circ} \mathrm{C}$ and at a strain rate of $5 \times 10^{-4} \mathrm{~s}^{-1}$. Wu and Liu [37] observed $320 \%$ elongation in $300 \mu \mathrm{m}$ large grain $\mathrm{Az} 31$ alloy at $500^{\circ} \mathrm{C}$ and at a strain rate of $1 \times 10^{-3} \mathrm{~s}^{-1}$. The coarse grains were refined to $25 \mu \mathrm{m}$ at a true strain of 0.024 . In this work, grain refinement was reported due to dislocation slip and climb, while lattice diffusion controls the superplastic deformation, as the test was performed at higher temperature.

The coarse-grained materials exhibit superplastic elongation from $100 \%$ to maximum of $600 \%$ by AZ91 Mg alloy. The superplastic deformation mechanisms reported in coarse-grained materials are two types. First is the solute-drag creep in solid solution alloys like Al-Mg alloy with elongated grains as shown in Figure 2 . The second one is the dynamic recovery and/or dynamic recrystallization followed by grain boundary sliding as shown in Figure 3.

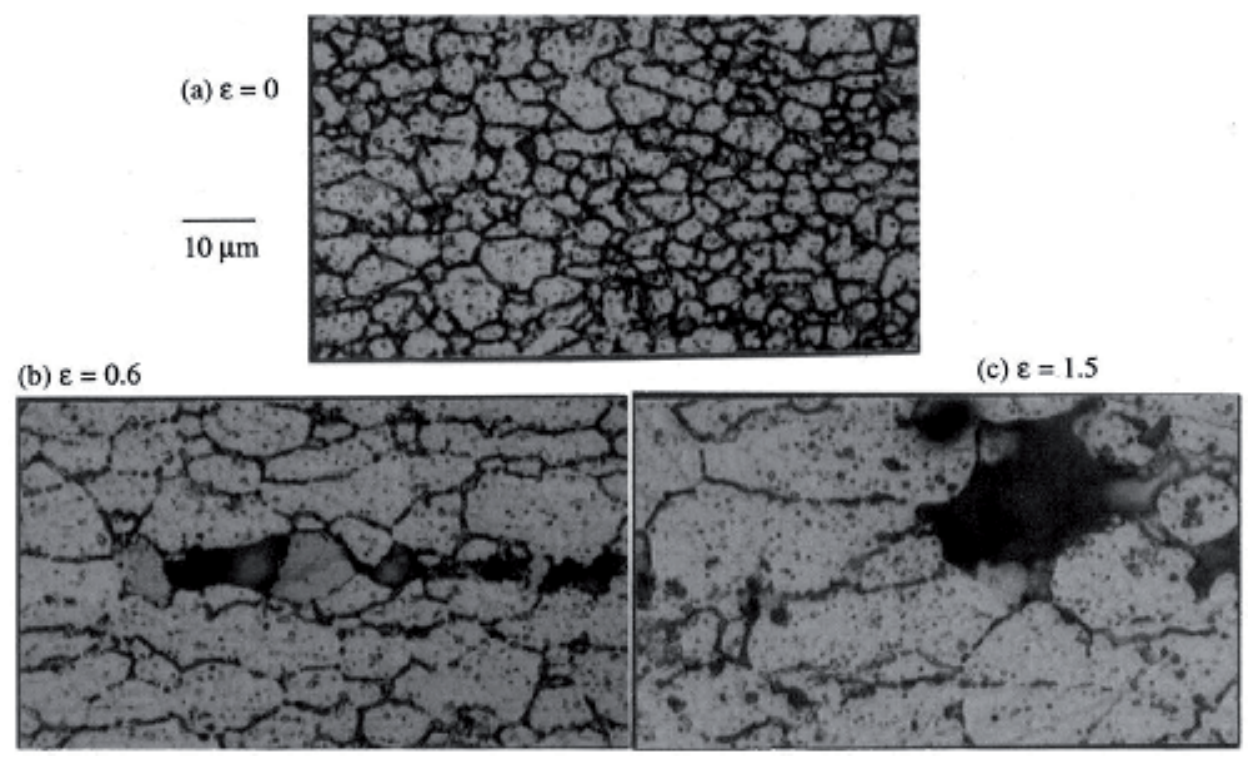

Figure 2.

Light optical micrographs of changes in the grain structure at a true strain of (a) zero, (b) 0.6, and (c) 1.5 at a tested strain rate of $5 \times 10^{-4} \mathrm{~s}^{-1}[30]$. 


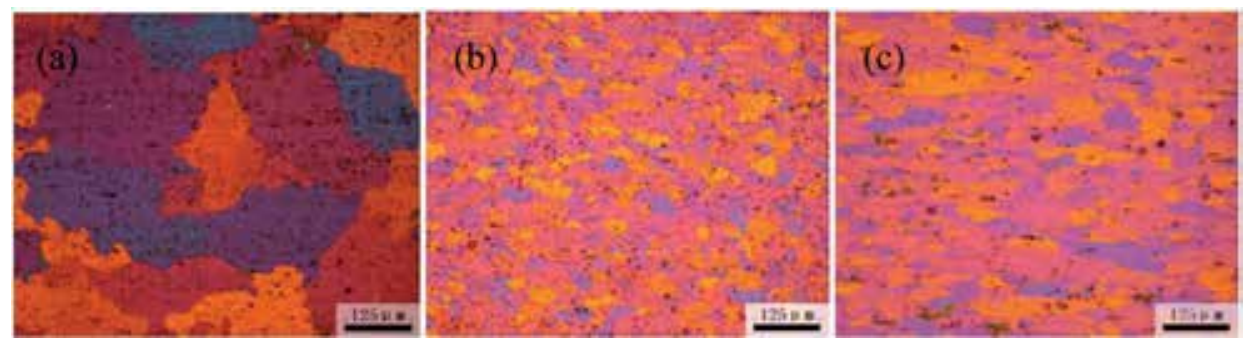

Figure 3.

Light optical micrographs of $\mathrm{Al} 5052$ alloy deformed at $425^{\circ} \mathrm{C}$ and at a strain rate of $1 \times 10^{-2} \mathrm{~s}^{-1}$ to (a) $10 \%$, (b) $100 \%$, and (c) $130 \%$ [31].

\section{Fine-grained superplasticity}

Fine-grained materials are generally preferred for superplastic deformation. Most of the materials deform by GBS; fine grains offer more fraction of grain boundaries when compared to coarse grains in a given area. As grain boundary slides, the moving dislocations need to be accommodated during the deformation process. Otherwise, dislocations would pile up at ledges or triple junction and generates stress concentration, eventually leads to cavitation and failure. Further, the slower accommodation mechanism if any or slower deformation mechanism which controls the superplastic deformation is termed as rate controlling mechanism. Hence, the deformation mechanism, accommodation mechanism, and ratecontrolling mechanism are important in the fine-grained material. Zhou et al. [38] observed low-temperature superplasticity in $6 \mu \mathrm{m}$ grain-sized Ti-6Al-4 V alloy at $700^{\circ} \mathrm{C}$ due to GBS accommodated by slip. However, the accommodation mechanism becomes grain boundary diffusion on increasing the temperature to $850^{\circ} \mathrm{C}$.

In a work by Rao and Mukerjee [39] in fine-grained Al 7475 alloy, 840\% elongation was attained during the tensile test at $457^{\circ} \mathrm{C}$ and at a strain rate of $1 \times 10^{-4} \mathrm{~s}^{-1}$. Grain elongation was observed with high dislocation density that leads to strain hardening in the material. Dislocation slip and climb through grains to the grain boundary was reported to cause grain elongation, together with grain boundary sliding. The measured activation energy, approximately $165 \mathrm{~kJ} / \mathrm{mol}$, was equal to self-diffusion of $\mathrm{Al}(142 \mathrm{~kJ} / \mathrm{mol})$. It describes that diffusion creep is the deformation mechanism rate controlled by dislocation climb. Mikhaylovskaya et al. [40] compared the superplastic deformation behavior in fine-grained Al 7475 alloy at primary stage and steady stage deformation. It was found that grain elongation occurred at primary stage due to diffusional creep, while at steady stage, diffusion creep becomes the accommodation process for GBS without any further change in the shape and size of the grain. Possibility of dislocation creep as an accommodation mechanism along with dislocation creep is also suggested in this work. This detailed study on the comparison between primary and steady stage deformation by Mikhaylovskaya et al. [40] elaborated and concurred with the work by Rao and Mukerjee [39].

In an interesting work by Fukuyo et al. [41], the accommodation mechanism for GBS in a fine-grained $(6 \mu \mathrm{m}) 10 \mathrm{wt} . \%$ Al-added ultrahigh carbon steel (UHCS$10 \mathrm{Al}$ ) was studied. It was alluded that if stress exponent is equal to 2 , then the accommodation mechanism was dislocation climb due to iron self-diffusion where if stress exponent reduced below 2, then dislocation glide due to solute drag is the accommodation mechanism. These values were confirmed by matching the measured Q values $191 \mathrm{~kJ} / \mathrm{mol}$ and $292 \mathrm{~kJ} / \mathrm{mol}$ with the theoretical Q values for selfdiffusion $(270 \mathrm{~kJ} / \mathrm{mol})$ and $\mathrm{Al}$ diffusion in $\mathrm{Fe}(155 \mathrm{~kJ} / \mathrm{mol})$, respectively. 
In a fine-grained $(2 \mu \mathrm{m}) \mathrm{Mg}-9 \mathrm{Li}$ alloy, the grain boundary diffusion accommodated GBS was reported as measured Q value of $67 \mathrm{~kJ} / \mathrm{mol}$ was approximately equal to that of GBD $(70 \mathrm{~kJ} / \mathrm{mol})$ [42]. This material exhibited superplastic elongation of $450 \%$ at $100^{\circ} \mathrm{C}$. In a work by Kin and Chung [43], the deformation mechanism of $5 \mu \mathrm{m}$ grain-sized AZ61 Mg alloy was reported to vary with the strain rate. At low strain rate, grain boundary diffusion-controlled GBS was deformation mechanism, whereas at high strain rates, pipe diffusion-controlled slip was the deformation mechanism. Maximum elongation of $560 \%$ was obtained at $400^{\circ} \mathrm{C}$ and at a low strain rate of $2 \times 10^{-4} \mathrm{~s}^{-1}$. As slip accommodates the GBS, slip systems in the direction of highest Schmidt factor has easier mobility which facilitates GBS accommodation. Anisotropy in superplastic elongation was observed in the fine-grained AZ61 alloy at $300-400^{\circ} \mathrm{C}$ by Wang and Huang [44]. However, the influence of Schmidt factors was limited to initial stages of deformation and below $400^{\circ} \mathrm{C}$. At large strain, GBS and GBM would greatly reduce the texture effect, and above $400^{\circ} \mathrm{C}$ the difference in CRSS between different slip systems becomes negligible. GBS mechanism was compared in $\mathrm{Al}$ and $\mathrm{Mg}$ alloys by Wang and Huang [45]. The contribution of GBS was approximately $60 \%$ in $\mathrm{Mg}$, while in the case of $\mathrm{Al}$ alloys, its contribution is around $20-30 \%$ at a true strain of below 0.5 . It was because warmextruded Mg alloy contains 88\% HAGBs, while warm-worked $\mathrm{Al}$ alloy had 45-65\% HAGBs. HAGBs favor GBS; hence, in Mg alloy almost every single grain contributes for GBS, whereas in Al alloys, the presence of LAGBs and CSL boundaries did not favor GBS. Hence, during initial stages of deformation, the group of grains with a common HAGB would undergo GBS, known as cooperative GBS. This initial strain promotes DRV/DRX to convert LAGBs into HAGBs and increase the fraction HAGBs at higher strain values. Further, in slip-accommodated GBS, slip process takes place by subsequent glide and climb. The distance of climb is an important factor in determining the strain rate. If the climb distance is of grain size, it would be absorbed by the grain boundary, and it would contribute for the elementary process of GBS. If the climb distance is of only core size of the grain, it would climb through the lattice and act as rate controlling process [46]. The superplasticity of AA 5083 alloy with and without $\mathrm{Cr}$ of grain sizes 7 and $10 \mu \mathrm{m}$ was studied by Mikhaylovskaya et al. [47]. The elongation in alloy with $\mathrm{Cr}$ is found to be marginally higher than the alloy without $\mathrm{Cr}$ attributed to it difference in the grain size. It was found that contribution of GBS negligible in both these alloys, instead diffusion creep, was observed to be contributed for $50 \%$ of the strain rate. In particle-containing Mg alloys, which exhibit superplastic deformation at low temperature or room temperature, the GBS is accompanied by grain boundary migration. The cooperative effect of grain boundary sliding and migration creates stress concentration around the grains. The larger the GBS distance, the larger is the stress concentration, and depending on the grain orientation, migration aids in either stress relaxation or stress concentration [48]. This effect nucleates cracking of the particles inside the grain due to disclination; a rotational line defect arises out of rotational misfit between the lattices [49].

\section{Ultrafine-grained superplasticity}

$\mathrm{Xu}$ et al. [50] stated that superplastic deformation is one of the innovative applications of UFG alloys. Reducing the grain size aids in increasing the rate of superplastic deformation where GBS is the operative deformation mechanism. Kim et al. [51] proposed lattice diffusion-controlled GBS as a deformation mechanism for high-strain-rate superplasticity in $0.3-0.4-\mu \mathrm{m}$-sized grain $\mathrm{Al}$ alloy. Superplastic elongation of $9000 \%$ was achieved in an ultrafine-grained Ti-6Al-4 V alloy at $850^{\circ} \mathrm{C}$ [52]. However, $\mathrm{Cu}-\mathrm{Zn}-\mathrm{Zr}$ alloy exhibited superplasticity at a temperature 
above $400^{\circ} \mathrm{C}$ and at strain rates below $1 \times 10^{-3} \mathrm{~s}^{-1}$. It was because UFG was obtained by ECAP method which contains elongated grains. At temperature higher than the recrystallization temperature of the alloy, it exhibited superplasticity. Mere $0.18 \%$ addition of $\mathrm{Zr}$ helps in increasing the recrystallization temperature from 100 to $500^{\circ} \mathrm{C}$ that prevents grain growth. Zn inhibits dislocation creep and assists GBS in the process [53]. Ma et al. [54] achieved superplasticity in UFG Al alloy at a strain rate of $1 \mathrm{~s}^{-1}$ and at a temperature of $425^{\circ} \mathrm{C}$ due to lattice diffusion-controlled GBS.

Kawasaki and Langdon [56-58] developed deformation mechanism map for UFG polycrystalline materials depending on the strain rate and temperature range. Most of the materials, namely, $\mathrm{Zn}-22 \% \mathrm{Al}$ and $\mathrm{Pb}-62 \% \mathrm{Sn}$ alloys, fall in the range of region II of the superplasticity regime. Lee and Horita [59] observed low-temperature superplasticity in Al7075 alloy at $200-250^{\circ} \mathrm{C}$ due to UFG generated by highpressure torsion process. In $\mathrm{Al} 5024$ alloy, UFG grains of $0.7 \mu \mathrm{m}$ was produced by ECAP and tested for superplasticity in the temperature range of $175-450^{\circ} \mathrm{C}$ and at a strain rate ranging from $10^{-3} \mathrm{~s}^{-1}$ to $10^{-1} \mathrm{~s}^{-1}$. The material exhibited superplasticity in all the tested conditions due to grain boundary diffusion-controlled GBS. At $175^{\circ} \mathrm{C}$ the maximum elongation of $365 \%$ was obtained at a strain rate of $1.4 \times 10^{-4} \mathrm{~s}^{-1}$, and at $450^{\circ} \mathrm{C}$ the maximum elongation of $3300 \%$ was obtained at a strain rate of $5.6 \times 10^{-1} \mathrm{~s}^{-1}$. At low temperature, strain hardening was observed at the primary deformation stage due to the accumulation of lattice dislocations, whereas at high temperature, strain-induced grain elongation causes the strain hardening which accounted for the high-strain-rate superplasticity [55]. Bobruk et al. [60] demonstrated that UFG grain promoted low-temperature and high-strain-rate superplasticity in Al 7050 alloy. Edalati et al. [61] observed low-temperature superplasticity in $\mathrm{Mg}$-Li alloy with $0.25 \mu \mathrm{m}$. The deformation mechanism was grain boundary sliding controlled by fast grain boundary diffusion due to Li segregation along the grain boundaries. The low-temperature superplasticity in this case was not attributed to UFG alone, but Li segregation in the boundary favors the grain boundary diffusion and GBS. Similar observation of maximum elongation of approximately $850 \%$ was found in UFG Ti-6Al-4 V $(\sim 0.4 \mu \mathrm{m})$ alloy due to high volume fraction of beta phase in a continuous network fashion acted as soft lubricant layer and increases the elongation [62]. Various deformation mechanisms that contribute for superplastic deformation in UFG regime were mapped with the optimum strain rate and temperature in Figure 4. It is evident that there

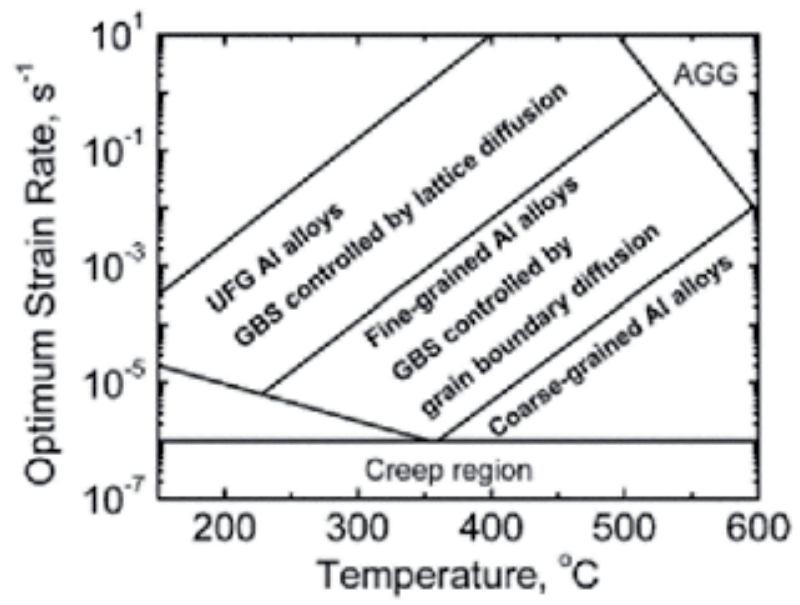

Figure 4.

Superplastic mechanism map of FSP Al alloys [54]. 


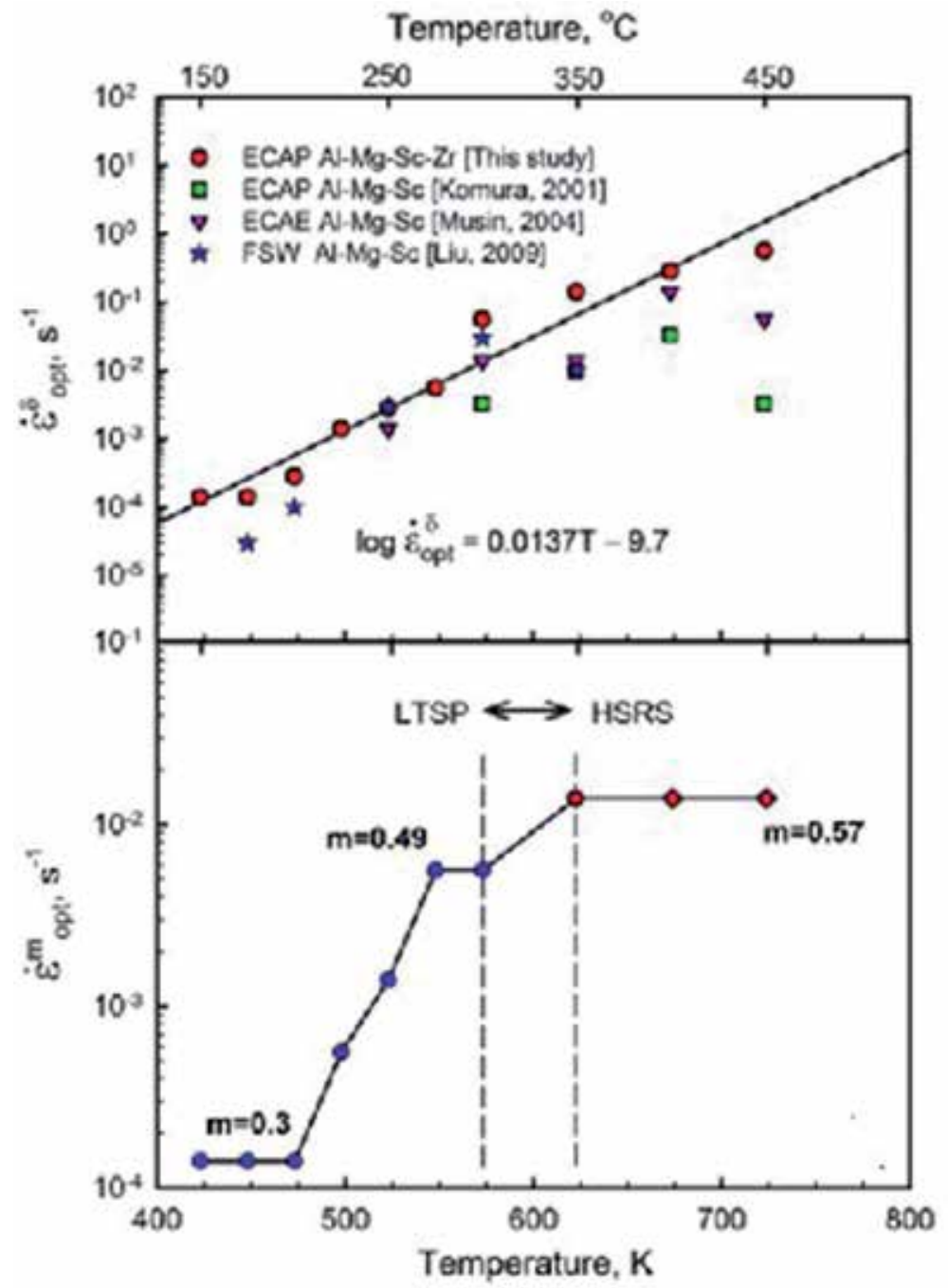

Figure 5.

Variation of optimum strain rate for maximum superplasticity (a) and optimum strain rate for the highest value of strain-rate sensitivity (b) with temperatures for ECAP Al-Mg-Sc-Zr and other UFG aluminum alloys [55].

is a relationship between temperature and strain rate. In Figure 5, an empirical relationship was presented with an illustration that HSRSP would take place at higher temperatures.

\section{Nano-grained superplasticity}

The kinetics of nano-grained superplasticity is different from the higher scale sized grains. Nano-grains show higher flow stress for superplastic deformation. It makes difficulty in activating the slip systems for the accommodation process [63]. The hypothesis for difficult slip accommodation is displayed in Figure 6. In the absence of slip as accommodation mechanism for GBS during nano-grained superplasticity, one of the possible accommodation mechanisms in nano-grains could be mobile triple junctions [64]. In nano-grained materials, partial dislocation slips can be activated at a lower stress level when compared to the perfect 


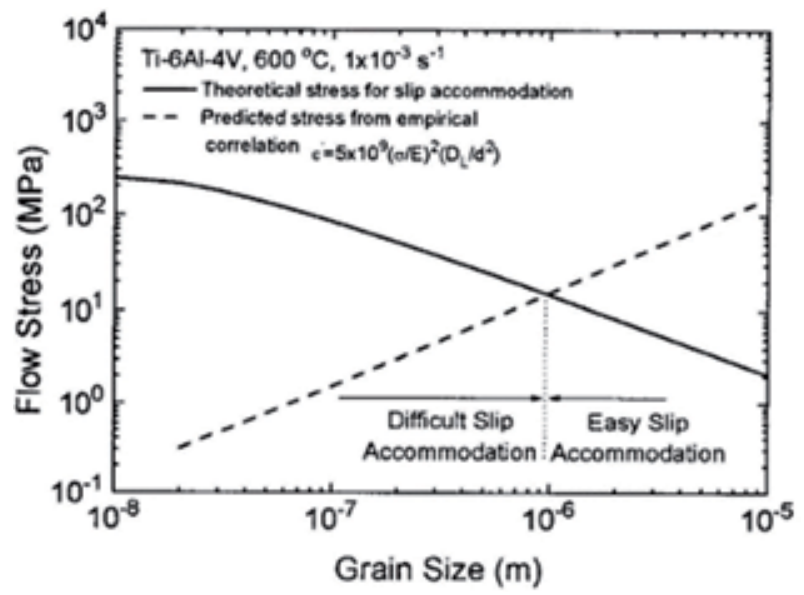

Figure 6.

A comparison of theoretical flow stress and empirical flow stress for slip accommodation in Ti-6Al-3.2Mo [63].

dislocation slips. As GBS occurs, dislocation accumulates at the triple junction which increases the system strain energy. The energy can be relaxed as Shockley partial dislocations emitted in to the neighboring grain. Thus, the emission of partial dislocations acts as an accommodation mechanism in nano-grained materials [65]. Similarly, dislocation transfer along a triple junction during grain boundary migration would increase the triple junction angle to accommodate the GBS [66]. Atomic shuffling accommodated GBS also suggested in nanomaterials [67]. The mechanism of atomic shuffling in tilt grain boundary during a shear is illustrated in Figure 7. This is called stress-induced grain boundary diffusion. In a defect-free single crystal, Au nano-wire superplastic deformation was found due to coherent twin propagation [68]. The test was carried in situ with SEM and HRTEM at room temperature, and the maximum elongation is only $50 \%$, but the deformation mechanism reported in his work was interesting and specific to
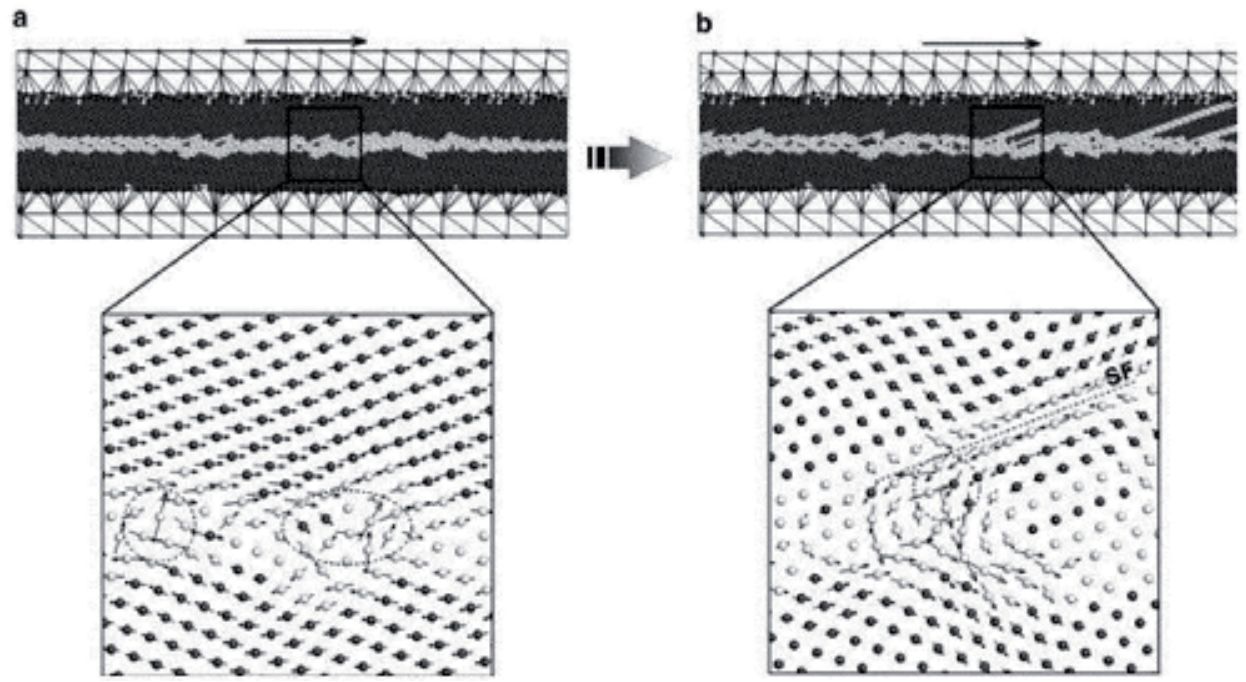

Figure 7.

Deformation mechanisms of a tilt GB under shear. (a) Early stage of GB sliding initiated by localized shuffling events (dashed circles) of atoms at the interface. Arrows correspond to the atomic displacement between two loading steps. (b) Subsequent stage of GB sliding where sites of atomic shuffling in the GB nucleate partial dislocations traveling into the grain and leaving a stacking fault (SF) [65]. 
(a)

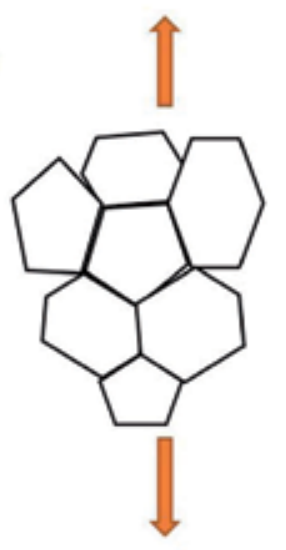

(b)

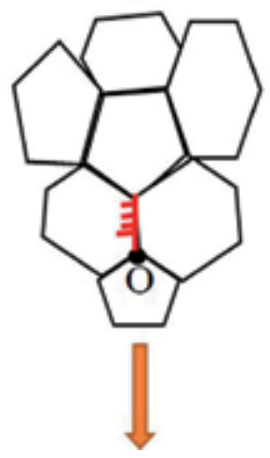

(c)

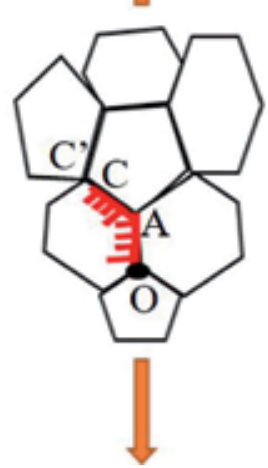

(d)

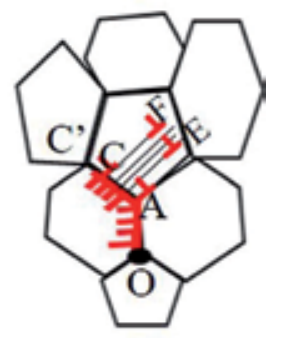

Figure 8.

Illustration of nano-twin formation during superplastic deformation. (a) Nanometer sized grains under tensile load, (b) GBS created dislocation pile up at triple junction $O,(c)$ climb of dislocations on grain boundary AC', and (d) Nano-twin formation due to mobile partial dislocations that move into the adjacent grain interior, as grain boundary dislocations become sessile dislocations [69].

nano-grain superplasticity. The nano-twins observed to originate at the beginning of plastic deformation contain partial dislocations. Generally, the $1.54 \mathrm{GPa}$ stress required to nucleate a partial in Au nano-wire, but due to nano-twins, the partials nucleated at the yield stress value of approximately $200 \mathrm{MPa}$. This nano-twin propagates by the glide of these partial dislocations. Ovid'ko and Skiba [69] figured out that the dislocation pile-up at the triple junction due to GBS caused nano-twin formation. The sequential step of GBS, dislocation pile-up, and twin formation are presented in Figure 8.

The piled-up dislocation splits in to two types: immobile GB dislocation and mobile partial dislocation. This partial dislocations then move cooperatively on every slip plane in a nanoscale region to generate nano-twin.

The evolution of nano-grains in to UFGs was observed in $\mathrm{Al}$ and Ti alloys which helps in improving the post-forming properties of the material [70]. Alizadeh et al. [71] reported grain boundary diffusion-controlled GBS in a nano-grained $\mathrm{Mg}-\mathrm{Gd}-\mathrm{Y}-\mathrm{Zr}$ alloy when tested in the temperature range of $300-500^{\circ} \mathrm{C}$. Similar to Li segregation at grain boundaries in UFG Mg-Li alloy, Edalati et al. [72] observed superplastic elongation at $300^{\circ} \mathrm{C}$ in nano-grained $\mathrm{Al}-\mathrm{Zn}$ alloy due to the $\mathrm{Zn}$ segregation-enhanced GBS.

\section{Superplasticity in materials with mixed grain sizes}

Mansoor and Ghosh [73] studied the effect of multi-pass FSP on extruded ZK60 Mg plate. They found improvement in room-temperature mechanical properties of processed alloy, which was attributed to layered microstructure with grain size of $2-5 \mu \mathrm{m}$ and $100 \mu \mathrm{m}$. Similarly, Witkin et al. [74] and Oskooie et al. [75] worked on $\mathrm{Al}$ alloys through cryo-milling and high-energy planetary ball-milling methods, respectively, to fabricate mixed-coarse and fine-grained structures and obtain optimum strength and ductility. Wang et al. [76] achieved enhanced strength and ductility in $\mathrm{Cu}$ after thermomechanical treatment with a mixed grain size distribution of micrometer-sized grains embedded inside a matrix of nanocrystalline and ultrafine $(<300 \mathrm{~nm})$ grains. The matrix grains impart high strength, whereas the coarse grains facilitate strain hardening mechanisms to give high tensile 
ductility. Moreover, modifying the surfaces was reported to improve fracture and fatigue properties. Cáceres and Selling [77] mentioned that the area fraction of defects on the fracture surface influences the tensile properties rather than the bulk defect content. Begum et al. [78] found that that the fatigue cracks were originated from the surfaces with large grains. Perron et al. [79] performed molecular dynamic simulation on polycrystalline $\mathrm{Al}$ samples and found a linear relationship between grain size and surface roughness to an extent of applied strain, while Liu et al. [80] reported that surface modification by shot peening decreases surface roughness due to grain refinement and becomes the reason for improvement in mechanical properties in $\mathrm{Mg}$ alloy.

At high temperature, the effect of fine grains is substantial; even roomtemperature superplasticity was observed after HPT in pure $\mathrm{Mg}$ [81] and in Mg-Li alloy [61]. However, few studies showed superplasticity in coarse-grained Mg alloys also. Watanabe et al. [82] achieved superplastic elongation of $196 \%$ in AZ31 Mg alloy with an average grain size of $130 \mu \mathrm{m}$. Wu and Liu [37] reported superplasticity of $320 \%$ in hot-rolled AZ31 Mg alloy with a mean grain size of $300 \mu \mathrm{m}$. Grain size was found to reduce to $25 \mu \mathrm{m}$ during deformation due to dislocation slip and climb. Hence, the idea of mixed grain size microstructure which showed promising improvement in room-temperature mechanical properties was explored at high temperature also. Fan et al. [83] observed more superplastic elongation in AA8090 $\mathrm{Al}-\mathrm{Li}$ alloy which inherently contains three distinct microstructural layers through the thickness when compared to superplasticity of surface layers (equiaxed grains) and middle layers (elongated grains) alone as shown in the Figure 9. Pancholi and Kashyap [84] obtained better bulge profile during superplastic bulge forming of AA8090 Al-Li alloy.

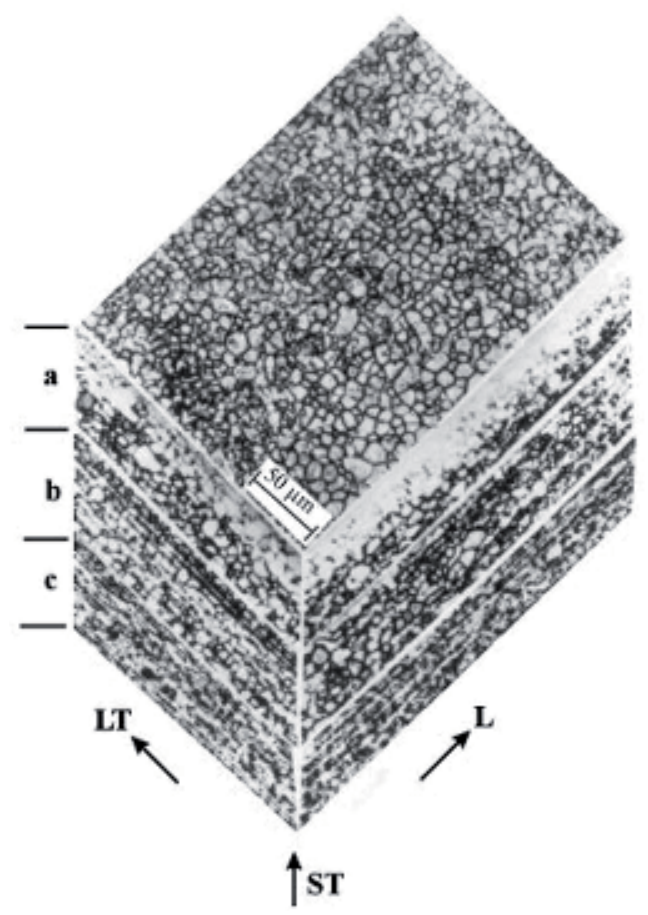

Figure 9.

Three-dimensional view of the microstructure after annealing at $540^{\circ} \mathrm{C}$ for 5 min: (a) Li-depleted layer, (b) layer with recrystallized microstructure, and (c) middle layer of un-recrystallized grains [84]. 
Later, Pradeep and Pancholi [85] deliberately fabricated layered microstructure containing coarse and fine grains in Al 5082 alloy using FSP and found that the inhomogeneous microstructures possess superior superplastic formability than the homogeneously grain-sized materials. It can be clearly observed in Figure 10 that the composite layer $(\mathrm{CL})$ contains the mixture of thermomechanically affected layer (TL) and nugget layer (NL) contains lesser fraction for cavities and maximum elongation as evident from its necking. Álvarez-Leal et al. [86] observed superplasticity in extruded ZK30 Mg alloy. During deformation the complex as received microstructure evolved into bimodal microstructure.

In general, inhomogeneity in initial material would lead to inhomogeneous deformation and strain localization which eventually lead to failure [89]. In classical superplastic literature, uniform fine-grained microstructure was considered favorable for superplasticity. However in Al alloys, inhomogeneous microstructure has shown to exhibit higher ductility than homogeneous fine-grained microstructure [74-76, 87]. Pancholi et al. [90] demonstrated that at least 50\% fine grain microstructure is required in the $\mathrm{Al} 5086$ alloy for it to exhibit superior superplasticity when compared to the homogeneous fine-grained material. It was argued that microstructural refinement in the remaining $50 \%$ of coarse-grained microstructure, which leads to fully homogenous microstructure in the material, was the reason for higher superplasticity $[84,87]$. However in the work by Raja and Pancholi [88], layered microstructure material exhibited elongation lower than fully fine-grained microstructure. The coarse grain with as-cast material is deformed by twins as shown in Figure 11(a). The nature twins were found out to be extension-type from the misorientation distribution in Figure 11(b). Lack of superplasticity in half thickness fine-grained material (HFG) and surface modified by fine-grained material (SFG) can be attributed to insignificant microstructural refinement in the coarse-grained as-cast microstructure during deformation, as shown in Figures 11(c) and 9(d). It is well established that Al alloys exhibit continuous dynamic recrystallization (CDRX) [91, 92], whereas AZ91 Mg alloys exhibit discontinuous dynamic recrystallization [93]. It appears that CDRX of coarse grains in the layer microstructure of $\mathrm{Al}$ alloys was the primary reason for higher
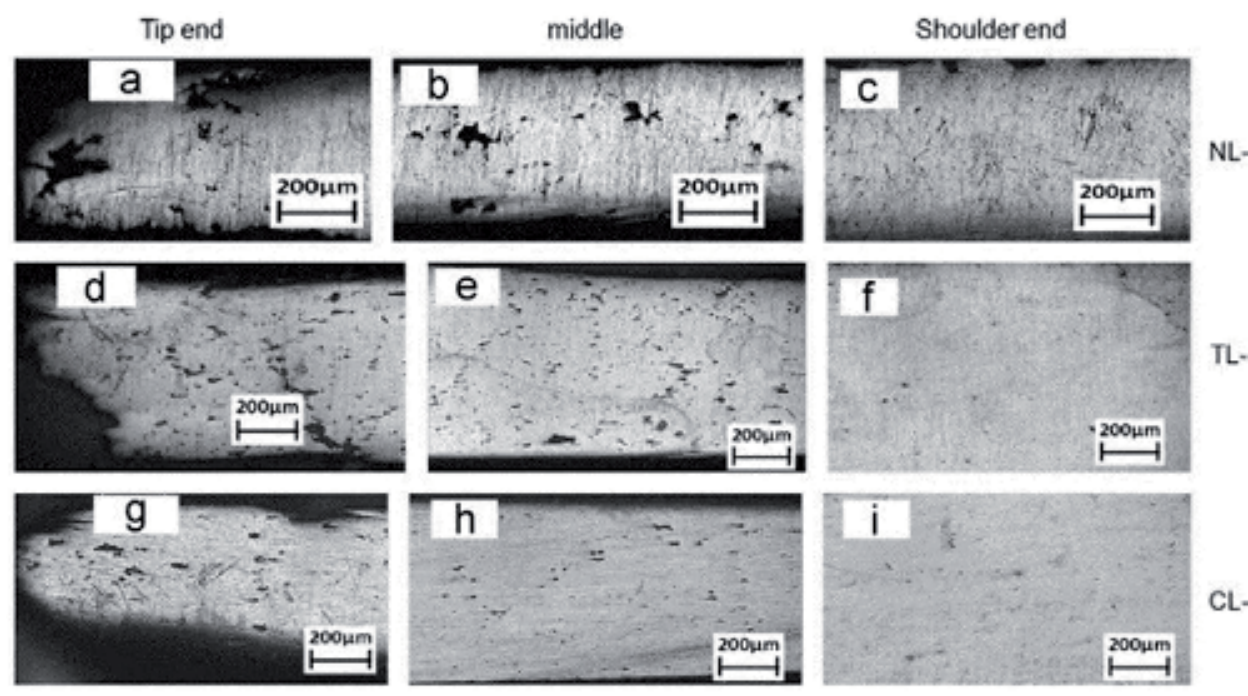

Figure 10.

Cavitation along the gauge length (in the thickness direction) at different points (tip end, mid-section, and shoulder end) of the tensile samples deformed at $500^{\circ} \mathrm{C}$ with a strain rate of $1 \times 10^{-3} s^{-1} .(a-c) N L,(d-f) T L$, and $(g-i) C L[87]$. 


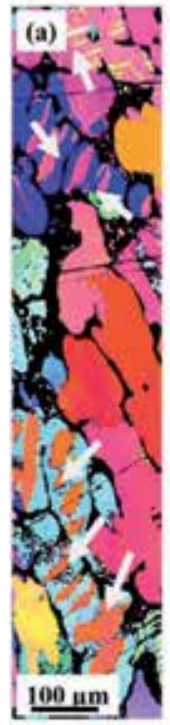

(b)
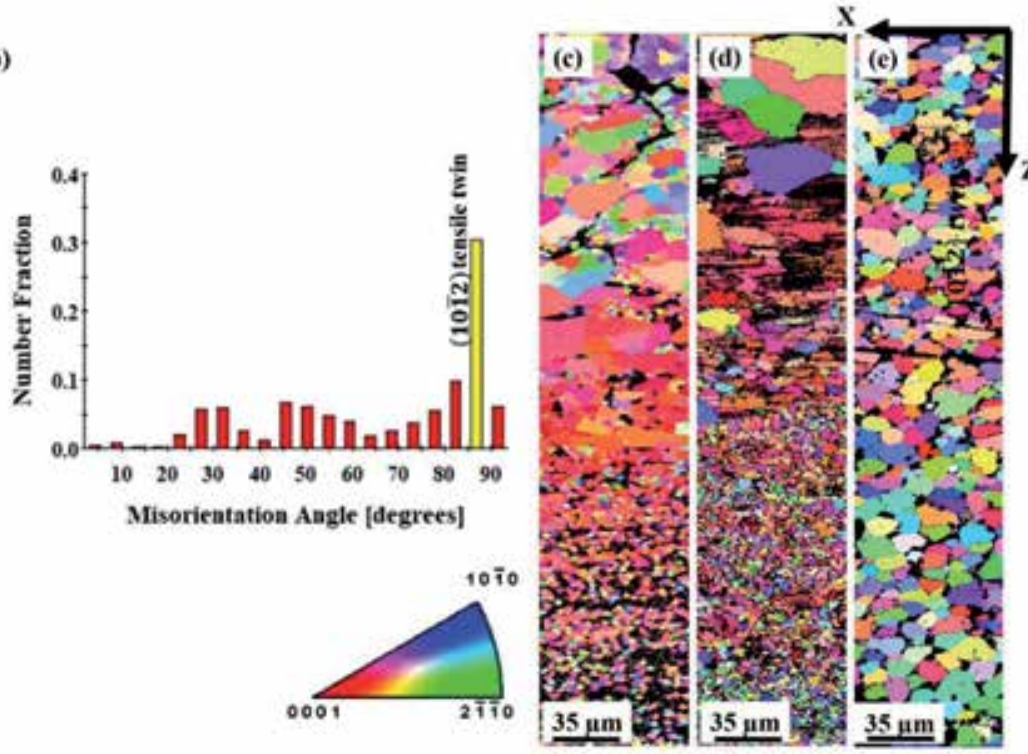

Figure 11.

IPF maps of deformed samples with tensile axis parallel to process direction (parallel to $X$-axis shown above) at a strain rate of $5 \times 10^{-4} \mathrm{~s}^{-1}$; (a) AC material with highlighted (yellow) extension twins indicated by arrows in its IPF map and (b) grain boundary misorientation distribution of as-cast material showing predominant tensile twin population around 86.3, (c) HFG, (d) SFG, and (e) FFG [88].

superplastic elongation in Al alloys which was not present in the AZ91 Mg alloy. However, elongation of more than $600 \%$ and strain-rate sensitivity of more than 0.5 in FFG material confirmed that friction stir processed AZ91 behave superplastically at temperature of $350^{\circ} \mathrm{C}$ and strain rate of $5 \times 10^{-4} \mathrm{~s}^{-1}$ due to dynamic grain growth can be observed from the Figure 11(e).

\section{Conclusions}

The effect of grain size on the superplastic deformation of metallic materials was studied. There were different combination of deformation mechanisms, accommodation mechanism, and rate-controlling mechanisms that governed the superplastic deformation which depends on the grain size, temperature, and strain rate. The following conclusions were obtained based on the detail study.

- The maximum elongation obtained by coarse-grained microstructure was between 500 and $800 \%$. Solute-drag creep controlled by diffusion and GBS preceded by CDRV/CDRX was the deformation mechanisms in the coarsegrained microstructure.

- In fine-grained materials, GBS dominated the deformation mechanism. The accommodation mechanism could be either by "glide and climb" or by diffusion. If diffusion is the accommodation mechanism, it can be divided either by grain boundary diffusion or lattice diffusion which depends on the required activation energy.

- In UFG regime most of the materials exhibited either low-temperature superplasticity or high-strain-rate superplasticity. The mechanism in both cases is mostly observed to be GBS accommodated by dislocation slip. 
Effect of Grain Size on Superplastic Deformation of Metallic Materials

DOI: http://dx.doi.org/10.5772/intechopen.86017

- The kinetics of nano-grained deformation is different from that of their higher-scale grain sizes. The deformation mechanism in nano-grain structure is also GBS, but its accommodation by slip becomes difficult. The piled-up dislocations give rise to different accommodation mechanisms, namely, nanotwins, emission of Shockley partials, and stress-induced atomic shuffling.

- In materials with mixed grain size microstructure, the microstructure evolution during deformation needs to favor CDRX in the coarse-grained region in order to exhibit superior superplastic elongation-else finer-grained region controls the deformation.

\section{Author details}

Allavikutty Raja, Rengaswamy Jayaganthan*, Abhishek Tiwari and Ch. Srinivasa Rakesh

Department of Engineering Design, Indian Institute of Technology Madras, Chennai, India

*Address all correspondence to: edjay@iitm.ac.in

\section{IntechOpen}

(C) 2019 The Author(s). Licensee IntechOpen. This chapter is distributed under the terms of the Creative Commons Attribution License (http://creativecommons.org/licenses/ by/3.0), which permits unrestricted use, distribution, and reproduction in any medium, provided the original work is properly cited. (cc) BY 


\section{References}

[1] Backofen JRTWA, Avery DH. Superplasticity in Al-Zn alloy. Transactions of American Society for Metals. 1964;57:980

[2] Liu FC, Ma ZY. Superplasticity governed by effective grain size and its distribution in fine-grained aluminum alloys. Materials Science and Engineering A. 2011;530:548-558. DOI: 10.1016/j.msea.2011.10.018

[3] Edington JW, Melton KN, Cutler CP. Superplasticity. Progress in Materials Science. 1976;21:61-158

[4] Langdon TG. Grain boundary sliding revisited: Developments in sliding over four decades. Journal of Materials Science. 2006;41:597-609. DOI: 10.1007/ s10853-006-6476-0

[5] Tan JC, Tan MJ. Superplasticity and grain boundary sliding characteristics in two stage deformation of $\mathrm{Mg}$-3Al$1 \mathrm{Zn}$ alloy sheet. Materials Science and Engineering A. 2003;339:81-89

[6] Todd RI. Critical review of mechanism of superplastic deformation in fine grained metallic materials. Materials Science and Technology. 2000;16:1287-1294. DOI: $10.1179 / 026708300101507118$

[7] Mukherjee AK. Superplasticity in Metals, ceramics and intermetallics, in: Plastic Deformation and Fracture of Materials. Wiley-VCH Verlag $\mathrm{GmbH} \&$ Co. KGaA; 2003. pp. 407-460

[8] Yogesha KK, Joshi A, Raja A, Jayaganthan R. High-Cycle Fatigue Behaviour of Ultrafine Grained $5052 \mathrm{Al}$ Alloy Processed Through Cryo-Forging. Cham: Springer; 2019. pp. 153-161. DOI: 10.1007/978-3-030-05728-2_14

[9] Logakannan KP, Verma R, Jayaganthan R, Velmurugan R. Effect of strain rate on tensile and fracture behavior of ultrafine grained Al6061 processed through cryorolling and warm rolling. Materials Today: Proceedings. 2018;5:17180-17187. DOI: 10.1016/J.MATPR.2018.04.127

[10] Verma R, Srinivasan A, Jayaganthan R, Nath SK, Goel S. Studies on tensile behaviour and microstructural evolution of UFG Mg-4Zn-4Gd alloy processed through hot rolling. Materials Science and Engineering A. 2017;704:412-426. DOI: 10.1016/J.MSEA.2017.08.032

[11] Laxmanappa SK, Jayaganthan R, Chakravarthy SR, Sarathi R.

Size-dependent energetics and thermodynamic modeling of $\mathrm{ZnO}$ nanoparticles produced by electrical wire explosion technique. Materials Today: Proceedings. 2018;5:17293-17303. DOI: 10.1016/J.MATPR.2018.04.141

[12] Balakrishnan V, Roshan P, Goel S, Jayaganthan R, Singh IV. Experimental and XFEM simulation of tensile and fracture behavior of Al 6061 alloy processed by severe plastic deformation. Metallography, Microstructure, and Analysis. 2017;6:55-72. DOI: 10.1007/ s13632-016-0332-7

[13] Fuloria D, Kumar N, Goel S, Jayaganthan R, Jha S, Srivastava D. Tensile properties and microstructural evolution of Zircaloy-4 processed through rolling at different temperatures. Materials and Design. 2016;103:40-51. DOI: 10.1016/J. MATDES.2016.04.052

[14] Mohammad H. Composition and microstructure effects on superplasticity in magnesium alloys. PhD thesis. 2010

[15] Kashyap BP, Arieli A, Mukherjee AK. Microstructural aspects of superplasticity. Journal of Materials Science. 1985;20:2661-2686. DOI: 10.1007/BF00553028 
[16] del Valle JA, Ruano OA. Effect of annealing treatments on strain rate sensitivity and anisotropy in a magnesium alloy processed by severe rolling. Materials Science Forum. 2010;638-642:1524-1529. DOI: $10.4028 /$ www.scientific.net/ MSF.638-642.1524

[17] Doherty RD, Hughes DA, Humphreys FJ, Jonas JJ, Jensen DJ, Kassner ME, et al. Current issues in recrystallization: A review. Materials Science and Engineering A. 1997. DOI: 10.1016/S0921-5093(97)00424-3

[18] Knauer E, Freudenberger J, Marr T, Kauffmann A, Schultz L. Grain refinement and deformation mechanisms in room temperature severe plastic deformed Mg-AZ31. Metals. 2013;3:283-297. DOI: 10.3390/ met3030283

[19] Jata KV, Semiatin SL. Continuous dynamic recrystallization during friction stir welding of high strength aluminum alloys. Scripta Materialia. 2000;43:743-749

[20] Huang K, Logé RE. A review of dynamic recrystallization phenomena in metallic materials. Materials and Design. 2016;111:548-574. DOI: 10.1016/j.matdes.2016.09.012

[21] Wadsworth J, Roberts CA, Rennhack EH. Creep behaviour of hot isostatically pressed niobium alloy powder compacts. Journal of Materials Science. 1982;17:2539-2546. DOI: 10.1007/BF00543885

[22] Morgan GC, Hammond C. Superplastic deformation properties of $\beta$-Ti alloys. Materials Science and Engineering. 1987;86:159-177. DOI: 10.1016/0025-5416(87)90450-2

[23] Lin D, Sun F. Superplasticity in a large-grained $\mathrm{TiAl}$ alloy. Intermetallics. 2004;12:875-883. DOI: 10.1016/J. INTERMET.2004.02.039
[24] Woo SS, Kim YR, Shin DH, Kim WJ. Effects of Mg concentration on the quasi-superplasticity of coarse-grained Al-Mg alloys. Scripta Materialia. 1997;37:1351-1358. DOI: 10.1016/ S1359-6462(97) 00275-3

[25] Taleff EM, Henshall GA, Nieh TG, Lesuer DR, Wadsworth J. Warmtemperature tensile ductility in Al-Mg alloys. Metallurgical and Materials Transactions A: Physical Metallurgy and Materials Science. 1998;29:1081-1091. DOI: 10.1007/ s11661-998-1017-x

[26] Hosokawa H, Iwasaki H, Mori T, Mabuchi M, Tagata T, Higashi K. Effects of Si on deformation behavior and cavitation of coarse-grained $\mathrm{Al}-4.5 \mathrm{Mg}$ alloys exhibiting large elongation. Acta Materialia. 1999;47:1859-1867. DOI: 10.1016/S1359-6454(99)00047-6

[27] Chezan AR, De Hosson JTM. Superplastic behavior of coarsegrained aluminum alloys. Materials Science and Engineering A. 2005;410-411:120-123. DOI: 10.1016/J. MSEA.2005.08.118

[28] García-Bernal MA, HernandezSilva D, Sauce-Rangel V. Superplastic behavior of coarse-grained Al-Mg-Zn alloys. Journal of Materials Science. 2007;42:3958-3963. DOI: 10.1007/ s10853-006-0368-1

[29] Ig Hong S. Influence of solutedislocation interaction on the superplastic behavior and ductility of Al-Mg alloys. Scripta Materialia. 1999;40:217-222

[30] Kannan K, Johnson CH, Hamilton $\mathrm{CH}$. A study of superplasticity in a modified 5083 Al-Mg-Mn Alloy. Metallurgical and Materials Transactions A. 1998;29A:1211-1998

[31] Diao H, Qayyume R, Wang T, Zhao S, Ma C. Superplastic behavior of coarse-grained Al-Mg alloy. 
International Journal of Modern Physics: Conference Series. 2012;6:401-406. DOI: 10.1142/ S2010194512003510

[32] Málek P. Superplasticity in a coarse-grained Zn-1.1 wt. \% Al alloy. Czechoslovak Journal of Physics. 1988;38:406-408. DOI: $10.1007 /$ BF01605414

[33] Lin D, Lin TL, Shan A, Li D. Superplasticity in Fe3Al-Ti alloy with large grains. Scripta Metallurgica et Materialia. 1994;31:1455-1460. DOI: 10.1016/0956-716X(94)90055-8

[34] Chu JP, Liu IM, Wu JH, Kai W, Wang JY, Inoue K. Superplastic deformation in coarse-grained Fe-27A1 alloys. Materials Science and Engineering A. 1998;258:236-242. DOI: 10.1016/S0921-5093(98)00939-3

[35] Mohri T, Mabuchi M, Nakamura M, Asahina T, Iwasaki H, Aizawa T, Higashi $\mathrm{K}$. Microstructural evolution and superplasticity of rolled Mg-9Al-1Zn. Materials Science and Engineering A. 2000;290:139-144

[36] Lin K, Kang Z, Fang Q, Zhang J. Superplasticity at elevated temperature of a coarse-grained $\mathrm{Mg}$-Li alloy. Advanced Engineering Materials. 2014;16:381-388. DOI: 10.1002/ adem.201300302

[37] Wu X, Liu Y. Superplasticity of coarse-grained magnesium alloy. Scripta Materialia. 2002;46:269-274. DOI: 10.1016/S1359-6462(01)01234-9

[38] Zhou G, Chen L, Liu L, Liu H, Peng H, Zhong Y, et al. Lowtemperature superplasticity and deformation mechanism of Ti-6Al-4V alloy. Materials. 2018;11:1212. DOI: 10.3390/ma11071212

[39] Rao MK, Mukherjee AK. Superplastic deformation behavior of a fine-grained aluminum alloy 7475. Materials Science and Engineering. 1986;80:181-193. DOI: 10.1016/0025-5416(86)90196-5

[40] Mikhaylovskaya AV, Yakovtseva OA, Sitkina MN, Kotov AD, Irzhak AV, Krymskiy SV, et al. Comparison between superplastic deformation mechanisms at primary and steady stages of the fine grain AA7475 aluminium alloy. Materials Science and Engineering A. 2018;718:277-286. DOI: 10.1016/J. MSEA.2018.01.102

[41] Fukuyo H, Tsal HC, Oyama T, Sherby OD. Super plasticity and Newtonian-viscous flow in fine-grained class I solid solution alloys. ISIJ Int. 1991;31:76-85

[42] Taleff EM, Ruano OA, Wolfenstine J, Sherby OD. Superplastic behavior of a fine-grained $\mathrm{Mg}-9 \mathrm{Li}$ material at low homologous temperature. Journal of Materials Research. 1992;7:2131-2135. DOI: 10.1557/JMR.1992.2131

[43] Kim WJ, Chung SW. Superplasticity in fine-grained AZ61 magnesium alloy. Metallic Materials. 2000;6:255-259. DOI: 10.1007/ BF03028220

[44] Wang YN, Huang JC. Texture characteristics and anisotropic superplasticity of AZ61 magnesium alloy. Materials Transactions. 2003;44:2276-2281

[45] Wang YN, Huang JC. Comparison of grain boundary sliding in fine grained $\mathrm{Mg}$ and $\mathrm{Al}$ alloys during superplastic deformation. Scripta Materialia. 2003;48:1117-1122. DOI: 10.1016/S1359-6462(02)00615-2

[46] Watanabe H, Mukai T, Higashi K. Deformation mechanism of fine-grained superplasticity in metallic materials expected from the phenomenological constitutive equation. Materials Transactions. 
2004;45:2497-2502. DOI: 10.2320/ matertrans.45.2497

[47] Mikhaylovskaya AV, Yakovtseva OA, Golovin IS, Pozdniakov AV, Portnoy VK. Superplastic deformation mechanisms in fine-grained $\mathrm{Al}-\mathrm{Mg}$ based alloys. Materials Science and Engineering A. 2015;627:31-41. DOI: 10.1016/J. MSEA.2014.12.099

[48] Xie C, Wang YN, Fang QH, Ma TF, Zhang AB, Peng WF, et al. Effects of cooperative grain boundary sliding and migration on the particle cracking of fine-grained magnesium alloys. Journal of Alloys and Compounds. 2017;704:641-648. DOI: 10.1016/j. jallcom.2017.02.057

[49] Wu MS, Nazarov AA, Zhou K. Misorientation dependence of the energy of symmetrical tilt boundaries in hcp metals: Prediction by the disclinationstructural unit model. Philosophical Magazine. 2006;84:785-806. DOI: $10.1080 / 14786430310001646817$

[50] Xu J, Guo B, Shan D. Severe plastic deformation techniques. In: Severe Plastic Deformation Technology. InTech; 2017. DOI: 10.5772/ intechopen.69503

[51] Kim WJ, Taleff E, Sherby OD. A proposed deformation mechanism for high strain-rate superplasticity. Scripta Metallurgica et Materialia. 1995;32:1625-1630. DOI: 10.1016/0956-716X(95)00246-R

[52] Nakahigashi J, Yoshimura H. Superplasticity and its application of ultra-fine grained $\mathrm{Ti}-6 \mathrm{Al}-4 \mathrm{~V}$ alloy obtained through protium treatment. Metallurgical and Materials. 2002;43:2768-2772

[53] Neishi K, Horita Z, Langdon TG. Achieving superplasticity in ultrafine-grained copper: Influence of $\mathrm{Zn}$ and $\mathrm{Zr}$ additions. Materials
Science and Engineering A.

2003;352:129-135. DOI: 10.1016/

S0921-5093(02)00868-7

[54] Ma ZY, Liu FC, Mishra RS.

Superplastic deformation

mechanism of an ultrafine-grained

aluminum alloy produced by friction

stir processing. Acta Materialia.

2010;58:4693-4704. DOI: 10.1016/J.

ACTAMAT.2010.05.003

[55] Yuzbekova D, Mogucheva A, Kaibyshev R. Superplasticity of ultrafine-grained Al-Mg-Sc-Zr alloy. Materials Science and Engineering A. 2016;675:228-242. DOI: 10.1016/J. MSEA.2016.08.074

[56] Kawasaki M, Langdon T. Developing superplasticity in ultrafine-grained metals. Acta Physica Polonica A. 2015;128:470-478. DOI: 10.12693/ APhysPolA.128.470

[57] Langdon TG. Achieving superplasticity in ultrafine-grained metals. Mechanics of Materials. 2013;67:2-8. DOI: 10.1016/J. MECHMAT.2013.06.005

[58] Kawasaki M, Langdon TG.

Evaluating the flow processes in ultrafine-grained materials at elevated temperatures. Materials Research. 2013;16:565-570

[59] Lee S, Horita ZJ. Superplasticity of ultra-fine grained 7075 alloy processed by high-pressure torsion. Materials Science Forum. 2014;794-796:807-810. DOI: $10.4028 /$ www.scientific.net/ MSF.794-796.807

[60] Bobruk EV, Murashkin MY, Lomakin IV, Kazykhanov VU, Valiev RZ. Low temperature superplasticity of high-strength ultrafine-grained Al 7050 alloy. IOP Conference Series. Materials Science and Engineering. 2019;461:1-6. DOI: 10.1088/1757-899X/461/1/012090 
[61] Edalati K, Masuda T, Arita M, Furui M, Sauvage X, Horita Z, et al. Room-temperature superplasticity in an ultrafine-grained magnesium alloy. Scientific Reports. 2017;7:2662. DOI: 10.1038/s41598-017-02846-2

[62] Kim D, Won JW, Park CH, Hong JK, Lee T, Lee CS. Enhancing superplasticity of ultrafine-grained Ti-6Al-4V without imposing severe plastic deformation. Advanced Engineering Materials. 2019;21:1-4. DOI: 10.1002/ adem.201800115

[63] Mishra RS, McFadden SX, Mukherjee AK. Analysis of tensile superplasticity in nanomaterials. Materials Science Forum. 1999; 304-306:31-38. DOI: 10.4028/www. scientific.net/MSF.304-306.31

[64] Ovid'ko IA. Superplasticity and ductility of superstrong nanomaterials. Reviews on Advanced Materials Science. 2005;10:89-104

[65] Warner DH, Sansoz F, Molinari JF. Atomistic based continuum investigation of plastic deformation in nanocrystalline copper. International Journal of Plasticity. 2006;22:754-774. DOI: 10.1016/J.IJPLAS.2005.04.014

[66] Sergueeva AV, Mara NA, Mukherjee AK. Grain boundary sliding in nanomaterials at elevated temperatures. Journal of Materials Science. 2007;42:1433-1438. DOI: 10.1007/s10853-006-0697-0

[67] Van Swygenhoven H, Derlet PM. Grain-boundary sliding in nanocrystalline fcc metals. Physical Review B. 2001;64:224105. DOI: 10.1103/PhysRevB.64.224105

[68] Seo JH, Yoo Y, Park NY, Yoon SW, Lee H, Han S, et al. Superplastic deformation of defect-free Au nanowires via coherent twin propagation. Nano Letters. 2011;11:3499-3502. DOI: 10.1021/nl2022306
[69] Ovid'ko IA, Skiba NV. Nanotwins induced by grain boundary deformation processes in nanomaterials. Scripta Materialia. 2014;71:33-36. DOI: 10.1016/J.SCRIPTAMAT.2013.09.028

[70] Valiev RZ, Islamgaliev RK, Semenova IP. Superplasticity in nanostructured materials: New challenges. Materials Science and Engineering A. 2007;463:2-7. DOI: 10.1016/J.MSEA.2006.08.121

[71] Alizadeh R, Mahmudi R, Ngan AHW, Huang Y, Langdon TG. Superplasticity of a nano-grained Mg-Gd-Y-Zr alloy processed by highpressure torsion. Materials Science and Engineering A. 2016;651:786-794. DOI: 10.1016/j.msea.2015.10.094

[72] Edalati K, Horita Z, Valiev RZ. Transition from poor ductility to room-temperature superplasticity in a nanostructured aluminum alloy. Scientific Reports. 2018;8:6740. DOI: 10.1038/s41598-018-25140-1

[73] Mansoor B, Ghosh AK. Microstructure and tensile behavior of a friction stir processed magnesium alloy. Acta Materialia. 2012;60:5079-5088. DOI: 10.1016/j. actamat.2012.06.029

[74] Witkin D, Lee Z, Rodriguez R, Nutt S, Lavernia E. Al-Mg alloy engineered with bimodal grain size for high strength and increased ductility. Scripta Materialia. 2003;49:297-302. DOI: 10.1016/S1359-6462(03)00283-5

[75] Oskooie MS, Asgharzadeh H, Kim HS. Microstructure, plastic deformation and strengthening mechanisms of an Al-Mg-Si alloy with a bimodal grain structure. Journal of Alloys and Compounds. 2015;632:540-548. DOI: 10.1016/j. jallcom.2015.01.229

[76] Wang Y, Chen M, Zhou F, Ma E. High tensile ductility in a 
nanostructured metal. Nature.

2002;419:912-914

[77] Cáceres CH, Selling BI. Casting defects and the tensile properties of an AlSiMg alloy. Materials Science and Engineering A. 1996;220:109-116. DOI: 10.1016/S0921-5093(96)10433-0

[78] Begum S, Chen DL, Xu S, Luo AA. Low cycle fatigue properties of an extruded AZ31 magnesium alloy. International Journal of Fatigue. 2009;31:726-735. DOI: 10.1016/J. IJFATIGUE.2008.03.009

[79] Perron A, Politano O, Vignal V. Grain size, stress and surface roughness. Surface and Interface Analysis. 2008;40:518-521. DOI: 10.1002/sia.2849

[80] Liu WC, Dong J, Zhang P, Korsunsky AM, Song X, Ding WJ. Improvement of fatigue properties by shot peening for Mg-10Gd-3Y alloys under different conditions. Materials Science and Engineering A. 2011;528:5935-5944. DOI: 10.1016/j. msea.2011.04.004

[81] Figueiredo RB, Sabbaghianrad S, Giwa A, Greer JR, Langdon TG. Evidence for exceptional low temperature ductility in polycrystalline magnesium processed by severe plastic deformation. Acta Materialia. 2017;122:322-331. DOI: 10.1016/j.actamat.2016.09.054

[82] Watanabe $H$, Tsutsui $H$, Mukai T, Kohzu M, Tanabe S, Higashi K. Deformation mechanism in a coarsegrained $\mathrm{Mg} \pm \mathrm{Al} \pm \mathrm{Zn}$ alloy at elevated temperatures. International Journal of Plasticity. 2001;17:387-397

[83] Fan W, Kashyap BP, Chaturvedi MC. Effect of layered microstructure and its evolution on superplastic behaviour of AA 8090 Al-Li alloy. Materials Science and Technology. 2001;17:439-445

[84] Pancholi V, Kashyap B. Effect of local strain distribution on concurrent microstructural evolution during superplastic deformation of Al-Li 8090 alloy. Materials Science and Engineering A. 2003;351:174-182. DOI: 10.1016/ S0921-5093(02)00849-3

[85] Pradeep S, Pancholi V. Superplastic forming of multipass friction stir processed aluminum-magnesium alloy. Metallurgical and Materials Transactions A: Physical Metallurgy and Materials Science. 2014;45:6207-6216. DOI: $10.1007 / \mathrm{s} 11661-014-2573-\mathrm{x}$

[86] Álvarez-Leal M, Orozco-Caballero A, Carreño F, Ruano OA. Superplasticity in a commercially extruded ZK30 magnesium alloy. Materials Science and Engineering A. 2018;710:240-244. DOI: 10.1016/J.MSEA.2017.10.093

[87] Pradeep S, Pancholi V. Effect of microstructural inhomogeneity on superplastic behaviour of multipass friction stir processed aluminium alloy. Materials Science and Engineering A. 2013;561:78-87

[88] Raja A, Biswas P, Pancholi V. Effect of layered microstructure on the superplasticity of friction stir processed AZ91 magnesium alloy. Materials Science and Engineering A. 2018;725:492-502. DOI: 10.1016/J.MSEA.2018.04.028

[89] Dunne FPE. Inhomoneneity of microstructure in superplasticity and its effect on ductility. International Journal of Plasticity. 1998;14:413-433

[90] Pancholi V, Raja A, Rohit K. Deformation Behavior of Inhomogeneous Layered Microstructure. 2017. DOI: 10.4028/www.scientific.net/ MSF.879.1437

[91] Gourdet S, Montheillet F. A model of continuous dynamic recrystallization. Acta Materialia. 2003;51:2685-2699

[92] Hallberg H, Wallin M, Ristinmaa M. Modeling of continuous dynamic 
recrystallization in commercial-purity aluminum. Materials Science and Engineering A. 2010;527:1126-1134. DOI: 10.1016/j.msea.2009.09.043

[93] Guo-Zheng Q. Characterization for dynamic recrystallization kinetics based on stress-strain curves. In: Wilson $\mathrm{P}$, editor. Recent Developments in the Study of Recrystallization. London, UK: InTech; 2013. pp. 61-88. DOI: $10.5772 / 54285$ 


\title{
Wear Behaviour of Aluminium Alloy 8011 with 4\% Fly Ash Composites by Using Sensitivity Analysis
}

\author{
Subramaniam Magibalan
}

\begin{abstract}
The current research work is focused on fabrication of Aluminium Alloy 8011 with $4 \%$ fly ash composite (AA8011-4\% FA) by using the stir casting method. Wear behaviour and description of the composite are evaluated in different process parameters by using a pin-on-disc at room temperature. Fly ash (FA) in the range of ( 4 wt. \%, average micron size $10-30 \mu \mathrm{m}$ ) is included into the matrix, and its sensitivity analysis is investigated. Three level of Central Composite Design model is developed by using Response Surface Methodology equation with different process parameters via load, time and sliding velocity are separate in the range of $(5-15 \mathrm{~N}),(5-15 \mathrm{~min})$ and $(1.5-4.5 \mathrm{~m} / \mathrm{s})$ respectively. The surface plot shows that wear rate increases with increasing load, time and sliding velocity. A sensitivity analysis is also carried out and compared with the relative impact of input parameters on wear behaviour in order to verify the measurement errors on the values of the uncertainty in estimated parameters of three inputs such as normal load, time and sliding velocity on wear rate (WR) and coefficient of friction (COF). The result shows that normal load is more sensitive than the other parameters. The variation of load causes more changes in wear rate.
\end{abstract}

Keywords: aluminium alloy 8011 (AA8011), fly ash (FA), response surface methodology (RSM), wear rate (WR), coefficient of friction (COF), sensitivity analysis (SA)

\section{Introduction}

Metal matrix composites (MMCs) occur as an essential category of material used in space and transportation industries. There is an inclusive in dropping the wear in demand to decrease the tradition of material properties and expenditure of energy. This controlling of wear should be considered cautiously from the idea of choosing the alloy composition, reinforcement and additionally the process techniques. The incorporation of hard reinforcement segments, particulates, fibres and whiskers has been capable of these composites through smart tribological characteristics $[2,8$, 12-18].

These reinforcements will either be value-added ex-situ or created as in-situ composites within the dissolved. It is glowing well-known that in-situ supports stay 
of the many smart benefits appreciate wholesome boundary and extraordinary affection power through the medium, homogenously circulated minor parts within the matrix, extraordinary mechanical assets and low cost. In-situ ceramic mixtures appreciate $\mathrm{Al}_{2} \mathrm{O}_{3}$ [23], $\mathrm{TiB}_{2}$ [1] and TiC [24] widely occupied as reinforcements in aluminium fabricated composites.

Aluminium ash composites can be synthesised through the liquid metal stir casting, compo casting (semi-solid processing), changed compo casting and squeeze casting techniques. The stir casting route product is well distributed, moderately agglomerate and consistent free fly ash particle composites [1-4].

AA2011 matrix reinforced with SiC reinforcement (5 \& 10\%) produced by liquid metallurgy route. $\mathrm{SiC}$ abrasive wear rate is increased with increasing applied load, sliding distance and element size compared for $\mathrm{Al}_{2} \mathrm{O}_{3}$ emery paper is used means the wear rate increase of element size, applied load decrease with increasing the sliding distance and at the same time, the abrasive size was more effective for both matrix and composite [5].

AA6061 with 1\% of CNT reinforcement is produced by ball milling and spark plasma process and it is reported that the mild wear rate and friction coefficient are low compared to the monolithic 6061 alloy [6].

The wear rate in a concession of weight loss per unit sliding distance, coefficient of friction and volume loss continues to achieve for the metal matrix composites. The results of the composite show higher wear resistance than matrix metal [7].

AA7075/graphite composite materials with (5-20) wt.\% are fabricated by a liquid casting technique and pin on disc method to calculate the wear rate. The coefficient of friction is compact with the calculation of graphite content and stretched a minimum at $5 \mathrm{wt}$. \% graphite content [8].

Develops the mathematical typical is settled by mistreatment regression analysis methodology for the expectation of damage performance of the MMC besides sufficiency of the prototypical has been valid expending analysis of variance (ANOVA) methods. Finally, the inflation of parameter has in addition been done using style trained software package. The results ensure unprotected that response surface methodology (RSM) may be a smart tool for expectation of wear behaviour below combined sliding and rolling action [9].

Develops a regression prototypical is valid by normal mathematics code SYSTAT 12 and normal arithmetic tools equivalent to analysis of variance (ANOVA) and student's t-check. It has been found that establishing the regression prototypical is also effectively wished to calculate the wear rate at 95\% confidence level and expected trends are mentioned with the assistance of worn surface morphologies. The results of the composite show higher wear of the metal matrix [10].

Develops a mathematical model to predict the wear rate of AA6061/ (0-10\%) $\mathrm{ZrB}_{2}$ in-situ composites. The factors thought of area unit sliding speed, sliding distance, traditional load and mass fraction of $\mathrm{ZrB}_{2}$ particles. The impact of those factors on the damage proportion of the made-up composite is examined and additionally, the expected trends are mentioned by perceptive the injury surface morphologies [11].

Sensitivity analysis of the process parameters of gas metal arc welding process of welding speed, voltage and current. Based on the result, we represent the success of the processing parameters and showed that the change of process parameters influences the bead width and bead height with further strong penetration [19].

The effect of welding on flux cored arc welding material of $317 \mathrm{~L}$ on a structural steel plate. The process parameters used in the experiment were welding current, speed and nozzle to plate distance. Sensitivity analysis has been applied to find out the process parameters with the most influence on the bead geometry. Sensitivity 
analysis shows that bead width, dilution, area of penetration and coefficient of internal shape are mostly affected by the change of process parameters [20].

We investigated the sensitivity analysis of weld bead parameters such as bead width, bead height and penetration to variations in current, voltage and speed in the submerged arc welding process. The result shows that bead width is more sensitive to voltage and speed variations than bead height and penetration [21].

Sensitivity analysis to predict the tensile strength of friction stir welded alloy AA7039 aluminium. Based on the result they concluded, it was found that the sensitivities of rotational speed cause large changes in tensile strength when the RPM increases compared with welding RPM and axial force [22].

In the present work, an attempt is made to develop a mathematical model to calculate the wear rate of (AA8011-4\% FA) composite and analyse the impact of normal load $(\mathrm{N})$, time $(\mathrm{min})$ and sliding velocity $(\mathrm{m} / \mathrm{sec})$ on wear rate and coefficient of friction. Interestingly, mathematical models are conducted consistent with central composite rotatable utilised. Mathematical models are established to predict the impact of method constraints on the responses. Finally, the sensitivity results are compared and verified with the experimental result.

\section{Dry sliding wear test}

The tribological properties of the samples were assessed using a dry sliding wear test for different number of specimens by using a pin-on-disc machine as shown in Table 1.

Figure 1 reveals that the surface of each pin and disc is clean with a soft paper soaked in resolving before actual testing. The fabric loss from the composite surface is measured employing exactness electronic balancing machine with an accuracy of $\pm 0.0001 \mathrm{~g}$. Wear rate is unique of the maximum significant criteria on behalf of formative the pin-on-disc operation. Higher wear rate is always preferred in such operations. Wear rate was measured from the weight loss. Each trial was repeated twice and the average weight loss was taken for the analysis of wear rate. In this study, the machining performance and the mathematical model were evaluated

\begin{tabular}{ccc}
\hline S.No. & Description & Details \\
\hline 1. & Make \& Model & DUCOM, TR-20LE-PHM-400 \\
\hline 2. & Normal load range & $5-15 \mathrm{~N}$ \\
\hline 3. & Disc speed & $100-1000 \mathrm{rpm}$ \\
\hline 4. & Pre-set timer range & $5-15 \mathrm{~min}$ \\
\hline 5. & Wear disc thickness & 8 mm (EN 31 steel (C, 1.00\%; Si, 0.20\%; Mn, 0.50\%; Cr, \\
& & $1.40 \% ;$ hardness of $60 \mathrm{HRC})$ \\
\hline 6. & Wear disc track diameter & $90 \mathrm{~mm}$ \\
\hline 7. & Specimen pin diameter & $10 \mathrm{~mm}$ \\
\hline 8. & Pin length & G99 mm \\
\hline 9. & ASTM standard & Wear, friction, COF and temperature. \\
\hline 10. & Measurement and real-time & \\
\hline
\end{tabular}

Table 1.

Specification of wear testing equipment. 

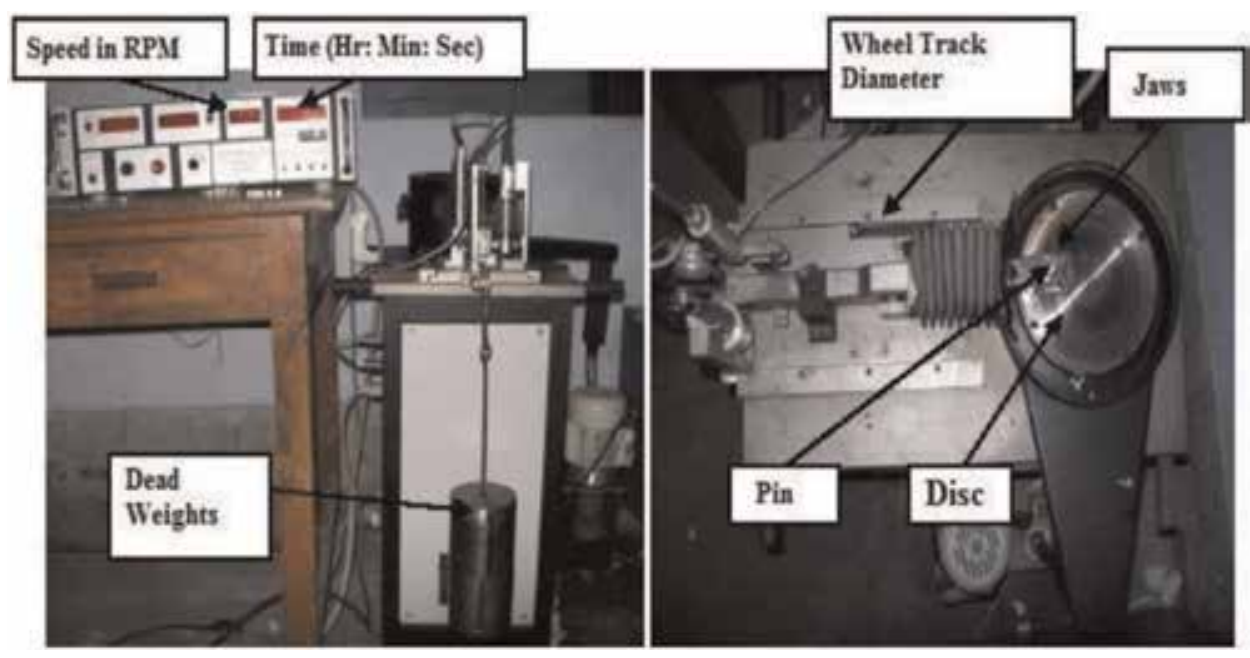

Figure 1.

Pin-on-disc wear experimental setup.

using Eqs. (1) and (2). Tables 2 and 3 show that the setup of the experiment was designed on the idea of the central composite design (CCD) technique.

$$
\text { Wear rate }(\mathrm{g} / \mathrm{min})=\frac{\begin{array}{c}
\text { metalremoved } \\
(\text { part })
\end{array}}{(\text { Timeofmachining })}
$$

The factorial portion of CCD is a full factorial design with all mixtures of the factors at three levels $(+1,0,-1)$ and composed of the eight-star points and six central points (coded level 0 ), which were the centre between the high and the low levels. The star points were at the face-centre of the cube portion that corresponds to an $\alpha$ value of 1 and this sort of design was usually known as the "face-centred CCD.” The tests were conducted using stipulated conditions in keeping with the face-centred CCD with 20 experimental observations at three independent input variables [15-18].

$$
Y_{u}=b_{o}+\sum_{i=1}^{k} b_{i} x_{i}+\sum_{i=1}^{k} b_{i i} x^{2}{ }_{i}+\sum_{j>1}^{k} b_{i j} x_{i} x_{j}
$$

$\mathrm{Y}_{\mathrm{U}}$ is the response.

$x_{i}(1,2 \ldots k)$ is the coded levels of $k$ numerical variables.

$b_{0}$-endless term.

$b_{i}$-linear term.

$b_{i i}$-quadratic term.

$b_{i j}$-interaction term.

\begin{tabular}{lccc}
\hline Parameter & -1 & 0 & 1 \\
\hline Load $(\mathrm{N})$ & 5 & 10 & 15 \\
\hline Time $(\mathrm{min})$ & 5 & 10 & 15 \\
\hline Sliding velocity $(\mathrm{m} / \mathrm{sec})$ & 1.5 & 3 & 4.5 \\
\hline
\end{tabular}

Table 2.

Process parameters and their levels. 
Wear Behaviour of Aluminium Alloy 8011 with 4\% Fly Ash Composites by Using Sensitivity... DOI: http://dx.doi.org/10.5772/intechopen.89554

\begin{tabular}{|c|c|c|c|c|c|}
\hline Run & Load $(N)$ & Time (min) & Sliding velocity $(\mathrm{m} / \mathrm{sec})$ & $\mathrm{WR}(\mathrm{g} / \mathrm{min}) \times 10^{-5}$ & $\operatorname{COF}(\mu) \times 10^{-2}$ \\
\hline 1 & 5 & 5 & 1.5 & 342 & 55.9 \\
\hline 2 & 15 & 5 & 1.5 & 434 & 37.2 \\
\hline 3 & 5 & 15 & 1.5 & 372 & 49.7 \\
\hline 4 & 15 & 15 & 1.5 & 484 & 54.2 \\
\hline 5 & 5 & 5 & 4.5 & 428 & 36.9 \\
\hline 6 & 15 & 5 & 4.5 & 534 & 33.4 \\
\hline 7 & 5 & 15 & 4.5 & 454 & 26.6 \\
\hline 8 & 15 & 15 & 4.5 & 585 & 45.2 \\
\hline 9 & 5 & 10 & 3.0 & 422 & 52.3 \\
\hline 10 & 15 & 10 & 3.0 & 535 & 52.3 \\
\hline 11 & 10 & 5 & 3.0 & 398 & 34.4 \\
\hline 12 & 10 & 15 & 3.0 & 434 & 37.5 \\
\hline 13 & 10 & 10 & 1.5 & 380 & 38.3 \\
\hline 14 & 10 & 10 & 4.5 & 466 & 24.9 \\
\hline 15 & 10 & 10 & 3.0 & 430 & 38.2 \\
\hline 16 & 10 & 10 & 3.0 & 435 & 38.0 \\
\hline 17 & 10 & 10 & 3.0 & 434 & 38.4 \\
\hline 18 & 10 & 10 & 3.0 & 430 & 38.6 \\
\hline 19 & 10 & 10 & 3.0 & 432 & 38.4 \\
\hline 20 & 10 & 10 & 3.0 & 432 & 38.2 \\
\hline
\end{tabular}

Table 3.

Design of experiment matrix and wear characteristics.

\subsection{Design of experiment}

In this study, a second-order polynomial was selected to develop empirical equations to represent responses (wear rate and COF) in terms of controllable variables such as normal load (A), time (B) and sliding velocity (C). The final response equations were developed for wear rate and COF using the experimental results.

This mathematical prototypical has been achieved to reproduce the independent, quadratic and interactive effects of some machining parameters on the machined for wear rate (WR) and coefficient of friction (COF). The empirical relationship for correlating the WR and COF the thought of dry sliding wear method parameters is obtained as follows:

$$
\begin{aligned}
\mathrm{WR}(\mathrm{g} / \min ) \times 10^{-5}= & 317.31-30.17 \mathrm{~A}+14.41 \mathrm{~B}+48.85 \mathrm{C}+1.8673 \mathrm{~A}^{2} \\
& -0.6327 \mathrm{~B}^{2}-3.919 \mathrm{C}^{3}+0.2250 \mathrm{~A} \times \mathrm{B}+0.550 \mathrm{~A} \times \mathrm{C} \\
& -0.050 \mathrm{~B} \times \mathrm{C}
\end{aligned}
$$

$$
\begin{aligned}
\operatorname{COF}(\mu) \times 10^{-2}= & 97.512-14.661 \mathrm{~A}+0.639 \mathrm{~B}+10.816 \mathrm{C}+0.54745 \mathrm{~A}^{2} \\
& -0.10655 \mathrm{~B}^{2}-3.1172 \mathrm{C}^{2}+0.22650 \mathrm{~A} \times \mathrm{B}+0.4883 \mathrm{~A} \times \mathrm{C} \\
& -0.1550 \mathrm{~B} \times \mathrm{C}
\end{aligned}
$$


Normal Probability Plot

(response is WR (g/min) x10-5)

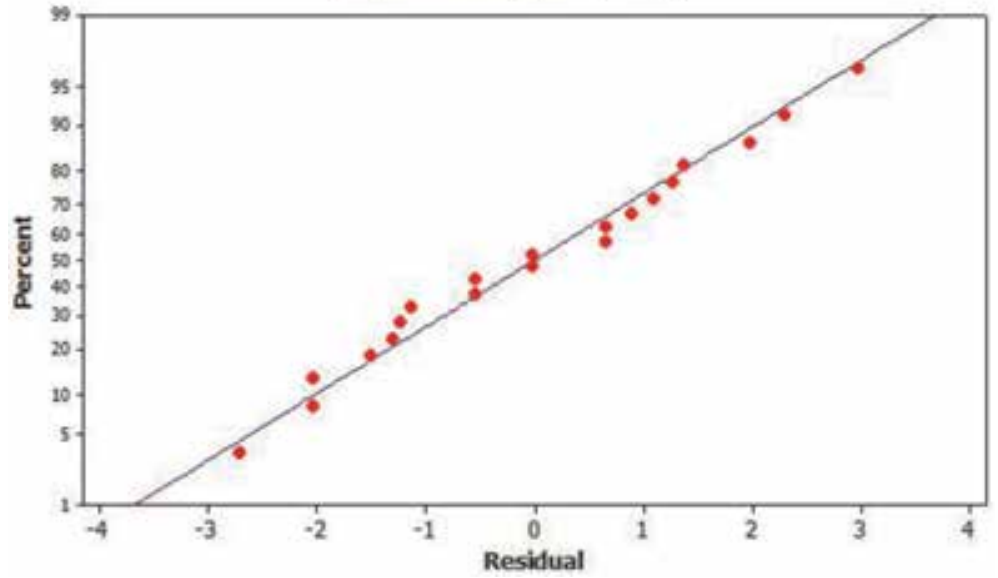

Figure 2.

Standard probability plot for wear rate.

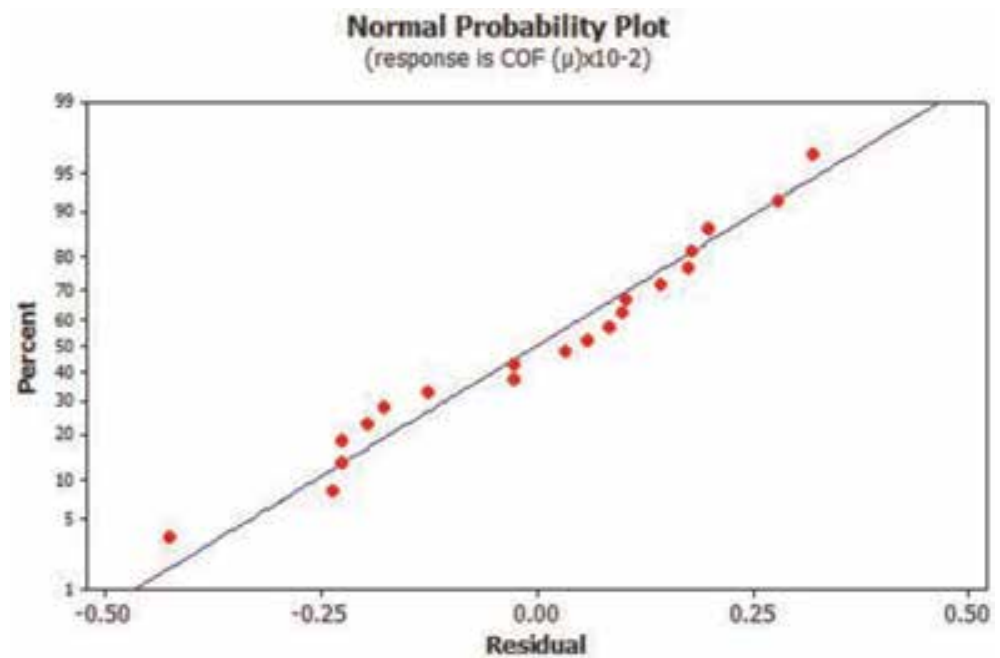

Figure 3.

Standard probability plot for COF.

\begin{tabular}{lccccc}
\hline Source & DF & Adj SS & Adj MS & F-value & P-value \\
\hline Model & 9 & 61981.7 & 6886.86 & 1458.03 & 0.000 \\
\hline Linear & 3 & 3875.2 & 1291.72 & 273.47 & 0.000 \\
\hline Square & 3 & 6472.3 & 2157.45 & 456.76 & 0.000 \\
\hline 2-Way interaction & 3 & 390.4 & 130.12 & 27.55 & 0.000 \\
\hline Error & 10 & 47.2 & 4.72 & & \\
\hline Lack-of-fit & 5 & 26.4 & 5.28 & 1.27 & 0.401 \\
\hline Pure error & 5 & 20.8 & 4.17 & & \\
\hline Total & 19 & 62029.0 & & $\mathrm{R}^{2}=99.92 \%$ & \\
\hline
\end{tabular}

Table 4.

Analysis of variance table for wear rate. 
Wear Behaviour of Aluminium Alloy 8011 with 4\% Fly Ash Composites by Using Sensitivity... DOI: http://dx.doi.org/10.5772/intechopen.89554

\begin{tabular}{lccccc}
\hline Source & DF & Adj SS & Adj MS & F-value & P-value \\
\hline Model & 9 & 1400.34 & 15.559 & 2051.03 & 0.000 \\
\hline Linear & 3 & 490.29 & 163.429 & 2154.31 & 0.000 \\
\hline Square & 3 & 535.42 & 178.475 & 2352.64 & 0.000 \\
\hline 2-Way interaction & 3 & 374.63 & 124.878 & 1646.13 & 0.000 \\
\hline Error & 10 & 0.76 & 0.076 & & \\
\hline Lack-of-fit & 5 & 0.54 & 0.108 & 2.45 & 0.174 \\
\hline Pure error & 5 & 0.22 & 0.044 & & \\
\hline Total & 19 & 1401.10 & & $\mathrm{R}^{2}=99.95 \%$ & \\
\hline
\end{tabular}

Table 5.

Analysis of variance table for COF.

Eq. (3) and (4) develop empirical models based on the composite desirability optimisation technique. Figures 2 and 3 show that the experimental values and predicted values from the mathematical model are scattered on both sides and close to $45^{\circ}$ line, which further proves the adequacy of the model.

The normal percentage point of F-ratio dispersal for 95\% confidence limit is 5.05 as shown in Tables 4 and 5. The F -values (1.27 and 2.45) aimed at deficiency of adequate are lesser than the normal value. Thus WR and COF the prototypically stand adequate.

\section{Sensitivity analysis}

After eliminating the non-significant terms in Eq. (3) and (4), the final response equations for wear rate and coefficient of friction are given below.

$$
\begin{aligned}
\mathrm{WR}(\mathrm{g} / \mathrm{min}) \times 10^{-5}= & 317.31-30.17 \mathrm{~A}+14.41 \mathrm{~B}+48.85 \mathrm{C}+1.8673 \mathrm{~A}^{2} \\
& -0.6327 \mathrm{~B}^{2}-3.919 \mathrm{C}^{2}+0.2250 \mathrm{~A} \times \mathrm{B}+0.550 \mathrm{~A} \times \mathrm{C} \\
\mathrm{COF}(\mu) \times 10^{-2}= & 97.512-14.661 \mathrm{~A}+0.639 \mathrm{~B}+10.816 \mathrm{C}+0.54745 \mathrm{~A}^{2} \\
- & 0.10655 \mathrm{~B}^{2}-3.1172 \mathrm{C}^{2}+0.22650 \mathrm{~A} \times \mathrm{B}+0.4883 \mathrm{~A} \times \mathrm{C} \\
- & 0.1550 \mathrm{~B} \times \mathrm{C}
\end{aligned}
$$

From the developed mathematical Eqs. (5) and (6) to be used for the estimation of wear rate and coefficient of friction, the sensitivity equations are obtained by differentiating Eqs. (5) and (6) with respect to process parameters of load (A), time (B), and sliding velocity (C) as given below.

$$
\begin{aligned}
& \frac{\mathrm{dWR}}{\mathrm{dA}}=-30.17+1.8673 * 2 \mathrm{~A}+0.2250 \mathrm{~B}+0.550 \mathrm{C} \\
& \frac{\mathrm{dCOF}}{\mathrm{dA}}=-14.661+0.5475 * 2 \mathrm{~A}+0.2265 \mathrm{~B}+0.4883 \mathrm{C} \\
& \quad \frac{\mathrm{dWR}}{\mathrm{dB}}=14.41-0.6327 * 2 \mathrm{~B}+0.2250 \mathrm{~A} \\
& \frac{\mathrm{dCOF}}{\mathrm{dB}}=0.639-0.1065 * 2 \mathrm{~B}+0.2265 \mathrm{~A}-0.1550 \mathrm{C}
\end{aligned}
$$




$$
\begin{gathered}
\frac{\mathrm{dWR}}{\mathrm{dC}}=48.85-3.919 * 2 \mathrm{C}+0.550 \mathrm{~A} \\
\frac{\mathrm{dCOF}}{\mathrm{dC}}=10.816-3.1172 * 2 \mathrm{C}+0.4883 \mathrm{~A}-0.1550 \mathrm{~B}
\end{gathered}
$$

Results of WR and COF for sensitivities of load, time, sliding velocity on WR and COF are presented in Tables 6 and 7.

\begin{tabular}{lccc}
\hline \multirow{2}{*}{ Load $(N)$} & \multicolumn{3}{c}{$\boldsymbol{B}=\mathbf{1 0} \mathbf{~ m i n}, C=\mathbf{~ m} / \mathbf{s e c}$} \\
\cline { 2 - 4 } & $\frac{\mathrm{dWR}}{\mathrm{dA}}$ & $\frac{\mathrm{dWR}}{\mathrm{dB}}$ & $\frac{\mathrm{dWR}}{\mathrm{dC}}$ \\
\hline 5 & -34.6796 & 15.4504 & 56.1380 \\
\hline 10 & -30.1700 & 14.4100 & 48.8500 \\
\hline 15 & -25.6604 & 13.3696 & 41.5620 \\
\hline
\end{tabular}

Table 6.

Wear rate for sensitivities of process parameters.

\begin{tabular}{lccc}
\hline Load (N) & \multicolumn{3}{c}{$\boldsymbol{B = 1 0} \mathbf{~} \mathbf{m i n}, \boldsymbol{C}=\mathbf{3} \mathbf{~ \mathbf { s e c }}$} \\
\cline { 2 - 4 } & $\frac{\mathrm{dCOF}}{\mathrm{dA}}$ & $\frac{\mathrm{dCOF}}{\mathrm{dB}}$ & $\frac{\mathrm{dCOF}}{\mathrm{dC}}$ \\
\hline 5 & -16.4708 & 0.7805 & 16.7171 \\
\hline 10 & -14.6610 & 0.6390 & 10.8160 \\
\hline 15 & -12.8512 & 0.4975 & 4.9149 \\
\hline
\end{tabular}

Table 7.

COF for sensitivities of process parameters.

\section{Results and discussion}

\subsection{Effects of load and time on wear rate}

The influence of response surface plot for wear rate is shown in Figure 4. Wear rate increases with the increase of applied load, but the time also increases when wear rate increases. The frictional heat can result in excessive deterioration of the composite transfer from materials to the disc counterpart. The increase of applied load inspiration to disproportionate damage of the composite and thus results shows an increase in wear rate.

\subsection{Effect of time and sliding velocity on COF}

In Figure 5 shows that the impression residues, the disc considerable develops worn and guarded material derives currently contact with the pin, scratching of the disc shallow origins the ploughing and later friction coefficient increase with a period of impression. After the period of impression the expansion of irregularity and alternative constraints might influence a particular solid value. Therefore, the standards of friction coefficient endure endless for the repose. This can be described by the mechanism that with the wear occurrence below process, supplementary fly ash particles are made with the effect of sliding velocity, consequently, the being of the fly ash disturbs at the connected area and intersection asset and so subsidises directly to the complex level of friction coefficient. 
Wear Behaviour of Aluminium Alloy 8011 with 4\% Fly Ash Composites by Using Sensitivity... DOI: http://dx.doi.org/10.5772/intechopen.89554

\section{Surface Plot of WR ( $g / \mathrm{min}) \times 10-5$ vs Time ( $\min )$, Load $(\mathrm{N})$}

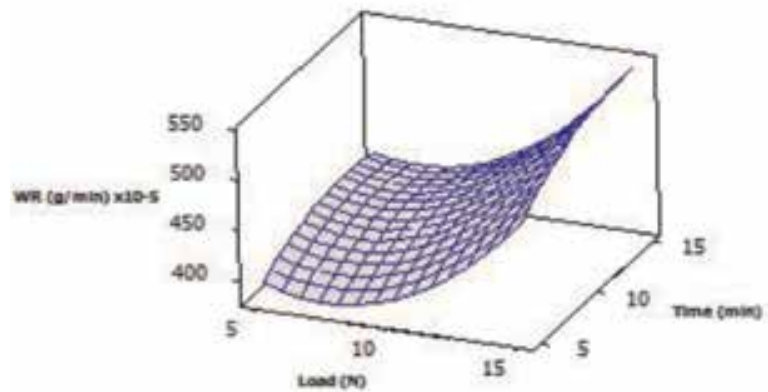

Figure 4 .

Effects of load and time on the wear rate.

Surface Plot of COF $(\mu) \times 10-2$ vs Sliding Velocity $(\mathrm{m} / \mathrm{sec})$, Load $(N)$

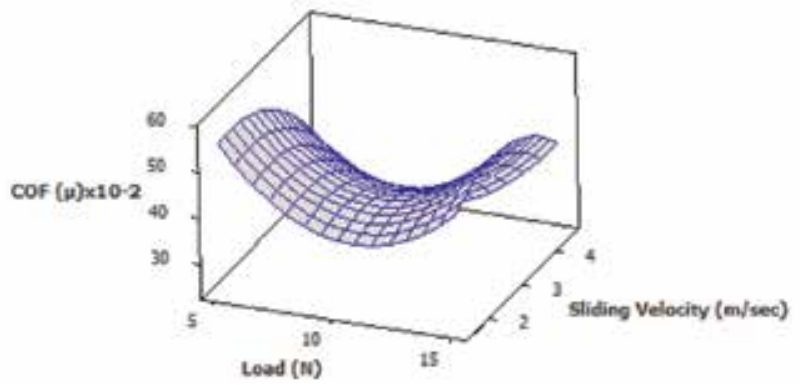

Figure 5 .

Influence of time and sliding velocity on COF.

$$
B=10 \mathrm{~min}, \mathrm{C}=3 \mathrm{~m} / \mathrm{sec}
$$

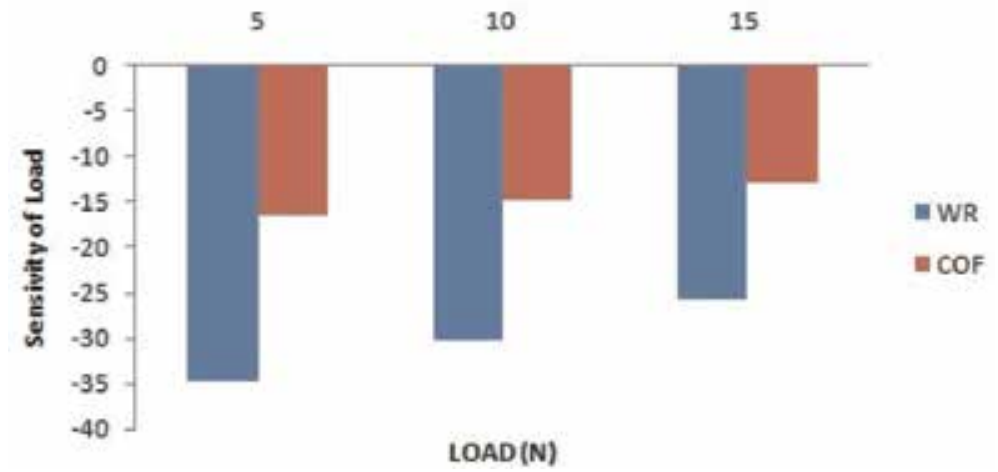

Figure 6.

Sensitivity analysis results of load. 


\section{$B=10 \mathrm{~min}, \mathrm{C}=3 \mathrm{~m} / \mathrm{sec}$}

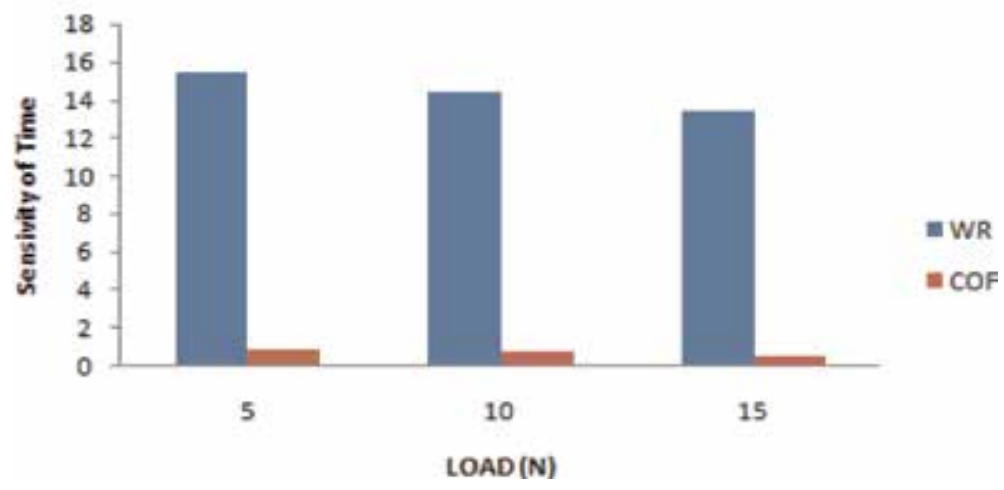

Figure 7.

Sensitivity analysis results of time.

\section{$B=10 \mathrm{~min}, \mathrm{C}=3 \mathrm{~m} / \mathrm{sec}$}

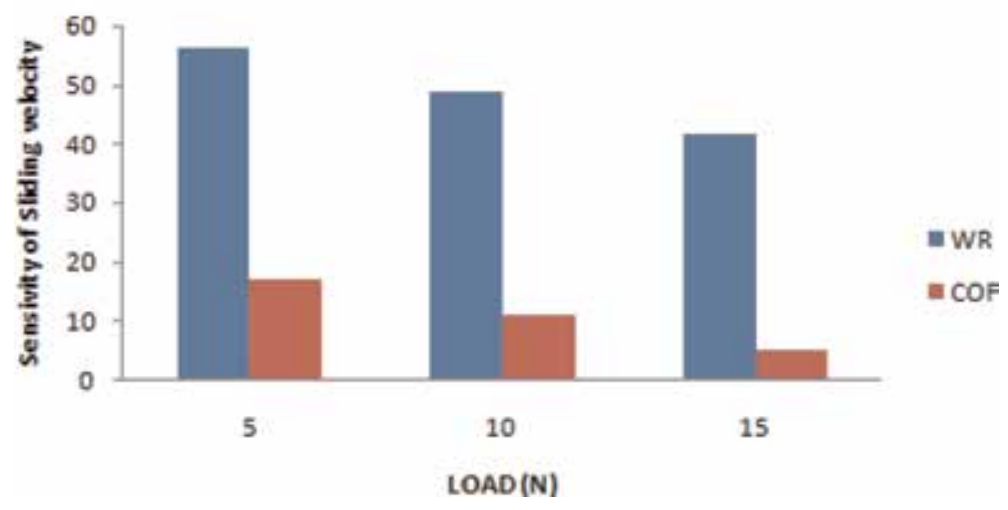

Figure 8.

Sensitivity analysis results of sliding velocity.

\subsection{Sensitivity analysis}

Figure 6 highlights the sensitivity analysis of load for WR and COF. Sensitivity analysis of load for WR and COF is negative for lower load values and it is negative as the value of sensitivity of load increases. Figure 7 illustrates the time sensitivity. Time sensitivity for WR is positive for lower load values and it is positive as the value of sensitivity of load increases and COF remains unchanged. Figure 8 reveals sliding velocity sensitivity. Sliding velocity sensitivity for WR is positive and increases with increase in load. COF is positive with increase in load.

\section{Conclusions}

- The developed regression prototypical is with success match the nearest predicted wear rate of cast AA 8011 - 4\% fly ash composites at $95 \%$ confidence level within the range of investigation.

- The wear rate of composite compound values strongly depends on the investigational limits, that is, normal load, time and sliding velocity. 
Wear Behaviour of Aluminium Alloy 8011 with 4\% Fly Ash Composites by Using Sensitivity... DOI: http://dx.doi.org/10.5772/intechopen.89554

- Wear rate increases as the sliding speed increases due to work hardening of the surface and crushing of the fly ash particles. The WR rises with the raise of the normal load. It is attributed to excessive damage to the composite. Wear rate increases dependably with regular interval due to deduction of the majority of the materials when exposed to sliding force.

- COF growths through an increase in sliding speed, whereas increase in coefficient of friction normal load decreases then before rises. The assessment of friction coefficient is raised nearly linear up to 10 minutes of impression and subsequently rests to constant.

- Response surface methodology has the potential for more stringent sensitivity analysis and may be used for optimal parameter estimation for other mathematical models.

\section{Author details}

Subramaniam Magibalan

Department of Mechanical Engineering, K.S.R. College of Engineering, Tiruchengode, Tamil Nadu, India

*Address all correspondence to: magibalan42@gmail.com

\section{IntechOpen}

(C) 2019 The Author(s). Licensee IntechOpen. This chapter is distributed under the terms of the Creative Commons Attribution License (http://creativecommons.org/licenses/ by/3.0), which permits unrestricted use, distribution, and reproduction in any medium, provided the original work is properly cited. (c) BY 


\section{References}

[1] Suresh S, Moorthi NSV, Vettivel SC, Selvakumar N. Mechanical behavior and wear prediction of stir cast $\mathrm{Al}-\mathrm{TiB}_{2}$ composites using response surface methodology. Materials \& Design. 2014; 59:383

[2] Radhika N, Raghu R. Dry sliding wear behaviour of aluminium $\mathrm{Al}_{-}$ $\mathrm{Si}_{2} \mathrm{Cu} / \mathrm{TiB}_{2}$ metal matrix composite using response surface methodology. Tribology Letters. 2015;59(1):2

[3] Baradeswaran A, Vettivel SC, Perumal AE, Selvakumar N, Issac RF. Experimental investigation on mechanical behaviour, modelling and optimization of wear parameters of $\mathrm{B}_{4} \mathrm{C}$ and graphite reinforced aluminium hybrid composites. Materials \& Design. 2014;63:620

[4] Koksal S, Ficici F, Kayikci R, Savas O. Experimental optimization of dry sliding wear behavior of in situ $\mathrm{AlB}_{2} / \mathrm{Al}$ composite based on Taguchi's method. Materials \& Design. 2012;42:124

[5] Sahin Y. Wear behaviour of aluminium alloy and its composites reinforced by $\mathrm{SiC}$ particles using statistical analysis. Materials \& Design. 2003;24(2):95

[6] Al-qutub AM, Khalil A, Saheb N, Hakeem AS. Wear and friction behavior of Al6061 alloy reinforced with carbon nanotubes. Wear. 2013;297(1):752

[7] Rao VR, Ramanaiah N, Sarcar MMM. Tribological properties of aluminium metal matrix composites (AA7075 reinforced with titanium carbide $(\mathrm{TiC})$ particles). International Journal of Advanced Science and Technology. 2016;88:13

[8] Baradeswaran A, Elayaperumal A. Effect of graphite on tribological and mechanical properties of AA7075 composites. Tribology Transactions. 2015;58(1):1
[9] Mandal N, Roy H, Mondal B, Murmu NC, Mukhopadhyay SK. Mathematical modeling of wear characteristics of 6061 Al-alloy-SiCp composite using response surface methodology. Journal of Materials Engineering and Performance. 2012;21(1):17

[10] Kumar BA, Murugan N, Dinaharan I. Dry sliding wear behavior of stir cast AA6061-T6/AlN p composite. Transactions of Nonferrous Metals Society of China. 2014;24(9): 2785

[11] Dinaharan I, Murugan N. Dry sliding wear behavior of AA6061/ZrB 2 in-situ composite. Transactions of Nonferrous Metals Society of China. 2012;22(4):810

[12] Selvi S, Rajasekar E. Theoretical and experimental investigation of wear characteristics of aluminum based metal matrix composites using RSM. Journal of Mechanical Science and Technology. 2015;29(2):785

[13] Basavarajappa S, Chandramohan G. Dry sliding wear behavior of hybrid metal matrix composites. Materials Science. 2005;11(3):253

[14] Rajmohan T, Palanikumar K, Ranganathan S. Evaluation of mechanical and wear properties of hybrid aluminium matrix composites. Transactions of Nonferrous Metals Society of China. 2013;23(9):2509

[15] Senthilkumar C, Ganesan G. Electrical discharge surface coating of EN38 steel with WC/Ni composite electrode. Journal of Advanced Microscopy Research. 2015;10(3):202

[16] Magibalan S, Senthilkumar P, Senthilkumar C, Palanivelu R, Prabu M. Dry sliding behavior of the aluminum alloy 8011 with $4 \%$ fly ash. Materials Testing. 2018;60(2):209 
[17] Magibalan S, Senthilkumar P, Senthilkumar C, Palanivelu R, Prabu M. Dry sliding behavior of the aluminum alloy 8011 with $8 \%$ fly ash. Materials Testing. 2018;60(7-8):777

[18] Magibalan S, Senthilkumar P, Senthilkumar C, Palanivelu R, Shivasankaran N, Prabu M, et al. Materials Research Express. 2018;5(5): 056505

[19] Kim IS, Jeong YJ, Son IJ, Kim IJ, Kim JY, Kim IK, et al. Sensitivity analysis for process parameters influencing weld quality in robotic GMA welding process. Journal of Materials Processing Technology. 2003;140(1-3):676

[20] Palani PK, Murugan N. Sensitivity analysis for process parameters in cladding of stainless steel by flux cored arc welding, Journal of Manufacturing Processes. 2006;8(2):90

[21] KaraoĞlu S, SeÇgin. Sensitivity analysis of submerged arc welding process parameters. Journal of Materials Processing Technology. 2008;202(1-3): 500

[22] Lakshminarayanan AK, Balasubramanian V. Comparison of RSM with ANN in predicting tensile strength of friction stir welded AA7039 aluminium alloy joints. Transactions of Nonferrous Metals Society of China. 2009;19(1):9

[23] Straffelini G, Bonollo F, Molinari A, Tiziani A. Influence of matrix hardness on the dry sliding behaviour of 20 vol.\% Al2O3-particulate-reinforced $6061 \mathrm{Al}$ metal matrix composite, Wear. 1997;211 (2):192

[24] Wang F, Liu H, Yang B. Effect of insitu TiC particulate on the wear resistance of spray-deposited $7075 \mathrm{Al}$ matrix composite. Materials Characterization. 2005;54(4-5):446 



\title{
Experimental Investigations on AA 6061 Alloy Welded Joints by Friction Stir Welding
}

\author{
Pothur Hema
}

\begin{abstract}
Aluminum and aluminum composites play important role in aerospace, automobile, marine and structural applications. Literature shows that some of the conventional fusion welding processes in joining of aluminum metals result in defects like porosity, distortion owing to elevated thermal conductivity and solidification shrinkage. To overcome such issues, experimental investigations are conducted using Friction Stir Welding (FSW) process in joining of metal plates of aluminum 6061 alloy. Weld joint samples are cut to required sizes and secured them in position by mechanical clamps. The setup is loaded onto Vertical Machining Centre. Nonconsumable tool tips of four different shapes of tungsten carbide and $\mathrm{H} 13$ materials are prepared and attached to the spindle. The machine is started and allowed spindle to rotate the tool to plunge onto metal plates along joint line. An axial force is continuously applied until sufficient heat is generated at mating surfaces for joining. Experiments are repeated at different levels by varying welding parameters. Joints are tested for their mechanical properties. The microstructural analysis is studied by SEM. Artificial Neural Network (ANN) simulation model is developed for validation. ANOVA is applied for validation of output results of mechanical properties and optimal process parameters are determined. Research shows that joints are influenced by profile of tool pin and, therefore, the rotational speed of the tool.
\end{abstract}

Keywords: AA6061 alloy, FSW, experiments, machining centre, joints

\section{Introduction}

Hardenable aluminum alloy namely AA6061 has played a key role in the production arena, to meet not only the strength to weight ratio but also light in weight. Magnesium and silicon are AA6061 main alloy components and thus Al-Mg-Si aluminum alloy is of medium strength and is widely used due to its superior formability, weldability, machinability, and corrosion resistance compared to other aluminum alloys. Magnesium and silicon forms $\mathrm{Mg}_{2} \mathrm{Si}$ which in turn forms a simple eutectic system with aluminum. It is the precipitation of $\mathrm{Mg}_{2} \mathrm{Si}$ after artificial aging and then allows the alloys to reach their full strength. Therefore, AA6061 alloy is extensively employed in ship building, marine frames, pipelines, storage tanks and applications of aircraft. Even though Al-Mg-Si alloys are without difficulty weldable, owing to reversion (dissolution) of $\mathrm{Mg}_{2} \mathrm{Si}$ precipitates during the welding thermal cycle, they suffer from serious softening in the HAZ. This sort of mechanical deficiency poses a significant engineering issue. To enhance the mechanical 
characteristics of welding, it will be more suitable to overcome or minimize HAZ softening. AA 6061 aluminum alloy cannot be Tungsten Inert Gas [TIG] welded without filler wire because it leads to solidification cracking.

Moreover, the weld fusion area of aluminum alloys typically has coarse columnar grains due to the prevailing heat circumstances during solidification of the welded metal. This often results in lower mechanical welding characteristics and bad cracking resistance to hot. Hence, such is particularly suited in accordance with monitoring solidification structure of welds, but such control is often tough because on higher temperatures then thermal gradients between welds between rapport in accordance with castings yet the epi-axial makeup about growth procedure. Further, into the past as inoculation with heterogeneous nucleants, micro-cooler additions, floor nucleation triggered by using gas impingement and commencement on physical disturbance.

So as to beat these troubles between the fusion welding tactics to that amount are mechanically chronic in imitation of be a part of structural alloys, the Friction Stir Welding (FSW) is an emerging solid-state joining process in which the metal is not softened and recast. In 1991, Friction Stir Welding (FSW) was created as a solidstate joining method at the United Kingdom's Welding Institute (TWI) and applied originally to aluminum alloys [1]. FSW's fundamental concept is remarkably easy. Friction Stir Welding is an uninterrupted, hot shear, auto-genous and environmentally friendly method with a non-consumable rotating tool of a harder material than the substrate. It is found that a contraption of onion circle structure during aluminum alloy FSW welds relies upon the extent of material mixing and between dispersion, whereas the thickness of twisted aluminum lamellae, and material stream designs exceptionally rely on the geometry of the apparatus [2]. Further the temperature of welding and the stress on the material flow are depending on the axial force. In additionally, opined so much at low axial force, the structure about non-symmetrical semi-circular capabilities at the top surface concerning the weld suggests poor plasticization yet consolidation on the material underneath the have an effect on about the device shoulder.

A non-consumable rotating tool along an exceptionally designed pin and shoulder is put into the edges of the sheets or plates in conformity to be joined and after that navigated along the joint line. Figure 1 suggests the schematic sketch of FSW. The new FSW method is noted to offer several benefits over fusion welding due to the lack of parent metal melting.

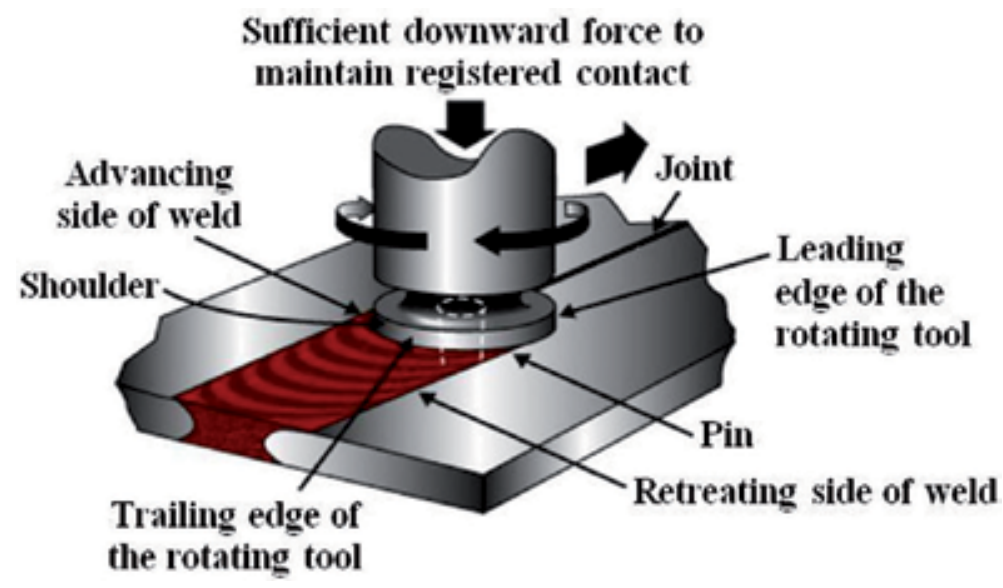

Figure 1.

Schematic representation of FSW principle. 


\section{Literature review}

A brief literature review is presented based on the earlier publications on FSW, to start with:

- CFD analyses the pin profile and shows that it plays a vital part in the material flow and controls the welding speed of the FSW process and is concentrated for refining weld fusion zones on the basis of several experimental methods but with only partial success [3]. Since the FSW is also dependent on the temperature distribution, the micro-structural evolution of the FSW of 6061 aluminum alloy (T6-temper condition) to copper [4] has been analysed. In FSW, the shoulder force is directly accountable for plunging the tool pin's depth into the work piece and load characteristics of linear friction stir welds. At steady state, the shoulder force varies depending upon the rotational speed. Increase in rotational speed is results in drop in initial axial force with increasing time [5]. Different micro-structural zones have been identified which show the hardness distribution on single and overlapped layers [6]. The nugget region with severe plastic deformation and exposure to elevated temperatures being characterized by fine and equiaxed recrystallized grains. Further, the thermo-mechanically affected region experiencing medium temperature and deformation having deformed and un-recrystallized grains and the heataffected zone have been experienced based on temperature, characterized by precipitate coarsening. Transient and quasi-stationary phases of FSP are revealed by roughness mapping. Just as each high rotational rates could raise strain rate, and there by impact the recrystallization procedure; which thus could impact the FSW procedure [7].

- The FSW is also extended to join the AA 6061 T-6 aluminum alloy and AZ31 alloy and to study hybrid laser FSW's microstructure and mechanical properties [8]. It is followed by the experimental study of butt joints of AA 6061 and ZRB2 metals in-situ Composite materials and studied the effect of those materials on sliding wear [9].

The literature also shows that a number of modelling techniques are developed for the analysis of FSW process parameters and their influence on the joints. In this context, the optimization of process parameters is studied by Taguchi method on cast aluminum alloy A319, it is followed by the modelling of AA6061-T6 butt joints and studied the tensile properties [10-13]. Further, a case study is presented with a review on the optimization of process parameters of $6061 \mathrm{Al}$ alloy using Taguchi method [14]. Though noted research has been taken place, the literature shows that there is no consideration on the effect of the various pin profiles on the joint geometry at various rotational speeds of FSW is still limping. Therefore the present chapter deals with experimentation on FSW.

Figure 2 shows the different regions of FSW joints. It consists of four elements: (a) unaffected base metal, (b) heat affected zone (HAZ), (c) thermo mechanically affected zone (TMAZ) and (d) friction stir processed (FSP) zone weld nugget zone. Structure of the above areas is influenced by the behaviour of the material stream under the activity of pivoting un-consumable instruments. Even though, the FSW tool profiles, FSW tool dimensions and FSW process parameters [5] predominantly influence the material flow behaviour. In fusion welding of aluminum amalgams, the imperfections like porosity, slag consideration, cementing splits and so on break down the weld quality and joint properties. Usually, FSW joints are free of such defects as there is no fusion during welding and the metals are joined by solid-state 


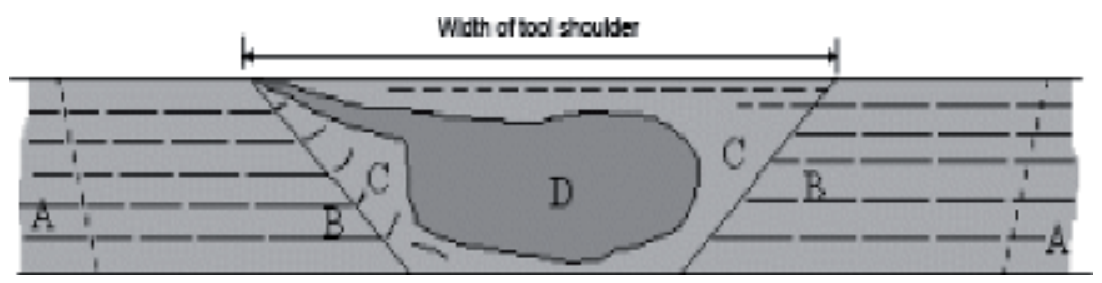

Figure 2.

Different regions of FSW joint. $A=$ unaffected metal base; $B=$ Heat Affected Zone (HAZ); $C=$ ThermoMechanically Affected Zone (TMAZ); D = Friction Stir Processed (FSP) zone.

because of the heat produced by the friction and the metal flow through the stirring action. On the other hand, owing to incorrect metal flow and inadequate metal consolidation in the FSP region, FSW Joints are susceptible to other defects such as cracks, tunnel defect, kissing bond, piping defect, pin hole, etc. Existing literature focuses on the impact of welding parameters and tool profiles on the formation of defect-free FSP is very limited.

Objectives of this present work: a Solemn attempt is made in the present investigation to conquer the limitations identified and to conduct experimentation on AA6061 Al alloys with the objectives as given in the following:

1. To fabricate FSW joints with different tool pin profiles and identify the process parameters

2. Investigation of the impact of tool pin profile and welding parameters (rotational speed, welding speed and axial force) on the formation of defect-free FSP as well as on tensile, impact properties and the hardness of the welded joints.

3. The ANN modelling of the process and to attain maximum tensile strength and analysis of variance for optimal process parameters.

4. Evaluation of the microstructure of FSP zone for different pin profiles.

5. Conducting the SEM analysis to analyse the flow of material.

\section{Experimental work}

Experimental work starts with the preparation of work pieces to be joined. Each work-piece of the base material of size $300 \times 150 \times 6.35 \mathrm{~mm}$ by power hacksaw cutting and milling. Configuration of the square butt joints is prepared to make FSW joints. The unique joint configuration is achieved by using mechanical clamps to secure the plates in place. The welding direction is normal for the rolling direction. The joints are manufactured using a single pass welding procedure. Non-consumable tools made of tungsten carbide material are utilized to fabricate the joints. Tables $\mathbf{1}$ and $\mathbf{2}$ show the chemical composition and mechanical characteristics of base metal.

Vertimach V-350. Vertical Machining Centre is used to fabricate the required joints. Three distinctive tool pin profiles are utilized to create the joints as appeared in Figure 3 and nearly 81 joints are manufactured to study the impact of tool pin profile, rotational velocity, welding velocity and axial force on stir welded AA6061 aluminum alloy tensile properties. Table 3 shows the levels of the experiment based on the Taguchi method. The experimental results are shown in Tables 4-6. 


\begin{tabular}{ccccccccc}
\hline $\mathbf{M n}$ & $\mathbf{S i}$ & $\mathbf{F e}$ & $\mathbf{C u}$ & $\mathbf{C r}$ & $\mathbf{Z r}$ & $\mathbf{M g}$ & $\mathbf{T i}$ & $\mathbf{A l}$ \\
\hline 1.2 & 0.8 & 0.7 & 0.4 & 0.35 & 0.25 & 0.15 & 0.15 & Balance \\
\hline
\end{tabular}

Table 1.

AA6061 alloy (weights \%) chemical composition.

\begin{tabular}{lcccc}
\hline $\begin{array}{l}\text { Yield strength } \\
(\mathrm{MPa})\end{array}$ & $\begin{array}{c}\text { Ultimate } \\
\text { strength }(\mathrm{MPa})\end{array}$ & $\begin{array}{c}\text { Elongation } \\
(\%)\end{array}$ & $\begin{array}{c}\text { Reduction in cross- } \\
\text { sectional area }(\%)\end{array}$ & $\begin{array}{c}\text { Hardness } \\
(\mathrm{VHN})\end{array}$ \\
\hline 276 & 310 & 18 & 12.24 & 105 \\
\hline
\end{tabular}

Table 2.

AA6061 mechanical characteristics.

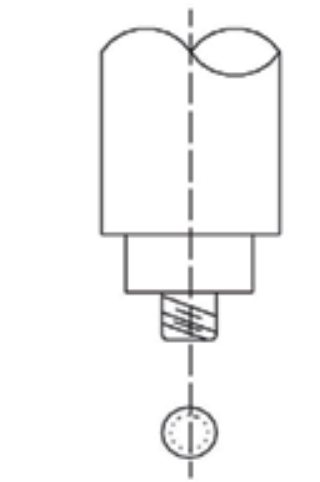

Threaded Cylindrical (TH)

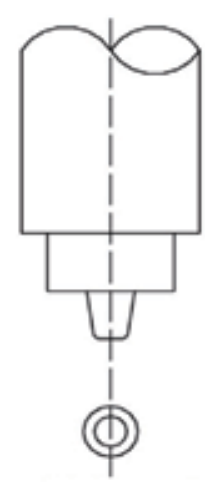

Conical (TC)

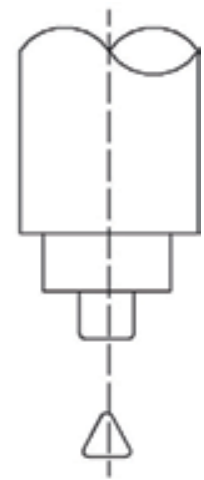

Triangle (TR)

Figure 3.

Tool pin profiles of FSW.

\begin{tabular}{lccccc}
\hline Process parameters & Symbol & Units & Level 1 & Level 2 & Level 3 \\
\hline Tool rotational speed & $\mathrm{N}$ & $\mathrm{rpm}$ & 1200 & 1600 & 2000 \\
\hline Welding speed & $\mathrm{S}$ & $\mathrm{mm} / \mathrm{min}$ & 48 & 60 & 72 \\
\hline Axial force & $\mathrm{F}$ & $\mathrm{KN}$ & 1.5 & 2.0 & 2.5 \\
\hline
\end{tabular}

Table 3.

Important factors and their levels for AA6061.

Using power hacksaw, the welded joints are sliced and then tensile specimens are machined to the necessary sizes. Guidelines for the preparation of sample samples are followed by the American Society for Testing of Materials (ASTM). In 400 KN, Electro-Mechanical Controlled Universal Testing Machine Tensile test has been carried. The specimen is recorded when the neck fails and the load versus the displacement. Charpy Impact Test is also conducted for the specimens. The Rockwell Hardness Test is conducted by indenting the test material with a diamond cone indenter. The indenter is compelled into tare using a Light Optical Microscope (Make: NIKON-LV 150) built into an Image Analysis Software. The specimens for metallographic examination are divided into FSP, TMAZ, HAZ and base metal areas according to the necessary dimensions. The samples are polished using various grades of emery documents. Final polishing is performed in the Disc Polishing Machine 


\begin{tabular}{lccc}
\hline & Setting level & Predicted & Experimental \\
\hline Tensile strength $(\mathrm{MPa})$ & $\mathrm{N} 3, \mathrm{~S} 3, \mathrm{~F} 3$ & 162.84 & 163.23 \\
\hline Impact strength $\left(\mathrm{N} / \mathrm{mm}^{2}\right)$ & $\mathrm{N} 1, \mathrm{~S} 2, \mathrm{~F} 3$ & 1.02 & 1.260 \\
\hline Hardness & $\mathrm{N} 3, \mathrm{~S} 3, \mathrm{~F} 3$ & 31 & 33 \\
\hline
\end{tabular}

Table 4.

Optimum parameters for the threaded pin profile.

\begin{tabular}{lccc}
\hline & Setting level & Predicted & Experimental \\
\hline Tensile strength $(\mathrm{MPa})$ & $\mathrm{N} 3, \mathrm{~S} 3, \mathrm{~F} 3$ & 159.84 & 160.23 \\
\hline Impact strength $\left(\mathrm{N} / \mathrm{mm}^{2}\right)$ & $\mathrm{N} 3, \mathrm{~S} 3, \mathrm{~F} 2$ & 0.766 & 0.770 \\
\hline Hardness & $\mathrm{N} 3, \mathrm{~S} 3, \mathrm{~F} 3$ & 28 & 30 \\
\hline
\end{tabular}

Table 5.

Optimum parameters for the conical pin profile.

\begin{tabular}{lccc}
\hline & Setting level & Predicted & Experimental \\
\hline Tensile strength $(\mathrm{MPa})$ & $\mathrm{N} 3, \mathrm{~S} 3, \mathrm{~F} 3$ & 218.34 & 215.82 \\
\hline Impact strength $\left(\mathrm{N} / \mathrm{mm}^{2}\right)$ & $\mathrm{N} 3, \mathrm{~S} 3, \mathrm{~F} 2$ & 0.880 & 0.901 \\
\hline Hardness & $\mathrm{N} 3, \mathrm{~S} 3, \mathrm{~F} 3$ & 29 & 31 \\
\hline
\end{tabular}

Table 6.

Optimum parameters for the triangular pin profile.

using the diamond compound ( $1 \mathrm{~mm}$ particle size). Specimens are etched with the Keller's reagent, to reveal the macro and micro structures. SEM analysis is conducted using the Scanning Electron Microscope. SEM produces a range of signals exterior of sample specimens by utilizing the high energy focused electrons. Signals derived from SEM reveal information on the sample, including exterior morphology (texture), chemical composition, crystalline structure and orientation of the sample material.

\section{Effect of tool pin profile}

The fundamental role of the non-consumable rotating tool pin is to stir and transfer the plasticized metal behind it to a good joint. Pin profiles with flat faces (square and triangular) are associated with eccentricity. This eccentricity allows incompressible material to pass around the pin profile. Figure 4 shows the effect of aluminum alloys of AA6061 on the FSW joints of tensile features. From this inquiry, it is discovered that the joints manufactured using the triangular pin tool profile have improved tensile characteristics for aluminum alloy. Figure 5 shows the impact of the tool pin profile on AA6061 aluminum alloy FSW joints. From this study, it is discovered that the joints manufactured using Triangular pin tool profile improved impact strength for aluminum alloy. Figure 6 shows the impact of tool pin profile on AA6061 aluminum alloy FSP area hardness. The FSP zone hardness is also maximum in the case of joints fabricated using threaded pin profile. Figures 7-9 show the different zone of the microstructure of FSW joints of AA6061 aluminum alloys. The joint's FSP area made from threaded pin profile contains very fine equiaxed microstructure (Figure 9) compared to other joints. 
Experimental Investigations on AA 6061 Alloy Welded Joints by Friction Stir Welding DOI: http://dx.doi.org/10.5772/intechopen.89797

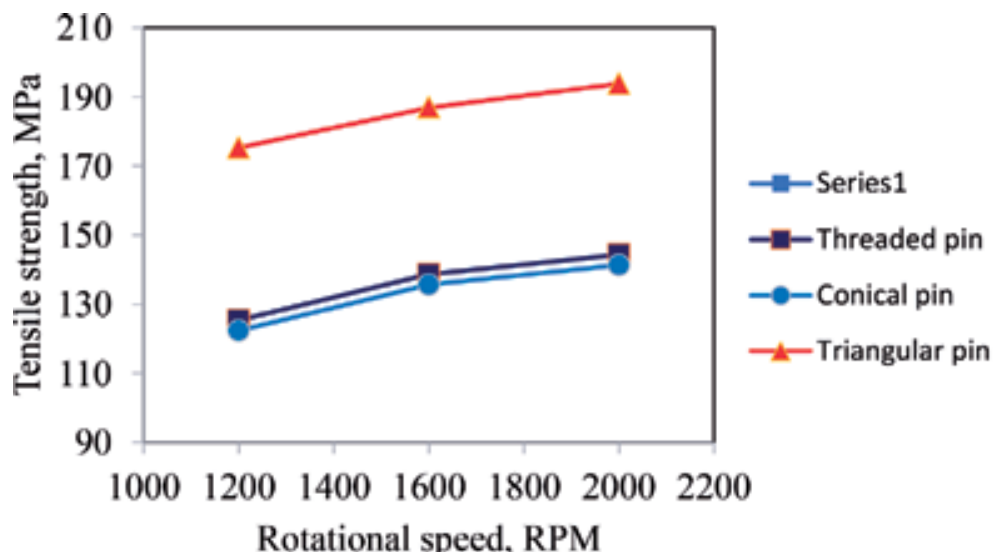

(a)

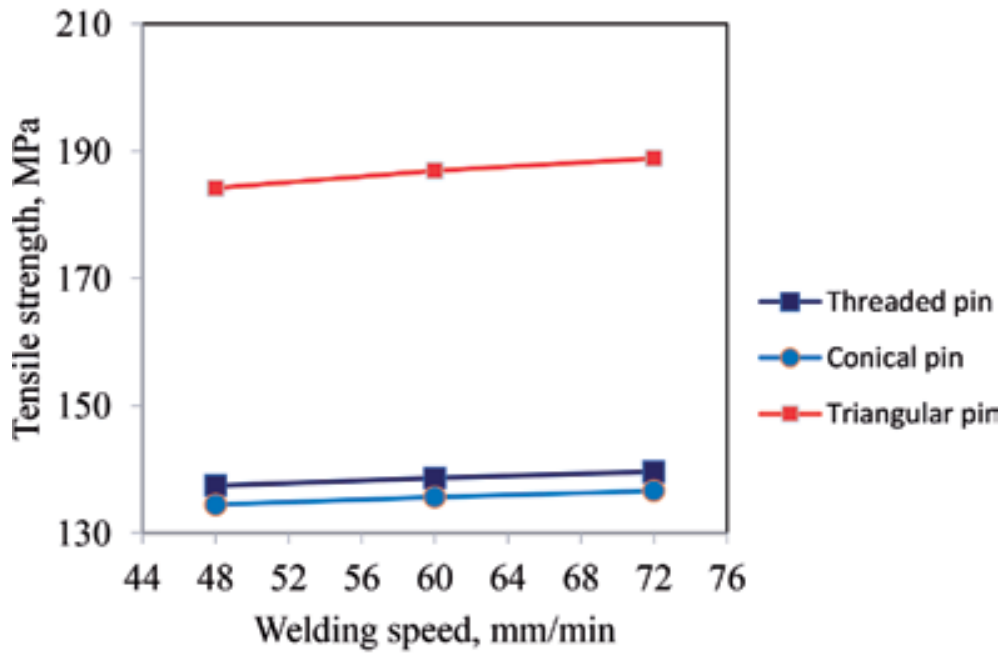

(b)

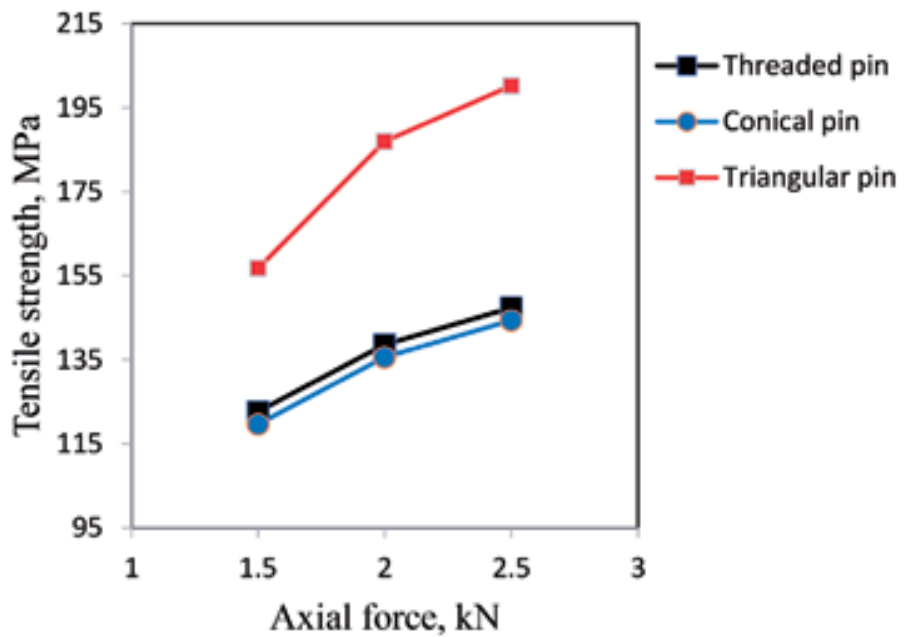

(c)

Figure 4.

Effect of FSW parameters on tensile strength: (a) effect of rotational speed; (b) effect of welding speed; and (c) effect of axial force. 


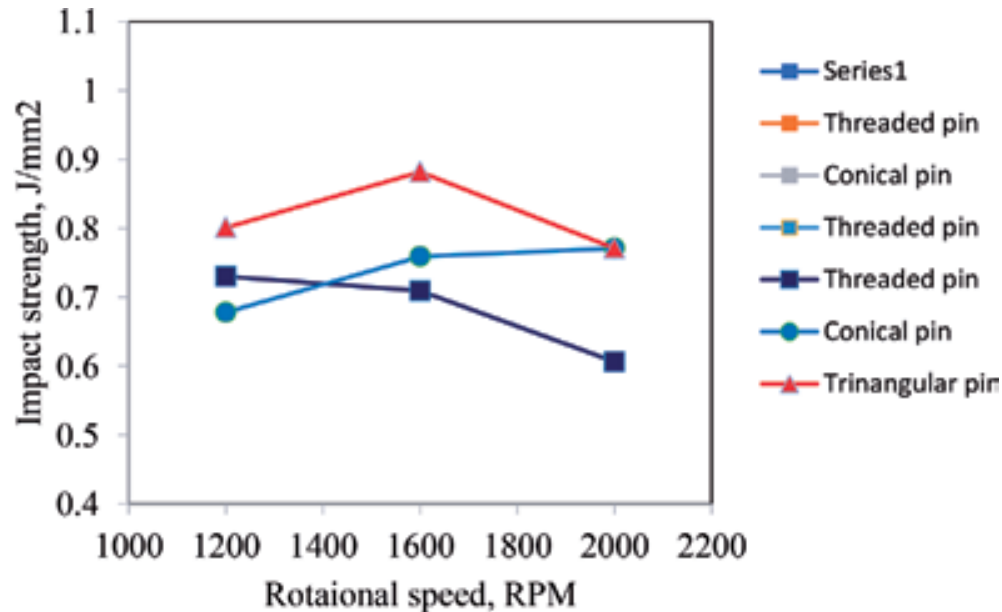

(a)

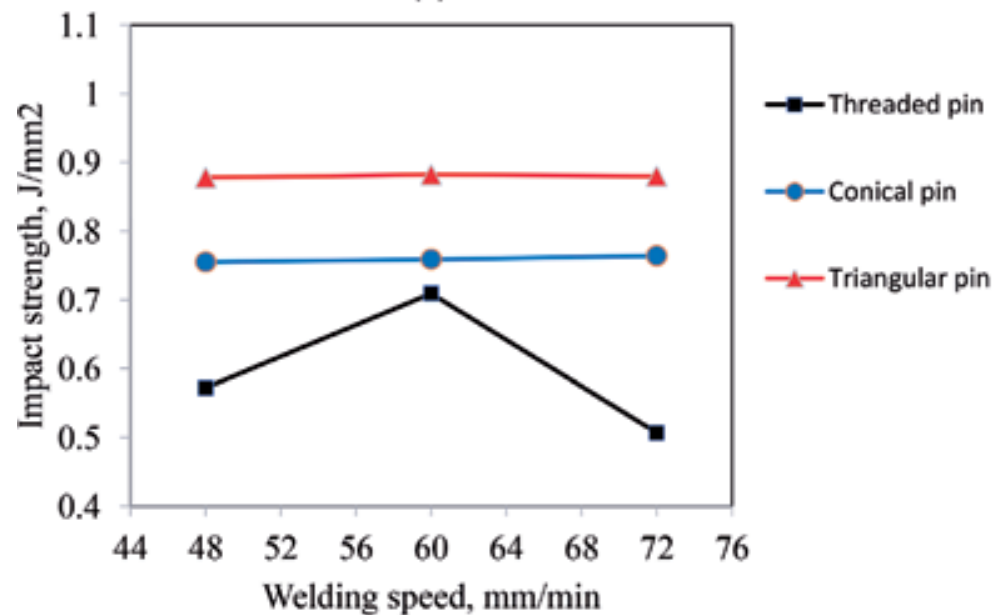

(b)

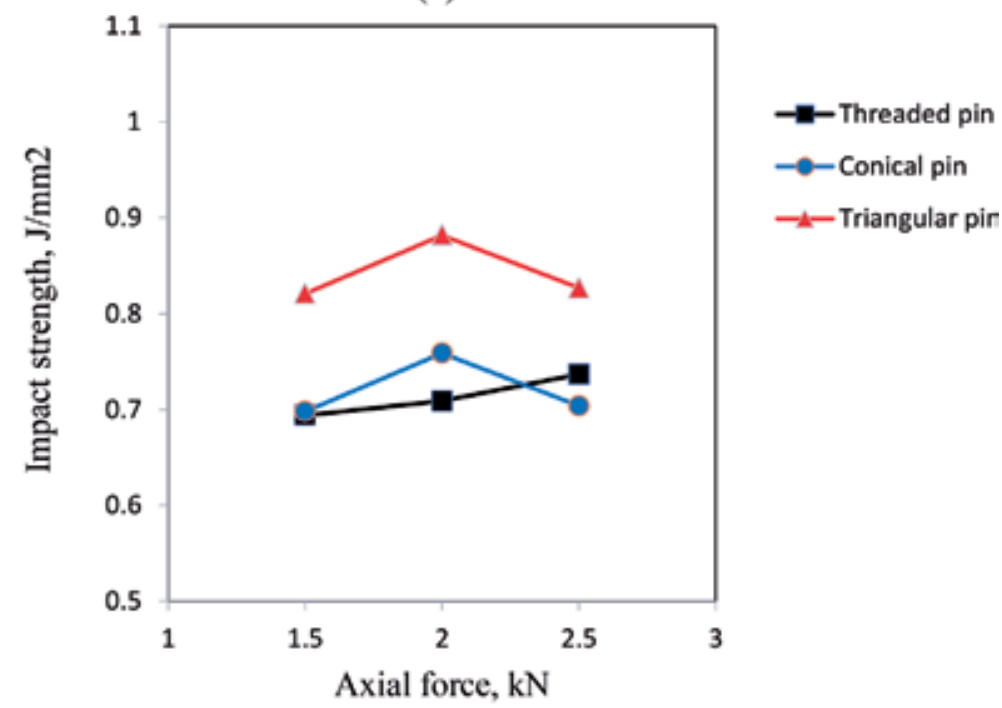

(c)

Figure 5.

Effect of FSW parameters on impact strength: (a) effect of rotational speed; (b) effect of welding speed; and (c) effect of axial force. 
Experimental Investigations on AA 6061 Alloy Welded Joints by Friction Stir Welding DOI: http://dx.doi.org/10.5772/intechopen.89797
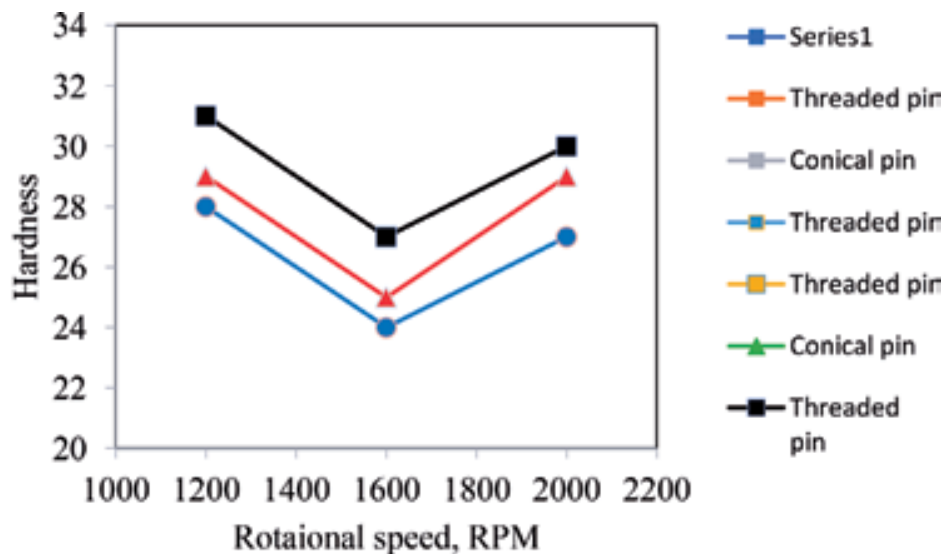

(a)

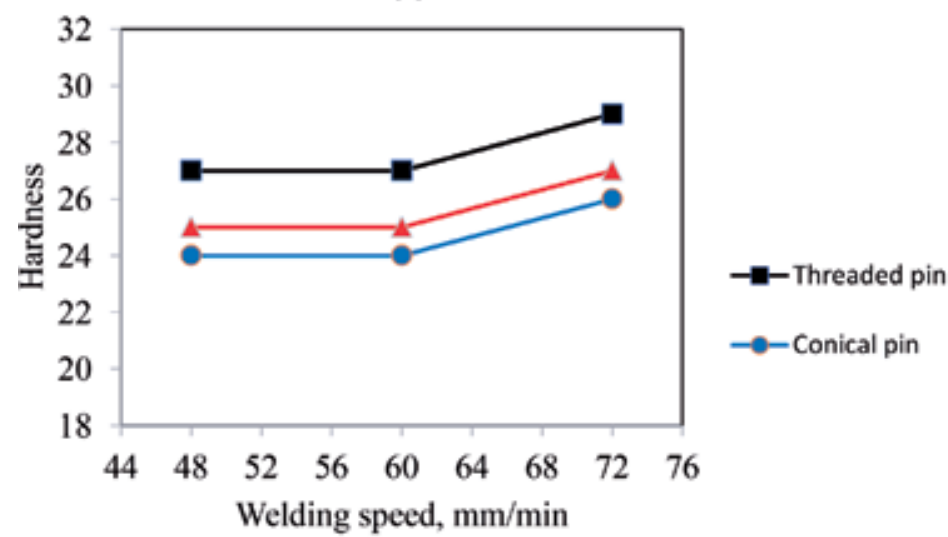

(b)

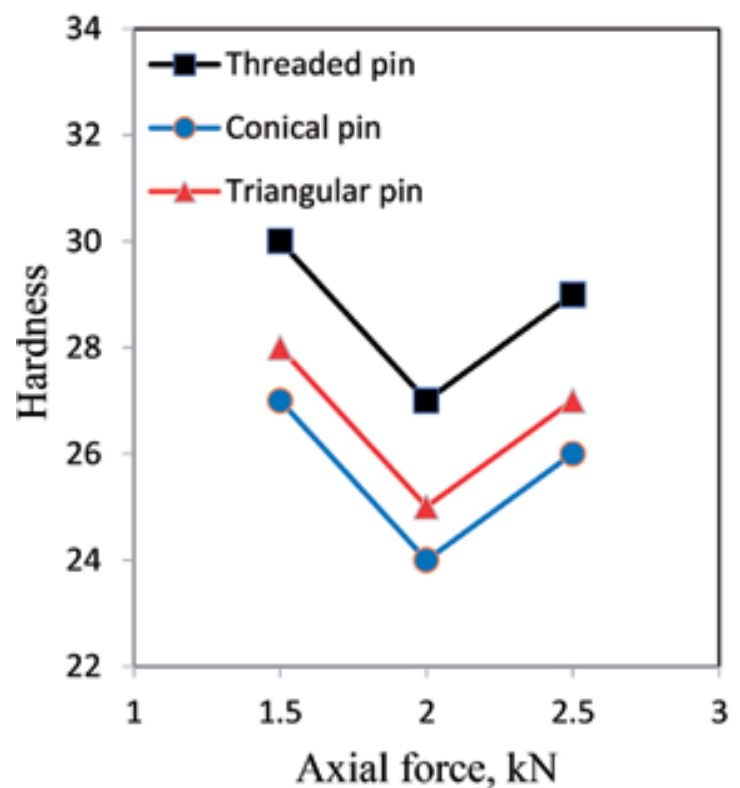

(c)

Figure 6.

Effect of FSW parameters on hardness: (a) effect of rotational speed; (b) effect of welding speed; and (c) effect of axial force. 


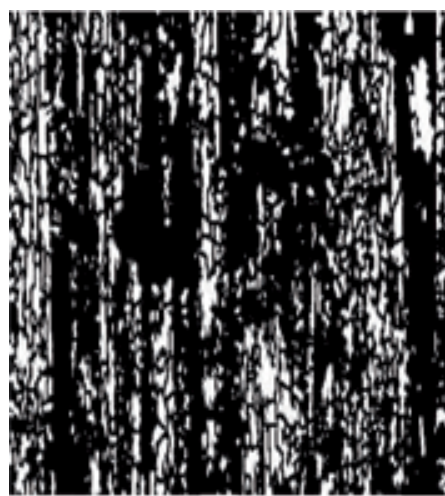

(a)

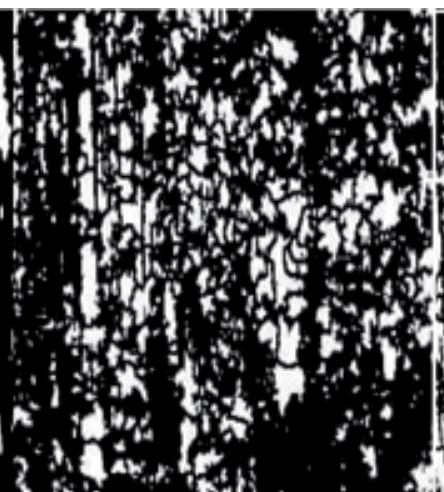

(b)

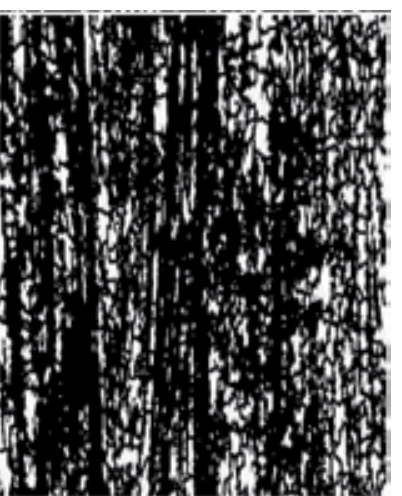

(c)

Figure 7.

Effect of conical pin profile on the microstructure of AA 6061: (a) FSP zone; (b) TMAZ; and (c) HAZ.

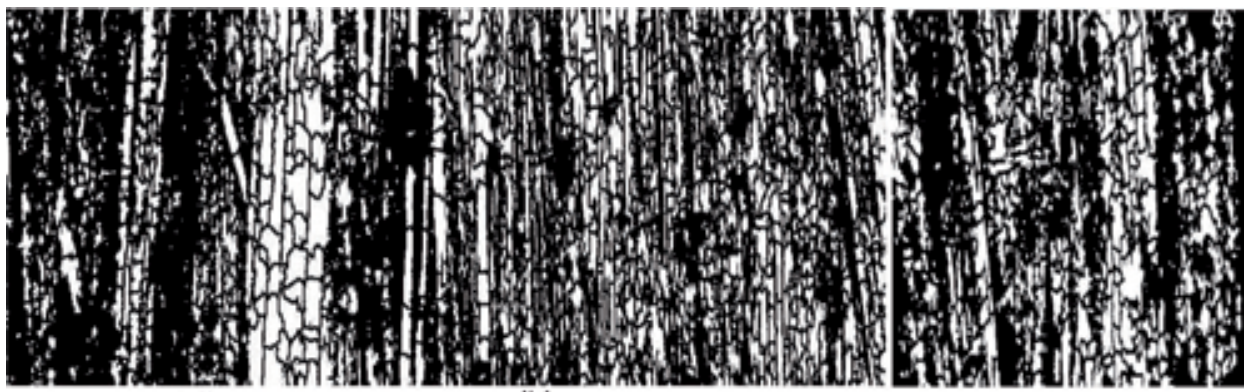

(a) (b) (c)

Figure 8.

Effect of triangular pin profile on the microstructure of AA 6061: (a) FSP zone; (b) TMAZ; and (c) HAZ.

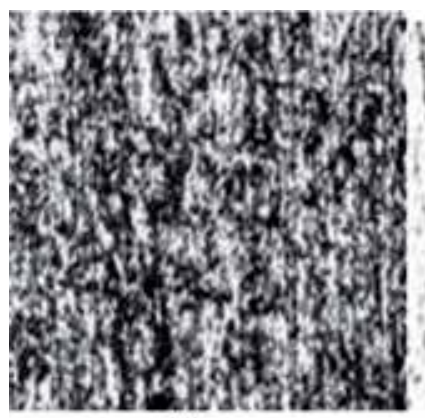

(a)

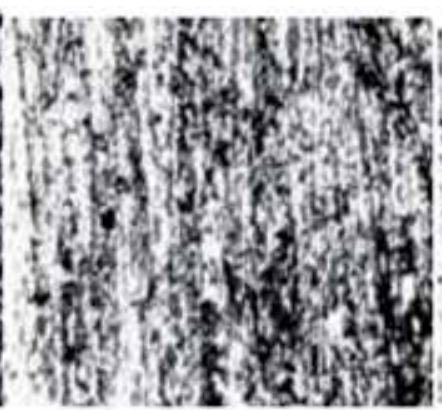

(b)

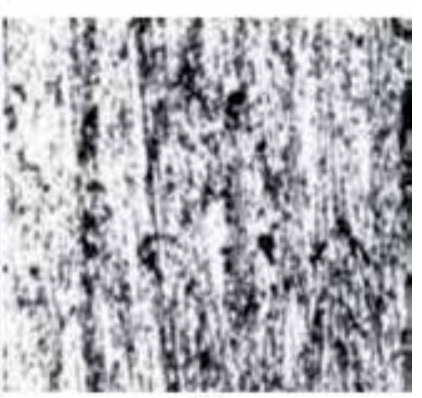

(c)

Figure 9.

Effect of threaded pin profile on the microstructure of AA 6061: (a) FSP zone; (b) TMAZ; and (c) HAZ.

\section{Effect of tool rotational speed}

To know the impact of rotational speed on FSW joints 'tensile characteristics, three distinct rotational speeds were selected to manufacture the joints. Figure 4(a) indicates that rotational speed affects the tensile strength of AA606l aluminum alloy of FSW joints. Figure 5(a) demonstrates the impact of rotational speed on AA6061 aluminum alloy FSW joints impact strength. Figure 6(a) demonstrates the impact of AA6061 
aluminum alloy rotational speed on FSP zone hardness. Rotational speed seems to be the most important variable of the process since it also affects the transfer speed. Higher tool rotational speed in the FSP area identified after soldering led in greater temperature and slower cooling rate. Higher rotation speed leads to excessive discharge from the top layer of the stirred materials which therefore leave voids in the FSP area. Lower heat entry situation owing to reduced rotational speed caused no stirring. As the speed of rotation rises, the stressed region expands and the place of the highest stress lastly shifts from the initial advancing side of the joint to the progressing side. This means that the position of the joint fracture is also influenced by the speed of rotation. The tensile characteristics of the joints under distinct welding circumstances led in the smallest tensile strength and ductility for a specified traverse speed at the smallest spindle speed. As the speed of the spindle increased, both power and elongation enhanced to a peak before dropping again at elevated rotational speeds. It is evident that the heat input increases in FSW as the rotational speeds increase. There are two reasons why this phenomenon can be explained: first, when a local melt happens, the coefficient of friction reduces and then reduces with heat input; secondly, some heat input is absorbed by latent heat. From this investigation, it is discovered that in the case of AA6061 aluminum alloy, the joints manufactured at a rotational speed of 2000 RPM produced better tensile strengths.

\section{Effect of welding speed}

To know the impact of welding speed on FSW joints' tensile strengths, three distinct welding speeds were selected to fabricate the joints. Figure 4(b) indicates the impact of welding speed on AA6061 aluminum alloy FSW joints tensile strength. Figure 5(b) demonstrates the impact of welding speed of AA606l aluminum alloy FSW joints. Figure 6(b) demonstrates the impact of welding speed on AA6061 aluminum alloy FSP zone hardness. Decreased welding speed reduces the cooling ratio resulting in larger equi-axed granules in the stirring region. Poor welding speed in the FSP region resulted in sub grain coarsening. Due to the restricted moment available for regeneration, greater welding speed led in a structure with greater dislocation density. Increase in welding speed can reduce the volume of grain owing to the reduction in heat input. As a result of this exploration, it was discovered that aluminum alloy in the case of AA6061, the joints manufactured at a welding speed of $72 \mathrm{~mm} / \mathrm{min}$ had better tensile strengths.

\section{Effect of axial force}

In order to understand the impact of axial force on the tensile strengths of FSW joints, three distinct axial forces were selected to fabricate the joints. Figure 4(c) shows the axial force impact on the tensile strength of the FSW AA 6061 aluminum joints. Figure 5(c) shows the axial force effect of FSW aluminum joints AA 6061. The Figure 6(c) demonstrates the axial force impact of AA6061 aluminum alloy FSP zone hardness. The flow of materials within the weld area is affected by an extrusion method where the material has experienced plastic deformation by the applied axial force and movement of the tool pin profile.

The difference in the measured forces is due to the decrease of the material flow stress at elevated weld temperature. Despite the fact that weld joint is great, the arrangement of shear lips or flashes with intemperate stature on both progressing and withdrawing sides of the weld line because of higher pivotal power brought about inordinate diminishing of the metal in the weld region yielding poor tensile properties. The axial force should therefore, be optimized in order to achieve an FSP 
region that is metal consolidated and does not dilute the base material. The results of this research showed that in the event of AA6061 aluminum alloy, the joints made with an axial force of $2 \mathrm{KN}$ had better tensile strengths. Table 4 shows the optimized welding conditions.

\section{Process parameters modelling using ANN}

The input layer in this work consists of four neurons that correspond to each of the three control factors and one neuron in the output layer that corresponds

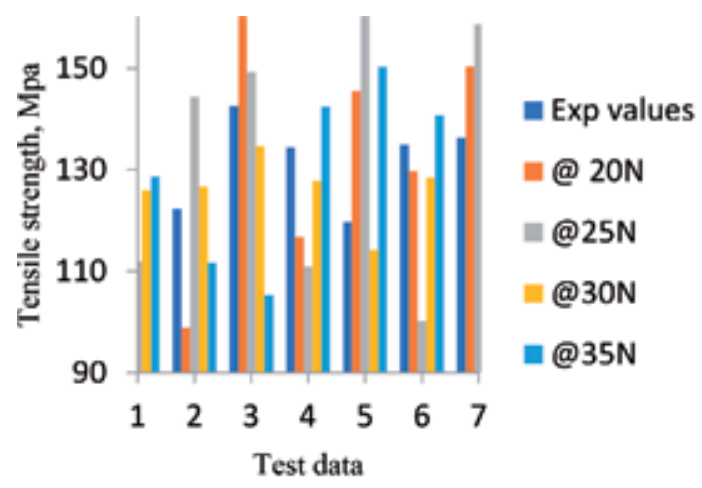

(a)

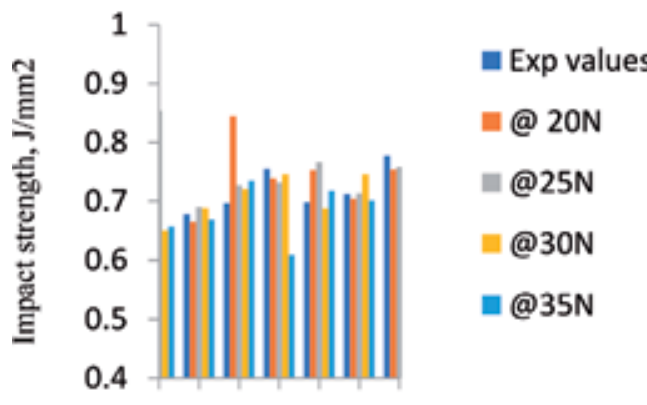

$\begin{array}{lllllll}1 & 2 & 3 & 4 & 5 & 6 & 7\end{array}$

Test data

(b)

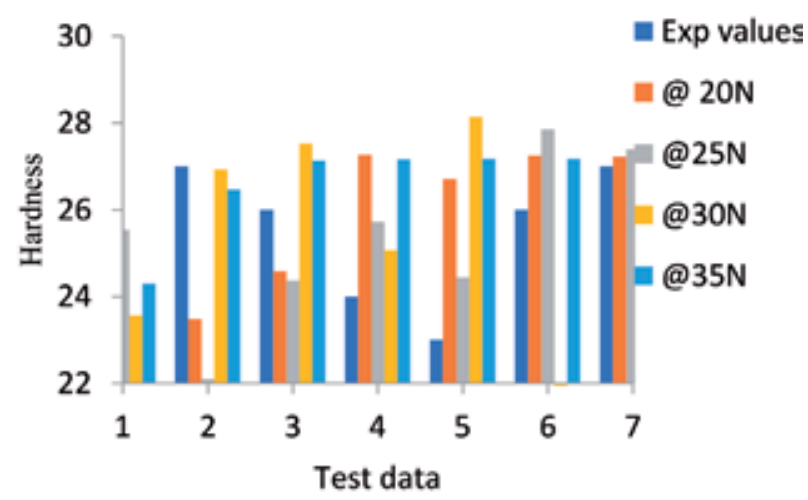

(c)

Figure 10.

Predicted mechanical properties of conical pin profile using ANN. 
to each response. To find the finest network architecture, differently hidden layer networks were created and tested with distinct numbers of hidden layers and neurons; various algorithms is used for practice; the hidden layer and output layer transfer functions are altered and the generalization ability of the various networks is noted. Finally, the ideal network is chosen to forecast the strengths. Twenty-five concealed neurons are trained for the ideal architecture of the network. The ANN network is run on MATLAB software. The data set with 27 models is randomly split into two classifications: The training dataset consists of $75 \%$ of information and

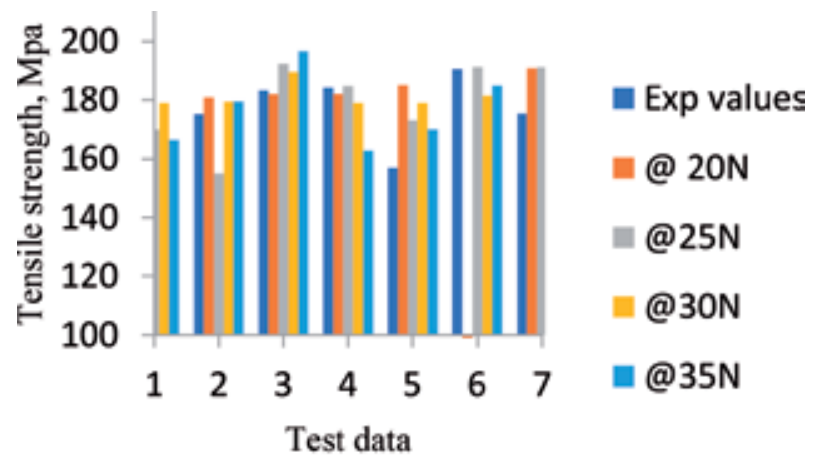

(a)

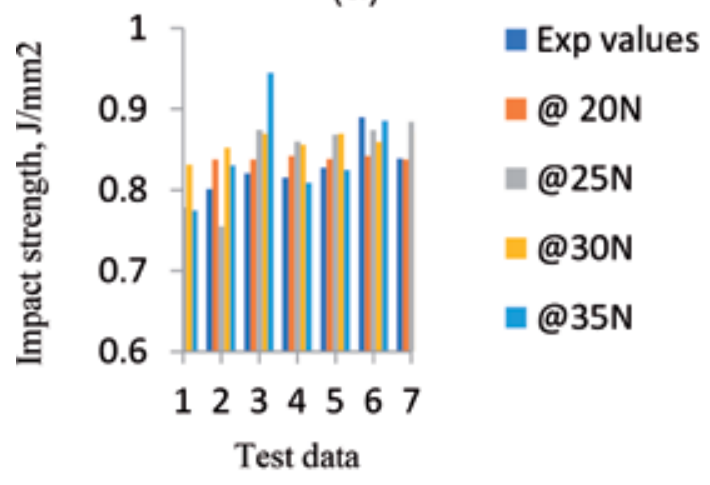

(b)

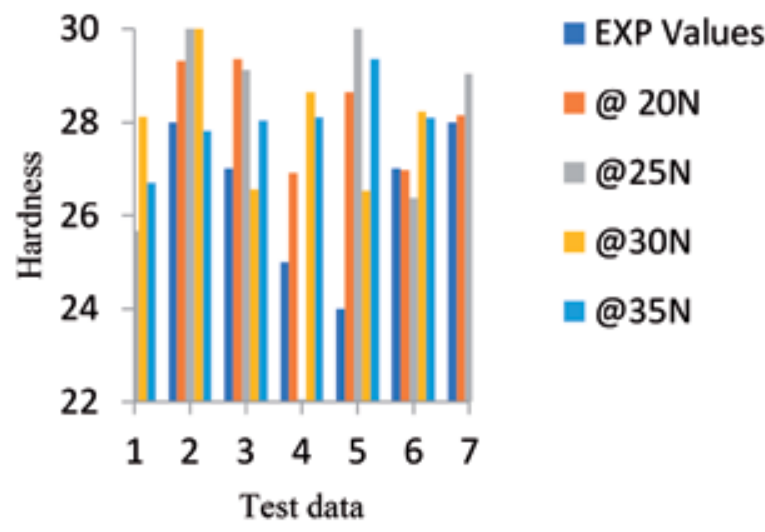

(c)

Figure 11.

Predicted mechanical properties of triangular pin profile using ANN. 
$25 \%$ of information in test information set. 20 training models for ANN strength modelling are considered. The weights are frozen after the training and the model is checked for experimental findings.

Figures 10(a), 11(a) and 12(a) show the experimental and ANN computed tensile strength values for AA6061 materials with a conical pin tool, triangular pin tool and threaded pin tool, and it is clear that the values predicted by ANN are very close to the experimental values. Figures 10-12 show the ANN prediction values and experimental values for the different mechanical properties.

The experimental investigation it is proved that the triangular pin profiles yield better results.

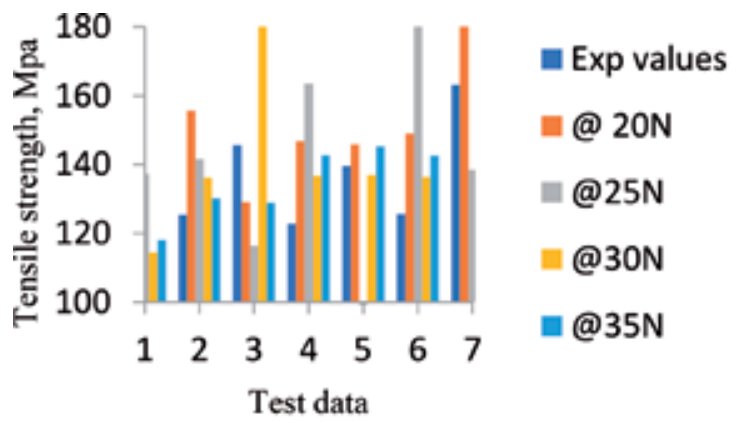

(a)

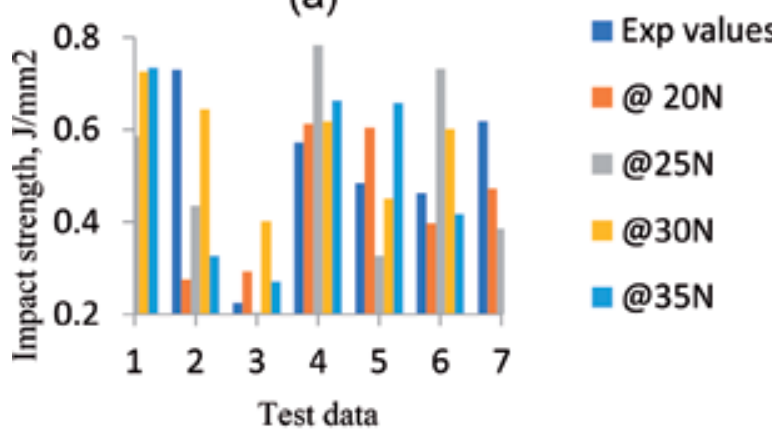

(b)

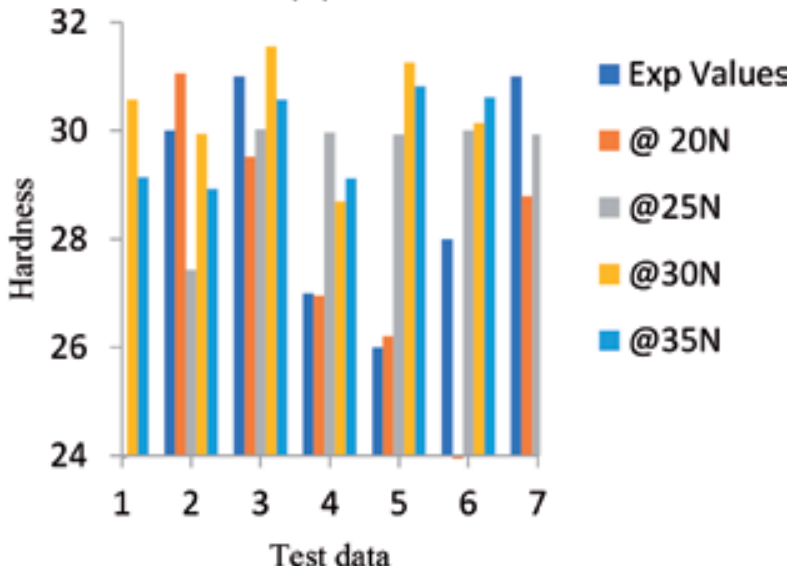

(c)

Figure 12.

Predicted mechanical properties of threaded pin profile using ANN. 
Experimental Investigations on AA 6061 Alloy Welded Joints by Friction Stir Welding DOI: http://dx.doi.org/10.5772/intechopen.89797

\section{SEM analysis}

SEM assessments are completed utilizing a Scanning Electronic Microscope for 6061 aluminum alloy to dissect the weld testimony on weld chunk surface. The SEM photos of the joints at different procedure parameters are appeared

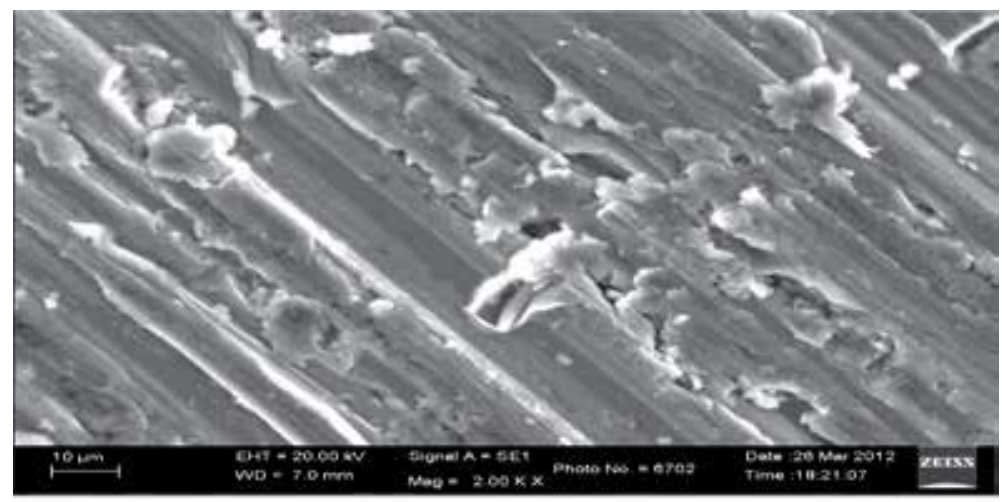

Threaded pin

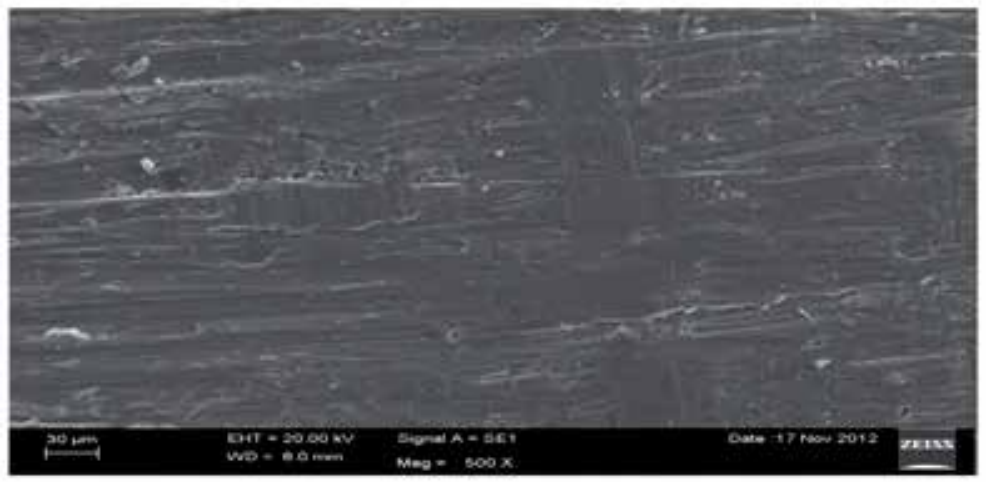

Conical pin

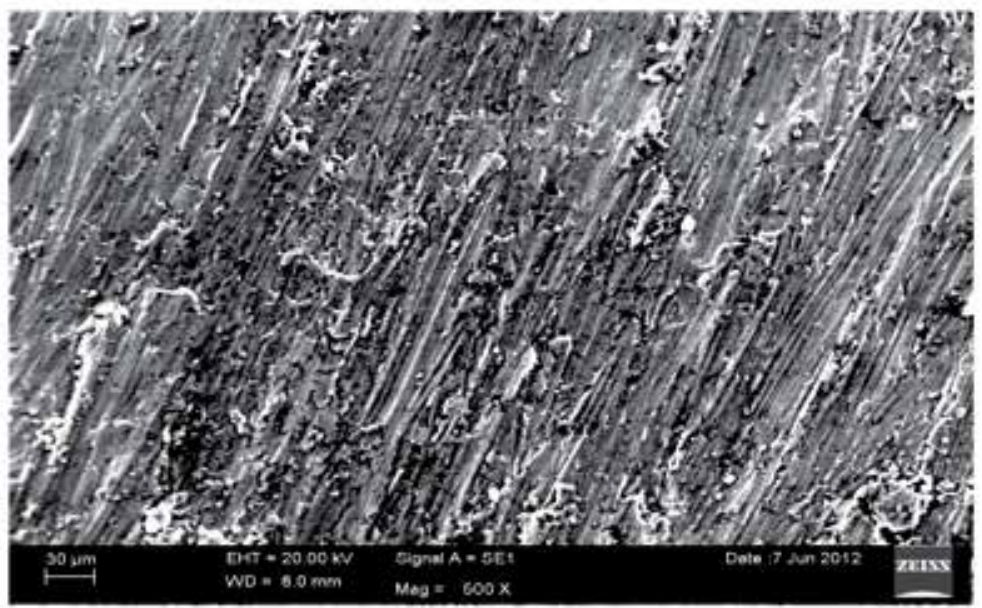

Triangular pin

Figure 13.

SEM images of different tool pin profiles of FSW joints of AA 6061. 
in Figure 13. The SEM analysis has been conducted at three different levels of magnification to analyse the weld defects. It is observed that no micro or microscopic voids and cracks observed in the FSP region. The thermal flow of material is being viewed clearly across the FSP zone.

\section{Conclusions}

- The attempt made in the present work for joining of age hardenable aluminum alloy AA6061 (medium strength) by FSW using Vertimach V-350 Vertical Machining Centre and the attempt was effective and proved to be consistent with the expected values with their mechanical properties of the joints.

- The tool with triangulated pin profiles produced mechanically sound and nonmetallurgically deficient joints for both AA6061 aluminum alloys, regardless of welding parameters, among the three tool pin profiles for this study.

- The macrostructure, tensile strengths, hardness, microstructure and SEM analysis have been evaluated in detail for the effect of rotational speed, welding speed and axial force on the formation of a defeat free FSP zone. The welding conditions for producing defect-free joints have been established for AA6061 aluminum alloy.

- An ANN modelling is developed to obtain the theoretical results and compared with the experimental results among all three different pin profiles, the triangular pin profile found to be closer value to the experimental strength of the weld joint at 30 neurons and validated at $95 \%$ confidence level.

- The SEM images clearly show the metal flow across the joints for three different pin profiles. It is also evident from SEM analysis that the triangular pin profile exhibits better stirring action than compared to a threaded pin profile.

\section{Limitations of the present work}

- The FSW joints are susceptible to defects such as pinhole, defects in the tunnel, piping failures, kissing attachment, cracks and so on due to poor metal flow and lack of metal build-up in the FSP area, although they are free from cracks of solidification.

\section{Acknowledgements}

The author is grateful to M/s. Bindu Tools India Pvt. Ltd. for supplying necessary tools and also to the department of mechanical engineering, S.V. University College of Engineering, Tirupati, for providing necessary facilities to carry out the work. 


\section{Author details}

Pothur Hema

Department of Mechanical Engineering, SVU College of Engineering, Tirupati, Andhra Pradesh, India

*Address all correspondence to: hemasvumech@gmail.com

\section{IntechOpen}

(C) 2019 The Author(s). Licensee IntechOpen. This chapter is distributed under the terms of the Creative Commons Attribution License (http://creativecommons.org/licenses/ by/3.0), which permits unrestricted use, distribution, and reproduction in any medium, provided the original work is properly cited. (cc) BY 


\section{References}

[1] Thomas WM, Nicholas ED, Needham JC, Murch MG, Temple Smith P, Dawes CJ. Friction-stir butt welding. GB Patent No: 9125978.8, International Patent No: PCT/ GB92/02203. 1991

[2] Krishnan KN. On the formation of onion rings in friction stir welds. Materials Science and Engineering. 2002;327:246-251

[3] Thomas WM, Johnson KI, Wiesner CS. Friction stir weldingRecent developments in tool and process technologies. Advanced Engineering Materials. 2003;5(7):485-490. DOI: 10.1002/adem.200300355

[4] Colegrove PA, Shercliff HR. 3-Dimensional CFD modeling of flow around a threaded friction stir welding tool profile. Journal of Materials Processing Technology. 2005;169:320-327

[5] Ouyang J, Yarrapareddy E, Kovacevic R. Microstructural evolution in the friction stir welded 6061 aluminum alloy (T6-temper condition) to copper. Journal of Materials Processing Technology. 2006;172:110-122

[6] Elangovan K, Balasubramanian V. Influences of tool pin profile and tool shoulder diameter on the formation of friction stir processing zone in AA6061 aluminum alloy. Journals of Materials and Design. 2008;29(2):362-373. DOI: 10.1016/j.matdes.2007.01.030

[7] Iordachescu M, Vilaca P, Iordachescu D, Porro JA. Aluminium friction stir processing of AA 6061 alloys. IIW Doc III-1433-07. 2007

[8] Sakthivel T, Sengar GS, Mukhopadhyay J. Effect of welding speed on microstructure and mechanical properties of friction-stir-welded aluminum. International Journal of Advanced Manufacturing Technology. 2009;43:468-473. DOI: $10.1007 /$ s00170-008-1727-7

[9] Jayaraman M, Sivasubramanian R, Balasubramanian V,

Lakshminarayanan AK.Optimization of process parameters for friction stir welding of cast aluminum alloy A319 by Taguchi method. Journal of Scientific \& Industrial Research. 2009;68:36-43

[10] Rajakumar S, Muralidharan C, Balasubramanian V. Sensitivity analysis on friction stir welding process and tool parameters for joining AA6061-T6 aluminium alloy joints. Indian Welding Journal. 2010;43(3):32-42

[11] Yokoyama T, Nakai K, Sukedai E. Tensile properties and constitutive modeling of friction stir welded AA6061-T6 butt joints. Journal of Solid Mechanics and Materials Engineering. 2011;5(12):780-792

[12] Chang W-S, Rajesh SR, Chun C-K, Kim H-J. Microstructure and mechanical properties of hybrid laser-friction stir welding between AA6061-T6 Al alloy and AZ31 Mg alloy. JMST. 2011;27(3):199-204

[13] Dinaharan I, Murugan N. Influence of friction stir welding parameters on sliding wear behavior of AA6061/010 wt.\% ZrB2 in-situ composite butt joints. Journal of Minerals \& Materials Characterization \& Engineering. 2011;10:1359-1377

[14] Nourani M, Milani AS, Yannacopoulos S. Taguchi optimization of process parameters in friction stir welding of 6061 aluminum alloy: A review and case study. Scientific Research. 2011;3:144-155 


\title{
Aluminum Alloys Behavior during Forming
}

\author{
Perumalla Janaki Ramulu
}

\begin{abstract}
Industrial revolution toward weight reduction and fuel efficiency of the automotive and aerospace vehicles is the major concern to replace heavy metals with light weight metals without affecting much strength. For this, aluminum alloys are the major contributors to those industries. Moreover, aluminum alloys are majorly categorized as $1 \mathrm{xxx}, 2 \mathrm{xxx}, 3 \mathrm{xxx}, 4 \mathrm{xxx}, 5 \mathrm{xxx}, 6 \mathrm{xxx}, 7 \mathrm{xxx}$, and $8 \mathrm{xxx}$ based on major alloying elements. Among all, 2xxx, 5xxx, 6xxx, and 7xxx are having majority of applications in the abovementioned industries. For manufacturing any engineering deformable components, forming characteristics are must. Forming behavior of aluminum alloys has been evaluated through different processes including deep drawing, stretching, incremental forming, bending, hydro forming etc., under different process conditions (cold, warm, and hot conditions) and process parameters. Each process has its own process feasibility to evaluate the formability without any forming defects in products. The present chapter discusses a few important processes and their parameter effect on the aluminum alloys through the experimentations and simulation works.
\end{abstract}

Keywords: ISF, hot forming, tube hydroforming, deep drawing, stretching

\section{Introduction}

Formability is defined as plastic deformation ability to produce a part with definite requirements on mechanics, dimension, and appearance of a material during a forming process, being mainly limited by the occurrence of flow localization or variability. The formability of any sheet material depends on the material properties, process parameters, and strain bounding criteria. The formability can be evaluated through simulation tests like stretching, deep drawing and drawing processes, mechanical tests, limiting dome height (LDH), and forming limit diagrams at various conditions. Evaluating the formability of aluminum alloys is crucial for industries like aerospace and automotive due to their significant advantages over other materials. Aluminum alloys are majorly categorized as $1 \mathrm{xxx}, 2 \mathrm{xxx}$, $3 \mathrm{xxx}, 4 \mathrm{xxx}, 5 \mathrm{xxx}, 6 \mathrm{xxx}, 7 \mathrm{xxx}$, and $8 \mathrm{xxx}$ based on major alloying elements. Among all, $2 \mathrm{xxx}, 5 \mathrm{xxx}, 6 \mathrm{xxx}$, and $7 \mathrm{xxx}$ are having majority of applications in any industry. Forming behavior of aluminum alloys has been evaluated through different processes including deep drawing, stretching, incremental forming, bending, hydroforming, etc., under different process conditions (cold, warm, and hot conditions) and process parameters. Each process has its own process feasibility to evaluate the formability without any forming defects in products. The significance of this chapter is to discuss and elaborate the effect of forming process parameters of different 
processes on various aluminum alloys. Specifically, the hot forming process, deep drawing process, incremental forming process, tube hydroforming process, and stretching process are discussed on different aluminum alloys.

\section{Aluminum alloy behavior during hot forming}

Hot forming of aluminum alloys is extensively used in the modern industry and has been explored by many researchers and scientists. The main intension to derive this process is to reduce in-flow stress, increase ductility, reduce work hardening, increase toughness of the material, etc. Furthermore, temperatures lower than those involved during hot forging make easier the obtaining of close tolerances and high surface finish [1]. To lead the hot forming process on different aluminum alloys, different process parameters were considered and the attachable results to the literature were derived.

For details, high-temperature tensile deformation of AA 6082-T4 was experimented in the temperature range of $623-773 \mathrm{~K}$ at several strain rates in the range of $5 \times 10^{-5}$ to $2 \times 10^{-2} \mathrm{~s}^{-1}$. By this, stress exponent $\mathrm{n}$ of 7 during the ranges of temperatures and strain rates was tested. This is higher than what is usually observed in $\mathrm{Al}-\mathrm{Mg}$ alloys under similar experimental conditions. Improvement in the strain exponent of any material leads to better formability [2]. Hot compression tests were performed on aluminum alloys 7150 and 2026 by varying the temperature from $300^{\circ} \mathrm{C}$ to $450^{\circ} \mathrm{C}$ and at a strain rate from $0.01 \mathrm{~s}^{-1}$ to $10 \mathrm{~s}^{-1}[3,4]$. Also, on AA 7075-T6 and AA 7085 aluminum alloy $[5,6]$ tested at different temperatures and strain rates $(450,500,520,550$, $580^{\circ} \mathrm{C}$ and $0.004,0.04$ and $0.4 \mathrm{~s}^{-1}$ for AA 7075 and AA 7085 in the temperature range from $250^{\circ} \mathrm{C}$ to $450^{\circ} \mathrm{C}$ and at strain rate from $0.01 \mathrm{~s}^{-1}$ to $10 \mathrm{~s}^{-1}$ using Gleeble- 1500 system, whereas hot deformation behavior was studied on aluminum alloys consisting of $\mathrm{Al}-6.2 \mathrm{Zn}-0.70 \mathrm{Mg}-0.3 \mathrm{Mn}-0.17 \mathrm{Zr}$ with temperature range of $623-773 \mathrm{~K}$ and strain rate of $0.01-20 \mathrm{~s}^{-1}$ [7]. Using the metallographic and transmission electron microscope, structural changes were studied. The results showed that the true stress-true strain curves exhibit a peak stress at a critical strain, after which the flow stresses decrease monotonically until high strains. The peak stress level decreases with increasing deformation temperature and decreasing strain rate. Similarly, Ag-containing 2519 aluminum alloy hot deformation behaviors were studied by isothermal compression at $300-500^{\circ} \mathrm{C}$ with strain rates from 0.01 to $10 \mathrm{~s}^{-1}$. Consequences indicated that by increasing the strain rate and decreasing the deformation temperature, the flow stress of the alloy increased. And also, at a strain rate lower than $10 \mathrm{~s}^{-1}$, the flow stress increases with increasing strain until the stress reached the peak value, and later on, a constant flow stress was noted [8]. Aluminum alloy of grade 7075 sheets fabricated by twin roll casting and deformation behavior was investigated at high temperature. At high temperatures from 350 to $500^{\circ} \mathrm{C}$ and strain rates from $1 \times 10^{-3}$ to $1 \times 10^{-2} \mathrm{~s}^{-1}$, hot tensile test was performed. The results showed that by increasing the strain rate and decreasing deformation temperature, flow stress was increased [9]. Similarly, three aluminum alloys containing different silicon contents were studied at a temperature range of $573-773 \mathrm{~K}$ with strain rates of $0.01,0.1,1$ and $5 \mathrm{~s}^{-1}$ [10].

Hot deformation behavior using processing map technique of stir cast 7075 alloy was studied. Based on the values of a dimensionless parameter like an efficiency index of energy dissipation, mapping was understood in terms of microstructural processes. Under the temperature and strain rate conditions, the processing map exhibited one distinct domain without any unstable flow conditions. In the processing map, the dynamic recrystallization zone and instable zones were identified. The processing maps can be used to select optimum strain rates and temperatures for effective hot deformation of 7075 alloy [11]. 
Elevated temperature and strain rate were aimed by stamping of AA5083 sheet components. To evaluate mechanical properties and forming behavior, tensile and Nakajima-type tests were carried out. The material flow stress, ductility, and fracture limit sensitivity to temperature and strain rate were evaluated. And also, the optimal combination of process parameters for maximum formability and effective post-deformation mechanical properties were determined [12]. A special device was developed to investigate the hot forming-quenching integrated process of cold-rolled 6A02 aluminum alloy sheet. The strengthening effect was replicated by hardness and uniaxial tensile tests. Microstructure examination was also conducted to clarify the strengthening mechanism. Results showed that hardness increases with solution time increase, and improves significantly after artificial aging. The faster the cooling rate, the greater the strengthening effect. On the same alloy, hot forming-quenching integrated process at different temperatures from 50 to $350^{\circ} \mathrm{C}$ was investigated. Results showed that the Vickers hardness and tensile strength decreased with increasing forming-dies temperature. To obtain enough strengthening effect, the forming-dies temperature should not be more than $250^{\circ} \mathrm{C}$ [13].

Springback and microstructure of the final products were analyzed and mechanical properties of the material were measured by tensile tests. The results show that HFSC can improve the formability of AA2024 aluminum alloy. After natural aging for $96 \mathrm{~h}$ at room temperature, the products were subjected to the hot bending process with synchronous cooling exhibiting a significant increase in strength. Springback of the aluminum alloy AA5754 under hot stamping conditions was characterized under stretch and pure bending conditions. It was found that elevated temperature stamping was beneficial for springback reduction, at hot dies $[14,15]$. Hot stamping was developed for aluminum alloy to improve formability and avoid thermal distortion by combining hot forming and quenching. The effects of heating temperature on formability and strengthening of a solution treated with $\mathrm{Al}-\mathrm{Mg}$-Si alloy sheet, uniaxial tensile test, deep drawing test, and free bulging test were carried out at temperatures ranging from 25 to $500^{\circ} \mathrm{C}$. It was observed that when temperature was raised to $400^{\circ} \mathrm{C}$, the fracture strain and limiting bulging height were increased, whereas the limiting drawing ratio increased as temperature elevated to $200^{\circ} \mathrm{C}$ and declined subsequently. The mechanical property hardness was changed by increasing temperature and at 200 and $500^{\circ} \mathrm{C}$, two peak hardness values were noted. Enhanced formability and strength were obtained simultaneously at 200 and $500^{\circ} \mathrm{C}$, either of which can be chosen as appropriate forming temperatures for hot stamping [16]. At different solution heat treatment (SHT) temperatures, SHT time and lubricant stamping experiments were performed with 6061 and 7075 aluminum alloy sheets to investigate the formability and lubrication off a B-pillar. After trimming precision level, forming detections were also carried out. From these observations, the B-pillar wrinkled badly and cracked or even broke into pieces in cold stamping with or without lubricants [17].

For AA 6061 tailor rolled blanks (TRBs), an integrated hot forming and heat treatment process was proposed to improve the formability and dimensional accuracy. The experimentation of this process for sheet forming of Al6061 TRB was evaluated by performing the Erichsen and V-bending tests. The integrated hot forming and heat treatment process was also compared with the conventional forming method in terms of formability, dimensional accuracy, and mechanical properties [18]. A hot AA6082 specimen and cold P20 tools were studied as a function of contact pressure, specimen thickness, and lubricant, using the inverse FE simulation method for the interfacial heat transfer coefficient (IHTC) evolutions. To predict IHTC evolutions with reductions of different lubricants of sliding distance at different contact pressures and sliding speeds as a function, an interactive model was developed. The interaction between the lubricant and IHTC was deducted such 
that it had three stages such as stage I: the lubricant is applied excessively and the IHTC is plateaued, stage II: in which the lubricant diminishes during sliding and the IHTC decreases, and stage III: lubricant breakdown occurs and the IHTC is equal to its values under dry conditions [19].

\section{Aluminum alloy behavior during deep drawing process}

The drawing of metal or "deep drawing" is the process by which a punch force is applied to sheet metal to flow between the surfaces of a punch die. By this, the sheet is formed into cylindrical, conic, or box-shaped parts. The development of the deep drawing process has paralleled scientific development, particularly in the aircraft and automotive industries. This process is more popular because of its swift press cycle times. Complex axisymmetric geometries and certain nonaxisymmetric geometries can be produced with a few operations. With respect to the functional perspective, the deep drawing process produces high-strength and lightweight parts as well as geometries unattainable with some other manufacturing processes [20]. A schematic illustration of these deep drawing processes is shown in Figure 1. This design is made in such a way that thickness reduction of the workpiece material has been avoided completely (Figure 1). For this process, the basic tools are the punch, the drawing die ring, and the blank holder.

Figure 2 shows the important process parameters involved in the deep drawing process. In addition, material properties such as the strain hardening coefficient ( $\mathrm{n}$ ) and normal anisotropy (R) affect the deep drawing operation.

Instead of tool temperatures, forming temperature curves (FTCs) were characterized from AA5754-O as a workpiece temperature at the warm deep drawing (WDD) process. The distinctive behavior of these curves was examined under nonisothermal WDD of AA 5754-O. The process parameters were considered such as FTC, blank holder force, and punch velocity to assure deep drawability. Optimum conditions were investigated by evaluating the cup volume and springback parameters. In the findings, $330^{\circ} \mathrm{C}$ in the flange-die radius region and $100^{\circ} \mathrm{C}$ in the cup wall-punch bottom region were the ideal optimum temperatures for the warm deep drawing process [21]. The stress-strain response of AA2014, AA5052, and AA6082 aluminum alloys at four temperatures: 303, 423, 523 and $623 \mathrm{~K}$, and three strain rates: $0.0022,0.022$, and $0.22 \mathrm{~s}^{-1}$ was evaluated through uniaxial tensile tests. It was found that the Cowper-Symonds model was not a robust constitutive model, and failed to predict the flow behavior. A comparative study was followed for modeling of three aluminum alloys under the mentioned strain rates and temperatures. For comparison, the capability of Johnson-Cook model, modified models

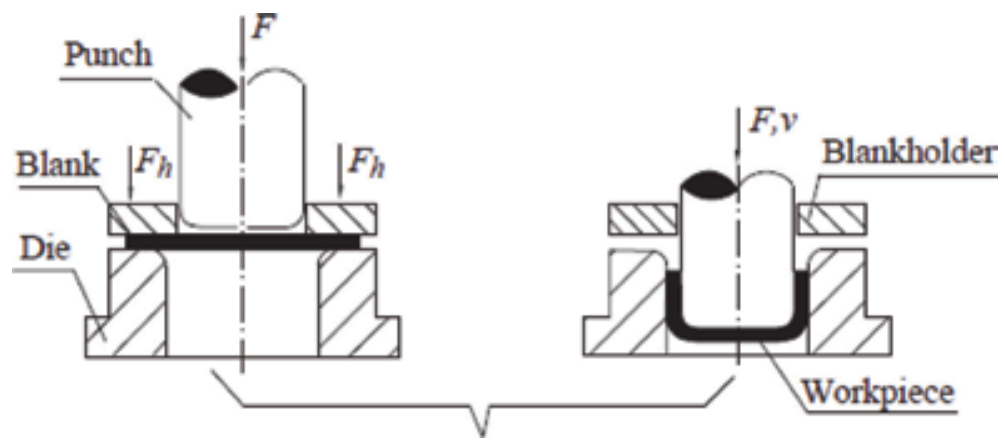

Figure 1.

Schematic illustration of deep drawing process [20]. 

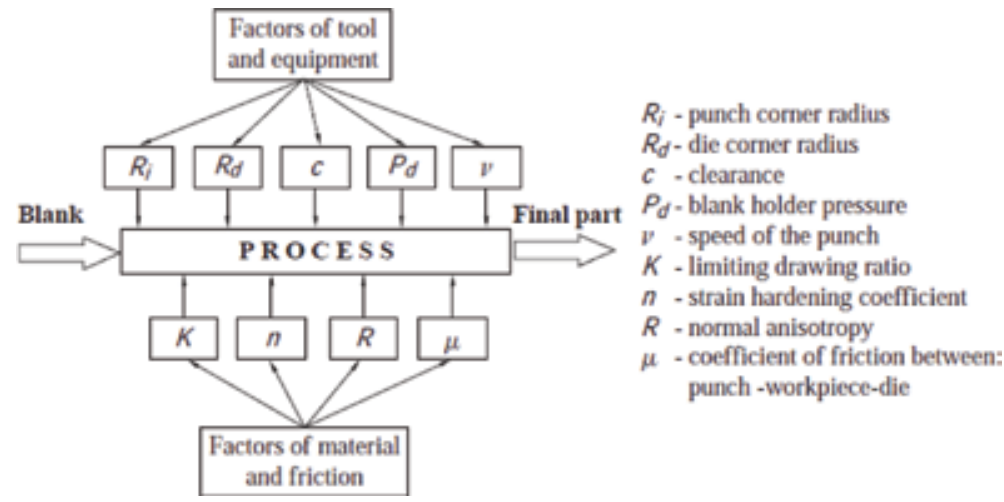

and friction

Figure 2.

Significant variables in deep drawing [20].

of Zerilli-Armstrong and Arrhenius and artificial neural network were considered for constitutive behavior. Better formability of the materials was observed at an elevated temperature of $623 \mathrm{~K}$ in terms of cup height and maximum safe strains by conducting cylindrical cup deep drawing experiments under two different punch speeds of 4 and $400 \mathrm{~mm} / \mathrm{min}$ [22]. Tensile tests of AA5754-H22 aluminum alloy were carried out at five different temperatures and three different strain rates to investigate the deformation behavior correlating with the Cowper-Symonds constitutive equation.

When punch and die were heated to $200^{\circ} \mathrm{C}$, the forming limit strain and dome height were improved. Significant enhancement was noted when the die and punch temperatures were maintained at 200 and $30^{\circ} \mathrm{C}$, respectively, in deep drawn cup depth. Using a thermo-mechanical FE model, the forming behavior at different isothermal and nonisothermal conditions was predicted. In the FE model, temperature-dependent properties in Barlat- 89 yield criterion and coupled with Cowper-Symonds hardening model were used. The validation had taken place using thinning/failure location in deformed cups by implementing the experimental limiting strains as damage model [23].

Deep drawing of aluminum alloy AA6111 at elevated temperatures was analyzed with the effect of friction coefficient through experiments and finite element method. Results indicated that the friction coefficient and lubrication position influence the minimum thickness, the thickness deviation, and the failure mode of the formed parts. During the hot forming process, the failure modes were draw mode, stretch mode, and equi-biaxial stretch mode. Fracture occurred at the center of cup bottom or near the cup corner in a ductile mode or ductile brittle mixed mode [24]. Simulations of deep drawing tests at elevated temperatures were carried out with experimental validation on aluminum alloy 7075. For stamping operations, some of the important parameters such as blank holder force, stamping speed, blank temperature, and friction coefficient were considered. During the experimentation, stamping tests were performed at temperature between 350 and $500^{\circ} \mathrm{C}$, 0 and $10 \mathrm{kN}$ blank holding force, 50 and $150 \mathrm{~mm} / \mathrm{s}$ stamping speed, and 0.1 and 0.3 frictional coefficient. At lower values of temperature, blank holder force and friction coefficient improvement were seen in thickness homogeneity whereas formability was improved with the well lubricated blank at about $400^{\circ} \mathrm{C}$ temperature and stamping speed $50 \mathrm{~mm} \mathrm{~s}^{-1}$ [25]. Tailor friction stir welded blanks (TFSWBs) of AA5754-H22 and AA5052-H32 sheet metals were fabricated using a tool with optimized design along with optimized process parameters. For optimization to design the friction stir welding experiments, Taguchi L9 orthogonal array was used. For 
the multi-objective optimization to maximize the weld strength and total elongation reducing the surface roughness and energy consumption, the gray relational analysis was applied. The formability was evaluated and compared with TFSWBs and parent materials using LDR tests. The analysis had proved that TFSWBs were comparable with parent materials more specifically without any failure in the weld zone area. For improvement in the LRD, a modified conical tractrix die was proposed and $27 \%$ improvement was observed.

Simulations of cylindrical cup drawing were carried out with experimental validation on AA6111 aluminum alloy at elevated temperatures. The influence of four important process parameters, namely, punch velocity, blank holder force (BHF), friction coefficient, and initial forming temperature of blank on drawing characteristics was investigated using design of experiments (DOE), analysis of variance (ANOVA), and analysis of mean (ANOM). Based on the results of ANOVA, the $\mathrm{BHF}$ had the greatest influence on minimum thickness. The significance of punch velocity for thickness deviation, BHF, friction coefficient, and initial forming temperature of blank was 44.35, 24.88, 15.77, and $14.995 \%$ respectively. Further, the effect of each factor on forming characteristics was analyzed by ANOM [26].

A design optimization problem was constructed to identify the formability window, in which the punch stroke was maximized subject to wrinkling and tearing. For this, the formability window of a difficult-to-draw material AA 5402 was explained with the pulsating blank holder force (PBHF) and the variable blank holder force (VBHF). Some parameters in the VBHF and PBHF were included and taken as the design variables. A sequential approximate optimization (SAO) using a radial basis function ( $\mathrm{RBF}$ ) network was used to determine the optimal parameter of PBHF and VBHF. From numerical simulation coupled with the SAO using the RBF network using the PBHF and VBHF, formability window was observed. It was identified that the proposed approach was highly useful for clarifying the formability window of a difficult-to-draw material [27]. The tailored heat treated blank (THTB) technique was demonstrated to create a material property gradient through a suitable artificial aging treatment carried out prior to the forming process on the effectiveness of combining the hydromechanical deep-drawing process. This method was coupled with a simple finite element model and a multi-objective optimization platform. For determining the effect of the aging treatment on the mechanical and deformative behavior of the AC170PX aluminum alloy, a preliminary experimental campaign was carried out. The adoption of aged blanks in the hydromechanical deep drawing allows to increase the limit drawing ratio and to simplify the process proved from the optimization results [28].

For increasing the drawability of AA1200 aluminum alloy cylindrical cups, one technique was developed. For optimal process design, effects of die and punch along with fillet radius of die and punch on LDR, drawing load with respect to punch stroke and strain of the cup wall was investigated numerically. To determine the optimum LDR form numerical analysis, a commercial finite element simulation package, ANSYS 14.0, was used. The effects of the original blank on the various LDR and punch load were numerically investigated. This process successfully produced cylindrical cups with considerable drawing ratio [29]. The effect of pulsating blankholder system was investigated on improving the formability of aluminum 1050 alloy. Using ABAQUS6.7 software, the deep drawing process was simulated for cylindrical cup of AA 1050. Later on, experimental and numerical analyses were compared for depth of cup, tearing, and thickness distribution. The results indicated that with proper frequency and gap, the cup depth and thickness distribution can be improved by using the pulsating blankholder system. Further, good agreement was observed between simulation and experimental results [30]. An analytical model was proposed for the nonuniform fluid pressure distribution 
in the cavity and for the hydrodynamic flow of the fluid film between the blank and die for AA5086 aluminum alloy. From Reynolds equation solution, the hydrodynamic flow was calculated and model was implemented in ABAQUS/Explicit, finite element software. The approach was validated and investigated for the influences of the blank holder force and the fluid pressure on the formability of the blank metal. The results exhibited that the choice of an appropriate blank holder force reduced the strain in the blank and prevented the risk of fracture [31]. A study was made on deep drawing of $\mathrm{SiCp} / 2024 \mathrm{Al}$ composite sheets by considering the effect of pulse current on heating performance and thermal. The high-intensity pulse current flows through the sheet and generates the tremendous Joule heat. The specimen temperature was kept around $673 \mathrm{~K}$ at a rate of $13.5 \mathrm{~K} / \mathrm{s}$ under the current density of $21.7 \mathrm{~A} / \mathrm{mm}^{2}$. The temperature difference was reduced by $73.3 \%$ by inserting the stainless-steel inserts. Besides, the $\mathrm{SiCp} / 2024 \mathrm{Al}$ composite was successfully deep drawn with good surface quality [32]. Deep drawing process characteristics of AA 6xxx alloy sheet were discussed under different process parameters such as punch force, lubrication, fillet radius, punch speed etc., and the formability was evaluated [33-37].

\section{Aluminum alloy behavior during incremental forming}

Incremental sheet forming (ISF) is a flexible process in which a sheet of metal is formed by a progression of localized deformation. This process does not require any specialized tool; a simple tool moves over the surface of the sheet metal by which localized plastic deformation is initiated. Hence, many shapes can be formed by designing a proper path to a tool. The main motto of this process is to form a sheet metal without any manufacturing of specialized dies [38]. Figure 3 shows an example of the incremental forming. In this Figure 3, according to computer numerical control (CNC) machine program instructions, the ball tool moves on the sheet to form the required shape. Hence, the process is in CNC machine; the program can be edited as per the requirement. From the shown Figure 3, the hollow and square in cross section will be formed [39].

A few observations are made and discussed on incremental forming process. Incremental forming behavior of 6111-T4 an alloy was investigated for exterior body panel applications. Tensile testing data were used to simulate the incremental forming

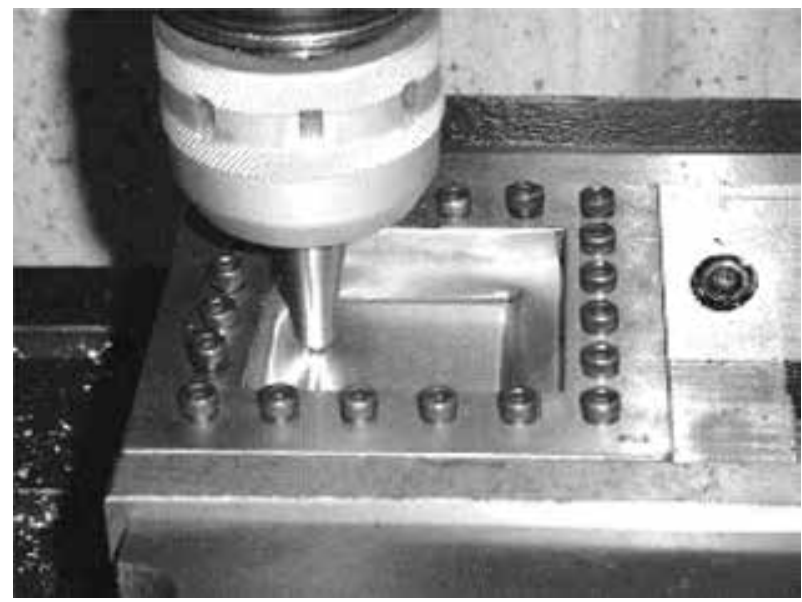

Figure 3.

Incremental forming of an aluminum sheet on CNC milling machine [34]. 
process. The heat treat regimen developed for uniaxial testing was then applied to a series of plane strain tests using a hemispherical punch [40]. The formability of AA-2024 sheets was investigated in the single-point incremental forming (SPIF) process. The process parameters, specifically step size, tool radius, and forming speed, of the SPIF process were varied over wide ranges. The formability was quantified through a response surface method. It was found that the interaction of step size and tool radius was very significant on the formability. The formability of pre-aged AA-2024 sheet decreases with the increase in the forming speed. Additionally, the annealed sheet shows higher formability than the pre-aged sheet [41].

AA7075-O aluminum alloy sheet forming was investigated using experimental campaign and the forming process mechanism was understood. Tensile tests were carried out to characterize the mechanical properties with three different thicknesses. To illuminate the formability of AA7075-O aluminum alloy sheet, the effects of tool path with different incremental steps and the part height were evaluated. To understand the design limits for strain, a fracture forming limit diagram was developed. The influence of different draw angles, sheet thicknesses, step-down sizes, and sheet orientations was considered to analyze forming forces. The part draw angle and incremental steps of the tool path were more effectible on the formability as concluded from the experimental results. The influences of process parameters on tool forces provide further insights into the deformation mechanics of AA7075-O sheets [42]. The formability of AA5052 aluminum alloy at room temperature was studied through truncated square pyramid and cone formed using a CNC machine. For both the shapes, the forming limit diagram (FLD) and thickness distribution were predicted and compared. The FLD obtained through this process and conventional FLD were different. Comparison of FLD and thickness distribution showed that cone had higher forming limit than square cup and the thickness after forming was better in cone shapes than in square cups [43]. An investigation was made on the deformation characteristic of embossed aluminum sheet in the incremental sheet forming process in which the surface quality of tool path along outward and inward movement was compared and noted as surface quality is better in the outward movement. Using ABAQUS software, a finite element simulation, the experimental results and detailed forming mechanism of the 3D structured sheet were reviewed [44].

Formability of friction welded blank made of aluminum 6061 was studied experimentally. Formability was evaluated through FLD, dome height, minimum thickness, and thickness distribution. Many experiments were conducted to know which joining direction caused higher formability and desired forming limit curve. Joints were prepared in three different rollings $\left(0,45\right.$, and $\left.90^{\circ}\right)$ and tested for formability test and compared with FLD, dome height, minimum thickness, and thickness distribution. From the formability comparison, the best joining direction was identified. Using the response surface methodology, the effect of welding process parameters such as rotational speed, plunge depth, and travel speed on formability of welded blanks was analyzed. After finding the effects, welded blanks with optimal parameter combination were fabricated and the effect of incremental forming parameters, that is, spindle speed, feeding rate, and axial step on thickness distribution was analyzed. From the results, it was obtained that joints with diagonal direction caused higher value of bowl height [45]. The effect of longitudinal ultrasonic vibrations on the performance of the incremental forming process of aluminum-1050 sheet was studied. In this technique, ultrasonic vibrations with high frequency and low amplitude were axially added to the movement of forming tool. This system is arranged with different parts including a mechanism attached into the chuck of CNC machine and ultrasonic power to the vibratory tool. Parameters like forming force and sheet formability were examined through straight groove 
test in both conventional and ultrasonic-assisted incremental forming process. The results showed that formability increased and forming force decreased with ultrasonic assistance [46].

Using the finite element method, the behavior of the state of stresses and strains in the hot incremental sheet forming of 1050 aluminum alloy was evaluated, with and without pre-heating. With the assistance of RADIOSS software, numerical simulation was performed. The results were presented a deterioration in the force during electric hot incremental sheet forming compared to the electric hot incremental sheet forming [47].

The formability of the AA2024-O aluminum alloy sheet material was evaluated with respect to the impact of forming tool shape, tool diameter, wall angle, step size, sheet thickness, and tool rotation. Forming depth was measured by scanning the components using a noncontact 3D scanner. Wall angle and step size had proved more significant factors which affect the formability greatly [48]. An attempt was made to optimize the incremental forming parameters (spindle speed, tool feed, and step size) for surface roughness to be least and wall thickness to be larger using the response surface method.

The formability of AA5052 alloy sheets at room temperature was checked with pre-cut holes at the center with different diameters. In the forming operation, coneshaped parts were formed with the optimized values. Formability was compared with sheet with smaller holes and larger holes and it was observed that smaller holes had better formability. Also, the thickness of the formed part wall without hole is less. As the diameter of the hole increases, the wall thickness also increases [49].

To evaluate deformation behavior of AA-6061 aluminum alloy sheet, the single point incremental forming (SPIF) process was chosen. To form the sheet into the desired conical shape, the SPIF experiments and finite element method simulation were performed and to measure the major and minor strains, the digital image correlation (DIC) method was used. The major and minor strains in post deformation results were compared with FEM results for AA6061 thin sheet material. An experimental fracture forming limit diagram was assessed using the punch stretching test.

Consequently, the effective plastic strains at the onset of fracture were predicted and compared with experimental data. In order to get insight into forming behavior and surface roughness, the microstructural examination on the truncated dome fabricated using optimized parameters was carried out through micro-texture analyses [50]. By using the electric hot incremental forming process (EHIF), the dimensional accuracy of parts has got more improvement compared to single-stage forming and double-stage forming at room temperature. The effect of EHIF process parameters, such as tool diameter, feed rate, step size, and current, on temperature was studied. For a cone of AA 1060, the maximum temperature, the average temperature, and the maximum temperature difference were measured. Besides, the response surface method and Box-Behnken design were employed, and they established corresponding models to predict targeted values [51].

AA 7075-O sheets were formed into variable angle funnels and $45^{\circ}$ wall angle cones by SPIF. The same material was deep drawn and a bulge test part was formed to compare with SPIF. Moreover, the formed parts were sectioned and characterized for texture and surface finish at equivalent strains. To compare the strain paths of SPIF and deep drawing, finite element models were used [52]. For AA 1050 sheet metal, the deformation characteristics, forming behavior, and deformation mechanism of the SPIF process were evaluated. For process deformation characteristics such as dimensional accuracy, thickness distribution, true surface strain, von Mises stress, and equivalent plastic strain, evolved at different forming stages, were estimated through experimental investigation and finite element analysis. Analysis was carried out to identify the reason of typical failure under biaxial strain mode [53]. 


\section{Aluminum alloy behavior during hydroforming process}

The metal forming process in which a pressurized fluid either plastically deforms or aids in deforming a given blank material (sheet or tube) into a desired shape as depicted is a hydroforming process. Figure 4 indicates the complete process. Using this process, more complex shapes with more strength and low cost can be manufactured as compared with stamping, forging, or casting processes [54].

Tube hydroforming process on different aluminum alloys is discussed in the following sections. At different temperatures, tube hydroforming analysis of aluminum alloy AA1050 was studied and the effect of temperature on thickness distribution of the final product was investigated. Also, for evaluating numerical results, a warm hydroforming set-up had been designed and manufactured. Conferring to numerical and experimental results in the case of free bulging, increase of the process temperature causes more uniform thickness distribution which leads to better material formability. A viscoplastic model was developed to consider the influence of microscopic evolution and macroscopic deformation to represent the deformation behavior of aluminum alloy sheet AA7075-O in the warm hydroforming process. By using the pressure rate, the evolution of dislocation density and kinematic isotropic hardening on a hydroforming environment, a set of rate dependent constitutive equations was constructed and proposed to predict stress-strain response of the material. The hydraulic bulge experiments on aluminum alloy at warm temperature indicated that the deformation behavior of the material was more sensitive to pressure rate. To determine the optimum values of a set of free material constants associated with the proposed constitutive model, the genetic algorithm optimization technique was used. The computed data were in good agreement with the test data on the basis of the optimized material constants $[55,56]$.

Friction stir welding (FSW) tube of 2024-O aluminum alloy rolled plates was coiled and produced by processing sequence. The plastic deformation characteristics were investigated experimentally and numerically during hydroforming with two types of end conditions. The performance of the FSW tubes was investigated by diebulge forming with fixed ends. The wrinkling behavior during hydroforming was analyzed by employing axial feed on the tube ends. Severe thinning was observed at one quarter of the expansion zone from symmetry plane. Along the hoop direction, the base material near the weld observed a severe thinning. The thickness distribution greatly depends on the sequence of the contacting die and the variations of the curvature radius of the tube during hydroforming. Moreover, the weld shows an inhibitory effect for the generation of the wrinkles and decreases the number of the wrinkles as compared to the seamless tube during hydroforming [57].

An experimental and numerical simulation was studied on 6063-T4 aluminum alloy cross member through the hydroforming process. Severe thinning and
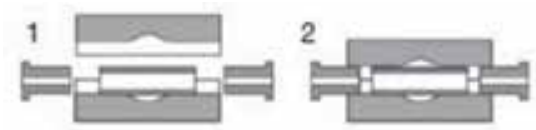

4
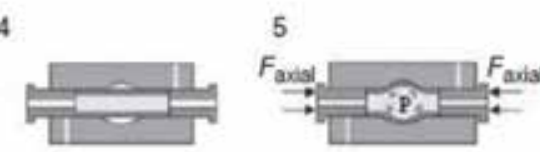

6

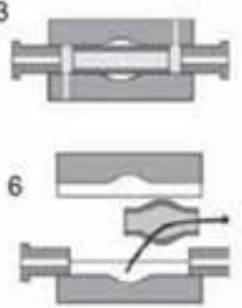

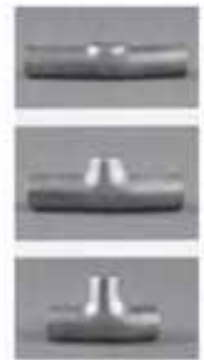

Figure 4.

Steps in a typical hydroforming process shown on a small tubular part [54]. 
bursting were avoided during hydroforming, composite design method was carried out, and the significance of pre-form structural parameters was discussed on thinning. An experimental research was conducted on thickness distribution of typical sectional profiles and dimension accuracy as per the optimum pre-form shape.

FEM simulations and experiments were conducted on the formability of aluminum alloy AA2024-O. The effects of strain rate on the formability during the active hydroforming process were investigated. Results indicated that aluminum alloy AA2024-O is not sensitive to pressure rate at room temperature. Furthermore, the deformation capacity of aluminum alloys can be improved effectively, and more uniform distribution of wall thickness can be obtained. The wrinkling behavior and thickness distribution of 5A06 aluminum alloy sheets in an annealed state was investigated numerically and experimentally under different hydraulic pressures in the hydroforming of single-layer and double-layer sheets. The upper, thicker sheet synchronously deforms with the lower, thinner sheet during hydroforming. When the double-layer sheets were separated, a thinner curved sheet part will be manufactured. From the simulation and experimental results, the upper, thicker sheet was effectively suppressing the wrinkles of the lower, thinner sheet and improved the thickness distribution. This was due to the increasing anti-wrinkle ability of the formed sheet and the interfacial friction between the double-layer sheets. In addition, the maximum hydraulic pressure was decreased via hydroforming of doublelayer sheets. This method reduced the drawing force for large sheet parts and meets the requirement of energy conservation [58-60].

A specialized hydroforming process set-up was designed for 2A12 aluminum alloy curved shell double-sided sheet. The influence of double-sided liquid pressure on the thickness distribution was evaluated. The thickness distribution of the formed shells was measured and compared under different loading paths. Using simulation analysis, the deformation mode and the stress state were analyzed to understand the mechanism of the thickness variation. It was shown that the forward pressure plays a negative role in the thickness distribution of the formed parts. The deformation mode of the shells varies slightly when forward pressures are added. The Von Mises stress and the effective strain of the components were improved when conducting the double-sided hydroforming process. The larger thinning phenomenon was noted by adding forward pressure and by increasing reduced third principle stress on the blank. Through a steam hydroforming process, an experimental formability study was carried out on aluminum sheet 2017A. The steam hydroforming process takes advantage of the coupling between the thermal and mechanical loads applied. The variation of the supplied electrical power on the hydroforming temperature and steam pressure effects was studied. The evolution of strains and stresses in metal sheets was analyzed. The experimental results showed that the supplied electrical power increases the heating rate and has no effect on bursting temperature or pressure. Furthermore, the evolution of the vapor pressure as a function of temperature was independent of the supplied electrical power and the deformation in the thin sheets under the steam pressure decreases the stress flow and raises the plastic deformation [61, 62].

Using elliptical bulging dies under various temperatures and pressure rates, warm/hot sheet bulging tests were conducted on 2A16-O aluminum alloy. The macroscopic and microscopic influence of the pressure rate on the formability and microstructural evolution of hydrobulging parts during warm/hot sheet hydroforming was investigated. The results revealed that the forming limit of the aluminum alloy was influenced by the pressure rate as the temperature rose, wherein a lower pressure rate resulted in a higher forming limit. This study demonstrated that warm/hot sheet hydroforming of aluminum alloy may lead to an improved forming limit and inhibit microstructural degradation during processing [63]. A 
hydroforming analysis was made on extruded aluminum tubular specimen made up of AA 6063 alloy bulged from the diameter of 38-54 $\mathrm{mm}$. The thickness distribution at bulging the region along lateral and longitudinal directions was analyzed. The parameters considered are axial feed, tube thickness, fluid pressure, and die semi-cone angle. The forming characteristics such as thickness distribution and bulged diameter were studied using toolmaker microscope and coordinate measuring machine. Maximum shear thinning is observed in the largest diameter of the bulged portion of the tube [64].

\section{Aluminum alloy behavior during bi-axial forming}

Here, some of the recent discussions are made based on the bi-axial forming process. It is also treated as a stretching process in which sheet material experiences the tensile load along plane direction in the same time.

Biaxial warm forming behavior in the temperature range $200-350^{\circ} \mathrm{C}$ was investigated for three aluminum sheet alloys: Al 5754, Al 5182, and Al 6111-T4. The formability for all the three alloys improved at elevated temperatures; the strain hardened alloys Al 5754 and Al 5182 showed considerably greater improvement than the precipitation hardened alloy Al 6111-T4. Formability was studied by forming rectangular parts at a rapid rate using internally heated punch and die in both isothermal and nonisothermal conditions. The temperature effect on drawing of the sheet was found to have a large effect on formability. FLD under warm forming conditions was also determined, which showed results that are consistent with the evaluation of part depth. Biaxial forming behavior was investigated for three aluminum sheet alloys of $\mathrm{Al} 5182, \mathrm{Al} 5754$, and 6111-T4 using a heated die and punch in the warm forming temperature range of $200-350^{\circ} \mathrm{C}$. It was found that all three alloys exhibited significant improvement in the formability compared with that at room temperature. The nonheat-treatable alloys of AA 5182 and AA 5754 showed a higher part depth than that of heat-treatable 6111-T4. The formidability characteristic was dependent on the blank holding pressure (BHP). When the BHP decreased, the formability increased, but increasing the forming temperature and/ or BHP minimizes the wrinkling tendency and improves the forming performance. By increasing temperature and BHP, the stretchability of the sheet alloys was increased. Through setting the temperature $50^{\circ} \mathrm{C}$ higher than the punch temperature to enhance the drawing component, the optimum formability was achieved. Strain distribution was also improved with setting the die temperature higher than the punch temperature in a part in such a manner that postpones necking and fracture by altering the location of the greatest thinning [65].

The Gurson-Tvergaard-Needleman (GTN) damage model combined with the finite element method was used to investigate the influence of double-sided pressure on the deformation behavior of biaxially stretched AA6111-T4 sheet metal. The Marciniak-Kuczynski (M-K) localized necking model was used to predict the right-hand side of the forming limit diagram (FLD) of sheet metal under superimposed double-sided pressure. The forming limit curve (FLC) of the biaxially stretched AA6111-T4 sheet metal under the superimposed double-sided pressure had improved and the fracture locus shifts to the left. Besides, the formability increase value is sensitive to the strain path [66].

Through the numerical biaxial tensile tests of the sheet, the biaxial tensile deformation behavior of 5182 aluminum alloy sheet was predicted. From the numerical simulations, the stress-strain curves and the shapes of the contours of plastic work were calculated and were quantitatively verified by the experimental biaxial tensile test using the cruciform specimen. Using the results of experimental and numerical 
biaxial tensile tests, parameters of the Yld2000-2d yield function were identified. Von Mises's and Hill's yield functions were identified using the experimental data and were compared. The simulation results confirmed that the forming simulation using the Yld2000-2d yield function identified by the numerical biaxial tensile tests was better than that of the Mises's and Hill's yield functions and was comparable to that of the Yld2000-2d yield function calibrated experimentally [67].

The forming limit strains at fracture for aluminum alloy 5086 were determined using an in-plane biaxial tensile test with a cruciform specimen. To identify the onset of fracture and the forming limit strains, a method based on the evolution of strain in the central area of the specimen and the observation of the macroscopic image of specimen surface was proposed. The forming limit strains at fracture were determined under different strain paths provided by the two independent axes of the experimental device. Finite element simulations were performed to determine and compare numerical forming limit strains with three ductile fracture criteria [68]. Warm temperature biaxial tension test apparatus was developed to achieve stress ratio and strain rate controls simultaneously. The warm temperature biaxial tension tests were conducted on AA5182-O aluminum alloy sheet with the thickness of $1 \mathrm{~mm}$. The obtained results showed that the shapes of equi-plastic work loci did not have strong temperature dependency [69].

\section{Summary}

Forming behavior of different aluminum alloys is discussed in the above sections. The forming processes considered included the hot forming process, deep drawing process, incremental process, hydroforming process, and bi-axial forming. The effect of their parameters on aluminum alloys is realized. From each forming process and test, the forming limit strain is determined to quantify the formidability of each aluminum alloy. Moreover, the quantification of the formability of $\mathrm{Al}$ alloys can help the industries.

\section{Author details}

Perumalla Janaki Ramulu

Program of Mechanical Design and Manufacturing Engineering, School of Mechanical, Chemical and Materials Engineering, Adama Science and Technology University, Adama, Ethiopia

*Address all correspondence to: perumalla.janaki@astu.edu.et

IntechOpen

(C) 2019 The Author(s). Licensee IntechOpen. This chapter is distributed under the terms of the Creative Commons Attribution License (http://creativecommons.org/licenses/ by/3.0), which permits unrestricted use, distribution, and reproduction in any medium, provided the original work is properly cited. (cc) BY 


\section{References}

[1] Cavaliere P. Hot and warm forming of 2618 aluminium alloy. Journal of Light Metals. 2002;2(4):247-252. DOI: 10.1016/S1471-5317(03)00008-7

[2] El-Danaf EA, AlMajid AA, Soliman MS. Hot deformation of AA6082-T4 aluminum alloy. Journal of Materials Science. 2008;43(18):6324. DOI: 10.1007/s10853-008-2895-4

[3] Jin N, Zhang H, Han Y, Wu W, Chen J. Hot deformation behavior of 7150 aluminum alloy during compression at elevated temperature. Materials Characterization. 2009;60(6):530-536. DOI: 10.1016/j.matchar.2008.12.012

[4] Huang X, Zhang H, Han Y, Wu W, Chen J. Hot deformation behavior of 2026 aluminum alloy during compression at elevated temperature. Materials Science and Engineering A. 2010;527(3):485-490. DOI: 10.1016/j. msea.2009.09.042

[5] Rokni MR, Zarei-Hanzaki A, Roostaei AA, Abedi HR. An investigation into the hot deformation characteristics of 7075 aluminum alloy. Materials and Design. 2011;32(4):23392344. DOI: 10.1016/j.matdes.2010.12.047

[6] Liu W, Zhao H, Li D, Zhang Z, Huang G, Liu Q. Hot deformation behavior of AA7085 aluminum alloy during isothermal compression at elevated temperature. Materials Science and Engineering A. 2014;596:176-182. DOI: 10.1016/j.msea.2013.12.012

[7] Yan J, Pan QL, Li B, Huang ZQ, Liu ZM, Yin ZM. Research on the hot deformation behavior of Al-6.2 Zn-0.70 Mg-0.3 Mn-0.17 Zr alloy using processing map. Journal of Alloys and Compounds. 2015;632:549-557. DOI: 10.1016/j.jallcom.2015.01.228

[8] Li H, Li Z, Song M, Liang X, Guo F. Hot deformation behavior and microstructural evolution of Ag-containing 2519 aluminum alloy. Materials and Design. 2010;31(4):21712176. DOI: $10.1016 /$ j.matdes.2009.10.061

[9] Wang L, Yu H, Lee Y, Kim HW. Hot tensile deformation behavior of twin roll casted 7075 aluminum alloy. Metals and Materials International. 2015;21(5):832841. DOI: $10.1007 /$ s12540-015-5093-3

[10] Rajamuthamilselvan M, Ramanathan S. Hot deformation behaviour of 7075 alloy. Journal of Alloys and Compounds. 2011;509(3):948-952. DOI: 10.1016/j. jallcom.2010.09.139

[11] Bariani PF, Bruschi S, Ghiotti A, Michieletto F. Hot stamping of AA5083 aluminium alloy sheets. CIRP Annals-Manufacturing Technology. 2013;62(1):251-254. DOI: 10.1016/j. cirp.2013.03.050

[12] Fan X, He Z, Yuan S, Zheng K. Experimental investigation on hot forming-quenching integrated process of 6A02 aluminum alloy sheet. Materials Science and Engineering A. 2013;573:154-160. DOI: 10.1016/j. msea.2013.02.058

[13] Fan X, He Z, Yuan S, Lin $\mathrm{P}$. Investigation on strengthening of $6 \mathrm{~A} 02$ aluminum alloy sheet in hot formingquenching integrated process with warm forming-dies. Materials Science and Engineering A. 2013;587:221-227. DOI: 10.1016/j.msea.2013.08.059

[14] Chen G, Chen M, Wang N, Sun $\mathrm{J}$. Hot forming process with synchronous cooling for AA2024 aluminum alloy and its application. The International Journal of Advanced Manufacturing Technology. 2016;86(1-4):133-139. DOI: 10.1007/s00170-015-8170-3

[15] Wang A, Zhong K, El Fakir O, Liu J, Sun C, Wang LL, et al. 
Springback analysis of AA5754 after hot stamping: Experiments and FE modelling. The International Journal of Advanced Manufacturing Technology. 2017;89(5-8):1339-1352. DOI: $10.1007 /$ s00170-016-9166-3

[16] Fan XB, He ZB, Zhou WX, Yuan SJ. Formability and strengthening mechanism of solution treated Al-Mg-Si alloy sheet under hot stamping conditions. Journal of Materials Processing Technology. 2016;228:179-185. DOI: 10.1016/j. jmatprotec.2015.10.016

[17] Liu Y, Zhu Z, Wang Z, Zhu B, Wang $Y$, Zhang Y. Formability and lubrication of a B-pillar in hot stamping with 6061 and 7075 aluminum alloy sheets. Procedia Engineering. 2017;207:723-728. DOI: 10.1016/j.proeng.2017.10.819

[18] Kim JH, Lee CJ, Lee SB, Ko DC, Kim BM. Integrated hot forming and heat treatment process on Al6061 tailor rolled blank. International Journal of Precision Engineering and Manufacturing. 2017;18(1):127-132. DOI: 10.1007/s12541-017-0016-5

[19] Liu X, El Fakir O, Meng L, Sun X, Li X, Wang L. Effects of lubricant on the IHTC during the hot stamping of AA6082 aluminium alloy: Experimental and modelling studies. Journal of Materials Processing Technology. 2018;255:175-183. DOI: 10.1016/j. jmatprotec.2017.12.013

[20] Boljanovic V. Sheet Metal Forming Processes and Die Design. South Norwalk, CT: Industrial Press Inc; 2004

[21] Pourboghrat F, Venkatesan S, Carsley JE. LDR and hydroforming limit for deep drawing of AA5754 aluminum sheet. Journal of Manufacturing Processes. 2013;15(4):600-615. DOI: 10.1016/j.jmapro.2013.04.003

[22] Panicker SS, Prasad KS, Basak S, Panda SK. Constitutive behavior and deep drawability of three aluminum alloys under different temperatures and deformation speeds. Journal of Materials Engineering and Performance. 2017;26(8):3954-3969. DOI: 10.1007/ s11665-017-2837-x

[23] Panicker SS, Singh HG, Panda SK, Dashwood R. Characterization of tensile properties, limiting strains, and deep drawing behavior of AA5754-H22 sheet at elevated temperature. Journal of Materials Engineering and Performance. 2015;24(11):4267-4282. DOI: $10.1007 /$ s11665-015-1740-6

[24] Wang BY, Lei FU, Jing ZH, Huang MD. Effect of friction coefficient in deep drawing of AA6111 sheet at elevated temperatures. Transactions of Nonferrous Metals Society of China. 2015;25(7):2342-2351. DOI: 10.1016/ S1003-6326(15)63849-3

[25] Xiao WC, Wang BY, Kang Y, Ma WP, Tang XF. Deep drawing of aluminum alloy 7075 using hot stamping. Rare Metals. 2017;36(6):485-493. DOI: 10.1007/s12598-017-0919-4

[26] Ma WY, Wang BY, Zhou J, Huang MD. Influence of process parameters on deep drawing of AA6111 aluminum alloy at elevated temperatures. Journal of Central South University. 2015;22(4):11671174. DOI: 10.1007/s11771-015-2630-7

[27] Kitayama S, Natsume S, Yamazaki K, Han J, Uchida H. Numerical investigation and optimization of pulsating and variable blank holder force for identification of formability window for deep drawing of cylindrical cup. The International Journal of Advanced Manufacturing Technology. 2016;82(1-4):583-593. DOI: $10.1007 /$ s00170-015-7385-7

[28] Piccininni A, Di Michele G, Palumbo G, Sorgente D, Tricarico L. Improving the hydromechanical deep-drawing process using aluminum tailored heat treated blanks. Acta 
Metallurgica Sinica. 2015;28(12):14821489. DOI: $10.1007 / \mathrm{s} 40195-015-0347-0$

[29] Dwivedi R, Agnihotri G. Numerical simulation and experimental analysis on the deep drawing of cylindrical cups. Transactions of the Indian Institute of Metals. 2015;68(1):31-34. DOI: $10.1007 /$ s12666-015-0598-5

[30] Liu ZY, Xiong BQ, Li XW, Yan LZ, Li ZH, Zhang YA, et al. Deep drawing of 6A16 aluminum alloy for automobile body with various blank-holder forces. Rare Metals. 2018;37:1-8. DOI: 10.1007/ s12598-018-1146-3

[31] Abbadeni M, Zidane I, Zahloul H, Fatu A, Hajjam M. Finite element analysis of fluid-structure interaction in the hydromechanical deep drawing process. Journal of Mechanical Science and Technology. 2017;31(11):5485-5491. DOI: 10.1007/s12206-017-1043-y

[32] Wang B, Wang GF, Jiang SS, Zhang KF. Effect of pulse current on thermal performance and deep drawing of $\mathrm{SiCp} / 2024 \mathrm{Al}$ composite sheet. The International Journal of Advanced Manufacturing Technology. 2013;67(1-4):623-627. DOI: $10.1007 /$ s00170-012-4510-8

[33] Pranavi U, Reddy PV, Lavanya K, Charyulu NN, Ramulu PJ. Effect of mechanical properties on deep drawing formability prediction. International Journal of Current Engineering and Technology. 2014;2:303-305. DOI: 10.14741/ijcet/spl.2.2014.5

[34] Pranavi U, Ramulu PJ, Chandramouli C, Govardhan D, Prasad PR. Formability analysis of aluminum alloys through deep drawing process. In: IOP Conference Series: Materials Science and Engineering. Vol. 149. IOP Publishing; 2016. p. 012025. DOI: 10.1088/1757-899X/149/1/012025

[35] Reddy PV, Ramulu PJ, Madhuri GS, Govardhan D, Prasad PR. Design and analysis of deep drawing process on angular deep drawing dies for different anisotropic materials. In: IOP Conference Series: Materials Science and Engineering. Vol. 149. IOP Publishing; 2016. p. 012142. DOI: 10.1088/1757-899X/149/1/012142

[36] Ramulu PJ, Rao PS, Yimer W. Springback analysis on AA 6061 aluminum alloy sheets. In: AIP Conference Proceedings. Vol. 1769. AIP Publishing; 2016. p. 200023. DOI: $10.1063 / 1.4963641$

[37] Reddy PV, Ramesha J, Rao PS, Ramulu PJ. Experimental and numerical analysis on deep drawing rectangular cups made of different anisotropic materials. Materials Today: Proceedings. 2018;5(13):27171-27177. DOI: 10.1016/j. matpr.2018.09.028

[38] Jackson K, Allwood J. The mechanics of incremental sheet forming. Journal of Materials Processing Technology. 2009;209(3):1158-1174. DOI: 10.1016/j.jmatprotec.2008.03.025

[39] Park JJ, Kim YH. Fundamental studies on the incremental sheet metal forming technique. Journal of Materials Processing Technology. 2003;140(1-3):447-453. DOI: $10.1016 /$ S0924-0136(03)00768-4

[40] Golovashchenko S, Krause A. Improvement of formability of 6xxx aluminum alloys using incremental forming technology. Journal of Materials Engineering and Performance. 2005;14(4):503-507. DOI: 10.1361/105994905X56133

[41] Hussain G, Gao L, Hayat N, Dar NU. The formability of annealed and pre-aged AA-2024 sheets in single-point incremental forming. The International Journal of Advanced Manufacturing Technology. 2010;46(5-8):543-549. DOI: 10.1007/s00170-009-2120-x

[42] Liu Z, Li Y, Meehan PA. Experimental investigation of 
mechanical properties, formability and force measurement for AA7075-O aluminum alloy sheets formed by incremental forming. International Journal of Precision Engineering and Manufacturing. 2013;14(11):1891-1899. DOI: $10.1007 / \mathrm{s} 12541-013-0255-\mathrm{z}$

[43] Mugendirana V, Gnanavelbabub A. Comparison of FLD and thickness distribution on AA5052 aluminium alloy formed parts by incremental forming process. Procedia Engineering. 2014;97:1983-1990. DOI: 10.1016/j. proeng.2014.12.353

[44] Do VC, Nguyen DT, Cho JH, Kim YS. Incremental forming of 3D structured aluminum sheet. International Journal of Precision Engineering and Manufacturing. 2016;17(2):217-223. DOI: $10.1007 /$ s12541-016-0028-6

[45] Alinaghian I, Ranjbar H, Beheshtizad MA. Forming limit investigation of aa6061 friction stir welded blank in a single point incremental forming process: RSM approach. Transactions of the Indian Institute of Metals. 2017;70(9):23032318. DOI: $10.1007 / \mathrm{s} 12666-017-1093-y$

[46] Amini S, Gollo AH, Paktinat $\mathrm{H}$. An investigation of conventional and ultrasonic-assisted incremental forming of annealed AA1050 sheet. The International Journal of Advanced Manufacturing Technology. 2017;90(5-8):1569-1578. DOI: $10.1007 /$ s00170-016-9458-7

[47] Pacheco PA, Silveira ME. Numerical simulation of electric hot incremental sheet forming of 1050 aluminum with and without preheating. The International Journal of Advanced Manufacturing Technology. 2018; 94(9-12):3097-3108. DOI: $10.1007 /$ s00170-017-0879-8

[48] Kumar A, Gulati V, Kumar P, Singh V, Kumar B, Singh H. Parametric effects on formability of AA2024-O aluminum alloy sheets in single point incremental forming. Journal of Materials Research and Technology. 2018;8(1):1461-1469. DOI: 10.1016/j. jmrt.2018.11.001

[49] Mugendiran V, Gnanavelbabu A. Analysis of hole flanging on AA5052 alloy by single point incremental forming process. Materials Today: Proceedings. 2018;5:8596-8603

[50] Barnwal VK, Chakrabarty S, Tewari A, Narasimhan K, Mishra SK. Forming behavior and microstructural evolution during single point incremental forming process of AA-6061 aluminum alloy sheet. The International Journal of Advanced Manufacturing Technology. 2018;95(1-4):921-935. DOI: $10.1007 /$ s00170-017-1238-5

[51] Li Z, Lu S, Zhang T, Zhang C, Mao Z. 1060 Al electric hot incremental sheet forming process: Analysis of dimensional accuracy and temperature. Transactions of the Indian Institute of Metals. 2018;71(4):961-970. DOI: $10.1007 /$ s12666-017-1229-0

[52] Nath M, Shin J, Bansal A, Banu M, Taub A. Comparison of texture and surface finish evolution during single point incremental forming and formability testing of AA 7075. In: TMS Annual Meeting \& Exhibition. Cham: Springer; 2018. pp. 225-232. DOI: 10.1007/978-3-319-72284-9_31

[53] Shrivastava P, Tandon P. Microstructure and texture-based analysis of forming behavior and deformation mechanism of AA1050 sheet during single point incremental forming. Journal of Materials Processing Technology. 2019;266:292-310. DOI: 10.1016/j.jmatprotec.2018.11.012

[54] Koç M, editor. Hydroforming for Advanced Manufacturing. Woodhead 
Publishing; 2008. https://www. elsevier.com/books/hydroformingfor-advanced-manufacturing/ koc/978-1-84569-328-2

[55] Hashemi SJ, Naeini HM, Liaghat G, Tafti RA, Rahmani F. Numerical and experimental investigation of temperature effect on thickness distribution in warm hydroforming of aluminum tubes. Journal of Materials Engineering and Performance. 2013;22(1):57-63. DOI: $10.1007 /$ s11665-012-0213-4

[56] Lang L, Du P, Liu B, Cai G, Liu K. Pressure rate controlled unified constitutive equations based on microstructure evolution for warm hydroforming. Journal of Alloys and Compounds. 2013;574:41-48. DOI: 10.1016/j.jallcom.2013.03.134

[57] Hu ZL, Wang XS, Pang Q, Huang F, Qin XP, Yuan SJ, et al. Experimental and numerical study on hydroforming characteristics of friction stir welded aluminum alloy tubes. The International Journal of Advanced Manufacturing Technology. 2015;80(5-8):959-969. DOI: $10.1007 /$ s00170-014-6613-x

[58] Kong D, Lang L, Sun Z, Ruan S, $\mathrm{GuS}$. A technology to improve the formability of thin-walled aluminum alloy corrugated sheet components using hydroforming. The International Journal of Advanced Manufacturing Technology. 2016;84(1-4):737-748. DOI: 10.1007/s00170-015-7727-5

[59] Zhou BJ, Xu YC. Wrinkle behavior of hydroforming of aluminum alloy double-layer sheets. Journal of Metals. 2016;68(12):3201-3207. DOI: 10.1007/ s11837-016-2025-8

[60] Cai Y, Wang XS, Yuan SJ. Preform design for hydro-forming of aluminum alloy automotive cross members. The International Journal of Advanced Manufacturing Technology.
2016;86(1-4):463-473. DOI: $10.1007 /$

s00170-015-8160-5

[61] Liu W, Chen YZ, Yuan SJ.

Mechanism analysis on thickness

distribution of aluminum alloy hemispherical shells in double-sided sheet hydroforming. The International Journal of Advanced Manufacturing Technology. 2017;89(5-8):2011-2020. DOI: $10.1007 / \mathrm{s} 00170-016-9248-2$

[62] Aissa S, Mohamed S, Tarek L. Experimental study of steam hydroforming of aluminum sheet metal. Experimental Techniques. 2017;41(5):525-533. DOI: $10.1007 /$ s40799-017-0191-4

[63] Cai G, Wu C, Gao Z, Lang L, Alexandrov S. Investigation on the effect of pressure rate on formability of aluminum alloy during warm/ hot sheet hydroforming. AIP Advances. 2018;8(9):095313. DOI: 10.1063/1.5050222

[64] Selvakumar AS, Rajan BS, Balaji MS, Selvaraj B. Strain analysis of AA6063 aluminum alloy by tube hydroforming process. In: Advances in Manufacturing Processes. Singapore: Springer; 2019. pp. 13-21. DOI: 10.1007/978-981-13-1724-8_2

[65] Li D, Ghosh AK. Effects of temperature and blank holding force on biaxial forming behavior of aluminum sheet alloys. Journal of Materials Engineering and Performance. 2004;13(3):348-360. DOI: 10.1361/10599490419225

[66] Liu J, Wang Z, Meng Q. Numerical investigations on the influence of superimposed double-sided pressure on the formability of biaxially stretched AA6111-T4 sheet metal. Journal of Materials Engineering and Performance. 2012;21(4):429-436. DOI: 10.1007/ s11665-011-9941-0

[67] Yamanaka A, Hashimoto K, Kawaguchi J, Sakurai T, Kuwabara T. 
Material modeling and forming simulation of 5182 aluminum alloy sheet using numerical biaxial tensile test based on homogenized crystal plasticity finite element method. Journal of Japan Institute of Light Metals. 2015;65:561-567

[68] Song X, Leotoing L, Guines D, Ragneau E. Investigation of the forming limit strains at fracture of AA5086 sheets using an in-plane biaxial tensile test. Engineering Fracture Mechanics. 2016;163:130-140. DOI: 10.1016/j. engfracmech.2016.07.007

[69] Hamasaki H, Tamashiro F. Biaxial deformation on AA5182-O aluminium alloy sheet at warm temperature. Journal of Physics: Conference Series. 2018;1063(1):012032. DOI: 10.1088/1742-6596/1063/1/012032 


\section{Edited by Kavian Omar Cooke}

Aluminium ( $\mathrm{Al})$ is a metal of great importance because of its excellent corrosion resistance, high electrical and thermal conductivity, good reflectivity, and very good recycling characteristics. The properties of heat-treatable $\mathrm{Al}$-alloys can be further enhanced by the inclusion of a reinforcing phase that increases the mechanical properties of the overall composite. This book is a comprehensive guide on the different types of aluminum alloys and the new advances that have been made in developing and manufacturing aluminum alloys and composites. This text provides a comprehensive overview of the processing, formability, and chemical composition of aluminum alloys and composites. Part One is focused on evaluating the types and properties of advanced aluminum alloys and composites, while Part Two explores characterization. The advantage of this book is that it provides a detailed review of major advances that have occurred in the development and application of aluminum alloys and composites while outlining a development strategy for these materials. 